Florida International University FIU Digital Commons

9-16-2014

\title{
Exposure to Endocrine Disrupting Compounds and Reproductive Toxicity in Women
}

Marisa L. Morgan

Florida International University, mmorg003@fiu.edu

DOI: $10.25148 /$ etd.FI14110713

Follow this and additional works at: https://digitalcommons.fiu.edu/etd

Part of the Environmental Public Health Commons

\section{Recommended Citation}

Morgan, Marisa L., "Exposure to Endocrine Disrupting Compounds and Reproductive Toxicity in Women" (2014). FIU Electronic Theses and Dissertations. 1586.

https://digitalcommons.fiu.edu/etd/1586 


\section{FLORIDA INTERNATIONAL UNIVERSITY}

Miami, Florida

\section{EXPOSURE TO ENDOCRINE DISRUPTING COMPOUNDS AND REPRODUCTIVE TOXICITY IN WOMEN}

A dissertation submitted in partial fulfillment of

the requirements for the degree of

DOCTOR OF PHILOSOPHY

in

PUBLIC HEALTH

by

Marisa Morgan

2014 
To: Dean Michele Ciccazzo

R. Stempel College of Public Health and Social Work

This dissertation, written by Marisa Morgan, entitled Exposure to Endocrine Disrupting Compounds and Reproductive Toxicity in Women, having been approved in respect to style and intellectual content, is referred to you for judgment.

We have read the dissertation and recommend that it be approved.

$\begin{array}{r}\text { Alok Deoraj } \\ \hline \text { Changwon Yoo } \\ \hline \text { Dentin Felty } \\ \hline \text { Deodutta Roy, Major Professor }\end{array}$

Date of Defense: September 16, 2014

The dissertation of Marisa Morgan is approved.

Dean Michele Ciccazzo

R. Stempel College of Public Health and Social Work

Dean Lakshmi N. Reddi
University Graduate School

Florida International University, 2014 


\section{ACKNOWLEDGMENTS}

I would like to gratefully acknowledge my major professor, Dr. Deodutta Roy for his guidance, dedication, and support. I would like to thank my wonderful committee members, Dr. Alok Deoraj, Dr. Changwon Yoo, and Dr. Quentin Felty for their availability, time, and further guidance during this process. I would like to thank my family members who helped me pursue this degree and complete this dissertation. I am most grateful for the support and encouragement from my husband and family. 


\title{
ABSTRACT OF THE DISSERTATION \\ EXPOSURE TO ENDOCRINE DISRUPTING COMPOUNDS AND REPRODUCTIVE TOXICITY IN WOMEN
}

\author{
by \\ Marisa Morgan \\ Florida International University, 2014 \\ Miami, Florida \\ Professor Deodutta Roy, Major Professor
}

The overall objective of the research presented in this dissertation was to assess exposure to endocrine disrupting chemicals (EDCs), polychlorinated biphenyls (PCBs), phthalates, and bisphenol A (BPA) in the general population and evaluate their associations with adverse reproductive health effects, including cancers, in women. Given the proven contribution of unopposed estrogens to the risk for endometrial neoplasia or breast cancer, renewed health concerns have aroused about estrogen mimicking EDCs found in food, personal care products or as environmental contaminants. Our meta-analysis showed that exposure to estrogen mimicking PCBs increased summary risk of breast cancer and endometriosis. We further evaluated the relationship between endometriosis and breast cancer, and EDCs using a bioinformatics method. Our bioinformatics approach was able to identify genes with the potential to be involved in interaction with PCB, phthalates and BPA that may be important to the development of breast cancer and endometriosis. Therefore, we hypothesized that exposure to EDCs such as PCBs, phthalates, and BPA, results in adverse reproductive health effects in women. Using subject data and biomarkers available from the Center for 
Disease Controls National Health and Nutrition Examination Survey database we conducted a cross-sectional study of EDCs in relation to self-reported history of endometriosis, uterine leiomyomas, breast cancer, cervical cancer, ovarian cancer, and uterine cancer. Significantly higher body burdens of PCBs were found in women diagnosed with breast cancer, ovarian cancer, and uterine cancer compared to women without cancer. PCB 138 was significantly associated with breast cancer, cervical cancer, and uterine cancer, while PCBs 74 and 118 were significantly associated with ovarian cancer. The sum of dioxin-like PCBs were significantly associated with ovarian cancer (OR of 2.02, 95\% CI: 1.06-3.85) and the sum of non-dioxin-like PCBs were significantly associated with uterine cancer (OR of 1.12, 95\%CI: 1.03-1.23). Significantly higher body burdens of PCBs were also found in women diagnosed with endometriosis and uterine leiomyomas. Documenting the exposure to EDCs among the general U.S. population, and identifying agents associated with reproductive toxicity have the potential to fill research gaps and facilitate our understanding of the complex role environmental chemicals play in producing toxicity in reproductive organs. 


\section{TABLE OF CONTENTS}

CHAPTER

PAGE

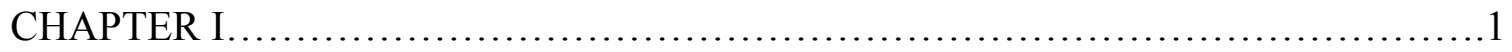

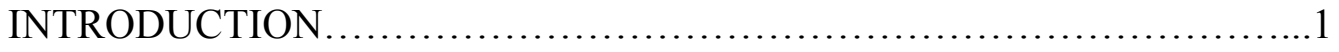

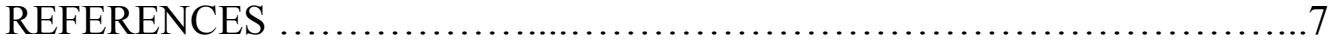

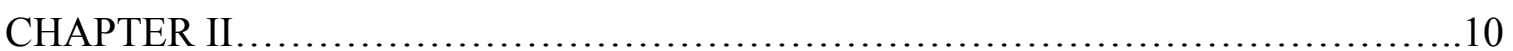

LITERATURE REVIEW ..............................................

Endocrine Disrupting Compounds..................................... 10

Polychlorinated Biphenyls..............................................

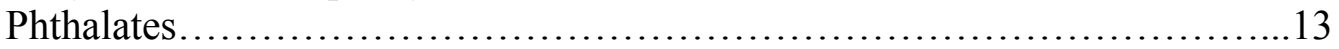

Bisphenol A........................................................... 14

Bioinformatics: PCBs, Breast Cancer, and Endometriosis...................15

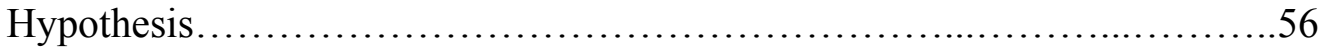

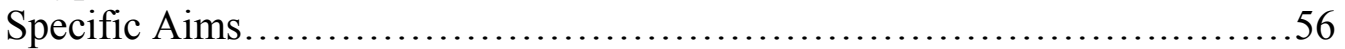

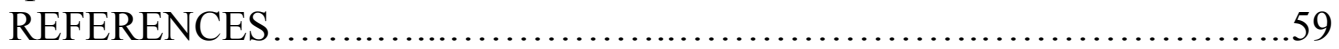

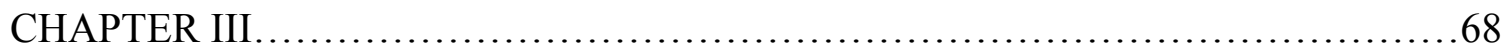

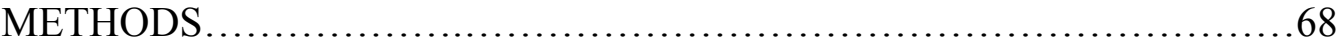

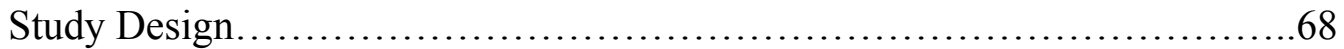

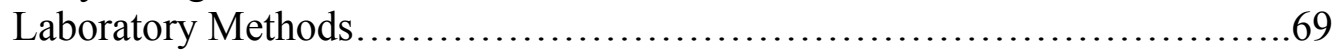

Questionnaire Methods.............................................. 70

Selection of Participants............................................... 71

Sample Weights and Limit of Detection.....................................72

EDC Exposure Assessment..............................................73

Reproductive and Medical Health Variables.................................74

Statistical Analysis.................................................. 76

Potential Confounding Variables............................................

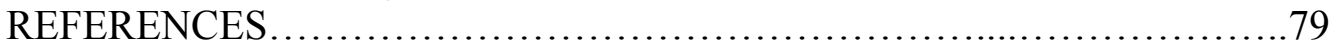

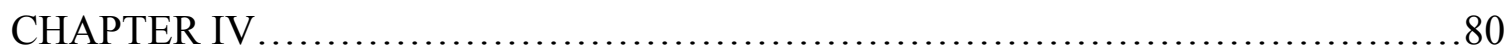

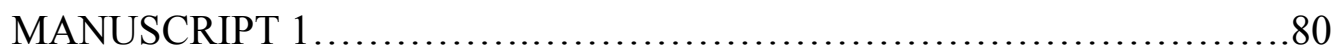

EXPOSURE TO POLYCHLORINATED BIPHENYLS AND BREAST CANCER AMONG U.S. WOMEN: ANALYSES OF NHANES DATA 1999-2004.

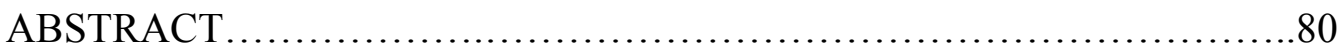

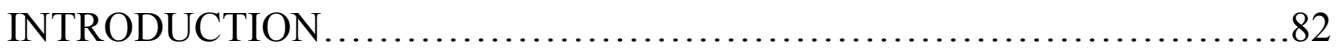

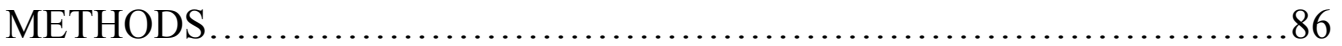

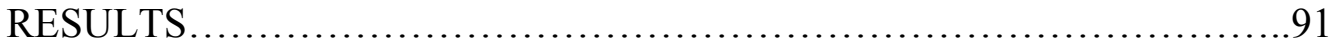

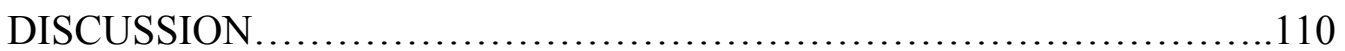

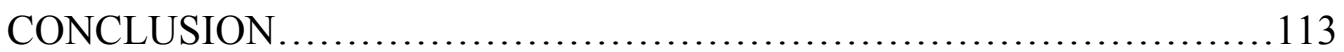

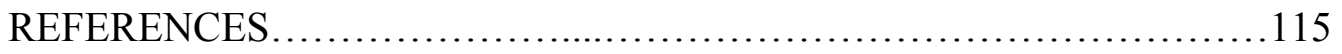




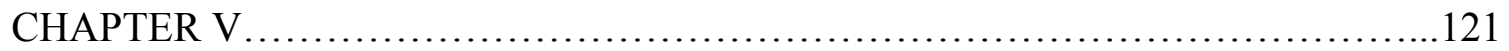

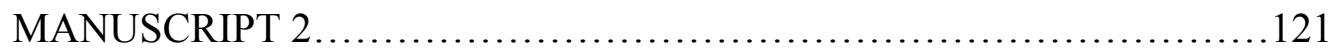

ASSOCIATION OF POLYCHLORINATED BIPHENYLS, ENDOMETRIOSIS, AND UTERINE LEIOMYOMAS AMONG U.S.

WOMEN: NHANES 1999-2004.

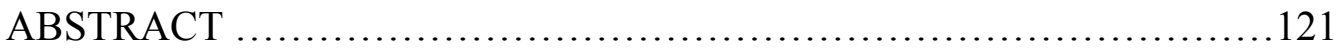

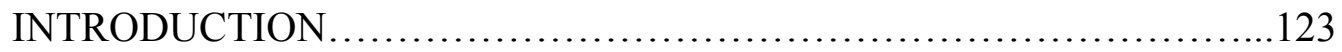

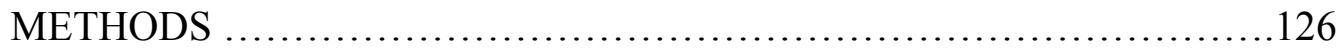

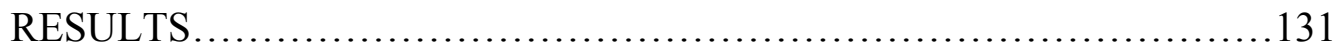

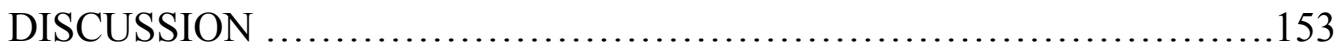

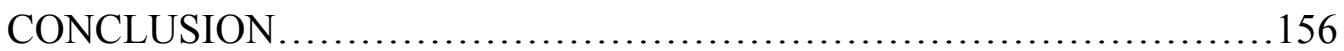

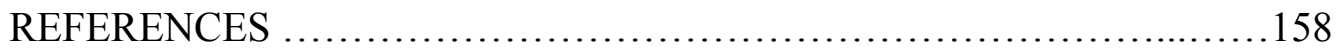

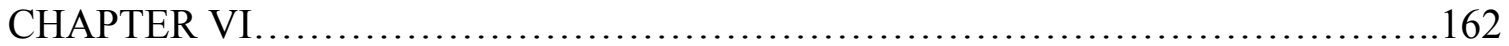

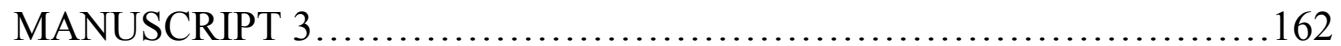

ENDOCRINE DISRUPTING COMPOUNDS AND REPRODUCTIVE

CANCERS AMONG U.S. WOMEN: NHANES 1999-2010.

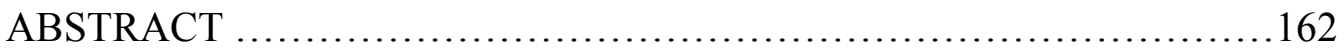

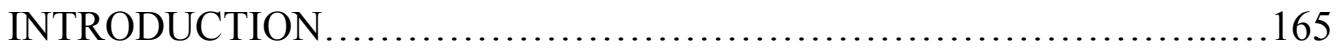

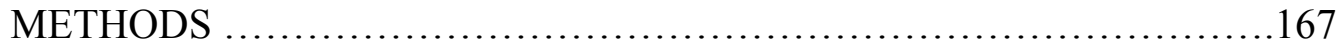

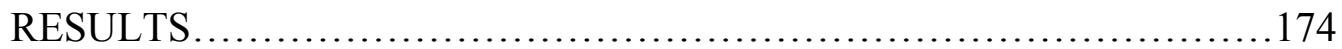

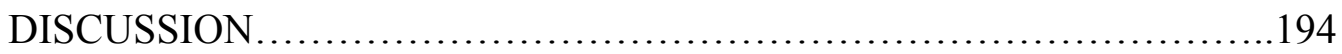

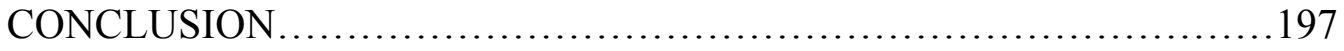

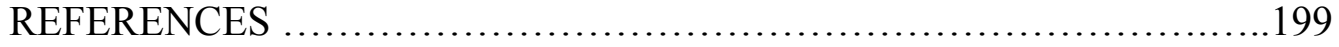

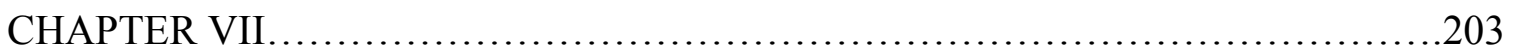

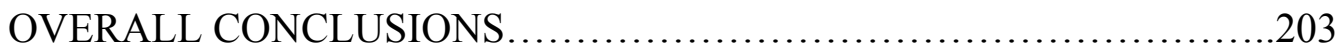

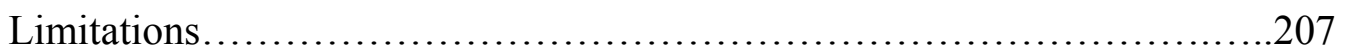

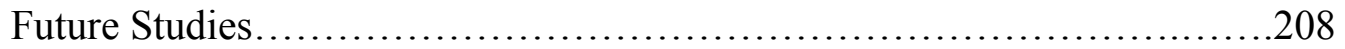

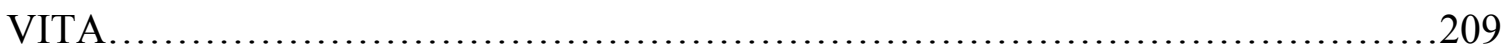




\section{LIST OF TABLES}

TABLE

PAGE

\section{LITERATURE REVIEW}

1. Epidemiological studies of the association between exposure to PCBs and risk of

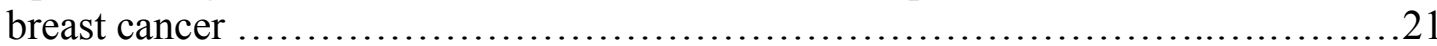

2. Genes interacting with polychlorinated biphenyls in breast neoplasms..................25

3. KEGG enrichment pathways for common AREG, CYP19A1, EGFR, FOS, IGFA, KRAS, and PGR genes in EDCs, breast cancer and endometriosis..................28

4. Epidemiological studies of the association between exposure to PCBs and risk of

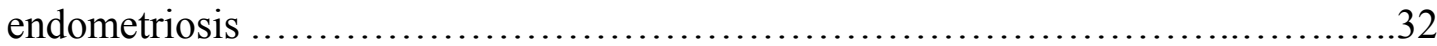

5. Epidemiological studies of the association between EDC's - Phthalate or BPA and

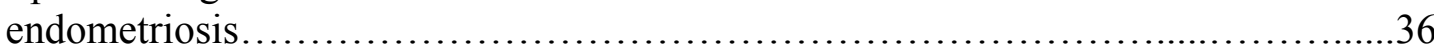

6. Genes interacting with PCBs and endometriosis..................................

7. EDC-interacting endometriosis, environmental response and inflammation associated estrogen responsive genes in breast neoplasms.

8. Integration of changes in the expression of genes showing common genes modified in EDCs, breast cancer and endometriosis

\section{MANUSCRIPT 1}

1.1 Descriptive statistics for breast cancer status and selected covariates among women $\geq 20$ years of age, NHANES 1999-2004

1.2 Geometric mean PCB levels (ng/g) by breast cancer status among women $\geq 20$ years of age with PCB concentrations above the LOD, NHANES 1999-2004.

1.3 Geometric mean PCB levels (ng/g) by cancer status among women $\geq 20$ years of age with PCB concentrations above the LOD, NHANES 1999-2004...

1.4 Age standardized geometric mean PCB levels (ng/g) by race/ethnicity among women $\geq 20$ years of age with PCB concentrations above the LOD, NHANES 1999-2004 
1.5 Serum levels of dioxin-like PCBs ( $\mathrm{ng} / \mathrm{g}$ ) in the study population, women $\geq 20$ years of age, NHANES 1999-2004.

1.6 Serum levels of non-dioxin-like PCBs (ng/g) in the study population, women $\geq 20$ years of age, NHANES 1999-2004.

1.7 Geometric mean PCB levels ( $\mathrm{ng} / \mathrm{g}$ ) by cancer status among women $\geq 20$ years of age, NHANES 1999-2004.

1.8 Geometric mean PCB levels (ng/g) by cancer status among women $\geq 20$ years of age, NHANES 1999-2004

1.9 Geometric mean PCB levels ( $\mathrm{ng} / \mathrm{g}$ ) by cancer status among women $\geq 20$ years of age, NHANES 1999-2004.

1.10 Estimated ORs (95\% CIs) of breast cancer by concentration of PCB levels among women $\geq 20$ years of age, NHANES 1999-2004

1.11 Estimated ORs (95\%CIs) of breast cancer by concentration of PCB levels among women $\geq 20$ years of age, NHANES 1999-2004

1.12 Estimated ORs (95\%CIs) of breast cancer by concentrations of dioxin-like and non-dioxin-like PCBs among women $\geq 20$ years of age, NHANES 1999-2004.

\section{MANUSCRIPT 2}

2.1 Descriptive statistics for endometriosis and uterine leiomyomas in the study population, women 20-54 years of age, NHANES 1999-2004 ..................133

2.2 Geometric mean PCB levels ( $\mathrm{ng} / \mathrm{g}$ ) by diagnosis of endometriosis and uterine leiomyomas for women 20-54 years of age, NHANES 1999-2004

2.3 Geometric mean PCBs levels ( $\mathrm{ng} / \mathrm{g}$ ) for race by endometriosis diagnosis among women 20-54 years of age, NHANES 1999-2004.

2.4 Age standardized geometric mean PCBs levels (ng/g) for race by uterine leiomyoma diagnosis among women $20-54$ years of age,

NHANES 1999-2004

2.5 Arithmetic mean dioxin-like PCB levels in the study population, women 20-54 years of age, NHANES 1999-2004

2.6 Mean non-dioxin-like PCB levels in the study population, women 20-54 years of age, NHANES 1999-2004. 
2.7 Geometric mean PCBs levels (ng/g) by diagnosis of endometriosis or uterine leiomyomas among women 20-54 years of age, NHANES 1999-2004 _.........143

2.8 Geometric mean PCB levels (ng/g) by endometriosis diagnosis among women 20-54 years of age, NHANES 1999-2004

2.9 Geometric mean PCB levels (ng/g) by uterine leiomyoma diagnosis among women 20-54 years of age, NHANES 1999-2004 .............................146

2.10 Estimated ORs (95\% CIs) of endometriosis or uterine leiomyomas by concentrations of PCBs among women 20-54 years of age, NHANES 1999-2004.

2.11 Estimated ORs ( $95 \%$ CIs) of endometriosis by concentrations of PCBs among women 20-54 years of age, NHANES 1999-2004 150

2.12 Estimated ORs (95\% CIs) of uterine leiomyomas by concentrations of PCBs among women 20-54 years of age, NHANES 1999-2004.

2.13 Estimated ORs (95\% CIs) of endometriosis or uterine leiomyomas by concentration of dioxin-like and non-dioxin-like PCBs among women 20-54 years of age, NHANES 1999-2004

\section{MANUSCRIPT 3}

3.1 Descriptive statistics for cancer diagnosis and selected covariates among women $\geq 20$ years of age with serum PCB measurements, NHANES 1999-2004.

3.2 Descriptive statistics for cancer diagnosis and selected covariates among women $\geq 20$ years of age with urinary phthalate or BPA measurements.

3.3 Geometric mean serum PCB, urinary phthalate and urinary BPA levels by cancer diagnosis among women $\geq 20$ years of age

3.4 Geometric mean PCB, urinary phthalate and urinary BPA levels by cancer diagnosis among women $\geq 20$ years of age with concentrations above the LOD

3.5 Estimated ORs (95\% CIs) of breast cancer by concentration of PCBs among women $\geq 20$ years of age, NHANES 1999-2004 .............................183

3.6 Estimated ORs (95\% CIs) of cervical cancer by concentration of PCBs among women $\geq 20$ years of age, NHANES 1999-2004 .............................184 
3.7 Estimated ORs (95\% CIs) of ovarian cancer by concentration of PCBs among women $\geq 20$ years of age, NHANES 1999-2004

3.8 Estimated ORs (95\% CIs) of uterine cancer by concentration of PCBs among women $\geq 20$ years of age, NHANES 1999-2004 ............................186

3.9 Estimated ORs ( $95 \%$ CIs) of a reproductive cancer by concentrations of dioxin- like and non-dioxin-like PCBs among women $\geq 20$ years of age, NHANES 1999-2004.

3.10 Estimated ORs (95\% CIs) of breast cancer by concentration of creatinine corrected urinary phthalate metabolite among women $\geq 20$ years of age, NHANES 2003-2010

3.11 Estimated ORs (95\% CIs) of cervical cancer by concentration of creatinine corrected urinary phthalate metabolite among women $\geq 20$ years of age, NHANES 2003-2010.

3.12 Estimated ORs (95\% CIs) of ovarian cancer by concentration of creatinine corrected urinary phthalate metabolite among women $\geq 20$ years of age, NHANES 2003-2010.

3.13 Estimated ORs (95\% CIs) of breast cancer by concentration of creatinine corrected urinary phthalate metabolite among women $\geq 20$ years of age, NHANES 2003-2010

3.14 Estimated ORs (95\% CIs) of a reproductive cancer by concentration of creatinine corrected urinary BPA among women $\geq 20$ years of age, NHANES 2005-2010 


\section{LIST OF FIGURES}

FIGURE

PAGE

\section{LITERATURE REVIEW}

1. Flow chart showing the steps involved in identifying genes that illustrate the link between endometriosis and breast cancer based on epidemiologic, genomic, and bioinformatics databases.................................................. 17

2. Forest plot of epidemiological studies of the association between exposure to

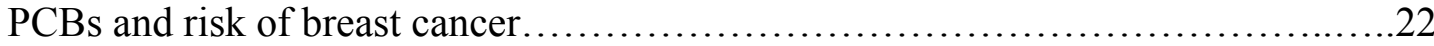

3. Venn diagram of list of genes common between breast neoplasms and PCBs, phthalates, and bisphenol A

4. Gene Set/Pathway enrichment analysis of genes associated with PCBs, phthalates, or bisphenol A in breast neoplasms.

5. Forest Plot of epidemiological studies of the association between exposure to PCBs and risk of endometriosis.

6. Venn diagram of list of genes common between endometriosis and PCBs, phthalates, and bisphenol A

7. Gene Set/Pathway enrichment analysis of genes associated with PCBs, phthalates, and bisphenol $\mathrm{A}$ in endometriosis.

8. Interaction of common genes between estrogen, PCBs, and breast neoplasms: AREG, CYP19A1, EGFR, ESR2, FOS, IGF1, KRAS, NCOA1, NCOR1, NR2F6, PGR, and STC2

9. Identification of the maximum likelihood structure of PCBs associated genes in breast neoplasm using the Bayesian network analysis on the Cancer Genome Atlas (TCGA) Research Network data...

\section{MANUSCRIPT 1}

1.1 Geometric mean PCB levels (ng/g) by cancer status among women $\geq 20$ years of age with PCB concentrations above the LOD, NHANES 1999-2004 


\section{MANUSCRIPT 2}

2.1 Geometric mean PCB levels (ng/g) by endometriosis status among women 20-54 years of age, NHANES 1999-2004...................................135

2.2 Geometric mean PCB levels ( $\mathrm{ng} / \mathrm{g}$ ) by endometriosis status among women $20-54$ years of age, NHANES 1999-2004...................................135

\section{MANUSCRIPT 3}

3.1 Geometric mean PCB levels ( $\mathrm{ng} / \mathrm{g}$ ) by cancer diagnosis among women $\geq 20$ years of age, NHANES 1999-2004 .......................................... 180

3.2 Geometric mean urinary phthalate levels $(\mathrm{ng} / \mathrm{mg})$ by cancer diagnosis among

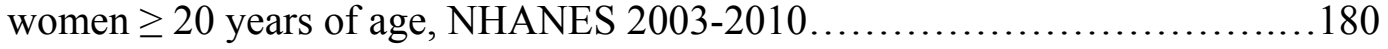




\section{ABBREVIATIONS AND ACRONYMS}

AGD

ATSDR

BBP

BMI

BPA

CCA

$\mathrm{CDC}$

CI

CYP1A1

DDT

DBP

DEHP

DEP

DMP

DES

EDC

EPA

GM

GSE

LOD

MBP

$\mathrm{MBzP}$
Anogenital distance

Agency for Toxic Substances and Disease Registry

butylbenzyl phthalate

Body Mass Index

Bisphenol A

clear-cell-adenocarcinoma

Centers for Disease Control and Prevention

Confidence Interval

cytochrome P-450 1A1

dichlorodiphenyl trichloroethane

dibutyl phthalate

di-(2-theylhexyl) phthalate

diethyl phthalate

dimethyl phthalate

diethylstilbestrol

Endocrine Disrupting Compound

Environmental Protection Agency

Geometric Means

Geometric Standard Error

Limit of Detection

monobutyl phthalate

monobenzyl phthalate 


$\begin{array}{ll}\text { MCPP } & \text { mono (3-carboxypropyl) phthalate } \\ \text { MEP } & \text { monoethyl phthalate } \\ \text { MEHP } & \text { mono-(2-ethylhexyl) phthalate } \\ \text { MEHHP } & \text { mono (2-ethyl-5-hydroxyhexyl) phthalate } \\ \text { MEOHP } & \text { mono (ethyl-5-oxohexyl) phthalate } \\ \text { MIB } & \text { mono-isobutyl phthalate } \\ \text { NHANES } & \text { National Health and Nutrition Examination Survey } \\ \text { OR } & \text { Odds Ratio } \\ \text { PCB } & \text { polychlorinated biphenyl } \\ \text { TCGA } & \text { The Cancer Genome Altas Research Network } \\ \text { UNEP } & \text { United Nations Environment Programme } \\ \text { U.S. } & \text { United States } \\ \text { WHO } & \text { World Health Organization }\end{array}$




\section{INTRODUCTION}

There are thousands of chemicals that are manufactured in or imported into the United States every year. These chemicals are released into the environment and pose a severe threat to the endocrine systems of wildlife and humans by interfering with normal growth and development functions (ATSDR 2000). These chemicals commonly known as endocrine disrupting compounds (EDCs) or endocrine disruptors (EDs) are both synthetic and natural compounds in the environment that have the ability to disrupt metabolic pathways by either mimicking or blocking endogenous hormones, or by altering hormone function. Many EDCs are highly carcinogenic and include a variety of chemicals such as pesticides, fungicides, industrial compounds, by-products of industrial processes, and chemicals used in the manufacturing of plastics. Of particular concern are the hormonally active agents that are persistent in the environment, highly lipophilic, and readily bio-accumulate and magnify within the food chain (Summarized in Meeker et al. 2009 \& Lyche et al. 2009).

Many of these chemicals are used in a variety of consumer products; therefore exposure to EDCs among the general population is widespread. Human exposure to EDCs may result from inhalation through the air, absorption through the skin, and most commonly through the ingestion of contaminated food and water (Balabanic et al. 2001). In addition, transgenerational exposure can result from exposure of the mother to a chemical at any time before producing offspring due to the persistence of EDCs in body fat. In the last decade, exposure to multiple EDCs such as polychlorinated biphenyls (PCBs), phthalates, and bisphenol A (BPA) have been detected in $>90 \%$ of blood and 
urine samples collected from the U.S. general population (Woodruff et al. 2011,Calafat et al. 2008, Silva et al. 2004).

The discovery that chemicals could cause reproductive and endocrine toxicity dates back to the 1940's when the usage of the insecticide dichlorodiphenyl trichloroethane (DDT) was at its peak. DDT was found to induce adverse reproductive effects in non-target species including feminized male embryos, weakened eggshells, reduced nesting behavior, and diminished birth rates in numerous bird species (Patisaul et al. 2009). DDT was ultimately banned in the United States in 1972, however, the widespread use of EDCs continued worldwide. The first discovery that exposure to estrogen could adversely affect reproductive health emerged from the widespread use of the synthetic estrogen diethylstilbestrol (DES). In the 1930's DES was prescribed to pregnant women to prevent miscarriage. DES was banned in 1971 when researchers identified a highly significant association between DES and the development of a very rare type of clear-cell-adenocarcinoma (CCA) of the vagina and cervix in female offspring born to mothers who took DES (Herbst et al. 1971). Subsequent studies of DES exposure in female offspring have since been associated with breast cancer in older women (Troisi et al. 2007), elevated risk of CCA with age (Smith et al. 2012), early uterine leiomyomata diagnosis (D'Aloisio et al. 2010), younger age at natural menopause (Hatch et al. 2006), and irregular menstrual periods (Titus-Ernstoff et al. 2006).

Many EDC's that persist in the environment today have demonstrated endocrine disrupting properties. PCBs have shown to have both estrogenic and anti-estrogenic properties depending on the congener, phthalates have shown the potential to interfere with male reproductive development through antiandrogenic mechanisms (Swan 2008), 
and BPA has shown to have estrogen mimicking properties. PCBs, BPA, and phthalates are the most extensively studied EDCs, and therefore, this research focused on analyzing the risk of reproductive toxicity in association with exposure to these three selected classes of EDCs - PCBs, BPA, and phthalates.

Polychlorinated biphenyls. PCBs are a group of synthetic organic chemicals that readily accumulate in the environment and have shown to cause a number of adverse health effects, including cancer, in humans and animals (ATSDR 2000). PCBs were introduced into industry in the 1930's and used primarily for heat exchange in transformers and capacitors, hydraulic and lubricating fluids, plasticizers, inks, paints, adhesives, flame retardants, and extenders for pesticides (Letz 1983). The manufacture of PCBs was banned in the United States in 1977, however, they are still being released into the environment from inadequately maintained hazardous waste sites; illegal dumping of PCB wastes; leaks from old transformers; disposal of PCB-containing consumer products into municipal landfills, and burning of PCB contaminated waste (ATSDR 2000).

PCBs are ubiquitous in the environment and have been found to contaminate air, land, and aquatic environments thousands of miles away from the disposal site (Letz 1983). Once in the environment, PCBs adsorb strongly to soil and sediment and continuously cycle between air, water, and soil (ATSDR 2000). Due to their persistence in the environment, PCBs bioaccumulate in the food chain primarily in fish and marine animals, eventually reaching levels that are thousands of times higher than in water (ASTDR 2000). The primary route of human exposure to PCBs is from eating contaminated food and breathing contaminated air. Once PCBs have entered a person's 
or animal's body, they are absorbed into adipose tissue and remain there for very long periods of time (Summarized in Johnson et al. 1999).

Phthalates. Phthalates are a group of synthetic chemicals that are widely used as plasticizers and additives in industrial products (Frederiksen et al. 2007). Highmolecular weight phthalates such as di(2-ethylhexyl) phthalate (DEHP), di-isononyl phthalate (DiNP), and di-isodecyl phthalate (DiDP) are primarily used to impart flexibility and durability in plastics and polyvinyl chloride (PVC) products, such as floor and wall coverings, clothing, food packaging, children's toys, paint, and medical devices (Summarized in Meeker et al. 2009 \& Lyche et al. 2009). Low-molecular weight phthalates such as diethyl phthalate (DEP), dibutyl phthalate (DBP), and dimethyl phthalates (DMP) are primarily used in insecticides, varnishes and coatings, pharmaceuticals, and as detergents in personal care products such as perfume, hair gels, hair sprays, shampoos, body lotion, deodorant, and nail polish, (Swan 2008, Meeker et al. 2009, Hauser et al. 2003, ATSDR 2002). Although phthalates are rapidly metabolized and excreted, the widespread use of both low and high molecular weight phthalates has led to a constant and unavoidable exposure to humans. Ingestion of contaminated food is the most common route of exposure for the general population, however, dermal and inhalation exposures are also important routes due to their presence in numerous personal-care products and cosmetics (Swan 2008, CDC 2005). According to the CDC's Third National Report on Human Exposure to Environmental Chemicals the majority of people in the United States have detectable levels of several phthalate monoesters or their metabolites in their urine with detectable levels of DEHP concentrations highest in children (CDC 2005). 
Bisphenol A. Bisphenol A (BPA) is a synthetic chemical that has shown to mimic estrogen and potentially impact reproductive and developmental function. BPA is one of the highest production volume chemicals in commerce and has been used extensively for the past 40 years to manufacture polycarbonate plastics, epoxy resins to line food and beverage cans and polyester-styrene (Summarized in Talsness et al. 2009 , Cantonwine et al. 2010, Meeker et al. 2009). BPA can also be found in dental sealants and fillings, carbonless paper, flame retardants, water storage tanks, and supply pipes (Summarized in Talsness et al. 2009, Meeker et al. 2009). The majority of human exposure to BPA is via ingestion of contaminated food products (Summarized in Meeker et al. 2009). This is of significant concern because many BPA containers are re-used or marketed as microwavable which accelerates the degradation of BPA into its monomeric form and leads to an increase in leaching into adjacent materials. Detectable levels of urinary BPA have been found in 93\% of samples from the 2003-2004 NHANES survey cycle (CDC 2005 ) and in $>92 \%$ of Americans tested with higher levels in children and adolescents (Calafat et al. 2008).

NHANES. Information regarding blood and urine concentrations and adverse health effects associated with EDCs is important in understanding how the exposure to EDCs affects the overall health of the U.S. general population. The National Health and Nutrition Survey (NHANES), conducted annually since 1999 by the Centers for Disease Control (CDC), is designed to measure the health of the U.S. general population in subjects $\geq 2$ months of age (CDC 2012). The surveys consist of a household interview, medical questionnaires, standardized physical examinations, and the collection of 
biological specimens (blood and urine from participants $\geq 1$ and $\geq 6$ years of age, respectively) (CDC 2012).

The overarching goal of this research was to determine if risk of reproductive toxicity in the general U.S. population is increased due to exposure to endocrine disrupting compounds (polychlorinated biphenyls, phthalates, and BPA) commonly found in the environment today. Using the CDC's continuous NHANES database, 19992010, statistical analysis was performed to analyze the associations between urinary and serum biomarkers of EDCs, reproductive health variables, and medical questionnaires (cancer). 


\section{REFERENCES}

1. Agency for Toxic Substances and Disease Registry (ATSDR). 2000. Toxicological Profile for Polychlorinated Biphenyls. Atlanta, GA: U.S. Department of Health and Human Services, Public Health Service.

2. Balabanic D, Rupnik M, Klemencic A. 2011. Negative impact of endocrinedisrupting compounds on human reproductive health. Reproduction, Fertility, and Development 23:403-416.

3. Calafat AM, Xiaoyun X, Wong LY, Reidy JA, Needham LL. 2008. Exposure of the U.S. Population to Bisphenol A and 4-tertiary-Octylphenol: 2003-2204. Environ Health Perspect 116(1): 39-44.

4. Cantonwine D, Meeker J.D, Hu H, Sanchez BN, Lamadrid-Figueroa H, et al. 2010. Bisphenol A exposure in Mexico City and risk of prematurity: a pilot nested case control study. Env Health 9:62-69.

5. CDC. 2005. Third National Report on Human Exposure to Environmental Chemicals. Atlanta, GA: Centers for Disease Control and Prevention; National Center for Environmental Health; Division of Laboratory Sciences. Available: http://www.cdc.gov/exposurereport/pdf/thirdreport.pdf

6. CDC. 2012. National Health and Nutrition Examination Survey: Introduction to NHANES. Atlanta, GA: Centers for Disease Control Control and Prevention, National Center for Health Statistics. Available: http://www.cdc.gov/nchs/nhanes.htm

7. D'Aloisoi AA, Baird DD, DeRoo LA, Sandler DP. 2010. Association of Intrauterine and Early-Life Exposures with Diagnosis of Uterine Leiomyomata by 35 Years of Age in the Sister Study. Environ Health Perspect 118(3):375-381.

8. Frederikson H, Skakkebaek NE, Andersson AM. 2007. Metabolism of phthalates in humans. Mol. Nutr. Food Res 51:899-911.

9. Hatch EE, Troisi R, Wise LA, Hyer M, Palmer JR, et al. 2006. Age at natural menopause is women exposed to diethylstilbestrol in utero. Am J Epidemiol 164(7): 682-688.

10. Hauser R, Duty S, Godfrey-Bailey L, Calafat A. 2004. Medications as a Source of Human Exposure to Phthalates. Environ Health Perspect 112(6): 751-753.

11. Herbst Al, Ulfelder H, \& Poskanzer DC. 1971. Adenocarcinoma of the vagina. Association of maternal stilbestrol therapy with tumor appearance in young women. New England Journal of Medicine 28(15):878-881. 
12. Johnson BL, Hicks HE, Cibulas W, et al. 1999. Public Health Implications of Exposure to Polychlorinated Biphenyls (PCBs), Agency for Toxic Substances and Disease Registry.

13. Letz, G. 1983. The Toxicology of PCB's - An Overview for Clinicians. West J Med 138:534-540.

14. Lyche JL, Gutleb AC, Bergman A, Eriksen GS, Murk AJ, et al. 2009. Reproductive and developmental toxicity of phthalates. Journal of Toxicology and Environmental Health Part B 12:225-249.

15. Meeker JD, Sathyanarayana S, Swan SH. 2009. Phthalates and other additives in plastics: human health exposure and associated health outcomes. Phil. Trans. R. Soc. B. 364:2097-2113.

16. Patisaul, HB, Adewale HB. 2009. Long-term effects of environmental endocrine disruptors on reproductive physiology and behavior. Frontiers in Behavioral Neuroscience 3(10): 1-12.

17. Smith EK, White MC, Weir HK, Peipins LA, Thompson TD. 2012. Higher incidence of clear cell adenocarcinoma of the cervix and vagina among women born between 1947 and 1971 in the United States. Cancer Causes Control 23:207211.

18. Silva MJ, Barr DB, Reidy, JA, Malek NA, Hodge CC, Caudill AP, Brock JW, Needham LL, Calafat AM. 2000. Urinary levels of seven phthalate metabolites in the U.S. population from the National Health and Nutrition Examination Survey (NHANES) 1999-2000. Environ Health Perpsect 112:331-338.

19. Swan SS. 2008. Environmental phthalate exposure in relation to reproductive outcomes and other health endpoints in humans. Env Res 108(2):177-184.

20. Talsness CE, Andrade AJM, Kuriyama SN, Taylor JA, vom Saal FS. 2009. Components of Plastic: experimental studies in animals and relevance for human health. Phil. Trans. R. Soc. B 364:2079-2096.

21. Titus-Ernstoff L, Troisi R, Hatch EE, et al. 2006. Menstrual and reproductive characteristics of women whose mothers were exposed in utero to diethylstilbestrol (DES). International Journal of Epidemiology 335:862-868.

22. Troisi R, Hatch EE, Titus-Ernstoff L, Hyer M, Palmer JR, et al. 2007. Cancer risk in women prenatally exposed to diethylstilbestrol. Int. J. Cancer 121: 356-360. 
23. Woodruff TJ, Zota AR, Schwartz JM. 2011. Environmental Chemicals in Pregnant Women in the United States: NHANES 2003-2004. Environ Health Perspect 119(6): 878-885. 


\section{CHAPTER II}

\section{LITERATURE REVIEW}

\section{Endocrine Disrupting Compounds}

A new recent report by the United Nations Environment Programme (UNEP) and World Health Organization (WHO) entitled "State of the Science: Endocrine Disrupting Chemicals - 2012" highlighted that approximately 800 chemicals are suspected to act as endocrine disruptors (EDs) or mimic natural hormones or disrupt hormone regulation (UNEP/WHO 2013, EU 2013). Some of these EDs mimic natural or synthetic estrogen. This recent UNO report has renewed concern by highlighting that there may be some associations between exposure to estrogen-mimicking EDs and an increased risk of hormonal cancer in women (UNEP/WHO 2013, EU 2013). EDCs may produce a wide range of adverse effects because of the complexity of the endocrine system with its multiple signaling pathways, feedback mechanisms and cross-talks. Although a number of experimental animal studies have shown many chemicals have potential endocrine disrupting activities, the data on their endocrine disrupting effects in humans is limited. The role of EDC's in the etiology of some of the human cancers and reproductive health hazards has been implicated, although the linkage between these two processes is highly controversial (Burantrevedh and Roy, 2001). In addition to their endocrine disrupting effects, some environmental estrogen-like chemicals produce multiple and multi-types of genetic and/or nongenetic hits which may contribute to the induction of genomic instability in stem cells (Roy et al. 1998).

Estrogens and environmental chemicals play a significant role in the development of adverse reproductive health effects in women and endogenous sex hormones are 
known to contribute to the development of reproductive cancers. Supporting evidence includes the known factors of early menarche, late menopause, and nulliparity associated with an increased risk of developing breast cancer. Both endometriosis and breast cancer have in common one of the etiological factors, i.e., estrogen (Evans 2008). The estrogen is a contributing factor in the development of endometriosis as well as in breast cancer. Tamoxifen, a hormonal therapy for breast cancer, stimulates the growth of endometrial cells and can cause endometriosis (Lin et al. 2009). The increased risk of endometriosis and breast cancer among postmenopausal women may be due to an altered endogenous estrogen (Bertelsen et al. 2007, Roy et al. 1997, Roy et al. 1998). There is a general agreement that human populations are continually exposed to a wide variety of environmental estrogen-like chemicals. We are beginning to acknowledge endocrine disrupting effects of these chemicals in humans through experimental animal data and epidemiological studies (Bertelsen et al. 2007 and Roy et al. 1997). Only a limited number of EDCs, such as diethylstilbestrol (DES), bisphenol A, polychlorinated biphenyls, phthalates and dichlorodiphenyltrichloroethane (DDT), have been studied extensively to assess the endocrine disrupting effects in experimental models and in humans. Both human exposure data and epidemiological studies focused on assessing potential risk of diseases in association with these chemicals have been reported.

\section{Polychlorinated Biphenyls}

PCBs are recognized as endocrine disruptors due to their ability to interfere with reproductive function and development in animals and humans by either increasing or blocking estrogen activity (Fielden et al. 2001; Ma and Sassoon 2006; McLachlan et al. 
2006). Adverse reproductive health effects have been established in numerous animal studies and have linked PCB exposure to prolonged estrus and decreased sexual receptivity in rats, decreased sperm fertilizing ability in mice (Fielden et al. 2001), decreased conception in mice, changes in the uterine myometrium and gland formation in mice (Ma and Sassoon 2006), prolonged menstruation, decreased birth weights, and decreased conception rates in rhesus monkeys (ASTDR 2000), and a significant dosedependent relationship in the prevalence and severity of endometriosis in rhesus monkeys (Rier et al. 2001). Human studies on reproductive end-points are less conclusive; however, some studies have linked PCB exposure to menstrual disturbances, early age at menarche (Schell and Gallo 2009), late miscarriages, a reduction in lactation time, preterm delivery, low birth weight, and endometriosis (Tsukimori et al. 2008, Yang et al. 2008, Yu et al. 2000, Buck Louis et al. 2005, Mendola et al. 1997, Baibergenova et al. 2003).

In retrospective studies from the Taiwan Yucheng cohort, Yucheng women exposed to PCBs reported having abnormal menstrual flow twice as often as controls, prolonged time to pregnancy, and reduced fertility (Yu et al. 2000; Yang et al. 2008). Japanese women from the Yusho cohort had a 2-fold increase in the proportion of spontaneous abortion and pregnancy loss and a 5 -fold increase in preterm delivery (Tsukimori et al. 2008). In a New York State Angler cohort PCB exposure level was significantly associated with a decrease in menstrual cycle lengths as well as a decrease in the number of months of lifetime lactation, however, time to pregnancy was not associated unless the duration of fish consumption was three to six years (Mendola et al. 1997; Buck et al. 2000; Kostyniak et al. 1999). 
Studies pertaining to PCBs and breast cancer are controversial. While some studies reported no significant associations (Xu et al. 2010; Silver et al. 2009; Gammon et al. 2002, Wolff et al. 2000, Hunter et al. 1997), others report slight increased risks among parous women who never breastfed (Moysich et al. 1998), or increased risks if genetic polymorphisms in the cytochrome P-450 1A1 (CYP 1A1) and menopausal status were considered (Zhang et al. 2004, Li et al. 2005; Moysich et al. 1999). Zhang et al. (2004) found that breast cancer risk was significantly increased among women with the CYP1A1 $\mathrm{m} 2$ variant genotype and among postmenopausal women with elevated serum PCB levels. In addition, an increased risk of breast cancer recurrence was found only in women who had PCB concentrations in the highest tertiles (Muscat et al. 2003).

\section{Phthalates}

Among various phthalates, di (2-ethylhexyl) phthalate (DEHP), di-butyl phthalate (DBP) and butylbenzylphthalate (BBP) have been studied for their endocrine disrupting effects. In numerous animal studies, phthalates have been shown to produce a variety of adverse effects including hepatic and renal damage, hepatocellular carcinoma, anovulation, decreased fetal growth, and most significantly anti-androgenic effects by suppressing testosterone and estrogen production (CDC 2005, Swan 2008). Reproductive abnormalities reported in rodent females include uterine and ovarian abnormalities (increased weights and malformations), advanced onset of puberty (delayed vaginal opening), reduced fecundity, decreased serum estradiol levels, prolonged estrus cycles, absence of ovulation, and modified morphology of the mammary gland (CDC 2005, Moral et al. 2011). 
While human studies associating phthalate exposure with adverse reproductive effects are less conclusive, many of the findings in male infants are consistent with the anti-androgenic action that has been demonstrated for phthalates in animal studies. In a follow-up analysis to the 2000 Study of Phthalates in Pregnant Women and Children, significant associations were found between AGD and 3 DEHP metabolites (MEHP, MEHHP and MEOHP) with mean metabolite concentrations found to be several times greater among males with shorter AGD compared to males with longer AGD (Swan 2008). Additional human studies with adverse reproductive endpoints including a significantly lower gestational age in newborns considered MEHP-positive (Latini et al. 2003), a dose-response relationship of MBP and low sperm concentration (Summarized in Swan 2008), a relationship between urinary MEP levels and sperm DNA damage, decreased sperm motility, and a reduction in serum free testosterone in men with occupational exposure to DBP and DEHP (Summarized in Frederiksen et al. 2007, summarized in Meeker et al. 2009). Human studies demonstrating the association between phthalate exposure and adverse reproductive effects in females are limited to only a few. Cobellis et al. (2003) reported higher plasma concentrations of DEHP and MEHP in women with endometriosis. More recently, Huang et al. (2010) reported that patients with leiomyomas had significantly higher levels of total urinary MEHP, patients with endometriosis had increased levels of urinary MnBP, and subjects who had the GSTMI null genotype had a significantly increased risk of adenomyosis.

\section{Bisphenol A}

Numerous studies have shown adverse effects of low doses of BPA on the development of male and female reproductive organs in experimental animals. In rodent 
females, BPA exposure has shown to cause alterations in the mammary gland development, changes in gene expression of the mammary gland, cystic ovaries, endometrial hyperplasia, adenomyosis, leiomyomas, atypical hyperplasia, stromal polyps, ductal hyperplasias and carcinoma, a decline in fertility and fecundity, decreased wet weight of the vagina, decreased volume of the endometrial lamina propria, and an increased expression of estrogen receptor- $\alpha(E R \alpha)$ and progesterone receptors (Talsness et al. 2009, Moral et al. 2008, Munoz-de-toro et al. 2005, Cabaton et al. 2011, Markey et al. 2004). Despite their widespread exposure human epidemiologic studies of BPA exposure and adverse reproductive endpoints are severely limited. In the few available studies, BPA levels were reported to be associated with miscarriages, fetuses with abnormal karyotype, and polycystic ovarian syndrome (Summarized in Meeker et al 2009). In a pilot nested case control study of BPA exposure and prematurity, pregnant women who delivered less than or equal to 37 weeks of gestation had higher urinary concentrations of BPA in a single spot urine sample collected during the third trimester compared to women who delivered after 37 weeks (Cantonwine et al. 2010).

\section{Bioinformatics: EDCs, Breast Cancer and Endometriosis}

While there are several studies which link EDCs - PCBs, BPA, and phthalate exposure to increased risk of a reproductive toxicity, there are other studies which have been inconsistent or showed no association between these EDCs and risk of breast cancer or endometriosis. In this study, we used a combined environmental epidemiologic, genomic, and bioinformatics approach to understand the relationship between EDCs and risk of developing estrogen-dependent complex chronic diseases - breast cancer and endometriosis by examining interactions between genes, diseases and these three selected 
EDCs. We have also evaluated the possibility that " estrogen mimicking endocrine disruptor responsive genes"' are potentially associated with systemic changes in breast cancer and endometriosis. To accomplish the objectives identified here, we introduce a comprehensive bioinformatics method using genomics, environmental and epidemiologic data integration that links with diseases - breast cancer and endometriosis to identify: 1) genes that interact with EDCs and link to the development of these diseases, and 2) important pathways that may be influenced by EDC exposures. The first and second steps in our method included modeling to assess estrogenicity of environmental chemicals to show the potential of endocrine disruption and assessing association between EDC exposure and diseases, respectively. The third step in our method included identifying genes responsive to EDC exposures using the Comparative Toxicology, Environmental Genome Project and KEGG. These EDC responsive genes were then compared to a curated list of genes in breast cancer and endometriosis. This comparison produced a list of genes responsive to the environment and important to breast cancer and endometriosis that was then further analyzed using gene networking tools such as RSpider, Cytoscape, and DAVID. Using this bioinformatics method we were able to identify environmentally responsive genes with the potential to be involved in interaction with EDCs that may be important to the development of breast cancer and endometriosis. We meta-analyzed environmental epidemiologic evidence for the risk of breast cancer and endometriosis with exposure to EDCs - PCB, phthalates, and BPA from 23 selected publications which we categorized by outcome: breast cancer and endometriosis. Metaanalysis was performed using the general variance-based method and homogeneity was tested by means of the Q statistic. Analysis was completed using Comprehensive Meta 
Analysis Version 2.2.046 from Biostat, Inc. which can be downloaded at www.MetaAnalysis.com (Borenstein et al. 2005). The resources, workflow, meta-analysis and bioinformatics tools and integration of environmental epidemiologic, genomic and disease databases are shown in Figure 1.

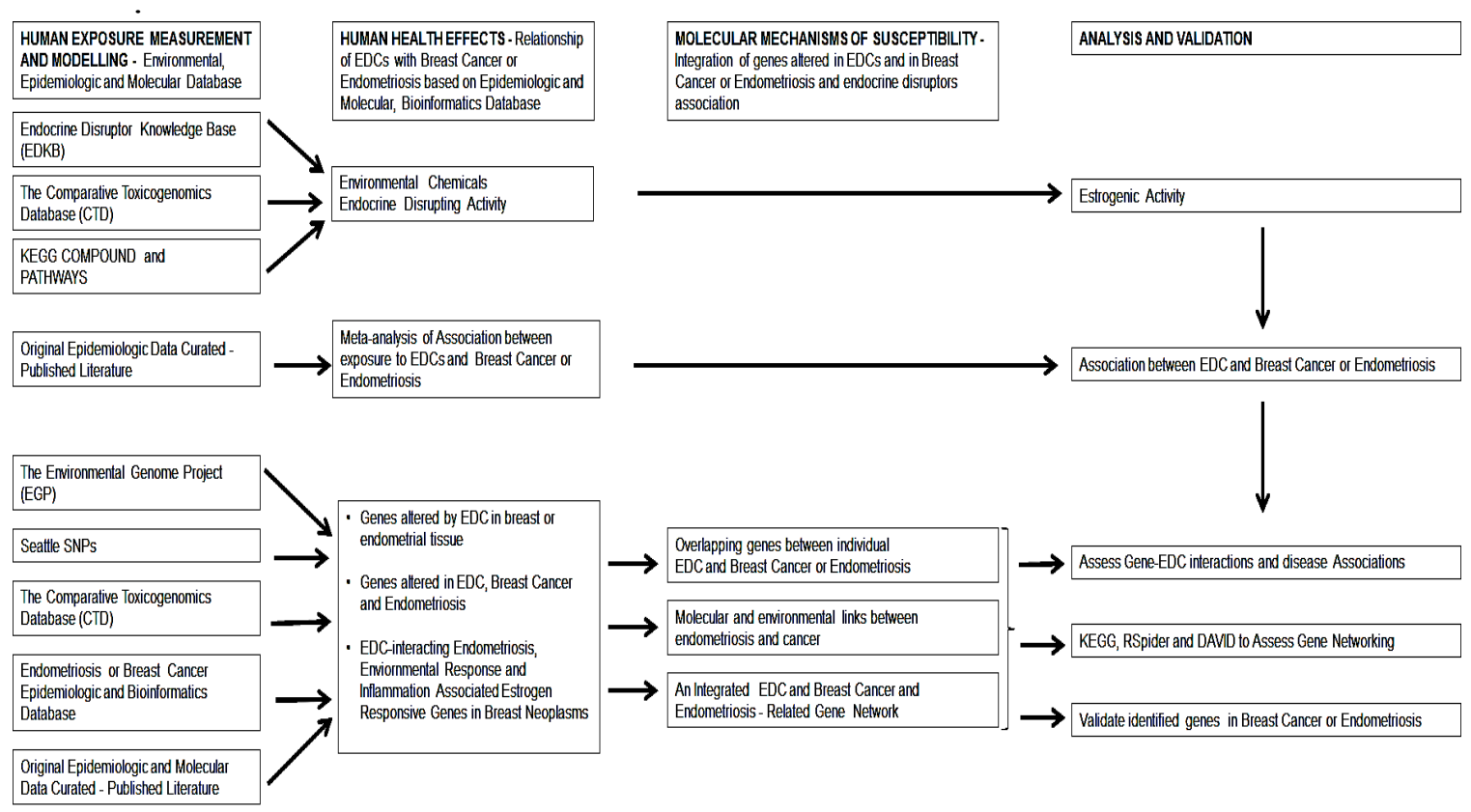

Figure 1. Flow chart showing the steps involved in identifying genes that illustrate link between endometriosis and breast cancer based on environmental response on epidemiologic, genomics, and bioinformatics databases.

\section{EDCs and Breast Cancer}

We identified twelve epidemiologic studies related to PCB, phthalate, or BPA exposure and breast cancer. Ten of the twelve studies assessed the relationship between PCB exposure and breast cancer (Charlier et al. 2004, Cohn et al 2012, Demers et al. 2002, Gammon et al. 2002, Gatto et al. 2007, Itoh et. al 2009, Millikan et al. 2013, Pavuk et. al 2003, Recio-Vega et al. 2001, Wolff et al. 2009), one study assessed the relationship between phthalate exposure and breast cancer (Lopez-Carillo et al. 2010), 
and one study assessed the relationship between BPA exposure and breast cancer (Yang et al. 2009). All twelve of the identified studies were case-control studies. In all of the studies, cases had histologically confirmed breast cancer and controls had no history of breast cancer diagnosis. In the majority of the studies, controls were matched on age and residence.

PCBs and Breast Cancer. Three of the ten PCB case-control studies failed to find any associations between exposure to total PCBs and breast cancer risk (Gammon et al. 2002, Gatto et al. 2007, Wolff et al. 2009) while two of the ten PCB studies found an inverse association between total PCB levels and breast cancer (Itoh et al. 2009, Pavuk et al. 2003). The largest case-control study conducted by Gammon et al. (2002) consisted of 646 newly diagnosed breast cancer cases and 429 matched controls failed to find any association between PCB exposure and breast cancer risk when comparing the highest quintile of serum Peak-4 (nos. 118, 153, 138, and 180) PCB levels to the lowest quintile $(\mathrm{OR}=0.83,95 \%$ CI $0.54-1.29)$. Gatto et al. (2007) did not find any associations with breast cancer when comparing the highest vs. lowest quintiles of mean total PCB levels in 355 cases and 327 controls $(\mathrm{OR}=1.01,95 \%$ CI 0.63-1.63) and Wolff et al. (2009) did not find any associations with breast cancer when comparing the highest vs. lowest quartiles of serum total PCB levels in 110 cases and 213 controls. Itoh et al. (2009) found a decreased risk of breast cancer when comparing the highest quartile of median total PCB levels to the lowest quartile $(\mathrm{OR}=0.33,95 \%$ CI 0.14-0.78) and Pavuk et al. (2003) found higher serum PCB levels to be inversely associated with breast cancer in total PCBs $(\mathrm{OR}=0.42,95 \% \mathrm{CI} 0.10-1.82)$ and in 3 sub-groups of PCBS: estrogenic, antiestrogenic/dioxin-like, and phenobarbital-type. 
Five of the PCB case-control studies found significant associations between breast cancer and exposure to individual PCB congeners, total PCBs, or specific sub-groups of PCBs (Charlier et al. 2004, Cohn et al. 2012, Demers et al. 2002, Millikan et al. 2013, Recio-Vega et al. 2001). Charlier et al. (2004) measured mean levels of 7 PCB congeners in 60 breast cancer cases and 60 healthy controls. They found total PCBs to be significantly different $(\mathrm{p}=0.012)$ between cases and controls $(7.08 \mathrm{vs.} 5.10 \mathrm{ppb})$ which can be attributed to significantly higher serum levels of PCB 153 in breast cancer cases when compared to controls ( 1.63 vs. $0.63 \mathrm{ppb}, \mathrm{p}<0.0001)$. The OR of breast cancer for PCB 153 was 1.8 (95\% CI 1.4-2.5). In a nested, matched case-control study of 112 cases and controls, Cohn et al. (2012) did not find any associations for total PCBs or PCB groupings, however, a significant association was found for PCB 203 when comparing the highest vs. lowest quartiles of exposure ( $\mathrm{OR}=6.3,95 \% \mathrm{CI} 1.9-21.7)$. In a matched case-control study of 314 cases and 523 controls, Demers et al. (2002) found breast cancer risk significantly associated with the sum of mono-ortho congeners (nos. 105, 118, 156) $(\mathrm{OR}=2.02,95 \% \mathrm{CI} 1.24-3.28), \mathrm{PCB} 118(\mathrm{OR}=1.60,95 \% \mathrm{CI} 1.01-2.53)$ and $\mathrm{PCB}$ $156(\mathrm{OR}=1.80,95 \% \mathrm{CI} 1.11-2.94)$ when comparing the fourth vs. first quartiles. In a population based case-control study with sub-groups of African-American women and white women, Millikan et al. (2013) did not find any associations with total PCBs and breast cancer among all participants $(\mathrm{OR}=1.09,95 \% \mathrm{CI} 0.79-1.52)$ or white women $(\mathrm{OR}=1.03,95 \% \mathrm{CI} 0.68-1.56)$, but did find a slightly elevated risk for African-American women (OR=1.74, 95\% CI 1.00-3.01). Recio-Vega et al. (2001) found the GM of total PCBs to be significantly higher in cases than controls (5.26 vs. $3.33 \mathrm{ppb})(\mathrm{OR}=1.09,95 \%$ CI 1.01-1.14) as well as an increased risk of breast cancer among PCBs grouped by 
structure-activity relationships and 8 individual PCB congeners (nos. 118, 128, 138, 170, 180, 195, 206, and 209).

Since the relationship between PCB exposure and breast cancer in ten epidemiologic studies was inconsistent or conflicting, risk estimates of PCBs on breast cancer from six case control studies were extracted and summarized using meta-analytic methods. Combining six studies of exposure to PCBs produced a summary risk estimate of 1.33 (95\% CI: $0.72-2.65)$ (Table 1; Fig. 2). PCB exposures were found to be associated with development of breast cancer as a meta-analysis of six studies produced an increased risk of 1.33; however, this was not statistically significant. 
Table 1. Epidemiological studies of the association between exposure to PCBs and risk of breast cancer.

\begin{tabular}{|c|c|c|c|c|c|c|c|}
\hline $\begin{array}{l}\text { Reference, } \\
\text { location }\end{array}$ & Study design & $\begin{array}{l}\text { Study } \\
\text { Population }\end{array}$ & $\begin{array}{c}\text { Measurement of } \\
\text { Exposure }\end{array}$ & Outcomes & Results & Comments & Confounders \\
\hline $\begin{array}{l}\text { Charlier et al. } \\
\text { (2004), } \\
\text { Belgium }\end{array}$ & $\begin{array}{l}\text { Case-control } \\
\text { study }\end{array}$ & $\begin{array}{l}60 \text { cases, } 60 \text { age } \\
\text { matched healthy } \\
\text { controls }\end{array}$ & $\begin{array}{l}\text { 7 PCBs from } \\
\text { serum, Total PCBs. }\end{array}$ & $\begin{array}{l}\text { Mean Total PCB levels } \\
\text { (ppb =ng/g) } \\
\text { Cases: } 7.08 \\
\text { Controls: } 5.10 \\
\text { Logistic Regression (OR- } \\
\text { 95\% CI). }\end{array}$ & $\begin{array}{l}\text { Total PCBs significantly } \\
\text { different in cases than } \\
\text { controls ( } p=0.012) \text {. High } \\
\text { concentrations of PCB153 } \\
\text { significantly associated } \\
\text { with an increased risk of } \\
\text { BC (OR=1.8, 95\% CI-1.4- } \\
\text { 2.5). }\end{array}$ & $\begin{array}{l}\text { Cases diagnosed with } \\
\text { breast cancer and } \\
\text { undergoing a surgical } \\
\text { intervention. } \\
\text { Controls free of BC at age } \\
\text { agnosis. }\end{array}$ & $\begin{array}{l}\text { Adjustments made for age, } \\
\text { menopausal status, number } \\
\text { of full-term pregnancies, } \\
\text { lactation, use of HRT, and } \\
\text { family history of BC. }\end{array}$ \\
\hline $\begin{array}{l}\text { Demers et al. } \\
\text { (2001), Canada }\end{array}$ & $\begin{array}{l}\text { Case-control } \\
\text { study }\end{array}$ & $\begin{array}{l}314 \text { cases, } 523 \\
\text { controls; matched } \\
\text { by age and } \\
\text { residence. }\end{array}$ & $\begin{array}{l}14 \text { PCB congeners } \\
\text { measured in } \\
\text { plasma (ug/ kg of } \\
\text { plasma lipids). } \\
\text { TEQ/ kg of lipids } \\
\text { for sum of mono- } \\
\text { ortho congeners } \\
\text { (nos. 105, 118, 156). }\end{array}$ & $\begin{array}{l}\text { Mean TEQ ng/g of lipids: } \\
\text { Cases: } 6.4 \\
\text { Controls: } 5.8 \\
\text { Logistic Regression (OR- } \\
95 \% \text { CI); Quartiles. }\end{array}$ & $\begin{array}{l}\text { Mean total of mono- } \\
\text { ortho congeners } \\
\text { significantly higher in } \\
\text { cases than controls } \\
\text { (p=0.005). } \\
\text { Significant associations } \\
\text { between breast cancer } \\
\text { risk and PCB 156, 118, \& } \\
\text { mono ortho congeners } \\
\text { In } 4^{\text {th }} \text { vs. 1st } \\
\text { quartiles.(OR=2.02, 95\% } \\
\text { CI: } 1.24-3.28) .\end{array}$ & $\begin{array}{l}\text { Cases: histologically } \\
\text { confirmed infiltrating } \\
\text { primary BC. Controls: no } \\
\text { history of BC diagnosis. }\end{array}$ & $\begin{array}{l}\text { Adjusted for age, residence, } \\
\text { BMI, history of benign brea: } \\
\text { disease, breastfeeding } \\
\text { duration. }\end{array}$ \\
\hline $\begin{array}{l}\text { Pavuk et al. } \\
\text { (2003), USA }\end{array}$ & $\begin{array}{l}\text { Case-control } \\
\text { study }\end{array}$ & $\begin{array}{l}24 \text { cases, } 88 \\
\text { controls }\end{array}$ & $\begin{array}{l}\text { Total PCBs from } \\
\text { serum (n=15); } \\
\text { Groups of PCBs: } \\
\text { (1) estrogenic, } \\
\text { (2) anti-estrogenic, } \\
\text { dioxin-like, } \\
\text { (3) phenobarbital- } \\
\text { type }\end{array}$ & $\begin{array}{l}\text { GMs Total PCBs (ng/g of } \\
\text { lipid): } \\
\text { Cases: } 3228.2 \\
\text { Controls: } 2885.8 \\
\text { Logistic Regression (OR- } \\
\text { 95\% CI); Tertiles }\end{array}$ & $\begin{array}{l}\text { Higher serum levels of } \\
\text { total PCBs (OR=0.42, } \\
95 \% \text { CI } 0.10-1.82) \\
\text { inversely associated with } \\
\text { BC. Groups } 1,2, \& 3 \text { also } \\
\text { inversely associated. }\end{array}$ & $\begin{array}{l}\text { Cases: histologically } \\
\text { confirmed invasive BC. } \\
\text { Controls: identified } \\
\text { through random } \\
\text { sampling of primary care } \\
\text { physicians. }\end{array}$ & $\begin{array}{l}\text { Adjusted for age, age at } \\
\text { menarche, education, alcohı } \\
\text { consumption, smoking. }\end{array}$ \\
\hline $\begin{array}{l}\text { Recio-Vega et } \\
\text { al. (2011), } \\
\text { Mexico }\end{array}$ & $\begin{array}{l}\text { Case-control } \\
\text { Study }\end{array}$ & $\begin{array}{l}70 \text { cases, } 70 \\
\text { controls }\end{array}$ & $\begin{array}{l}\text { Individual and } \\
\text { total PCBs from } \\
\text { serum (n=20); } \\
\text { 5PCB grous by } \\
\text { structure-activity } \\
\text { relationships. }\end{array}$ & $\begin{array}{l}\text { GMTotal PCB levels } \\
\text { (ppb): } \\
\text { Cases: } 5.26 \\
\text { Controls: } 3.33 \\
\text { Logistic Regression (OR- } \\
\text { 95\% CI). }\end{array}$ & $\begin{array}{l}\text { Total PCBs significantly } \\
\text { higher among cases than } \\
\text { controls (OR=1.09, } 95 \% \\
\text { CI 1.01-1.14). Risk of BC } \\
\text { positively associated with } \\
8 \text { PCB congeners: } 118 \text {, } \\
128,138,170,180,195, \\
206 \text {, and 209. }\end{array}$ & $\begin{array}{l}\text { Cases: first diagnosis of } \\
\text { BC by biopsy. } \\
\text { Controls: negative } \\
\text { biopsies from same } \\
\text { hospitals and geographic } \\
\text { area. }\end{array}$ & $\begin{array}{l}\text { Adjusted for age, age at } \\
\text { menarche, lactation, } \\
\text { menopause status, BMI. }\end{array}$ \\
\hline $\begin{array}{l}\text { Wolff et al. } \\
\text { (2000), US }\end{array}$ & $\begin{array}{l}\text { Prospective } \\
\text { case-control } \\
\text { Study }\end{array}$ & $\begin{array}{l}148 \text { cases, } 295 \\
\text { individually } \\
\text { matched controls }\end{array}$ & $\begin{array}{l}\text { Total PCBs from } \\
\text { serum. }\end{array}$ & $\begin{array}{l}\text { GMTotal PCBs (ng/g of } \\
\text { lipids): } \\
\text { Cases: } 683 \\
\text { Controls: } 663 \\
\text { Logistic Regression (OR- } \\
\text { 95\% CI); Quartiles }\end{array}$ & $\begin{array}{l}\text { GM Total PCB levels not } \\
\text { significantly different. } \\
\text { No association between } \\
\text { PCB exposure and BC } \\
\text { (OR=2.02 95\% CI 0.76- } \\
\text { 5.37). }\end{array}$ & $\begin{array}{l}\text { BC cases identified } \\
\text { through active follow-up } \\
\text { of the NYY Women's } \\
\text { Health Study Cohort. } \\
\text { Controls selected at } \\
\text { random from cohort who } \\
\text { were alive and free of } \\
\text { disease at the time of } \\
\text { case diagnosis. }\end{array}$ & $\begin{array}{l}\text { Adjusted for age at } \\
\text { menarche, \# of full-term } \\
\text { pregnancies, age at first } \\
\text { birth, family history of BC, } \\
\text { lifetime history of lactation, } \\
\text { BMI, menopausal status at } \\
\text { time of blood donation. }\end{array}$ \\
\hline $\begin{array}{l}\text { Itoh et al. } \\
\text { (2008), J apan }\end{array}$ & $\begin{array}{l}\text { Matched case- } \\
\text { control study }\end{array}$ & $\begin{array}{l}403 \text { pairs; matched } \\
\text { by age ( } \text { years) } \\
\text { and residence. }\end{array}$ & $\begin{array}{l}\text { Total PCBs from } \\
\text { serum (Sum of } 41 \\
\text { PCB peaks). }\end{array}$ & $\begin{array}{l}\text { Median Total lipid- } \\
\text { adjusted PCBs (ng/g): } \\
\text { Cases: } 170 \\
\text { Controls: } 180 \\
\text { Logistic Regression (OR, } \\
\text { 95\% CI), Quartiles. }\end{array}$ & $\begin{array}{l}\text { Total PCBs associated } \\
\text { with a decreased risk of } \\
\text { BC. } \\
\text { (OR=0.33, 95\% CI: 0.14- } \\
0.78 \text {, p-value 0.008); } \\
\text { highest vs. lowest } \\
\text { quartile. }\end{array}$ & $\begin{array}{l}\text { Cases: histologically } \\
\text { confirmed invasive BC. } \\
\text { Controls: selected from } \\
\text { medical checkup } \\
\text { examinees, no BC } \\
\text { diagnosis. }\end{array}$ & $\begin{array}{l}\text { Adjusted for lipids, BMI, } \\
\text { menopausal status \& age, } \\
\text { smoking, fish \& veg } \\
\text { consumption, family history } \\
\text { parity, age at first childbirth } \\
\text { age at menarche, history of } \\
\text { BC screening }\end{array}$ \\
\hline
\end{tabular}


Figure 2. Forest plot of epidemiological studies of the association between exposure to PCBs and risk of breast cancer.

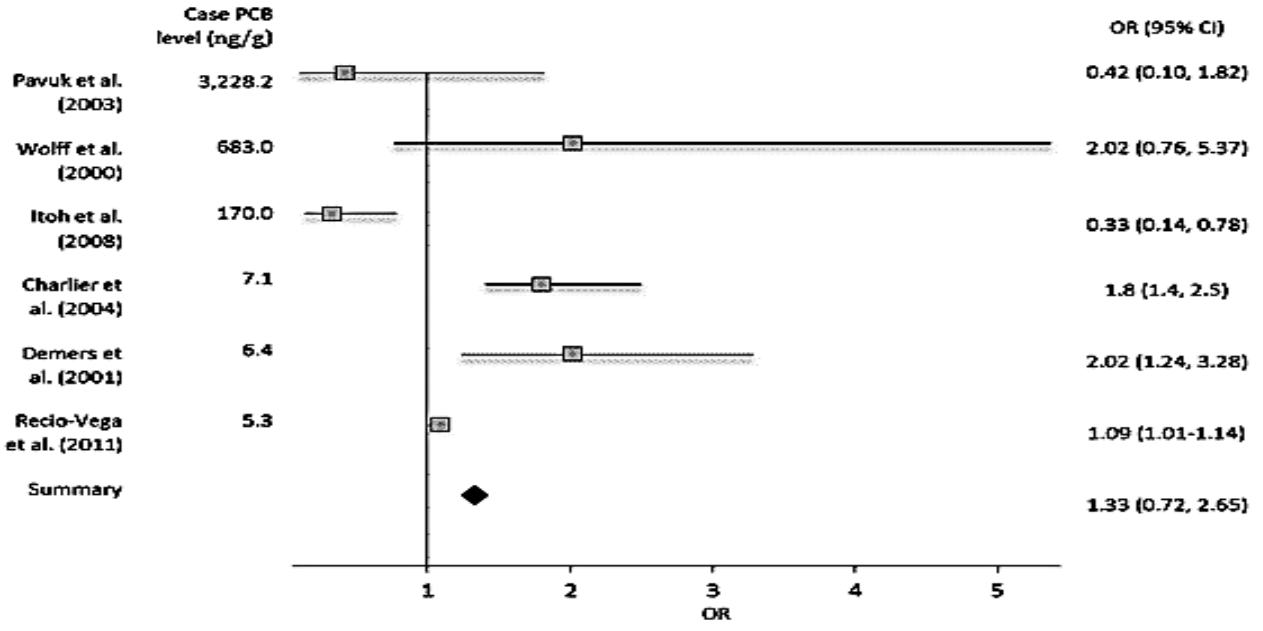

Bisphenol A or phthalate and breast cancer: No meta-analysis was performed on exposure to BPA or phthalates, because only one study for each chemical fit the criteria. Lopez-Carillo et al. (2010) found urinary concentrations of monoethyl phthalate (MEP) to be significantly higher in cases than controls when comparing the highest vs. lowest tertile of exposure (169.58 vs $106.78 \mathrm{ug} / \mathrm{g}$ creatinine). The OR of breast cancer risk in the highest tertile of urinary MEP, compared with the lowest tertile, was 2.20 (95\% CI 1.33-3.63) and became higher when estimated for premenopausal women $(\mathrm{OR}=4.13,95 \%$ CI 1.60-10.7). On the contrary, significant negative associations were found for urinary concentrations of monobenzyl phthalate $(\mathrm{MBzP})(\mathrm{OR}=0.46,95 \% \mathrm{CI} 0.27-0.79)$ and mono (3-carboxypropyl) phthalate $(\mathrm{MCPP})(\mathrm{OR}=0.44,95 \% \mathrm{CI} 0.24-0.80)$. In a matched 
case-control study Yang et al. (2009) measured median blood BPA levels in 70 cases and 80 controls. Median BPA levels were higher in cases than controls ( $0.61 \mathrm{vs.} 0.03 \mathrm{ug} / \mathrm{L})$, however, the differences were not found to be statistically significant $(\mathrm{p}=0.42)$.

PCBs-Breast Cancer-Gene Association: The CTD search revealed that besides polychlorinated biphenyls, the five most common PCB congeners studied for gene interaction were 3,4,3',4'-tetrachlorobiphenyl (77), 2',3,3',4',5-pentachloro-4hydroxybiphenyl (4'-OH-PCB-86), 3,4,5,3',4'-pentachlorobiphenyl (126), 2,3,3',4,4',5hexachlorobiphenyl (153), and 2,2',3,4,4',5,5'-Heptachlorobiphenyl (180) (Table 2). There were 5289 genes related to PCBs as a family of chemicals and 386 genes related to breast cancer (Fig. 3). The common genes between PCBs and breast cancer were 200. The top interacting genes with polychlorinated biphenyls as a chemical class were CYP1A1, AHR, CYP1A2, AR, CYP1A, CYP1B1, VCAM1, MAPK1, MAPK3, and PTGS2. The top interacting genes with polychlorinated biphenyls in breast neoplasms were AR, CYP1A1, CYP1B1, ESR1, ESR2, PTGS2, and RAF1. Out of a total 200 gene interactions observed with individual PCBs, the interaction of genes AR, BAX, CYP1A1, CYP1B1, KDR, PARP1, PTGS2, and RAF1 was common with tetrachloride-, pentachloride-, and hexachloride biphenyls in breast neoplasms (Table 2). CYP1A1, AHR, AR, CYP1A, CYP1B1, and PTGS2 genes are common in both PCB-gene and PCB-gene-breast cancer groups. Interactions among these genes are shown in Figure 4. Enrichment pathway analysis revealed that these genes are part of: 1) pathways in cancer (KEGG:05200); 2) signal transduction (REACT:111102), 3) mTOR signaling pathway (KEGG:04150); 4) focal adhesion (KEGG:04510); 5) VEGF signaling pathway (KEGG:04370); and 6) ErbB signaling pathway (Table 3). 
BPA, Phthalate and Breast Cancer-Gene Association: There were 6365 genes related to BPA as chemicals. There were 385 genes known to be related to breast cancer. There were 209 common genes between BPA and breast cancer (Fig. 2). There were 5754 genes related to phthalate as a family of chemicals and 385 genes related to breast cancer (Fig. 2). The common genes between dibutyl phthalate and breast cancer and diethylhexyl phthalate and breast cancer were 162 , and 89 , respectively. Identification of the common genes with breast cancer and both dibutyl phthalate and diethylhexyl phthalate further revealed that there were 54 common genes between dibutyl phthalate and diethylhexyl phthalate and breast cancer: ABCG2, AHR, AKT1, ALDOA, AR, BCL2, BMP2, BMP4, CADM1, CASP7, CCND1, CD40, CTNNB1, CYP17A1, CYP19A1, CYP1A1, CYP1B1, CYP3A4, DNMT1, DNMT3A, DNMT3B, EDNRB, EEF2, EGFR, ESR1, ESR2, ESRRA, F3, FASN, FOS, GPX1, HADHB, HSP90AA1, IGF1, IGFBP7, JUN, LOXL2, MMP2, MMP9, NDRG1, NFKBIA, NOTCH2, OCLN, PER3, PIK3CA, PTPRD, RPL31, RPS4X, SOD2, THBS1, TNF, TUBB3, WNT10B, and YBX1 (Table 2). Interactions among these genes are shown in Figure 3. Enrichment pathway analysis revealed that some of these genes are part of: 1) pathways in cancer (KEGG:05200); 2) signal transduction (REACT:111102), and 3) MAPK signaling pathway ( KEGG:04150) (Table $3)$. 
Table 2. Genes interacting with polychlorinated biphenyls in breast neoplasms.

\begin{tabular}{|c|c|}
\hline IUPAC Name (congener number) & Interacting genes \\
\hline Polychlorinated Biphenyls & $\begin{array}{l}65 \text { genes: ACHE } \mid \text { AFP } \mid \text { AGR2 | AHR | AKAP12 | AKT1 | ANGPTL4 | APOBEC3B | } \\
\text { AR | ARAF | AREG | AURKA | BCHE | BIRC5 | CDKN1B | CENPF | CLDN4 | } \\
\text { COMT | CXCL12 | CXCL2 | CYP17A1 | CYP19A1 | CYP1A1 | CYP1B1 | CYP2B1 | } \\
\text { CYP3A4 | DNMT1 | DNMT3A | DNMT3B | ESR1 | ESR2 | FOS | GPI | GPNMB | } \\
\text { H2AFX | HEY1 | HMOX1 | HP | IFNG | IL6 | JUN | KRAS | MKI67 | MMP3 | NCOA3 } \\
\text { | NQO1 | PPARGC1B | PTGS2 | RAD51 | RAD51C | RAD54L | RAF1 | RPS8 | SOD2 | } \\
\text { SPP1 | STC2 | STMN1 | TGM2 | THBS1 | THEMIS2 | TNF | TOP2A | TYMS | UBE2C }\end{array}$ \\
\hline 2,4,4'-trichlorobiphenyl (28) & $\begin{array}{l}\text { 11 genes: AR | CYP1A1 | CYP1B1 | CYP2B1 | ESR1 | ESR2 | HIF1A | KDR | PTGS2 | } \\
\text { RAF1 | TP53 }\end{array}$ \\
\hline 2,4',5-trichlorobiphenyl (31) & 3 genes: AR | ESR1 | ESR2 \\
\hline 2,5,2',5'-tetrachlorobiphenyl (55) & $\begin{array}{l}\text { 13 genes: ACHE | AHR | AKT2 | APC2 | AR | CYP1A1 | CYP2B1 | EPB41L3 | IGF1R } \\
\mid \text { MMP2 | PARP1 | PLA2G4A | ZEB2 }\end{array}$ \\
\hline 3,4,3',4'-tetrachlorobiphenyl (77) & $\begin{array}{l}27 \text { genes: AHR | AR | BAX | CAV1 | CCNE1 | CYP1A1 | CYP1B1 | ESR1 | ESR2 | } \\
\text { GPI | GPX1 | HADHB | HIF1 A | HNRNPK | IL1B | IL6 | KDR | MRPL19 | NDRG1 | } \\
\text { NOS3 | NQO1 | PARP1 | PER3 | PTGS2 | RAF1 | RELA | TNF }\end{array}$ \\
\hline $\begin{array}{l}\text { 2',3,3',4',5-pentachloro-4- } \\
\text { hydroxybiphenyl (4'-OH-PCB-86;4- } \\
\text { hydroxy-2 , 2' , 3' , 4' , 5'- } \\
\text { pentachlorobiphenyl ) }\end{array}$ & $\begin{array}{l}75 \text { genes: ACVR1 | AFP | APC2 | ARAF | ATM | BIRC5 | BMPR2 | CASP8 | CAV1 | } \\
\text { CD40 | CHEK2 | CSF1 | CSF3 | CST6 | CXCL12 | CXCL2 | CYP17A1 | CYP1A1 } \mid \\
\text { DAP3 | DDIT3 | DNMT3A | DNMT3B | DPYD | EEF2 | EFNA1 | EGF | ERBB2 | F3 | } \\
\text { FABP7 | FGFR2 | FHL2 | FKBPL | GDF10 | HIF1A | HRG | IL24 | JAG1 | JAG2 | JUN } \\
\mid \text { LDHB | LEPR | LPAR1 | MFGE8 | MME | MMP2 | MMP3 | MMP9 | MRPL13 | } \\
\text { MTDH | MTHFR | MTR | NDRG1 | NOTCH3 | NOTCH4 | NRCAM | NUDT2 | OCLN } \\
\mid \text { PARP1 | PDE2A | PDGFA | PHB | PPARGC1B | PTPRD | RGS2 | SLC28A1 | STAT3 } \\
\mid \text { SYNE1 | SYNJ2 | TFRC | THBS1 | THEMIS2 | TOP2A | VEGFC | VPS39| ZEB1 }\end{array}$ \\
\hline 2,2',4,6,6'-pentachlorobiphenyl (104) & 9 genes: AKT1 | AR | CXCL8 | EGFR | FOS | JUN | MMP3 | OCLN | SRC \\
\hline 2,3,3',4,4'-pentachlorobiphenyl (105) & 4 genes: AHR $\mid$ AR $\mid$ CYP1A1 $\mid$ CYP2B1 \\
\hline 2,3',4,4',5-pentachlorobiphenyl (107) & $\begin{array}{l}\text { 10 genes: AHR | AR | CASP7 | CYP1A1 | CYP1B1 | CYP2B1 | HIF1A | KDR | OCLN | } \\
\text { PTGS2 }\end{array}$ \\
\hline 2,3,4,4',5-pentachlorobiphenyl (114) & 2 genes: AHR |CYP1A1 \\
\hline $2,3^{\prime}, 4,4^{\prime}, 5$-pentachlorobiphenyl (118) & $\begin{array}{l}\text { 10 genes: AHR | AR | CASP7 | CYP1A1 | CYP1B1 | CYP2B1 | HIF1A | KDR | OCLN | } \\
\text { PTGS2 }\end{array}$ \\
\hline 3,4,5,3',4'-pentachlorobiphenyl (126) & $\begin{array}{l}77 \text { genes: ACVR1 | ADAMTS1 | AFP | AHR | AKAP12 | AKT1 | APRT | AR | AREG | } \\
\text { BARD1 | BAX | BCL2 | BMP4 | BRCA1 | CADM1 | CAV1 | CCL20 | CCND1 | CD74 | } \\
\text { CXCL12 | CXCL8 | CYP17A1 | CYP19A1 | CYP1A1 | CYP1B1 | CYP2B1 | EGF | } \\
\text { ESR1 | F3 | FASN | FGFR2 | FHL2 | FST | GPNMB | HES1 | HIF1A | HMOX1 | } \\
\text { ICAM5 | IGF1 | IGF1R | IGFBP5 | IGFBP7 | IL1B | IL6 | JUN | KDR | LDHAL6B | } \\
\text { LPAR1 | MME | MMP9 | NOS2 | NOS3 | NOTCH1 | NQO1 | NRG1 | OCLN | PAK1 | } \\
\text { PARP1 | PDGFA | PER3 | PHGDH | PLA2G4A | PTGS2 | PTPRD | RAF1 | SERPINB2 } \\
\text { | SLC2A5 | SLC5A5 | SNAI1 | SPP1 | STC2 | SYNJ2 | TBX3 | TGM2 | TNF | TP53 | } \\
\text { VEGFC }\end{array}$ \\
\hline $\begin{array}{l}\text { 2,3,4,2',3',4'-hexachlorobiphenyl } \\
(128)\end{array}$ & 2 genes: AHR |AR \\
\hline 2,3,3',4,4',5-hexachlorobiphenyl (129) & 5 genes: AHR $\mid$ AR $\mid$ CYP1A1 | CYP1B1 | ESR1 \\
\hline 2,2',3',4,4',5-hexachlorobiphenyl & 27 genes: ACHE $\mid$ AHR $\mid$ AKT2 $\mid$ APC2 $\mid$ AR $\mid$ BRCA1 $\mid$ CCT5 | CENPF | CFL1 $\mid$ \\
\hline
\end{tabular}

\begin{tabular}{|c|c|}
\hline $2,3,6,2^{\prime}, 3^{\prime}, 6^{\prime}$-hexachlorobiphenyl (136) & 2 genes: AR | CYP2B1 \\
\hline $2,4,5,2^{\prime}, 4^{\prime}, 5^{\prime}$-hexachlorobiphenyl (153) & $\begin{array}{l}51 \text { genes: AHR | AKAP12 | AR | BAX | BCL2 | BRCA1 | CASP8 | CCND1 | CDH1 } \\
\text { | CTNNB1 | CXCL12 | CYP19A1 | CYP1A1 | CYP1B1 | CYP2B1 | CYP3A4 | } \\
\text { EGFR | ESR1 | ESR2 | FASN | FOS | GPX1 | GPX2 | HIF1A | HSPA1B | IFNG | } \\
\text { IGF1 | IL1B | JUN | KDR | MAP3K1 | MEIS1 | NDRG1 | NOTCH1 | NQO1 | NRG1 } \\
\text { | OCLN | PARP1 | PTGS2 | PTPRD | RAF1 | SPP1 | SRC | STAT5A | STMN1 | } \\
\text { TFPI2 | TNF | TNFSF10 | TP53 | TUBB3 | XRCC3 }\end{array}$ \\
\hline $3,4,5,3^{\prime}, 4^{\prime}, 5^{\prime}-\mathrm{hc}$ & 7 genes: AHR | BAX | CYP1A1 | CYP1B1 | HIF1A | KDR | PTGS2 \\
\hline $2,2^{\prime}, 3,4,4^{\prime}, 5,5^{\prime}-$ Heptachlorobiphenyl (180) & $\begin{array}{l}19 \text { genes: ABL1 | AHR | AR | BAX | BCL2 | BRCA1 | CYP1A1 | CYP1B1 | } \\
\text { CYP2B1 | FOS | HIF1A | IGF1 | KDR | MMP2 | MMP9 | NOTCH1 | PTGS2 | TP53 } \\
\text { | ZEB2 }\end{array}$ \\
\hline 17 beta Estradiol & $\begin{array}{l}255 \text { genes: ABCG2 } \mid \text { ACHE } \mid \text { ADAMTS1 } \mid \text { AFP } \mid \text { AGR2 } \mid \text { AHR } \mid \text { AKAP12 } \mid \text { AKT1 } \mid \\
\text { AKT2 } \mid \text { ALDOA } \mid \text { APOBEC3B } \mid \text { AR } \mid \text { ARAF } \mid \text { AREG } \mid \text { ARHGDIA } \mid \text { ARTN } \mid \text { ATM } \mid \\
\text { ATP7B } \mid \text { AURKA } \mid \text { BARD1 } \mid \text { BAX } \mid \text { BCAR3 | BCHE } \mid \text { BCL2 } \mid \text { BIRC5 | BMP2 } \mid \\
\text { BMP4 | BMPR2 | BRCA1 | BRCA2 | C10ORF10 | CADM1 | CASP7 } \mid \text { CASP8 } \mid \\
\text { CAV1 } \mid \text { CCL20 } \mid \text { CCND1 } \mid \text { CCNE1 } \mid \text { CD109 } \mid \text { CD40 } \mid \text { CDA } \mid \text { CDH1 } \mid \text { CDH5 } \mid\end{array}$ \\
\hline
\end{tabular}




\begin{tabular}{|c|c|}
\hline & 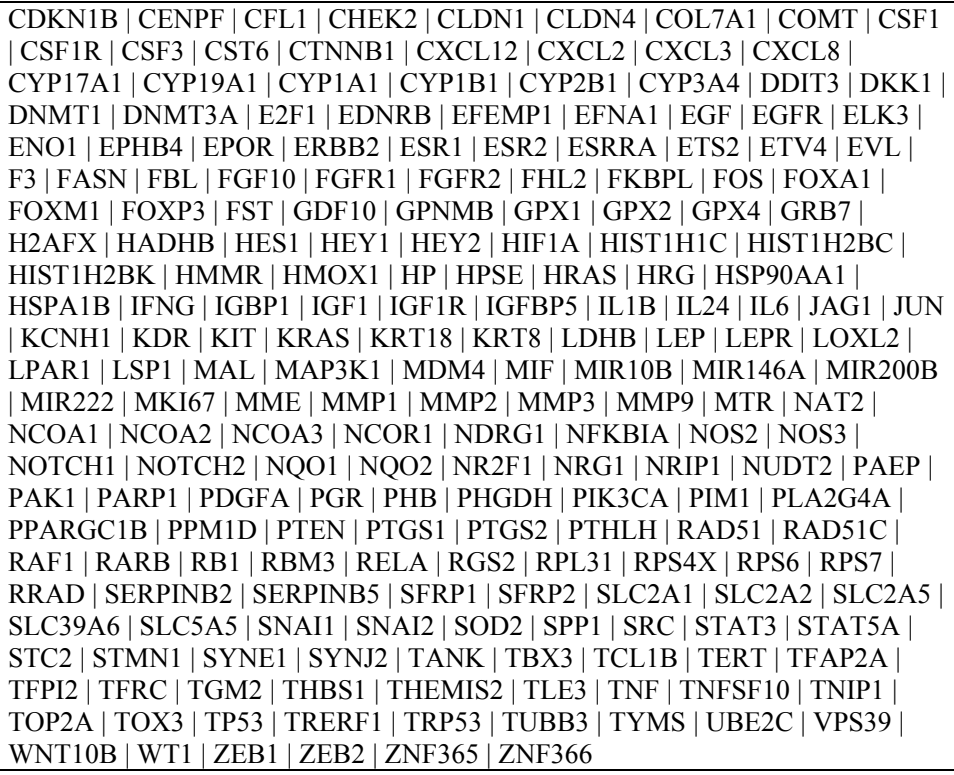 \\
\hline Diethyl phthalate & AFP, AHR, AR, CXCL8, CYP17A1, CYP1B1, ESR1, ESR2, IFNB1 \\
\hline $\begin{array}{l}\text { Dibutyl Phthalate and Diethylhexyl } \\
\text { Phthalate }\end{array}$ & $\begin{array}{l}\text { 54 Common genes: ABCG2, AHR, AKT1, ALDOA, AR, BCL2, BMP2, BMP4, } \\
\text { CADM1, CASP7, CCND1, CD40, CTNNB1, CYP17A1, CYP19A1, CYP1A1, } \\
\text { CYP1B1, CYP3A4, DNMT1, DNMT3A, DNMT3B, EDNRB, EEF2, EGFR, ESR1, } \\
\text { ESR2, ESRRA, F3, FASN, FOS, GPX1, HADHB, HSP90AA1, IGF1, IGFBP7, } \\
\text { JUN, LOXL2, MMP2, MMP9, NDRG1, NFKBIA, NOTCH2, OCLN, PER3, } \\
\text { PIK3CA, PTPRD, RPL31, RPS4X, SOD2, THBS1, TNF, TUBB3, WNT10B, } \\
\text { YBX1. }\end{array}$ \\
\hline Bisphenol A & 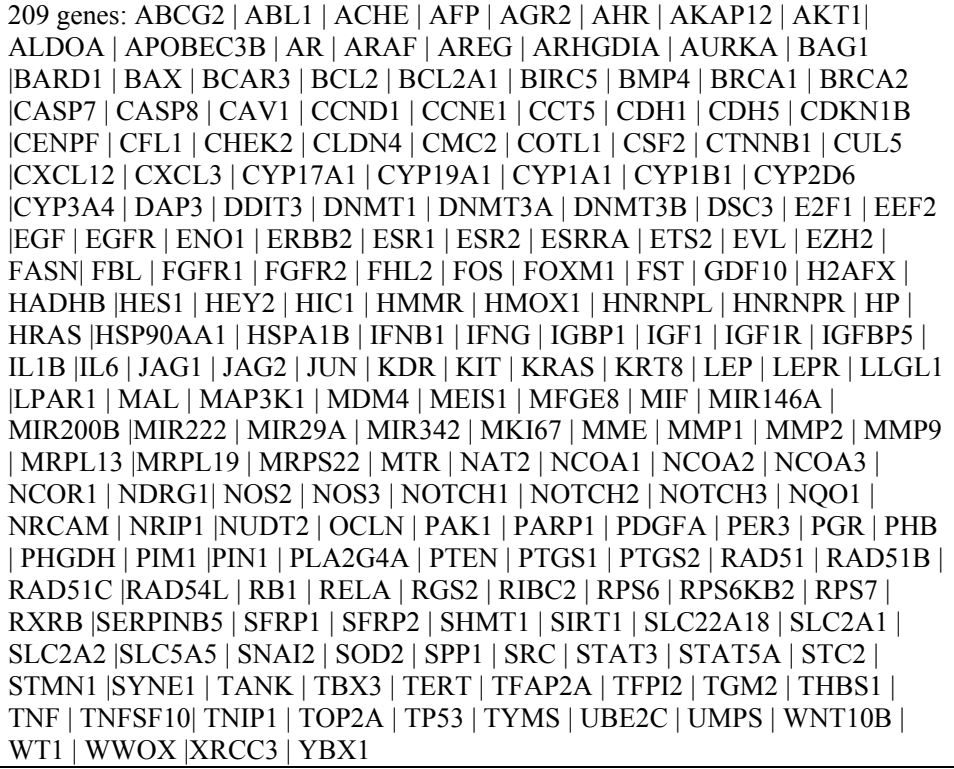 \\
\hline
\end{tabular}


Figure 3. Venn diagram of list of genes common between breast neoplasms and PCBs, phthalates or bisphenol A.
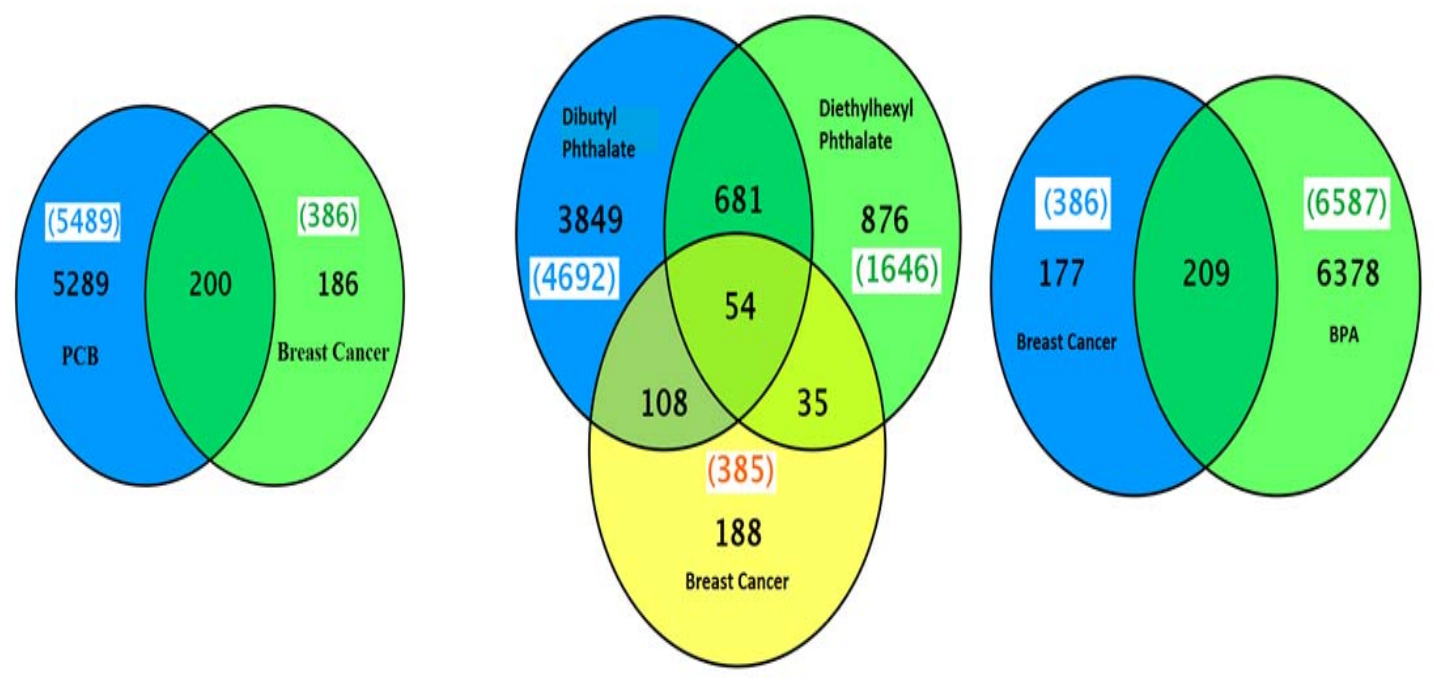

Figure 4. Gene Set/Pathway enrichment analysis of genes associated with PCBs, phthalates, or bisphenol A in breast neoplasms.
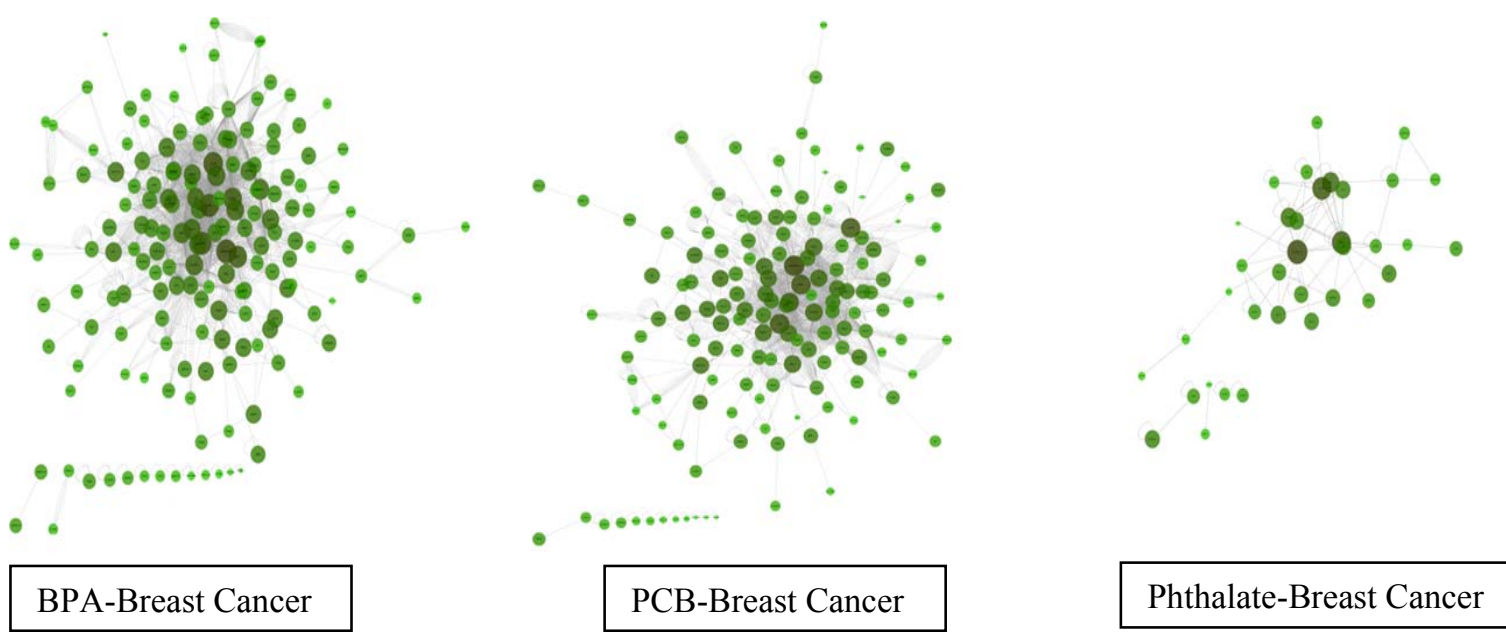

BPA-Breast Cancer

PCB-Breast Cancer

Phthalate-Breast Cancer 
Table 3. KEGG enrichment pathways for common AREG, CYP19A1, EGFR, FOS, IGF1, KRAS, and PGR genes in EDCs, breast cancer and endometriosis.

\begin{tabular}{c|c|c|c}
\hline Pathways & Pathway ID & Gene association & $\begin{array}{c}\text { Number of } \\
\text { associated genes }\end{array}$ \\
\hline Steroid hormone biosynthesis & KEGG:00140 & CYP19A1 & 1 \\
\hline Metabolic pathways & KEGG:01100 & CYP19A1 & 1 \\
\hline MAPK signaling pathway & KEGG:04010 & EGFR|FOS|KRAS & 3 \\
\hline ErbB signaling pathway & KEGG:04012 & AREG|EGFR|KRAS & 3 \\
\hline Chemokine signaling pathway & KEGG:04062 & KRAS & 1 \\
\hline p53 signaling pathway & KEGG:04115 & IGF1 & 1 \\
\hline mTOR signaling pathway & KEGG:04150 & IGF1 & 1 \\
\hline Dorso-ventral axis formation & KEGG:04320 & EGFR|KRAS & 2 \\
\hline VEGF signaling pathway & KEGG:04370 & KRAS & 1 \\
\hline Focal adhesion & KEGG:04510 & EGFR|IGF1| & 2 \\
\hline Adherens junction & KEGG:04520 & EGFR & 1 \\
\hline Tight junction & KEGG:04530 & KRAS & 1 \\
\hline Gap junction & KEGG:04540 & EGFR|KRAS & 2 \\
\hline $\begin{array}{c}\text { Toll-like receptor signaling } \\
\text { pathway }\end{array}$ & KEGG:04620 & FOS & 1 \\
\hline $\begin{array}{c}\text { Natural killer cell mediated } \\
\text { cytotoxicity }\end{array}$ & KEGG:04650 & KRAS & 1 \\
\hline $\begin{array}{c}\text { T cell receptor signaling } \\
\text { pathway }\end{array}$ & KEGG:04660 & FOS|KRAS & 2 \\
\hline $\begin{array}{c}\text { B cell receptor signaling } \\
\text { pathway }\end{array}$ & KEGG:04662 & FOS|KRAS| & 2 \\
\hline Fc epsilon RI signaling pathway & KEGG:04664 & KRAS & 1 \\
\hline Regulation of actin cytoskeleton & KEGG:04810 & EGFR|KRAS & 2 \\
\hline Insulin signaling pathway & KEGG:04910 & KRAS & 1 \\
\hline GnRH signaling pathway & KEGG:04912 & EGFR|KRAS & 2 \\
\hline Pathways in cancer & KEGG:05200 & EGFR|FOS|IGF1|KRAS & 4 \\
\hline Pancreatic cancer & KEGG:05212 & EGFR|KRAS & 2 \\
\hline Endometrial cancer & KEGG:05213 & EGFR|KRAS & 2 \\
\hline & & & \\
\hline
\end{tabular}


Association between endometriosis and exposure to PCB, phthalates, or BPA: We identified 11 epidemiologic studies related to PCB, phthalate, or BPA exposure and endometriosis. Seven of the studies assessed the relationship between PCB exposure and endometriosis (Buck et al. 2005, Heiler et al. 2005, Niskar et al. 2009, Pauwels et al. 2001, Porpora et al. 2009, Trabert et al. 2010, Tsukino et al. 2005), two studies assessed the relationship between phthalate exposure and endometriosis (Kim et al. 2001 and Upson et al. 2013), one study assessed the relationship between BPA exposure and endometriosis (Itoh et al. 2007) and one study assessed the relationship between phthalate and BPA exposure and endometriosis (Buck et al. 2013). Of these studies, eight were case-control studies, one was a cross-sectional study; and two were cohort studies. In all of the studies, endometriosis cases were confirmed with a laparoscopic examination and/or biopsy and in nine of the eleven studies controls were also confirmed to be disease free through laparoscopic examination. Controls in the remaining two studies were randomly selected from a list of Group Health Enrollees that were known to not have endometriosis.

PCBs and endometriosis. All seven of the studies that addressed the relationship between PCB exposure and endometriosis presented individual congener results as well as a measure of total PCBs, the sum of individual congeners. Only three of the eight PCB case-control studies found any associations between exposure to total PCBs and risk of endometriosis (Buck et al. 2005, Heiler et al. 2005, Porpora et al. 2009). Buck Louis et al. (2005) measured total PCBs ( $\mathrm{n}=62)$, the sum of estrogenic PCBs $(\mathrm{n}=12)$, and the sum of anti-estrogenic PCBs $(n=4)$ in a cohort study of 84 women undergoing laparoscopy (32endometriosis cases, 52 controls). They found a significant increased risk of 
endometriosis for the sum of anti-estrogenic PCBs for women in the third tertile $(\mathrm{OR}=3.77,95 \% \mathrm{CI} 1.12-12.68)$, however, the risk remained elevated but not significant when adjusted for all listed covariates. In a case-control study of 158 women (80 cases and 78 controls), Porpora et al. (2009) found the GM of total PCBs to be significantly higher in cases than controls (301.3 vs. 203.0, p < 0.01). The OR of endometriosis risk in the highest tertile of total PCBs compared with the lowest tertile, was 5.63 (95\% CI 2.2514.10). Significant increased risk of endometriosis was also found for PCB congeners $118,138,153$, and 170. Heiler et al. (2005) conducted a case-control study of 50 cases (25 with peritoneal endometriosis ( $\mathrm{PE}$ ) and 25 with deep endometriotic (DE) nodules) and 21 controls. Multiple dioxin-like PCBs were measured and expressed as toxic equivalent (TEQ) per gram of serum lipids. Dioxin-like PCB concentrations were higher in women with DE compared to controls $(12.4$ vs. $8.5, \mathrm{p}=.026)$ but did not significantly differ for women with PE compared to controls (11.0 vs. 8.5) and for women with DE compared to women with PE (12.4 vs. 11.0).

Four of the PCB case-control studies failed to find significant associations between endometriosis and exposure to individual PCB congeners, total PCBs, or specific sub-groups (Niskar et al. 2009, Trabert et al. 2010, Pauwels et al. 2001, Tsukino et al. 2005). Niskar et al. (2009) conducted a case-control study with 60 confirmed endometriosis cases staged as I (minimal), II (mild), III (moderate), and IV (severe) and 30 controls. Mean lipid-adjusted PCB concentrations were not significantly different (179.98 vs. 217.33 vs. 194.76 vs. 193.37) between stage I-II cases, stage III cases, stage IV cases, and controls, respectively. In the largest case-control study, conducted by Trabert et al. (2010), total PCBs ( $\mathrm{n}=20)$, estrogenic PCBs $(\mathrm{n}=6)$, and individual PCB 
congeners were measured in the serum from 251 cases and 538 controls, matched for age and reference year. Adjusted total and estrogenic PCBs in the highest quartiles were not associated with an increased risk of endometriosis (Total: $\mathrm{OR}=1.2,95 \% \mathrm{CI}$ : 0.6-2.3, Estrogenic: $\mathrm{OR}=0.9,95 \% \mathrm{CI}: 0.5-1.4)$. In two case-control studies measuring median TEQ values (pg TEQ/g lipid) Pauwels et al. (2001) found no association between endometriosis and the median TEQ values (pg TEQ/g lipid) in cases and controls (29 vs. 27) and Tsukino et al. (2005) found no difference in median TEQ values for endometriosis cases (stage II-IV) and controls (stage 0-I) (cPCBs: 3.40 vs. 3.59, PCBs: 4.61 vs. 5.14), respectively. The OR of endometriosis risk in the highest quartile of total PCBs compared with the lowest quartile was 0.41 (95\% CI: 0.14-1.27).

Like breast cancer, results of the association between PCB exposure and endometriosis in eight epidemiologic studies were inconsistent or conflicting, therefore, we extracted and summarized risk estimates of PCBs on endometriosis from four case control studies using meta-analytic methods. Combining four studies of exposure to PCBs produced a summary risk estimate of 1.91 (95\% CI: 1.05 - 5.54) (Table 4; Fig. 5). PCB exposures were found to be significantly associated with development of endometriosis as a meta-analysis of four studies produced an increased risk of 1.91. However, there is not much confidence in the combined risk estimate of endometriosis with exposure to PCBs because of the lower estimate of CI being barely higher than 1 (1.05). 
Table 4. Epidemiological studies of the association between exposure to PCBs and risk of endometriosis.

\begin{tabular}{|c|c|c|c|c|c|c|c|}
\hline $\begin{array}{l}\text { Reference, } \\
\text { location }\end{array}$ & Study design & Study Population & $\begin{array}{l}\text { Measurement of } \\
\text { Exposure }\end{array}$ & Outcomes & Results & Comments & Confounders \\
\hline $\begin{array}{l}\text { Heiler et al. } \\
\text { (2005), } \\
\text { Belgium }\end{array}$ & $\begin{array}{l}\text { Case-control } \\
\text { Study }\end{array}$ & $\begin{array}{l}50 \text { cases: (25 with } \\
\text { PE, } 25 \text { with DE), } 21 \\
\text { controls. }\end{array}$ & $\begin{array}{l}\text { Multiple PCBs from } \\
\text { serum - 12 dioxin- } \\
\text { like PCBs (pg } \\
\text { TEQ/ glipids). }\end{array}$ & $\begin{array}{l}\text { Mean serum PCB } \\
\text { Range (pg TEQ/g } \\
\text { lipids): } \\
\text { Controls: 6.9-10.5 } \\
\text { PE Cases: 9.1-13.3 } \\
\text { DE Cases: 0.3-14.9; } \\
\text { Logistic Regression } \\
\text { (OR-95\% CI). }\end{array}$ & $\begin{array}{l}\text { Significant risk with } \\
\text { DE nodules (OR=6.7; } \\
95 \% \text { CI, 1.4-31.2). }\end{array}$ & $\begin{array}{l}\text { Controls did not } \\
\text { present for infertility; } \\
\text { normal pelvic exam. } \\
\text { Cases confirmed with } \\
\text { histological exam of } \\
\text { lesions. }\end{array}$ & $\begin{array}{l}\text { Adjusted for age, BMI, } \\
\text { tobacco consumption, } \\
\text { age at menarche, } \\
\text { duration of OC use, } \\
\text { family history, } \\
\text { menstrual cycle } \\
\text { regularity, \# of } \\
\text { children, breast- } \\
\text { feeding duration. }\end{array}$ \\
\hline $\begin{array}{l}\text { Niskar et al. } \\
\text { (2009), USA }\end{array}$ & $\begin{array}{l}\text { Case-control } \\
\text { study }\end{array}$ & $\begin{array}{l}60 \text { cases, } \\
30 \text { controls/ } \\
64 \text { controls. }\end{array}$ & $\begin{array}{l}\text { Serum total PCBs } \\
(\mathrm{ng} / \mathrm{g})(\mathrm{n}=36) .\end{array}$ & $\begin{array}{l}\text { GM Total PCBs (ng/g } \\
\text { lipid): } \\
\text { Cases stage I-II } \\
\text { (179.98), } \\
\text { stage III (217.33), } \\
\text { stage IV (194.76), } \\
\text { Controls (193.37). } \\
\text { Logistic Regression } \\
\text { (OR-95\% CI). }\end{array}$ & $\begin{array}{l}\text { No significant } \\
\text { differences in GMs } \\
\text { ( } p=97 \text { ). } \\
\text { No significant } \\
\text { associations (OR= } \\
1.00,95 \% \text { CI } 0.99- \\
1.01) \text {. }\end{array}$ & $\begin{array}{l}\text { Cases confirmed with } \\
\text { laparoscopic } \\
\text { examination and/ or } \\
\text { biopsy. } \\
30 \text { controls confirmed } \\
\text { with laparoscopy, } 27 \\
\text { with infertile partner } \\
\text { and } 7 \text { with ovulation } \\
\text { problems. }\end{array}$ & $\begin{array}{l}\text { Adjusted for age, } \\
\text { gravidity, education, } \\
\text { income. }\end{array}$ \\
\hline $\begin{array}{l}\text { Pauwels et al. } \\
\text { (2001), Belgium }\end{array}$ & $\begin{array}{l}\text { Prospective } \\
\text { case-control } \\
\text { study }\end{array}$ & 42 cases, 27 controls & $\begin{array}{l}\text { Multiple PCBs from } \\
\text { serum; Total PCBs, } \\
\text { TEQ (pg TEQ/g } \\
\text { lipid). }\end{array}$ & $\begin{array}{l}\text { Median TEQ (pg } \\
\text { TEQ/ glipid): } \\
\text { Cases (29), Controls } \\
\text { (27). } \\
\text { Logistic Regression } \\
\text { (OR, 95\% CI). }\end{array}$ & $\begin{array}{l}\text { No significant } \\
\text { associations found } \\
\text { (OR=4.33, 95\% CI } \\
0.49-38.19 \text { ). }\end{array}$ & $\begin{array}{l}\text { Cases and controls } \\
\text { infertile. } \\
\text { Endometriosis } \\
\text { confirmed with } \\
\text { laparoscopic } \\
\text { examination. }\end{array}$ & $\begin{array}{l}\text { Age, BMI, alcohol } \\
\text { consumption. }\end{array}$ \\
\hline $\begin{array}{l}\text { Porpora et al. } \\
\text { (2009), Italy }\end{array}$ & $\begin{array}{l}\text { Case-control } \\
\text { study }\end{array}$ & $\begin{array}{l}80 \text { cases, } 78 \\
\text { controls }\end{array}$ & $\begin{array}{l}\text { Multiple PCBs from } \\
\text { serum, Total PCBs. }\end{array}$ & $\begin{array}{l}\text { GM of Total PCBs } \\
\text { (ng/g of fat): } \\
\text { Cases: } 301.3 \\
\text { Controls: 203.0; } \\
\text { Logistic Regression } \\
\text { (OR-95\% CI). }\end{array}$ & $\begin{array}{l}\text { Total PCB } \\
\text { concentrations } \\
\text { significantly higher in } \\
\text { cases (OR=5.63, } 95 \% \\
\text { CI } 2.25-14.10) ; \\
\text { Significant increased } \\
\text { risk for PCBs } 118,138, \\
153 \text {, and } 170 \text {,or } 2^{\text {nd }} \\
\text { and 3rd tertiles when } \\
\text { compared to the } \\
\text { lowest tertile. }\end{array}$ & $\begin{array}{l}\text { Cases and controls } \\
\text { confirmed with } \\
\text { laparoscopic } \\
\text { examination. }\end{array}$ & $\begin{array}{l}\text { Adjusted for age, BMI, } \\
\text { smoking habits, } \\
\text { weight modification. }\end{array}$ \\
\hline $\begin{array}{l}\text { Trabert et al. } \\
\text { (2010), USA }\end{array}$ & $\begin{array}{l}\text { Case-control } \\
\text { study }\end{array}$ & $\begin{array}{l}251 \text { cases, } 538 \\
\text { controls; matched } \\
\text { for age (5 year) and } \\
\text { reference year. }\end{array}$ & $\begin{array}{l}\text { Multiple PCB } \\
\text { congeners in serum } \\
\text { (n=20); Total PCBs, } \\
\text { Estrogenic PCBs. }\end{array}$ & $\begin{array}{l}\text { Logistic Regression } \\
\text { (OR-95\% CI); } \\
\text { Quartiles. }\end{array}$ & $\begin{array}{l}\text { No significant } \\
\text { associations found. }\end{array}$ & $\begin{array}{l}\text { Cases: Group Health } \\
\text { (GH) enrollees with } \\
\text { endometriosis } \\
\text { diagnosis, } \\
\text { Controls: randomly } \\
\text { selected from list of } \\
\text { GH enrollees. }\end{array}$ & $\begin{array}{l}\text { Adjusted for matching } \\
\text { factors, serum lipids, } \\
\text { income, alcohol } \\
\text { consumption, DDE } \\
\text { exposure. }\end{array}$ \\
\hline $\begin{array}{l}\text { Tsukino et al. } \\
\text { (2005), J apan }\end{array}$ & $\begin{array}{l}\text { Case-control } \\
\text { study }\end{array}$ & $\begin{array}{l}\text { 139 women: } \\
\text { Controls: Stage } 0 \text { \& } \\
\text { I, } \\
\text { Cases: Stage II-IV; } \\
\text { Stage } 0=59 \\
\text { Stage I=22 } \\
\text { Stage II }=10 \\
\text { Stage III }=23 \\
\text { Stage IV=25 }\end{array}$ & $\begin{array}{l}\text { Multiple PCBs in } \\
\text { serum; Total TEQ } \\
\text { values of cPCBs and } \\
\text { PCBs. }\end{array}$ & $\begin{array}{l}\text { Median TEQ values } \\
\text { (pgTEQ/glipid); } \\
\text { Logistic Regression } \\
\text { (OR-95\% CI); } \\
\text { Quartiles. }\end{array}$ & $\begin{array}{l}\text { No significant } \\
\text { associations found } \\
\text { (OR=1.2, 95\% CI 0.6- } \\
\text { 2.3). }\end{array}$ & $\begin{array}{l}\text { Cases and controls } \\
\text { confirmed with } \\
\text { laparoscopic } \\
\text { examination. }\end{array}$ & $\begin{array}{l}\text { Adjusted for } \\
\text { menstrual regularity } \\
\text { and average cycle } \\
\text { days. }\end{array}$ \\
\hline
\end{tabular}


Figure 5. Forest plot of epidemiological studies of the association between exposure to PCBs and risk of endometriosis.

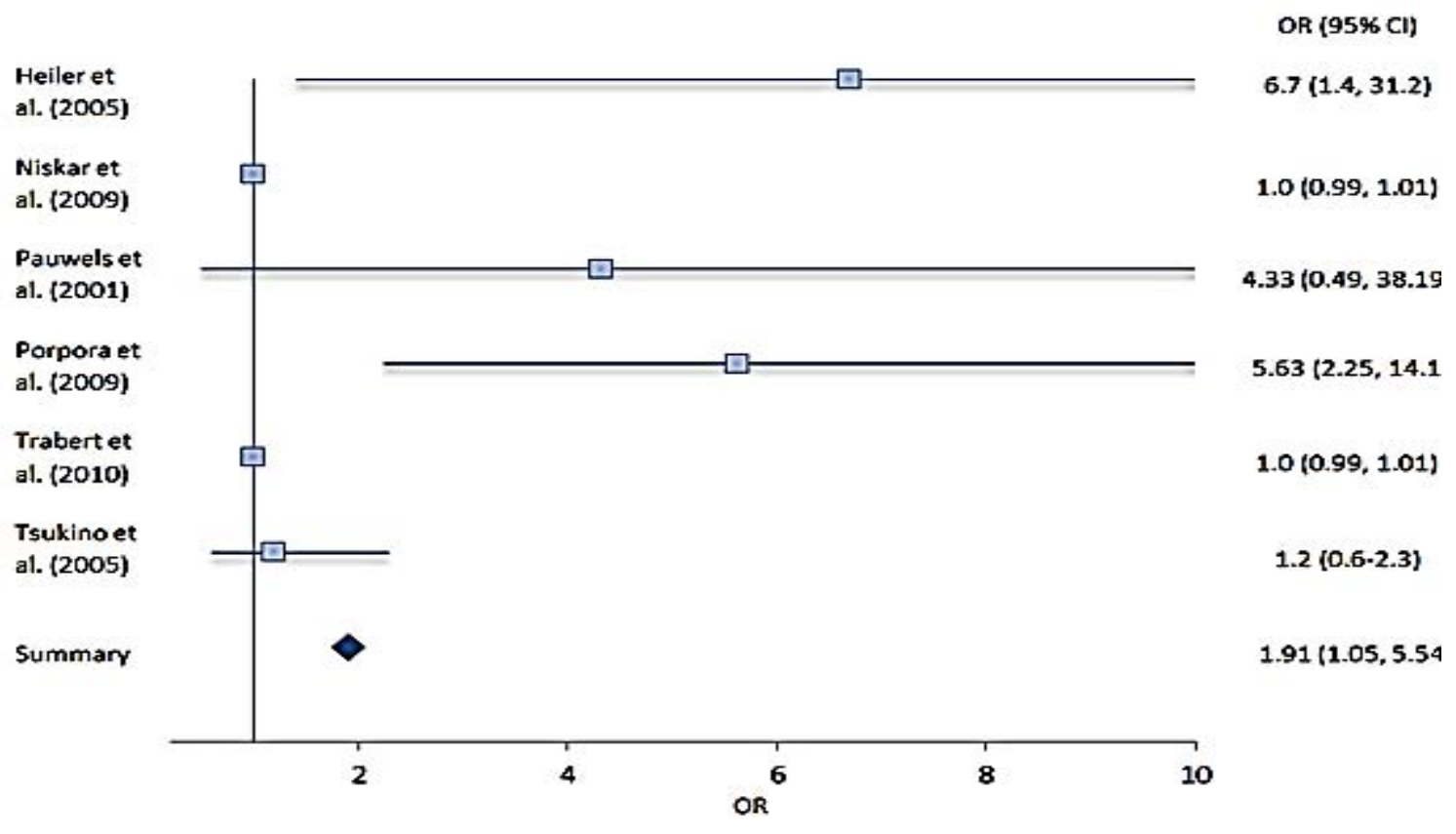

Bisphenol A or phthalate and breast cancer. Table 5 lists epidemiological studies of the association between EDCs - phthalate or BPA and endometriosis. No meta-analysis was performed on exposure to BPA or phthalates and endometriosis, because only two studies that met our criteria of selection examined the association between endometriosis and phthalates (Kim et al. 2011 and Upson et al. 2013), one study addressed the association between endometriosis and BPA (Itoh et al. 2007) and one study addressed the association between both BPA and phthalates and endometriosis (Buck et al. 2013). Besides these two studies, there are several other epidemiological studies that have examined the association between phthalate or BPA exposure and endometriosis (Table 
5). Kim et al. (2011) measured plasma levels of mono (2-ethylhexyl) phthalate (MEHP) and di-(2-ethylhexyl) phthalate (DEHP) in 97 women with advanced-stage endometriosis and 169 control women. Mean plasma levels of MEHP and DEHP were found to be significantly higher in cases than controls (MEHP: 17.4 vs. 12.4, p <.001, DEHP: 179.7 vs. $92.5, \mathrm{p}=.010)$. In a population-based case-control study conducted by Upson et al. (2013) 8 urinary phthalate metabolites were measured in 92 surgically-confirmed endometriosis cases and 195 controls. A significant inverse association was found between urinary MEHP and risk of endometriosis $(\mathrm{OR}=0.3,95 \% \mathrm{CI} 0.1-0.7)$. The ENDO study was designed to assess the relationship between exposure to environmental chemicals and endometriosis. Buck Louis et al. (2013) analyzed 14 phthalate metabolites and total BPA in urine from 495 women who underwent laparoscopy (operative cohort) and 131 women (population cohort) who underwent pelvic magnetic resonance imaging (MRI) for the assessment of endometriosis. In the operative cohort, GMs of phthalate metabolites were not found to be significantly higher in women with endometriosis, whereas, in the population cohort, GMs of six phthalate metabolites were found to be significantly higher for women with endometriosis and a twofold or higher increase in ORs was observed for mono- $n$-butyl phthalate (mBP), mono- (2-ethyl-5-carboxyphentyl) phthalate (mECPP), mono-[(2-carboxymethyl) hexyl] phthalate (mCMHP), mono (2ethyl-5-hydroxyhexyl) phthalate (mEHHP), mono (2-ethyl-5-oxohexyl) phthalate (mEOHP), and mono (2-ethylhexyl) phthalate (mEHP). No significant associations were found for urinary BPA concentrations in either the operative cohort or the population cohort. In a hospital based cross-sectional study, conducted by Itoh et al. (2007), urinary BPA concentrations were analyzed in 140 women who underwent laparoscopy. The 
severity of endometriosis was classified into 5 stages: $0(n=60)$, I $(n=21)$, II $(n=10)$, III $(\mathrm{n}=24)$, and IV $(\mathrm{n}=25)$. Median creatinine adjusted urinary BPA concentrations did not significantly differ by endometriosis stage $(0.74$ vs. $0.93, \mathrm{p}=0.24)$ for stage 0 -I and stage II-IV, respectively. 
Table 5: Epidemiological studies of the association between EDCs - Phthalate or BPA and endometriosis.

\begin{tabular}{|c|c|c|c|c|}
\hline EDCs & Biological samples & Study Population & Outcomes & References \\
\hline Bisphenol A & Serum & $\begin{array}{l}69 \text { fertile women } \\
\text { undergoing laparoscopy, } \\
\text { Naples, Italy }\end{array}$ & Detected in cases & Cobellis et al. 2009 \\
\hline Bisphenol B & Serum & $\begin{array}{l}69 \text { fertile women } \\
\text { undergoing laparoscopy, } \\
\text { Naples, Italy }\end{array}$ & Detected in cases & Cobellis et al. 2009 \\
\hline \multirow[t]{2}{*}{ Phthalate esters } & Plasma & $\begin{array}{l}220 \text { South Indian women } \\
\text { undergoing laparoscopy }\end{array}$ & Increased risk & Reddy et al. 2006b \\
\hline & Serum & $\begin{array}{l}108 \text { South Indian women } \\
\text { undergoing laparoscopy }\end{array}$ & Increased risk & Reddy et al. 2006a \\
\hline Diethylphthalate & $\begin{array}{l}\text { Blood/perit- } \\
\text { oneal fluid }\end{array}$ & $\begin{array}{l}59 \text { fertile women } \\
\text { undergoing laparoscopy }\end{array}$ & Higher in cases & Cobellis et al. 2003 \\
\hline Monoethylphthalate & $\begin{array}{l}\text { Blood/peri- } \\
\text { toneal fluid }\end{array}$ & $\begin{array}{l}59 \text { fertile women } \\
\text { Undergoing laparoscopy }\end{array}$ & No association & Cobellis et al. 2003 \\
\hline \multirow[t]{2}{*}{ Monobutylphthalate } & Urine & $\begin{array}{l}1,227 \text { women from the } \\
\text { NHANES study, United } \\
\text { States }\end{array}$ & No association & Weuve et al. 2010 \\
\hline & Urine & $\begin{array}{l}109 \text { women undergoing } \\
\text { laparotomy, Taiwan }\end{array}$ & Increased in cases & Huang et al. 2010 \\
\hline \multirow[t]{3}{*}{ Monobutylphthalate } & Urine & $\begin{array}{l}1,227 \text { women from } \\
\text { the NHANES study, USA }\end{array}$ & No association & Weuve et al. 2010 \\
\hline & Urine & $\begin{array}{l}109 \text { women undergoing } \\
\text { laparotomy, Taiwan }\end{array}$ & Increased in cases & Huang et al. 2010 \\
\hline & Urine & $\begin{array}{l}137 \text { infertile } \\
\text { Japanese women } \\
\text { undergoing } \\
\text { laparoscopy }\end{array}$ & No association & Itoh et al. 2009 \\
\hline
\end{tabular}


Several hundred genes are altered by exposure to PCBs, phthalate or bisphenol A (Fig. 6). The genes related to polychlorinated biphenyls and PCB congeners - 3,4,3',4'tetrachlorobiphenyl (77), 3,4,5,3',4'-pentachlorobiphenyl (126), and 2,4,5,2',4',5'hexachlorobiphenyl (153) in endometriosis were 19,11, 36 and 18, respectively (Table 6). All these PCBs or their congener-related endometriosis genes were also associated with 17 beta estradiol. The top interacting genes with polychlorinated biphenyls and endometriosis were ESR2, NR3C1, CYP19A1, EGFR, FKBP5, ITGB8, MAOB, PGR, PRLR, SLC16A6, SST, and TXNIP. There were 80 common genes between BPA and endometriosis (Fig. 6). The two phthalates with most gene interactions were: dibutyl phthalate and diethylhexyl phthalate. The genes related to dibutyl phthalate and diethylhexyl phthalate were 4692 and 1646, respectively. There were 71 common genes between dibutyl phthalate and endometriosis and 29 common genes between diethylhexyl phthalate and endometriosis (Fig. 6). The common genes between both phthalates dibutyl phthalate and diethylhexyl phthalate, and endometriosis were 22: CNR1, CYP19A1, CYP26A1, DUSP1, EGFR, ESR2, FKBP5, FOS, GPX3, IGF1, ITGB1, MAOA, MED1, NR3C1, NR4A1, NR5A1, PRLR, PTGER2, PTGER4, SRD5A1, TGFB2, and TXNIP (Table 6). Interactions among these genes are shown in Figure 7. Enrichment pathway analysis revealed that some of these genes are part of: 1) pathways in cancer (KEGG:05200); 2) signal transduction (REACT:111102), and 3) MAPK signaling pathway ( KEGG:04150) (Table 3). 
Figure 6. Venn diagram of list of genes common between endometriosis and PCBs, phthalates, and bisphenol A.
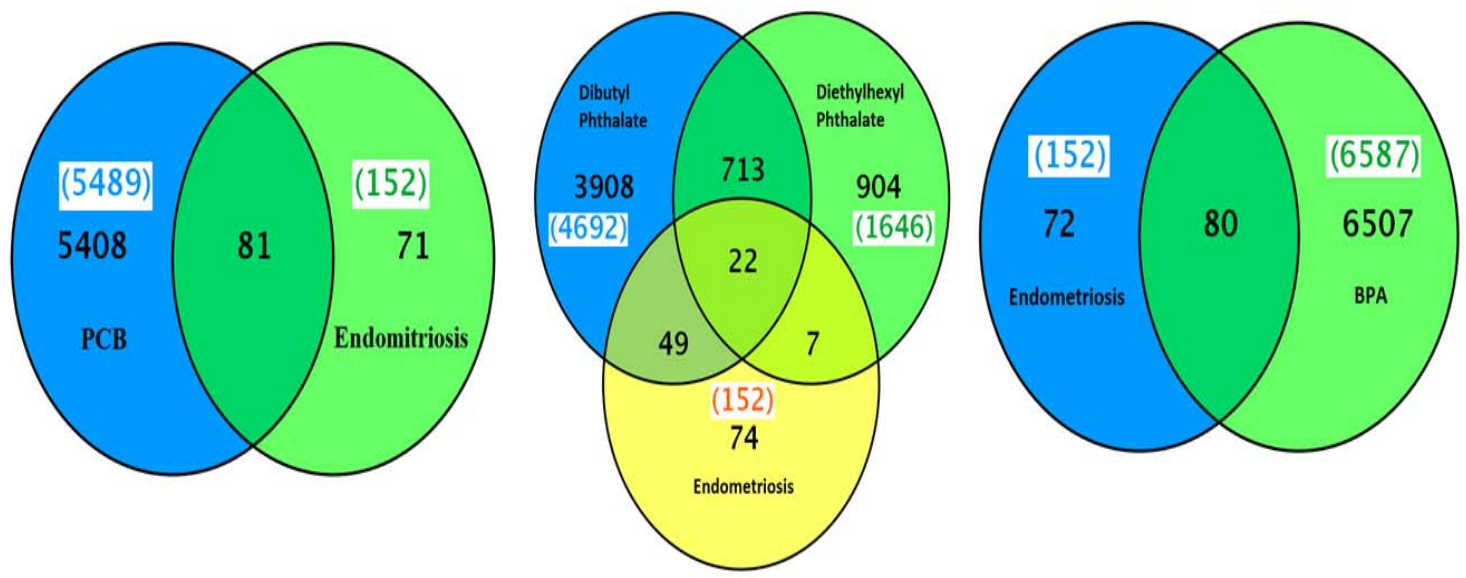

Figure 7. Gene Set/Pathway enrichment analysis of genes associated with PCBs, phthalates, and bisphenol A in endometriosis.
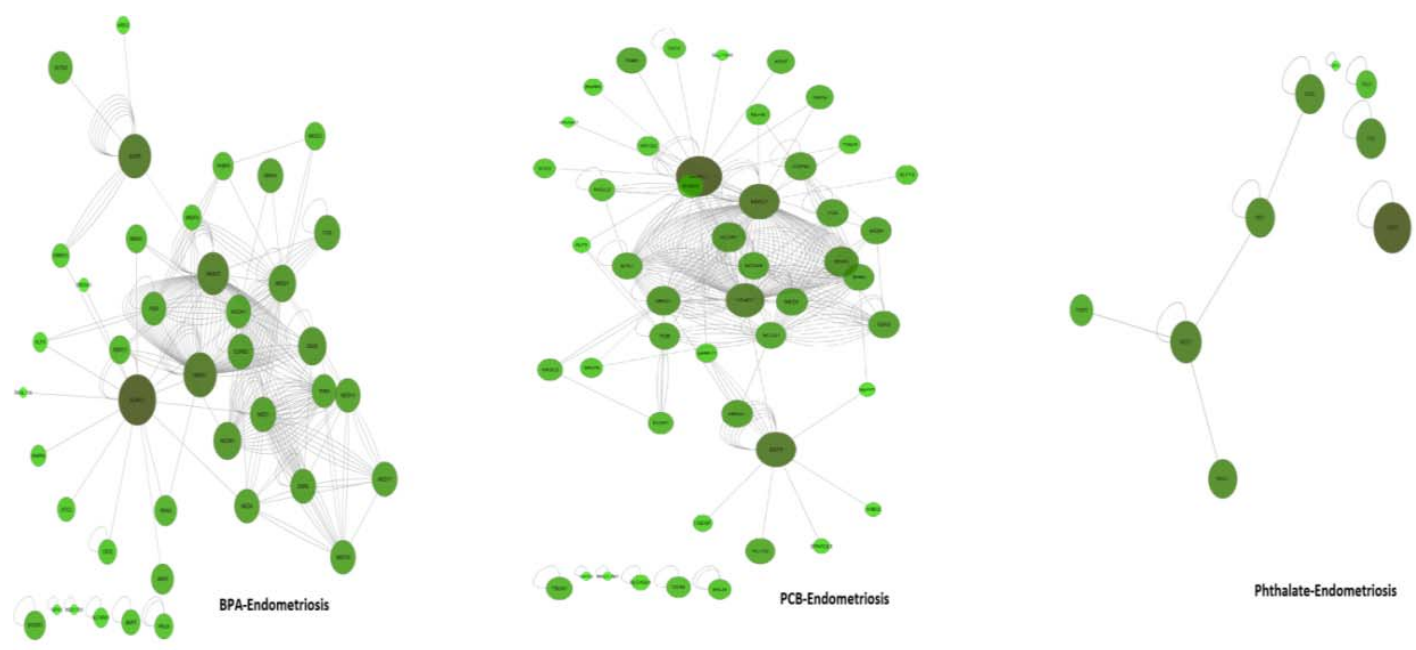
Table 6. Genes interacting with PCBs and endometriosis.

\begin{tabular}{|c|c|}
\hline IUPAC Name (congener number) & Interacting genes \\
\hline Polychlorinated Biphenyls & $\begin{array}{l}19 \text { genes: AKR1C3 | ANKRD1 | AREG | ARNT | CYP19A1 | DUSP1 | ESR2 | FBN1 | FOS | GREB1 | } \\
\text { IGFBP1 } \mid \text { KRAS } \mid \text { NR2C2 } \mid \text { NR3C1 | PAPPA | PTGER4 | STC2 | TGFB2 | THRA }\end{array}$ \\
\hline 2,4,4'-trichlorobiphenyl (28) & 2 genes: ESR2 | NR3C1 \\
\hline 3,4,3',4'-tetrachlorobiphenyl (77) & 11 genes: ARNT | DDX5 | ESR2 | FKBP5 | ITGB8 | KLF13 | MAOB | NR1D2 | PRLR | SULF2 | TXNIP \\
\hline $\begin{array}{l}\text { 2',3,3',4',5-pentachloro-4-hydroxybiphenyl } \\
\text { (4'-OH-PCB-86;4-hydroxy-2, 2', 3', 4', } \\
\text { 5'-pentachlorobiphenyl ) }\end{array}$ & $\begin{array}{l}25 \text { genes: ABCC9 | BRD8 | CD55 | CNR1 | ELAVL1 | ERRFI1 | FKBP5 | IFNGR1 | IGFBP1 | MED1 | } \\
\text { MED4 | MTA1 | NCOA6 | NR2C1 | NR3C1 | NR3C2 | NR4A1 | NRP1 | PRLR | SLC16A6 | SPARCL1 | } \\
\text { SST | TAGLN | THRA | TNC }\end{array}$ \\
\hline $2,2^{\prime}, 4,6,6^{\prime}$-pentachlorobiphenyl (104) & 2 genes: EGFR |FOS \\
\hline 3,4,5,3',4'-pentachlorobiphenyl (126) & $\begin{array}{l}36 \text { genes: AREG | CD55 | CXCL14 | CYP19A1 | DUSP1 | ENPP1 | FBN1 | GPX3 | HBEGF | HSD17B1 | } \\
\text { HSD17B2 | IGF1 | IGFBP1 | IGFBP6 | IL1R1 | IMPA2 | MAOA | MAOB | MED1 | NEDD4L | NR3C1 | } \\
\text { OSR2 | PRLR | RASL11A | SEPP1 | SLC20A1 | SLC40A1 | SLC7A8 | SPARCL1 | SRD5A1 | SRD5A2 | } \\
\text { SST | STC2 | TAGLN | TGFB2 | TXNIP }\end{array}$ \\
\hline 2,2',3',4,4',5-hexachlorobiphenyl (137) & 10 genes: FBLN1 | FOS | HBEGF | IGF1 | NEFM | PRL | SLC16A6 | SRD5A1 | SRD5A2 | SST \\
\hline 2,3,6,2',3',6'-hexachlorobiphenyl (136) & 2 genes: AR |CYP2B1 \\
\hline $2,4,5,2^{\prime}, 4^{\prime}, 5^{\prime}$-hexachlorobiphenyl (153) & $\begin{array}{l}18 \text { genes: CYP19A1 | DCSTAMP | EGFR | ESR2 | FOS | HSD17B1 | HSD17B2 | IFIT1 | IGF1 | ITGB8 | } \\
\text { MAOB } \mid \text { NR3C1 } \mid \text { SEPP1 } \mid \text { SLC16A6 | SRD5A1 | SRD5A2 | SST | TXNIP }\end{array}$ \\
\hline $17 \beta$ Estradiol & $\begin{array}{l}114 \text { genes: ABCC9 | ABI3BP | ACTA2 | AKR1C1 | AKR1C2 | AKR1C3 | ANKH | ANKRD1 | AREG | } \\
\text { ARHGAP28 | ARNT | BMP7 | C10ORF10 | C1R | CCNE2 | CD55 | CFD | CLDN1 | CNIH3 | CNR1 | CPM | } \\
\text { CXCL14 | CYB5A | CYP19A1 | CYP26A1 | DDX5 | DICER1 | DIO2 | DKK1 | DUSP1 | EGFR | ELAVL1 | } \\
\text { ERRFI1 | ESR2 | FBLN1 | FBN1 | FKBP5 | FOS | GPX3 | GREB1 | HDAC1 | HDAC2 | HERC5 | } \\
\text { HS3ST3B1 | HSD17B1 | HSD17B2 | IDO1 | IFIT1 | IGF1 | IGFBP1 | IGFBP6 | IHH | IL15 | IL1R1 | IL7R | } \\
\text { ITGA2 | ITGB1 | ITGB8 | KLF13 | KLF9 | KRAS | LMOD1 | LTF | MAOA | MAOB | MED1 | MED14 | } \\
\text { METTL7A | MIR21 | MYLIP | NCOA1 | NCOA6 | NCOR1 | NEDD4L | NR2F2 | NR3C1 | NR3C2 | NR4A1 } \\
\text { | NR5A1 | NRP1 | NTRK3 | OLFM4 | OSR2 | PAPPA | PGR | PRL | PRLR | PTGER2 | PTGER4 | RARB | } \\
\text { RASGRP1 | RGS4 | RORB | RXFP1 | SEPP1 | SLC16A6 | SLC1 A1 | SLC20A1 | SLC40A1 | SLC7A8 | } \\
\text { SMPDL3A | SPARCL1 | SRD5A2 | STC2 | SULF2 | TACSTD2 | TAGLN | TGFB2 | THRA | TNC | TOB1 | } \\
\text { TRH | TXNIP | VCAN ZEB2 }\end{array}$ \\
\hline Dibutyl Phthalate & $\begin{array}{l}71 \text { genes: AB13BP | ACTA2 | AKR1C1 | ANKRD1 | AREG | ARNT | BMP7 | BRD8 | C1R | CCNE2 | CD55 } \\
\text { | CLDN1| CNR1 | COPS2 | CYB5A | CYP19A1 | CYP26A1 | DDX5 | DICER1 | DUSP1 | EGFR | ELAVL1 | } \\
\text { ENPP1 | ERRFI1 | ESR2 |FKBP5 | FOS | GPX3 | HDAC1 | HSD17B1 | IGF1 | IL1R1 | ITGB1 | ITGB8 | } \\
\text { KLF9 | LMOD1 | MAOA | MAOB | MED1 |MED14 | MED17 | NR1D2 | NR2F2 | NR2F6 | NR3C1 | } \\
\text { NR4A1 | NR5A1 | NRP1 | OSR2 | PAPPA | PGR | PRLR | PTGER2 |PTGER4 | RASL11 | SEPP1 | } \\
\text { SLC16A6 | SLC20A1 | SLC40A1 | SLC7A8 | SMPDL3A | SRD5A1 | STC2 | SUCLG2 |SULF2 | TAGLN | } \\
\text { TGFB2 | THRA | TOB1 | TXNIP | VCAN. }\end{array}$ \\
\hline Diethylhexyl Phthalate & $\begin{array}{l}29 \text { genes: CNR1 | CYP19A1 | CYP26A1 | EGFR | ESR2 | FKBP5 | FOS | HERC5 | IGF1 | IGFBP1 | ITGB1 | } \\
\text { MAOA | NCOA1 | NR3C1 | NR4A1 | NR5A1 | PAX2 | PRL | PRLR | PTGER2 | PTGER4 | SRD5A1 | } \\
\text { TGFB2 | DUSP1 | FMO2 | GPX3 | MED1 | NCOR1 | TXNIP }\end{array}$ \\
\hline $\begin{array}{l}\text { Dibutyl Phthalate and Diethyl-hexyl } \\
\text { Phthalate }\end{array}$ & $\begin{array}{l}22 \text { genes: CNR1, CYP19A1, CYP26A1, DUSP1, EGFR, ESR2, FKBP5, FOS, GPX3, IGF1, ITGB1, } \\
\text { MAOA, MED1, NR3C1, NR4A1, NR5A1, PRLR, PTGER2, PTGER4, SRD5A1, TGFB2, TXNIP }\end{array}$ \\
\hline Bisphenol A & $\begin{array}{l}80 \text { genes: ABCC9 | ACTA2 | AREG | ARHGAP28 | ARNT | BMP7 | BRD8 | CCNE2 | COPS2 |CYB5A | } \\
\text { CYP19A1 | CYP26A1 | DDX5 | DICER1 | DIO2 | DUSP1 | EGFR | ELAVL1 | ENPP1 | ERRFI1 | ESR2 | }\end{array}$ \\
\hline
\end{tabular}




\section{Integration of genes overlapped among EDCs, Breast Cancer and Endometriosis:}

Integration of genes associated with exposure to PCBs, and breast cancer and endometriosis based enriched disease analysis showed that there were 16 endometriosis genes overlapped with breast neoplasms - AREG, C10ORF10, CLDN1, CYP19A1, DKK1, EGFR, ESR2, FOS, IGF1, KRAS, NCOA1, NCOR1, NR2F6, PGR, RARB, and STC2 (Tables 2 and 6). All of these genes were also associated with estrogen in breast neoplasms. Out of these 16 genes, there were 14 genes - AREG, CLDN, CYP19A1, DKK1, EGFR, ESR2, FOS, IGF1, KRAS, NCOA1, NCOR1, NR2F6, PGR, RARB, and STC2 common among 17 beta estradiol, breast cancer, and endometriosis (Tables 2, 6

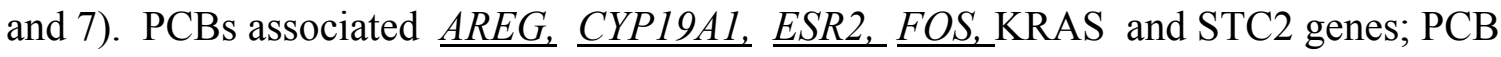
126 associated $\underline{A R E G, C Y P 19 A 1}$, and STC2 genes and PCB 15 associated CYP19A1,EGFR,ESR2,FOS and IGF1 genes overlapped with 17 beta estradiol, breast cancer, and endometriosis (Tables 2, 6 and 7). Similarly, we identified dibutyl phthalate and diethyl-hexyl phthalate associated overlapping genes with 17 beta estradiol, breast cancer, and endometriosis: AREG, CLDN1, CYP19A1, EGFR, ESR2, FOS, IGF1, NR2F6, PGR and STC2; and CYP19A1,EGFR,ESR2,FOS,IGF1 and NCOA1. There were 5 common overlapped genes between these two phthalates, 17 beta estradiol, breast cancer and endometriosis: CYP19A1, EGFR, ESR2, FOS, and IGF1. We also identified another 11 EDC -BPA associated genes that were common among 17 beta estradiol, breast cancer and endometriosis: AREG, CYP19A1, EGFR, ESR2, FOS, IGF1, KRAS, NCOA1, NCOR1, PGR, and STC2. Five genes - CYP19A1, EGFR, ESR2, FOS, and IGF1 were common among all three EDCs -PCBs, phthalates and BPA, 17 beta estradiol, 
breast cancer, and endometriosis. For the gene ontology terms associated with each gene, please see Table 8 .

Since both of these diseases are dependent on unopposed estrogen for their growth, we examined whether estrogen receptor signaling pathway genes are common among estrogen, EDCs, breast cancer and endometriosis. PCBs and congeners 3,4,5,3',4'-pentachlorobiphenyl (126) and 2,4,5,2',4',5'-hexachlorobiphenyl (153) were associated with some of the same estrogen receptor signaling pathway genes - AR, ESR1, ESR2, NCOA3, and PPARGC1B; AR, BRCA1, ESR1, IGF1, and PAK1; and AR, BRCA1, CTNNB1, ESR1, ESR2, IGF1, and SRC, respectively (Table 7). The following were also observed with 17 beta estradiol - AR, BRCA1, CCNE1, CTNNB1, ESR1, ESR2, FHL2, FOXA1, IGF1, NCOA1, NCOA2, NCOA3, NRIP1, PAK1, PGR, PHB, PPARGC1B, RB1, SFRP1, SRC, and ZNF366. Similarly, common genes of estrogen receptor signaling pathways were also observed with another three EDCs. Dibutyl phthalate associated AR, BRCA1, CCNE1, CTNNB1, ESR1, ESR2, FHL2,HEYL, IGF1,PGR, RB1 and SRC genes; diethylhexyl phthalate associated - AR, CTNNB1, ESR1, ESR2, IGF1, NCOA1, and PPARGC1B, and BPA associated AR, BRCA1, CCNE1, CTNNB1, ESR1, ESR2, FHL2, IGF1, NCOA1, NCOA2, NCOA3, NRIP1, PAK1, PGR, PHB, RB1, SFRP1, SIRT1, and SRC genes which are also associated with 17 beta-estradiol in breast neoplasms (Table 7). Another factor that appears to be common in both diseases is inflammation. Therefore, we also examined whether inflammation associated genes are common among estrogen, EDCs and breast cancer. PCBs and congeners 3,4,5,3',4'-pentachlorobiphenyl (126) and 2,4,5,2',4',5'hexachlorobiphenyl (153) were associated with the following inflammation related genes 
- AHR, CXCL2, HMOX1, IFNG, IL6, PTGS2, SOD2, and TNF; AHR, CXCL8, HMOX1, IL1B, IL6, MMP9, NOS2, NOS3, PARP1, PTGS2, and TNF; and AHR, IFNG, IL1B, PARP1, PTGS2, and TNF, respectively (Table 7). Dibutyl phthalate, diethyl-hexyl phthalate and BPA-associated set of inflammation-related genes were AHR, CXCL8, HMOX1, IL1B, IL6, MIF, MMP9, PARP1, SOD2, TFRC and TNF; AHR, CSF2, CXCL8, IFNG, LEP, MMP9, SOD2 and TNF; and AHR, CSF2, HMOX1, IFNG, IL1B, IL6, LEP, MIF, MMP9,NOS2, NOS3, PARP1, PTGS2,SOD2, and TNF, respectively. All of these genes were also associated with 17 beta estradiol in breast neoplasms. In summary, EDC associated inflammation set of genes in breast neoplasms are estrogen responsive. 
Table 7. EDC-interacting endometriosis, environmental response and inflammation associated estrogen responsive genes in breast neoplasms.

\begin{tabular}{|c|c|c|c|}
\hline $\begin{array}{l}\text { EDC interacting } \\
\text { with genes in } \\
\text { breast } \\
\text { neoplasms }\end{array}$ & $\begin{array}{l}\text { Steroid hormone receptor } \\
\text { signaling pathway }\end{array}$ & Endometriosis & Inflammation \\
\hline $\begin{array}{l}17 \text { beta } \\
\text { Estradiol }\end{array}$ & $\begin{array}{l}21 \text { genes AR, BRCA1, CCNE1, } \\
\text { CTNNB1, ESR1, ESR2, FHL2, } \\
\text { FOXA1, IGF1, NCOA1, NCOA2, } \\
\text { NCOA3, NRIP1, PAK1, PGR, } \\
\text { PHB, PPARGC1B, RB1, SFRP1, } \\
\text { SRC, ZNF366 }\end{array}$ & $\begin{array}{l}\text { AREG, CLDN1, } \\
\text { CYP19A1, DKK1, } \\
\text { EGFR, ESR2, FOS, } \\
\text { IGF1, KRAS, } \\
\text { NCOA1, NCOR1, } \\
\text { PGR, RARB, STC2 }\end{array}$ & $\begin{array}{l}\text { AHR,CSF3,CXCL2, } \\
\text { CXCL8,HMOX1, } \\
\text { IFNG,IL1B,IL6 } \\
\text { LEP,MIF,MMP9 } \\
\text { NOS2,NOS3,PARP1 } \\
\text { PTGS2,SOD2,TFRC } \\
\text { TNF }\end{array}$ \\
\hline PCBs & $\begin{array}{l}\text { AR,ESR1,ESR2,NCOA3, } \\
\text { PPARGC1B }\end{array}$ & $\begin{array}{l}\text { AREG,CYP19A1, } \\
\text { ESR2,FOS,KRAS } \\
\text { STC2 }\end{array}$ & $\begin{array}{l}\text { AHR,CXCL2,HMO } \\
\text { X1, IFNG,IL6 } \\
\text { PTGS2,SOD2,TNF }\end{array}$ \\
\hline $\begin{array}{l}3,4,5,3^{\prime}, 4^{\prime}- \\
\text { pentachlorobiph } \\
\text { enyl (126) }\end{array}$ & AR, BRCA1, ESR1, IGF1, PAK1 & $\begin{array}{l}\text { AREG, CYP19A1, } \\
\text { STC2 }\end{array}$ & $\begin{array}{l}\text { AHR,CXCL8,HMO } \\
\text { X1,IL1B,IL6,MMP9, } \\
\text { NOS2,NOS3, } \\
\text { PARP1,PTGS2,TNF }\end{array}$ \\
\hline $\begin{array}{l}2,4,5,2^{\prime}, 4^{\prime}, 5^{\prime}- \\
\text { hexachlorobiph } \\
\text { enyl (153) }\end{array}$ & $\begin{array}{l}\text { AR,BRCA1,CTNNB1,ESR1,ESR } \\
\text { 2,IGF1,SRC }\end{array}$ & $\begin{array}{l}\text { CYP19A1,EGFR, } \\
\text { ESR2,FOS,IGF1 }\end{array}$ & $\begin{array}{l}\text { AHR,IFNG,IL1B, } \\
\text { PARP1,PTGS2,TNF }\end{array}$ \\
\hline $\begin{array}{l}\text { Dibutyl } \\
\text { Phthalate }\end{array}$ & $\begin{array}{l}\text { AR,BRCA1,CCNE1,CTNNB1,E } \\
\text { SR1,ESR2,FHL2,HEYL,IGF1,PG } \\
\text { R,RB1,SRC }\end{array}$ & $\begin{array}{l}\text { AREG,CLDN1, } \\
\text { CYP19A1,EGFR } \\
\text { ESR2,FOS,IGF1 } \\
\text { NR2F6,PGR,STC2 }\end{array}$ & $\begin{array}{l}\text { AHR,CXCL8,HMO } \\
\text { X1, IL1B, IL6, MIF } \\
\text { MMP9, PARP1, } \\
\text { SOD2, TFRC,TNF }\end{array}$ \\
\hline $\begin{array}{l}\text { Diethylhexyl } \\
\text { Phthalate }\end{array}$ & $\begin{array}{l}\text { AR,CTNNB1,ESR1 } \\
\text { ESR2,IGF1,NCOA1 } \\
\text { PPARGC1B }\end{array}$ & $\begin{array}{l}\text { CYP19A1,EGFR } \\
\text { ESR2,FOS,IGF1 } \\
\text { NCOA1 }\end{array}$ & $\begin{array}{l}\text { AHR,CSF2,CXCL8 } \\
\text { IFNG,LEP,MMP9 } \\
\text { SOD2,TNF }\end{array}$ \\
\hline Bisphenol A & $\begin{array}{l}\text { AR,BRCA1,CCNE1,CTNNB1,E } \\
\text { SR1,ESR2,FHL2,IGF1 } \\
\text { NCOA1,NCOA2,NCOA3 } \\
\text { NRIP1,PAK1,PGR,PHB } \\
\text { RB1,SFRP1,SIRT1,SRC }\end{array}$ & $\begin{array}{l}\text { AREG,CYP19A1, } \\
\text { EGFR, ESR2, FOS, } \\
\text { IGF1, KRAS, } \\
\text { NCOA1, NCOR1, } \\
\text { PGR, STC2 }\end{array}$ & $\begin{array}{l}\text { AHR, CSF2, } \\
\text { HMOX1, IFNG, } \\
\text { IL1B, IL6, LEP, } \\
\text { MIF, MMP9, NOS2, } \\
\text { NOS3, PARP1, } \\
\text { PTGS2,SOD2, TNF }\end{array}$ \\
\hline
\end{tabular}


Table 8. Integration of changes in the expression of genes showing common genes modified in EDCs, breast cancer and endometriosis.

\begin{tabular}{lcccl}
\hline Gene name & Gene ID & Location & Database* & Gene function \\
\hline AREG & 374 & $4 \mathrm{q} 13-\mathrm{q} 21$ & $\mathrm{E}$ & Amphiregulin \\
$\underline{\text { CYP19A1 }}$ & 1588 & $15 \mathrm{q} 21.1$ & $\mathrm{E}$ & cytochrome P450, family 19, subfamily A, polypeptide 1 \\
$\underline{\text { EGFR }}$ & 1956 & $7 \mathrm{p} 12$ & $\mathrm{E}$ & epidermal growth factor receptor \\
$\underline{\text { ESR2 }}$ & 3468 & $14 \mathrm{q} 23.2$ & $\mathrm{H}$ & estrogen receptor 2 (ER beta) \\
$\underline{\text { FOS }}$ & 2353 & $14 \mathrm{q} 24.3$ & $\mathrm{E}$ & v-fos FBJ murine osteosarcoma viral oncogene homolog \\
$\underline{\text { IGF1 }}$ & 3479 & $12 \mathrm{q} 22-\mathrm{q} 23$ & $\mathrm{E}$ & insulin-like growth factor 1 (somatomedin C) \\
KRAS & 6407 & $12 \mathrm{p} 12.1$ & $\mathrm{H}$ & Kirsten rat sarcoma viral oncogene homolog \\
NCOA1 & 7668 & $2 \mathrm{p} 23$ & $\mathrm{H}$ & nuclear receptor coactivator 1 \\
NCOR1 & 7672 & $17 \mathrm{p} 11.2$ & $\mathrm{H}$ & nuclear receptor corepressor 1 \\
PGR & 5241 & $11 \mathrm{q} 22-\mathrm{q} 23$ & $\mathrm{E}$ & progesterone receptor \\
STC2 & 11374 & $5 \mathrm{q} 35.1$ & $\mathrm{H}$ & stanniocalcin 2 \\
\hline
\end{tabular}

Underline shows 5 genes that were common among all three EDCs -PCBs, phthalate and bisphenol A, breast cancer and endometriosis. Environmentally responsive genes are indicated in database column.

*(E): Environmental responsive gene based on Environmental Genome Project; (H): HGNC database. 


\section{Literature based validation of genes showing links between endometriosis and}

breast cancer: The set of estrogen responsive genes from EDCs, environmental, inflammation, and toxicogenomics showing a link between endometriosis and breast cancer is shown in Table 7. Research supporting the potential involvement and importance of all EDC responsive common genes in breast cancer and endometriotic lesions was found in the literature and human genome databases. The search of the environmental genome project databases showed that six genes out of 12 PCBs associated genes - AREG, CYP19A1, EGFR, FOS, IGF1, and PGR were environmentally responsive genes (Table 8). These common genes were then compared to a curated list of genes in PCB exposed human cell lines. PCB congeners 77 and 153 increased the expression of the following estrogen responsive genes AREG, CYP19A1, EGFR, ESR2, FOS, IGF1, KRAS, NCOA1, NCOR1, NR2F6, PGR,STC2 (De et al. 2010). The expression of estrogen responsive genes common to breast cancer: AREG, CYP19A1, EGFR, ESR2, FOS, IGF1, KRAS, NCOA1, NCOR1, NR2F6, PGR,STC2 genes was upregulated in human endometriotic lesions (Burney et al. 2007, Hever et al. 2007, Sha et al. 2007).

We also analyzed the interaction among AREG, CYP19A1, EGFR, ESR2, FOS, IGF1, KRAS, NCOA1, NCOR1, NR2F6, PGR, and STC2 genes using enrichment pathway analysis (Fig. 8). In order to investigate connections between PCBs responsive gene lists in breast cancer and endometriosis, we performed Bayesian network analysis. The Bayesian network analysis on the Cancer Genome Atlas (TCGA) Research Network data available through cbioportal.org identified the maximum likelihood structure of PCBs associated genes in breast neoplasm (Fig. 9). Figure 9 shows plausible interactions 
among genes. Parents of a variable in Bayesian networks are defined as variables that arcs are originated to that variable. For example, in Figure 9, parents of BCHE are PTGS2 and HMOX1. Ancestors of a variable are all the parents of the variable, all parents of parents, and so on. Arcs in Figure 9 indicate correlations and they indicate Markov conditions. In Figure 9, from the arcs, the relationships between PTGS2 and BCHE was the strongest among all pairwise relationships, but also they formed a special Y structure (Spirtes et al. 2000) that indicates plausible causality, i.e., PTGS2 regulating BCHE. Similarly we have analyzed mRNA expression endometriosis data (Fig.10). These genes were more sparsely connected.

Some of the common estrogen responsive interacting genes are part of steroid hormone biosynthesis; metabolic pathways; MAPK signaling pathway; ErbB signaling pathway; chemokine signaling pathway; p53 signaling pathway; mTOR signaling pathway; VEGF signaling pathway; focal adhesion; adherens junction; tight junction; gap junction; toll-like receptor signaling pathway; natural killer cell mediated cytotoxicity; $\mathrm{T}$ cell receptor signaling pathway; B cell receptor signaling pathway; Fc epsilon RI signaling pathway; regulation of actin cytoskeleton; insulin signaling pathway; GnRH signaling pathway; and pathways in cancer (Table 3). We also compared these common genes to a curated list of genes in breast cancer, endometriosis as well as EDC exposed populations. The search of the environmental databases showed that some of these common genes were environmentally responsive. All these EDC associated set of genes are estrogen responsive (Table 8). All these PCB, Phthalate and BPA associated common genes are altered in human breast tumor, uterine tumor tissues and endometriosis lesions (Table 8). 
Figure 8. Interaction of common genes between estrogen, PCBs and breast neoplasms: AREG, CYP19A1, EGFR, ESR2, FOS, IGF1, KRAS, NCOA1, NCOR1, NR2F6, PGR, and STC2.

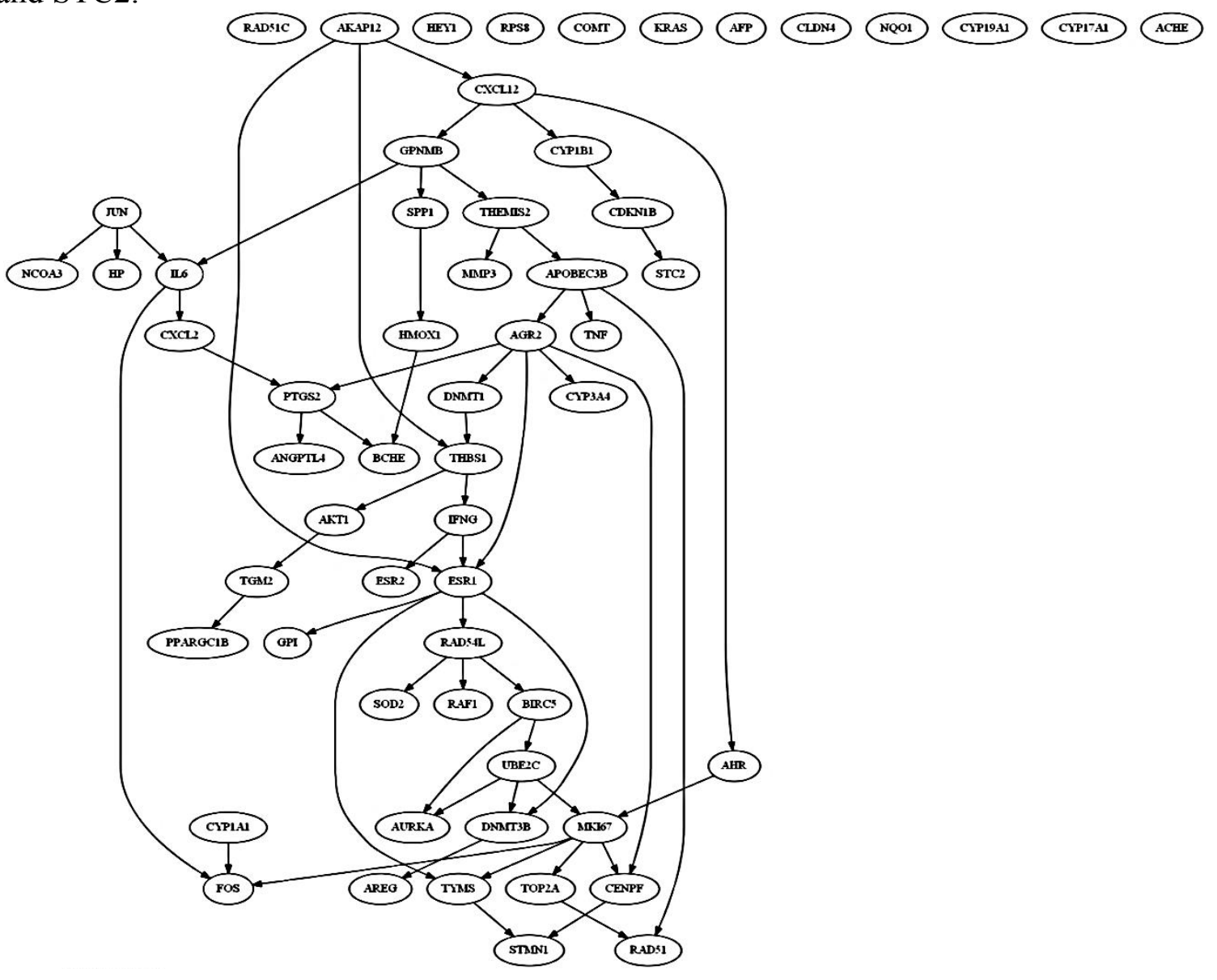

Figure 9. Identification of the maximum likelihood structure of PCBs associated genes in breast neoplasm.

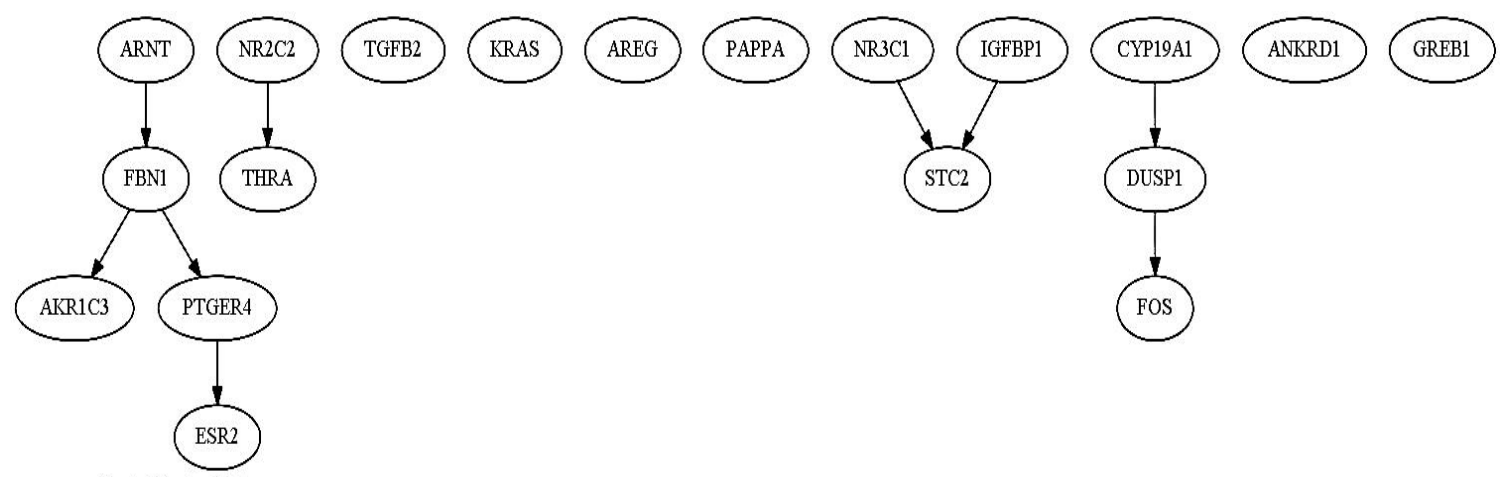




\section{Discussion}

In the present study, we determined whether estrogen mimicking EDCsassociated gene expression contributed to the risk of breast cancer among women with endometriosis with the aim of elucidating the role of environmental endocrine disrupting chemicals- PCBs, phthalates and BPA while focused on identifying environmental epidemiologic evidence and molecular signatures. Women with endometriosis have been implicated to develop certain types of cancer, including breast and ovarian cancers (Melin et al 2007). Although several molecular and environmental risk factors are common to endometriosis and breast cancer, the results of epidemiologic studies have been inconsistent on whether endometriosis is linked to particularly breast cancer. Both of these diseases are dependent on unopposed estrogen for their growth. Endometrial tissue shows elevated activity of aromatase, and this enzyme is a key for the biosynthesis of estrogens (Irahara et al. 2006). Our meta-analysis showed that exposure to estrogen mimicking EDC - PCBs increased summary risk of both breast cancer and endometriosis. We further evaluated the relationship between endometriosis and breast cancer, and EDCs using a bioinformatics method. Our bioinformatics approach was able to identify genes with the potential to be involved in interaction with PCBs and other EDCs phthalates and BPA that may be important to the development of breast cancer and endometriosis. We identified six PCBs associated genes - AREG, CYP19A1, EGFR, FOS, IGF1, and PGR that are environmentally responsive. Similarly, we also observed dibutyl phthalate and diethyl-hexyl phthalate associated 5 common genes - CYP19A1, EGFR, ESR2, FOS, and IGF1 in breast cancer and endometriosis; and BPA associated 11 genes - AREG, CYP19A1, EGFR, ESR2, FOS, IGF1, KRAS, NCOA1, NCOR1, 
PGR, and STC2 that were common in both breast cancer and endometriosis. Five genes CYP19A1, EGFR, ESR2, FOS, and IGF1 were common among all three EDCs -PCB 153, phthalates and BPA, breast cancer, and endometriosis. All five common genes are modified in human breast tumor, uterine tumor tissues and endometriosis lesions. All of these genes are estrogen responsive. These findings suggest that the increased risk associated with endometriosis may be due to common environmental and molecular risk factors between endometriosis and breast cancer.

Human and wild life populations are continually exposed to a wide variety of EDCs. Experimental animal and human studies have indicated that EDCs have the ability to cause endocrine toxicity. For example, exposure to PCBs has been reported to show a significant delay in puberty in boys. De-feminization, early secondary breast development, or thelarche have been reported in girls exposed to phthalates (Roy et al. 2009). Despite existing debates over the form and amount of BPA to which developing and adult humans are exposed, there is considerable data indicating that exposure of humans to BPA is associated with increased risk for breast cancer and reproductive dysfunctions (Bertelsen et al. 2007 and Roy et al. 1997). Postmenopausal women with high serum levels of BPA and mono-ethyl phthalate have been reported to have elevated breast density, one of the risk factors for breast cancer (Buck Louis et al. 2005). These findings are consistent with parallel research in experimental models (Colerangle et al. 1997, Munoz-de-Toro et al. 2005, Newbold et al. 2007, Murray et al. 2007). For example, fetal bisphenol A exposure induces the development of preneoplastic and neoplastic lesions in the mammary gland in rats (Newbold et al. 2007). Fetal exposure of BPA significantly increases susceptibility to DMBA to produce mammary tumors in 
mice (Murray et al. 2007). BPA has also been reported to promote tumor growth of human breast cancer cells -MCF-7 in ovariectomized NCR nu/nu female mice. Excess exposures to polychlorinated dioxins and certain PCBs in women who lack detoxifying enzymes are risk factors in breast cancer. A landmark UN report assessing effects of human exposure to hormone-disrupting chemicals acknowledges that approximately 800 chemicals are suspected to act as endocrine disruptors or mimic natural hormones or disrupt hormone regulation (UNEP, 2013). This report highlights that there is some associations between exposure to many of the endocrine disruptors, particularly, estrogen-mimicking chemicals and an increased risk of breast cancer in women. Exposure to EDCs, such as, PCBs and BPA during early development of the breast, endometrium, and prostate can alter their development, and possibly contribute to the susceptibility to diseases through effects on stem cells.

Breast cancer and endometriosis are complex chronic diseases and they are not caused by one agent or one environmental factor. The majority of the epidemiologic studies have largely focused on a single EDC and have ignored the possibility that multiple environmental agents may act in concert. It is important to consider that during the development of an individual from the single cell to prenatal stages to adolescent to adulthood and through the complete life span, humans are exposed to countless environmental EDCs. Like genes, environmental factors also interact among themselves. A single exposure to an EDC alone cannot explain the development of a complex chronic disease - like breast cancer, rather it appears that exposure to multiple EDCs across the lifespan and their interactions influence the development of breast cancer in an individual. A recent study from Spain lends support to the above concept. They have 
shown that the body burden of lipophilic estrogenic organ halogen chemicals through cumulative exposure is associated with breast cancer risks (Ibarluzea et al. 2000). The temporal and spatial environmental modulations of the normal genetic and phenotypic changes in a cell lead to the development of a particular type of disease phenotype. However, the majority of epidemiologic studies measured EDC exposures later in a woman's life, when the breast or endometrium tissue is less vulnerable. In-utero exposure to the estrogenic anti-miscarriage compound- diethylstilbestrol (DES) underlines the importance of early life EDC exposure in breast cancer development and is apparent from the recent report showing elevated breast cancer risks in the daughters of exposed women (Palmer et al. 2006). Given the proven contribution of unopposed estrogens in the development of breast cancer and endometriosis, it is biologically plausible that less potent EDCs may also contribute to risks of chronic diseases, such as breast cancer and endometriosis (Bertelsen et al. 2007 and Roy et al. 1997).

To date, most research on the endometriosis connection to breast cancer biology has focused on a few mechanisms and pathways in their development. Genes involved in estrogen biosynthesis, metabolism, estrogen signaling pathway and signal transduction have been suggested to affect susceptibility of breast cancer and endometriosis. ESR is an important molecular risk factor in the pathogenesis of breast cancer (Treek et al. 2009). We examined the association of estrogen receptor ESR2 and estrogen biosynthesis enzyme, aromatase, CYP19A1 with endometriosis and breast cancer. Both mRNA and protein levels of estrogen receptor 2 (ESR2) were found higher in endometriotic tissue (Xue et al 2007). Increased expression of aromatase has been found in breast tumors (Irahara et al. 2006). In women with endometriosis, elevated tissue levels of estradiol due 
to increased aromatase activity are found (Bulun et al. 2009). In this we found that five common estrogen responsive genes, including CYP19A1 and ESR2 were associated with all three EDCs -PCBs, phthalates and BPA, breast cancer, and endometriosis. We also observed association of EGFR, FOS and IGF1 genes with EDCs, endometriosis and breast cancer. Increased circulating IGF1 level is associated with and increased risk of breast cancer (Al Zahrani et al. 2006). Another common gene identified in both endometriosis and breast cancer in this study was stanniocalcin 2 (STC2). This is a downstream target of estrogen signaling pathways (Raulic et al. 2008). The expression of STC2 is induced in MCF-7 cells and the endometrial gland of women by 17 beta estradiol and in breast tumors (Wood et al. 2010 and Gruvberger et al. 2001). Modified expression of these genes is known to be involved in pathway of cancer, including breast cancer, mTOR signaling pathway, focal adhesion, VEGF signaling pathway and ErbB signaling pathway. However, the link of these common genes between the 2 diseases and EDCs does not prove that one causes the other. Furthermore, our study also revealed that PCBs and congeners 3,4,5,3',4'-pentachlorobiphenyl (126) and 2,4,5,2',4',5'hexachlorobiphenyl (153) are associated with some of the same estrogen receptor signaling pathway genes in breast neoplasm that are also observed with 17 beta estradiol. Similarly, common genes of estrogen receptor signaling pathways were also observed with EDCs -dibutyl phthalate; diethylhexyl phthalate; and BPA and breast neoplasms that are also observed with 17 beta-estradiol. These finding support genes involved in estrogen biosynthesis and estrogen signaling pathway may contribute to the susceptibility of breast cancer and endometriosis. 
Another factor that appears to be common in both diseases is inflammation. The role of estrogen in inflammation is complex. On one hand, studies have observed suppression of inflammation with increased estrogen in several animal models of chronic inflammatory diseases. On the other hand, there is evidence of proinflammatory effects in some chronic autoimmune diseases in humans. Estrogen induces proinflammatory cytokines, such as interleukin-1 beta (IL-1beta) and tumor necrosis factor alpha (TNFalpha), and a number of other inflammation associated genes. Inflammation-mediated oxidative stress is involved in the development of both of these diseases (Roy et al. 2007). Prostaglandin E2 is up regulated in endometriosis as a result of inflammation, which increases estrogen synthesis by up regulating aromatase. A proinflammatory milieu can also directly increase estrogen production. Hence, inflammation may work in conjunction with or in addition to estrogen exposure in the development of breast cancer in women with endometriosis (Modungo et al. 2005).

There are several strengths of the meta-analysis of EDCs associated with breast cancer or endometriosis. The use of the general variance based method gave more weight to larger studies, considered confounding, and limited the number of studies excluded because of missing data. Most studies used interview data to assess exposure, providing a more direct accounting of exposure. Finally, the combining of similar exposure time periods and splitting of occupational and household agricultural/nonagricultural exposures allowed for assessment of the range of possible external etiological factors involved in breast cancer or endometriosis development. Limitations of the study include those typical of the epidemiological studies combined in meta-analyses such as publication bias, recall bias and exposure misclassification. Also, EDCs and breast 
cancer type, along with individual practices of participants, were not distinguished in most studies. There are also obvious limitations to this type of bioinformatics analyses. While this analysis provides numerous hypotheses for potential gene-EDC interactions, it can only suggest possibilities, and therefore further research in a lab setting is necessary to validate their involvement in breast cancer and endometriosis. While we did choose studies and databases we felt would provide a comprehensive set of modified genes, we did not assess the entire set of literature on breast cancer and endometriosis-related genes, and therefore may have missed some potential modified genes in our analysis.

Furthermore, we have not included epigenetic genes in our analysis and therefore may have missed other potential gene-EDC interaction pathways to breast cancer and endometriosis through these mechanisms. While these are shortcomings of this type of research, the clear benefit of this study in particular, is the identification of genes with potential to contribute to breast cancer and endometriosis. Furthermore, generation of gene-EDCs interaction data relevant to breast cancer and endometriosis through this bioinformatics method provides highly useful information for a more comprehensive understanding of gene-EDCs interaction in the development breast cancer and endometriosis. Further research with an integrated bioinformatic, biostatistic and molecular epidemiologic approach is needed to study

\section{CONCLUSION}

In summary, the major novel findings emerged from the meta-analyses that PCBs exposure may increase risk of breast cancer and endometriosis. A single exposure to an internal or external environmental factor alone cannot explain the development of a 
complex chronic disease, such as breast cancer and endometriosis, rather it appears that exposure to multiple environmental and molecular factors across the lifespan and their interactions influence the development of these chronic diseases in an individual. There may be common molecular risk factors between endometriosis and breast cancer and it is biologically plausible that an altered endogenous estrogen levels presumably from exposure to estrogen mimicking EDCs may contribute to the risk of these diseases. Our bioinformatics approach helps to identify genes associated with EDCs, and to generate a new hypothesis to evaluate the relationship between endometriosis and breast cancer. Endocrine disruptor responsiveness and systems impacts consistent with system-wide findings in breast cancer and endometriosis are thus supported as important considerations in identifying the numerous and complex modes of gene-EDCs interaction in these diseases. Given the proven contribution of unopposed estrogens to the risk for endometriosis or endometrial neoplasia or breast cancer, renewed health concerns have aroused about estrogen mimicking EDCs found in food, personal care products or as environmental contaminants. Although limited and inconsistent evidence exists for an association between some EDC's and adverse human reproductive outcomes, the widespread human exposure to EDC's and the increasing concern for their potential to induce reproductive toxicity, especially in susceptible populations with sensitive gene polymorphisms, demonstrates a clear need for more research. 


\section{HYPOTHESIS}

Exposure to EDCs through altering hormone levels results in an increased risk of reproductive toxicity in females.

\section{SPECIFIC AIMS}

This research was designed in response to the recent resurgence of findings related to the potential reproductive and endocrine toxicity of endocrine disrupting compounds (EDCs). Using the CDC's NHANES database, statistical analysis was performed to analyze the associations between urinary and blood biomarkers of EDCs, reproductive health variables, and medical questionnaires (cancer). The objective of this research was to assess exposure to endocrine disrupting compounds in the general U.S. population through the CDC's National Health and Nutrition Examination Survey and determine if risk of reproductive dysfunction is increased due to exposure to endocrine disrupting compounds (polychlorinated biphenyls, phthalates, and bisphenol A) commonly found in the environment today.

Specific Aim 1: To assess exposure to PCBs in the general U.S. population using blood serum PCB biomarkers available in the CDC's 1999-2004 NHANES database and conduct secondary statistical analysis to determine if there is an association between higher body burdens of PCBs and breast cancer in women.

Sub Aim 1a: Female participants in the 1999-2004 NHANES cycles, 20 years of age and older who have higher body burdens of PCBs will have an increased risk of breast cancer. 
Specific Aim 2: To assess exposure to PCBs in the general U.S. population using blood serum PCB biomarkers available in the CDC's 1999-2004 NHANES database and conduct secondary statistical analysis to determine if there is an association between higher body burdens of PCBs and adverse reproductive health effects in women.

Sub Aim 2a: Female participants in the 1999-2004 NHANES cycles, 20-54 years of age who have higher body burdens of PCBs will have an increased risk of endometriosis.

Sum Aim 2b: Female participants in the 1999-2004 NHANES cycles, 20-54 years of age who have higher body burdens of PCBs will have an increased risk of uterine leiomyomas.

Specific Aim 3: To assess exposure to EDCs in the general U.S. population using blood serum and urinary biomarkers available in the CDC's 1999-2010 NHANES database and conduct secondary statistical analysis to determine if there is an association between higher body burdens of EDCs and reproductive cancers (breast cancer, cervical cancer, ovarian cancer, and uterine cancer) in women.

Sub Aim 3a: Female participants in the 1999-2004 NHANES cycles, 20 years of age and older who have higher body burdens of PCBs will have an increased risk of cervical cancer, ovarian cancer, or uterine cancer.

Sum Aim 3b: Female participants in the 2003-2010 NHANES cycles, 20 years of age and older who have higher body burdens of phthalates will have an increased risk of breast cancer, cervical cancer, ovarian cancer, or uterine cancer. 
Sum Aim 3c: Female participants in the 2005-2010 NHANES cycles, 20 years of age and older who have higher body burdens of bisphenol A will have an increased risk of breast cancer, cervical cancer, ovarian cancer, or uterine cancer. 


\section{REFERENCES}

1) UNEP/ WHO Expert Advisory Group. 2013. State of the Science of Endcorine Disrupting Chemicals - 2012. Eds: Åke Bergman, Jerrold J. Heindel, Susan Jobling,Karen A. Kidd and R. Thomas Zoeller, WHO Press.

2) EU Commission Expert Advisory Group. 2013. Key scientific issues relevant to the identification and characterisation of endocrine disrupting substances. JRC Scientific and Policy Reports.

3) Burantrevedh S. and Roy D. 2001. Occupational exposure to endocrine disrupting pesticides and the potential of developing hormonal cancers. Journal of Environmental Health 64:17-30.

4) Roy D, Colerangle J, Singh KP. 1998. Is exposure of environmental or industrial endocrine disrupting estrogen-like chemicals able to cause genomic instability? Front Biosci 3: d913-921.

5) Evans JM. 2008. An Integrative Approach to Fibroids, Endometriosis, and Breast Cancer Prevention. Integrative Medicine 7: 28-31.

6) Lin BC, Suzawa M, Blind RD, Tobias SC, Bulun SE, Scanlan TS, Ingraham HA. 2009 .Stimulating the GPR30 Estrogen Receptor with a Novel Tamoxifen Analogue Activates SF-1 and Promotes Endometrial Cell Proliferation. Cancer Research 69:5415-5423.

7) Bertelsen L, Mellemkjaer L, Frederiksen K, Kjaer SK, Brinton LA, Sakoda LC, van Valkengoed I, Olsen JH. 2007. Risk for breast cancer among women with endometriosis. Int J Cancer 15:1372-1375.

8) Roy D, Palangat M, Chen CW, Thomas RD, Colerangle J, Atkinson A, Yan ZJ. 1997. Biochemical and molecular changes at the cellular level in response to exposure to environmental estrogen-like chemicals. J Tox Env Hlth 50:1-29.

9) Fielden, MR, Halgren, RG, Tashiro C, Yeo BR, Chittim B, Chou K, Zacharewski TR. 2001. Effects of gestational and lactational exposure to Aroclor 1242 on sperm quality and in vitro fertility in early adult and middle-aged mice. Reproductive Toxicology 15:281-92.

10) Ma R. \& Sassoon D. 2006. PCBs Exert and Estrogenic Effect through Repression of the Wnt7a Signaling Pathway in the Female Reproductive Tract. Environ Health Perspect 114: 898-904.

11) McLachlan JA, Simpson E, Martin M. 2006. Endocrine disrupters and female reproductive health. Best Pract Res Clin Endocrinol Metab 20(1):63-75. 
12) Agency for Toxic Substances and Disease Registry (ATSDR). 2000.

Toxicological Profile for Polychlorinated Biphenyls. Atlanta, GA: U.S.

Department of Health and Human Services, Public Health Service.

13) Rier SE, Turner WE, Martin DC, Morris R, Lucier GW, Clark GC. 2001. Serum levels of TCDD and dioxin-like chemicals in rhesus monkeys chronically exposed to dioxin: correlation of increased serum PCB levels with endometriosis. Toxicol Sci 59:147-159.

14) Schell LM \& Gallo MV. 2009. Relationships of putative endocrine disruptors to human sexual maturation and thyroid activity in youth. Physio Behav 99(2): 246265.

15) Tsukimori K, Tokunaga S, Shibata S, Uchi H, Nakayama D, et al. 2008. Longterm effects of polychlorinated biphenyls and dioxins on pregnancy outcomes in women affected by the Yusho incident. Environ Health Perspect 116.5:626-630.

16) Yang M, Ryu JH, Jeon R, Kang D, Yoo KY. 2009. Effects of bisphenol A on breast cancer and its risk factors. Arch Toxicol 83:281-285.

17) $\mathrm{Yu}$ M, Guo YL, Hsu CC, Rogan WJ. 2000. Menstruation and reproduction in women with polychlorinated biphenyl (PCB) poisoning: long-term follow-up interviews of the women from the Taiwan Yucheng cohort. International Journal of Epidemiology 29:672-677.

18) Buck GM, Vena JE, Schisterman EF, Dmochowski J, Mendola P, et al. 2000. Parental consumption of contaminated sport fish from Lake Ontario and predicted fecundability. Epidemiology 11:388-393.

19) Mendola P, Buck GM, Sever LE, Zielezny M, Vena JE, et al. 1997. Consumption of PCB-contaminated freshwater fish and shortened menstrual cycle length. Am J Epidemiol 146(11):955-960.

20) Baibergenova A, Kudyakov R, Zdeb M, Carpenter DO. 2003. Low birth weight and residential proximity to PCB-contaminated waste sites. Environ Health Perspect 111(10):1352-1357.

21) Kostyniak PJ, Stinson C, Greizerstein HB, Vena J, Buck G, Mendola P. 1999. Relation of Lake Ontario fish consumption, lifetime lactation, and parity to break milk polychlorobiphenyl and pesticide concentrations. Environ Res 80:S166S174. 
22) Xu X, Dailey AB, Talbott EO, Ilacqua VA, Kearney G, Asal NR. 2010. Associations of serum concentrations of organochlorine pesticides with breast cancer and prostate cancer in U.S. adults. Environ Health Perspect 118(1):60-66.

23) Silver SR, Whelan EA, Deddens JA, Steenland NK, Hopf NB, Waters MA, Ruder AM, Prince MM, et al. 2009. Occupational exposure to polychlorinated biphenyls and risk of breast cancer. Environ Health Perspect 117(2):276-282.

24) Gammon MD, Wolff MS, Neugut AI, Eng SM, Teitelbaum SL, Britton JA. et al. 2002. Environmental Toxins and Breast Cancer on Long Island. II. Organochlorine Compound Levels in Blood. Cancer Epidemiol Biomark Prev 11:686-697.

25) Wolff MS, Zeleniuch-Jacquotte A, Dubin N, Toniolo P. 2009. Risk of breast cancer and organochlorine exposure. Cancer Epidemiol Biomarkers Prev 9: 271277.

26) Hunter DJ, Hankinson SE, Laden F, Colditz GA, Manson JE, et al. 1997. Plasma organochlorine levels and the risk of breast cancer. New England Journal of Medicine 337:1253-1258.

27) Moysich KB, Shields PG, Freudenheim JL, Schisterman EF, Vena JE, Kostyniak $\mathrm{P}$, Greizerstein H, et al. 1999. Polychlorinated biphenyls, cytochrome P4501A1 polymorphism, and postmenopausal breast cancer risk. Cancer Epidemiol Biomarkers Prev 8(1):41-44.

28) Zhang Y, Wise JP, Holford TR, Xie H, Boyle P, Zahm SH, Rusiecki J, Zoum K, et al. 2004. Serum polychlorinated biphenyls, cytochrome P-450 1A1 polymorphisms, and risk of breast cancer in Connecticut women. Am J Epidemiol 160(12):1177-83.

29) Muscat, JE, Britton, JA, Djordjevic, MV, Citron, ML, Kemeny M, BuschDevereauxE, Pittman, B., Stellman SD. 2003. Adipose concentrations of organochlorine compounds and breast cancer recurrence in Long Island, New York. Cancer Epidemiol Biomarkers Prev 12(12):1474-1478.

30) CDC. 2005. Third National Report on Human Exposure to Environmental Chemicals. Atlanta, GA: Centers for Disease Control and Prevention; National Center for Environmental Health; Division of Laboratory Sciences. Available: http://www.cdc.gov/exposurereport/pdf/thirdreport.pdf

31) Swan SS. 2008. Environmental phthalate exposure in relation to reproductive outcomes and other health endpoints in humans. Env Res 108(2):177-184. 
32) Moral R, Wang R, Russo IH, Lamartiniere CA, Pereira J, Russo J. 2008. Effect of prenatal exposure to the endocrine disruptor bisphenol A on mammary gland morphology and gene expression signature. J Endocrin 196: 101-112.

33) Latini G, De Felice C, Presta G, Del Vecchio A, Paris I, et al. 2003. In utero exposure to di-(2-ethylhexyl) phthalate and duration of human pregnancy. Environ Health Perspect 111(14): 1783-1785.

34) Frederikson H, Skakkebaek NE, Andersson AM. 2007. Metabolism of phthalates in humans. Mol. Nutr. Food Res 51:899-911.

35) Meeker JD, Sathyanarayana S, Swan SH. 2009. Phthalates and other additives in plastics: human health exposure and associated health outcomes. Phil. Trans. R. Soc. B 364:2097-2113.

36) Cobellis L, Latini G, DeFelice C, Razzi S, Paris I, Ruggieri F, Mazzeo P, Petraglia F. 2003. High plasma concentrations of di-(2-ethylhexyl)-phthalate in women with endometriosis. Human Reprod 18:1512-1515.

37) Huang PC, Tsai EM, Li WF, Liao PC, Chung MC, et al. 2010. Association between phthalate exposure and glutathione S-transferase MI polymorphism in adenomyosis, leiomyoma, and endometriosis. Human Reprod 25(4): 986-994.

38) Talsness CE, Andrade AJM, Kuriyama SN, Taylor JA, vom Saal FS. 2009. Components of Plastic: experimental studies in animals and relevance for human health. Phil. Trans. R. Soc. B 364:2079-2096.

39) Munoz-de-Toro M, Markey CM, Wadia PR, Luque EH, Rubin BS, Sonnenschein C, Soto AM. 2005. Perinatal exposure to bisphenol-A alters peripubertal mammary gland development in mice. Endocrinology 146: 4138-4147.

40) Cabaton NJ, Wadia PR, Rubin BS, Zalko D, Schaeberle CM, Askenase MH, et al. 2011. Perinatal Exposure to Environmentally Relevant Levels of Bisphenol A Decreases Fertility and Fecundity in CD-1Mice. Environ Health Perspect 119: 547-552.

41) Markey CM, Wadia PR, Rubin BS, Sonnenschein C, Soto AM. 2004. LongTerm Effects of Fetal Exposure to Low Doses of the Xenoestrogen Bisphenol-A in the Female Mouse Genital Tract. Biology of Reproduction 72: 1344-1351.

42) Cantonwine D, Meeker JD, Hu H, Sanchez BN, Lamadrid-Figueroa H, et al. 2010. Bisphenol A exposure in Mexico City and risk of prematurity: a pilot nested case control study. Env Health 9:62-69. 
43) Borenstein M, Hedges L, Higgins J, Rothstein H. 2005.Comprehensive Metaanalysis, Version 2, Biostat., Englewood, NJ.

44) Charlier CJ, Albert AI, Zhang L, Dubois NG, Phoenix GJ. 2004. Polychlorinated biphenyls contamination in women with breast cancer. Clinica Chimica Acta 347:177-181.

45) Cohn BA, Terry MB, Plumb M, Cirillo PM. 2012. Exposure to polychlorinated biphenyl (PCB) congeners measured shortly after giving birth and subsequent risk of maternal cancer before age 50. Breast Cancer Res Treat 136: 267-275.

46) Demers A, AYotte P, Brisson J, Dodin S, Robert J, Dewailly E. 2002. Plasma Concentrations of Polychlorinated Biphenyls and the Risk of Breast Cancer: A Congener-specific Analysis. Am J Epidemiol 155: 629-635.

47) Gatto NM, Longnecker MP, Press MF, Sullivan-Halley J, McKean-Cowdin R, Bernstein L. 2007. Serum organochlorines and breast cancer: a case-control study among African-American women. Cancer Causes Control 18:29-39.

48) Itoh H, Iwasaki M, Hanaoka T, Kasuga Y, Yokoyama S, Onuma H, et al. 2009. Serum organochlorines and breast cancer risk in Japanese women: a case-control study. Cancer Causes Control 20:567-580.

49) Millikan R, DeVoto E, Duell EJ, Tse CK, Savitz DA, Beach J, et al. 2013. Dichlorodiphenyldichloroethane, polychlorinated biphenyls, and breast cancer among African-American and white women in North Carolina. Cancer Epidemiol Biomark Prev 9:1233-1240.

50) Pavuk M, Cerhan JR, Lynch CF, Kocan A, Petrik J, Chovancova J. 2003. Casecontrol study of PCBs, other organochlorines and breast cancer in Eastern Slovakia. J of Exp Ana Env Epidemiol 13: 267-275.

51) Recio-Vega R, Velazco-Rodriguez V, Ocampo-Gomez G, Hernandez-Gonzalez S, Ruiz-Flores P, Lopez-Marquez F. 2001. Serum levels of polychlorinated biphenyls in Mexican women and breast cancer risk. J Appl Toxicol 31:270-278.

52) Lopez-Carillo L, Hernandez-Ramirez RU, Calafat AM, Torres-Sanchez L, Galvan-Portillo M, Needham LL, Ruiz-Ramos R, Cebrian ME. 2010. Exposure to phthalates and breast cancer risk in Northern Mexico. Environ Health Perspect 118 (4): 539-545.

53) Atkinson A \& Roy D. 1995. In vivo genotoxicity of bisphenol A. Env Mutagen 26:60-66. 
54) Colerangle JB \& Roy D. 1997. Profound effects of the weak environmental estrogen-like chemical bisphenol A on the growth of the mammary gland of Noble rats. J Steroid Biochem Mol Biol 60:153-60.

55) Newbold RR, Jefferson WN, Padilla-Banks E. 2007. Long-term adverse effects of neonatal exposureto bisphenol A on the murine female reproductive tract. Reprod Toxicol 24:253-258.

56) Murray TJ, Maffini MV, Ucci AA, Sonneschein C, Soto AM. 2007. Induction of mammary gland ductal hyperplasia and carcinoma in situ following fetal bisphenol A exposure. Reprod Toxicol 23:383-390.

57) Signorile PG, Spugnini EP, Mita L, Mellone P, D’Avino A, Bianco M, et al. 2010. Pre-natal exposure of mice to bisphenol A elicits and endometriosis-like phenotype in female offspring. General and Comparative Endocrinol 168:318325 .

58) The Cancer Genome Atlas Network. 2012. Comprehensive molecular portraits of human breast tumours. Nature 490, 61-70.

59) Buck Louis GM, Weiner JM, Whitcomb BW, Sperrazza R, Schisterman EF, Lobdell DT, Crickard K, Greizerstein H, Kostyniak PJ. 2005. Environmental PCB exposure and risk of endometriosis. Human Reprod 20: 279-285.

60) Heiler JF, Nackers F, Verougstraete V, Tonglet R, Lison D, Donnez J. 2005. Increased dioxin-like compounds in the serum of women with peritoneal endometriosis and deep endometriotic (adenomyotic) nodules. Fertil Steril 84: 305-312.

61) Niskar AS, Needham LL, Rubin C, Turner WE, Martin CA, Patterson DG, Hasty L, Wong LY, Marcus M. 2009 Serum dioxins, polychlorinated biphenyls, and endometriosis: A case-control study in Atlanta. Chemosphere 74:944-949.

62) Pauwels A, Schepens PJ, Hooghe TD, Delbeke I, Dhont M, Brouwer A, Weyler J. 2001. The risk of endometriosis and exposure to dioxins and polychlorinated biphenyls: a case-control study of infertile women. Human Reprod 16: 20502055 .

63) Porpora MG, Medda E, Abballe A, Bolli S, De Angelis I, di Domenico A, Ferro A, Ingelido AM, Maggi A, Panici PB, De Felip E. 2009. Endometriosis and organochlorinated environmental pollutants: A case-control study on Italian women of reproductive age. Env Health Perspect 117:1070-1075. 
64) Trabert B, De Roos AJ, Schwartz SM, Peters U, Scholes D, Barr DB, Holt VL. 2010. Non-dioxin-like polychlorinated biphenyls and risk of endometriosis. Env Health Perspect 118:1280-1285.

65) Tsukino H, Hanaoka T, Sasaki H, Motoyama H, Hiroshima M, Tanaka T, Kabuto M, Niskar AS, Rubin C, Patterson Jr DG, Turner W, Needham L, Tsugane S. 2005. Associations between serum levels of selected organochlorine compunds and endometriosis in infertile Japanese women. Environ Res 99:118-125.

66) Kim SH, Chun S, Jang JY, Chae HD, Kim CH, Kang BM. 2011. Increased plasma levels of phthalate esters in women with advanced stage endometriosis: a prospective case-control study. Fertil Steril 95: 357-359.

67) Upson K, Sathyanarayana S, De Roos AJ, Thompson ML, Scholes D, Dills R, Holt V. 2013. Phthalates and risk of endometriosis. Environ Res 126:91-97.

68) Itoh H, Iwasaki M, Hanaoka T, Sasaki H, Tanaka T, Tsugane S. 2007. Urinary bisphenol-A concentration in infertile Japanese women and its association with endometriosis: A cross-sectional study. Env Health Prev Med 12:258-264.

69) Buck Louis GM, Peterson M, Chen Z, Croughan M, Sundaram R, Stanford J, Warner M, Kennedy A, Gludice L, Fujimoto V, Sun L, Wang L, Guo Y, Kannan K. 2013. Bisphenol A and phthalates and endometriosis. Fertil Steril 100: 162169.

70) Huang PC, Tsai EM, Li WF, Liao PC, Chung MC, Wang YH, Wang SL. 2010. Association between phthalate exposure and glutathione S-transferase M1 polymorphism in adenomyosis, leiomyoma and endometriosis. Human Reprod 25:986-994.

71) Itoh H, Iwasaki M, Hanaoka T, Sasaki H, Tanaka T, Tsugane S. 2009. Urinary phthalate monoesters and endometriosis in infertile Japanese women. Sci Total Environ 408:37-42.

72) Itoh H, Iwasaki M, Nakajima $Y$, Endo $Y$, Hanaoka T, Sasaki H, Tanaka T, Yang B, Tsugane S. 2008. A case-control study of the association between urinary cadmium concentration and endometriosis in infertile Japanese women. Sci Total Environ 402:171-175.

73) Weuve J, Hauser R, Calafat AM, Missmer SA, Wise LA. 2010. Association of exposure to phthalates with endometriosis and uterine leiomyomata: Findings from NHANES, 1999-2004. Environ Health Perspect 118:825-832. 
74) Reddy BS, Rozati R, Reddy BV, Raman NV. 2006. Association of phthalate esters with endometriosis in Indian women. Int J Obstetrics Gynaecol 113:515520.

75) Reddy BS, Rozati R, Reddy S, Kodampur S, Reddy P, Reddy R. 2006. High plasma concentrations of polychlorinated biphenyls and phthalate esters in women with endometriosis: a prospective case control study. Fertil and Steril 85:775-779.

76) De S, Ghosh S, Chatterjee R, Chen YQ, Moses L, Kesari A, Hoffman EP, Dutta SK. 2010. PCB congener specific oxidative stress response by microarray analysis using human liver cell line. Environ Int 36:907-917

77) Burney RO, Talbi S, Hamilton AE,Vo KC, Nyegaard M, Nezhat CR, Lessey BA, Giudice LC. 2007. Gene expression analysis of endometrium reveals progesterone resistance and candidate susceptibility genes in women with endometriosis. Endocrinol 148:3814-3826.

78) Hever A, Roth RB, Hevezi P, Marin ME, Acosta JA, Acosta H, Rojas J, Herrera R, Grigoriadis D, White E, Conlon PJ, Maki RA, Zlotnik A. 2007. Human endometriosis is associated with plasma cells and overexpression of B lymphocyte stimulator. Proc Natl Acad Sci USA 104:12451-12456.

79) Sha G, Wu D, Zhang L, Chen X, Lei M, Sun H, Lin S, Lang J. 2007. Differentially expressed genes in human endometrial endothelial cells derived from eutopic endometrium of patients with endometriosis compared with those from patients without endometriosis. Hum Reprod 22:3159-3169.

80) Spirtes P, Glymour C and Scheines R. 2000 Causation, Prediction, and Search, 2nd ed. New York, N.Y.: MIT Press.

81) Melin A, Sparen P, Bergqvist A. 2007. The risk of cancer and the role of parity among women with endometriosis. Human Reprod 22:i27-i28.

82) Irahara N, Miyoshi Y, Taguchi T, Tamaki Y, Noguchi S. 2006. Quantitative analysis of aromatase mRNA expression derived from various promoters and its association with expression of TNF- $\alpha$, IL-6 and COX-2 mRNAs in human breast cancer. Int J Cancer 118:1915-1921.

83) Roy JR, Chakraborty S, Chakraborty TR. 2009. Estrogen-like endocrine disrupting chemicals affecting puberty in humans - a review. Med Sci Monit15:RA137-RA145.

84) Ibarluzea JJ, Fernandez MF, Santa-Marina L, Olea-Serrano MF, Rivas AM, Aurrekoetxea JJ, Exposito J, Lorenzo M, TorneP, Villalobos M, Pedraza V, Sasco 
AJ, Olea N. 2000. Breast cancer risk and the combined effect of environmental oestrogens. Cancer Causes Control 15:591-600.

85) Palmer JR, Wise LA, Hatch EE, Troisi R, Titus-Ernstoff L, Strohsnitter W, Kaufman R, Herbst AL, Noller KL, Hyer M, Hoover RN. 2006. Prenatal diethylstilbestrol exposure and risk of breast cancer. Cancer Epidemiol Biomarkers Prev 15:1509-1514.

86) Treeck O, Elemenler E, Kriener C, Horn F, Springwald A, Hartmann A, Ortmann O. 2009. Polymorphisms in the promoter region of ESR2 gene and breast cancer susceptibility. J Steroid Biochem Mol Biol 114: 207-211.

87) Xue Q1, Lin Z, Cheng YH, Huang CC, Marsh E, Yin P, Milad MP, Confino E, Reierstad S, Innes J, Bulun SE. 2007. Promoter methylation regulates estrogen receptor 2 in human endometrium and endometriosis. Biol Reprod 77:681-687.

88) Bulun SE. 2009. Endometriosis. New Engl J Med 360:268-279.

89) Al Zahrani A, Sandhu MS, Luben RN, Thompson D, Baynes C, Pooley KA, Luccarini C, Munday H, Perkins B, Smith P, Pharoah PD, Wareham NJ, Easton DF, Ponder BA, Dunning AM. 2006. IGF1 and IGFBP3 tagging polymorphisms are associated with circulating levels of IGF1, IGFBP3 and risk of breast cancer. Hum Mol Genet 15: 1-10.

90) Raulic S, Ramos-Valdes Y, DiMattia GE. 2008. Stanniocalcin 2 expression is regulated by hormone signaling and negatively affects breast cancer cell viability in vitro. J Endocrinol 197:517-529.

91) Wood CE, Kaplan JR, Fontenot MB, Williams JK, Cline JM. 2010. Endometrial profile of tamoxifen and low-dose estradiol combination therapy Clin Cancer Res 16: $946-956$.

92) Gruvberger S, Ringnér M, Chen Y, Panavally S, Saal LH, Borg A, Fernö M, Peterson C, Meltzer PS. 2001. Estrogen receptor status in breast cancer is associated with remarkably distinct gene expression patterns. Cancer Res 61:5979-5984.

93) Roy D, Cai Q, Felty Q, Narayan S. 2007. Estrogen-induced generation of reactive oxygen and nitrogen species, gene damage, and estrogen-dependent cancers. J Toxicol Environ Health B Crit Rev 10:235-57.

94) Modugno F, Ness RB, Chen C, Weiss NS. 2005. Inflammation and endometrial cancer: A hypothesis. Cancer Epidemiol Biomarkers Prev14:2840-2847. 


\section{CHAPTER III}

\section{METHODS}

\section{Study Design}

The primary objective of this study was to assess exposure to EDCs (PCBs, BPA, and phthalates) and determine whether exposure to these agents is a contributing factor in reproductive dysfunction in the U.S. general population. To support or refute the proposed role of EDCs, secondary statistical analysis was conducted using data from the CDCs 1999-2010 National Health and Nutrition Examination Study. The National Center for Health Statistics (NCHS), a branch of the U.S. Public Health Service in the U.S. Department of Health and Human Services, developed the National Health and Nutrition Examination Survey (NHANES). NHANES, conducted annually since 1999 by the Centers for Disease Control and Prevention (CDC), is an ongoing cross-sectional survey designed to be nationally representative of the non-institutionalized, U.S. civilian population. The survey design is a complex multistage probability sample, with oversampling of adolescents 12-19 years of age, adults greater than or equal to 60 years of age, low-income persons, Mexican Americans, and non-Hispanic blacks.

Oversampling of subgroups is done to allow for more precise and valid estimates to be derived than a simple random sampling would allow. To obtain a representative sample of the U.S. population, the country is divided into geographic areas known as primary sampling units which are then combined to form strata, each strata is then divided into a series of neighborhoods. From these neighborhoods, households are chosen at random and inhabitants are interviewed to determine if they are eligible for participation in the study. Once eligibility is determined participants complete a confidential and voluntary 
home interview followed by a standardized physical examination in a specially equipped mobile evaluation clinic (MEC). The MEC examination consists of a physical examination, dental examination, detailed face-to-face personal interview, and collection of biological specimens. Blood is obtained by venipuncture from a subsample of participants aged 1 year and older and urine specimens were collected from a subsample of participants aged 6 years and older. Each survey includes a nationally representative sample of approximately 5,000 participants. The study protocol was reviewed and approved by the CDC institutional review board and informed consent was obtained from all subjects prior to participating in the NHANES. All data collected is held in the strictest confidence and cannot be given out without consent. Code numbers are assigned in place of names or other identifying factors to maintain confidentiality. All participants received a cash payment for time and effort, as well as, reimbursement for transportation and baby/elder care (CDC, 2012)

\section{Laboratory Methods}

In each 2-year survey period, environmental chemicals or their metabolites were measured in blood serum or urine specimens from random subsamples of approximately 2,500 participants. The measurement of environmental chemicals in blood, serum, and urine reflect the amount of the chemical that enters the body through ingestion, inhalation, or dermal exposure routes. Environmental exposure measurements were made by the CDC's Environmental Health Laboratory (Division of Laboratory Sciences, National Center for Environmental Health) by isotope dilution mass spectrometry, inductively coupled plasma mass spectrometry, or graphite furnace atomic absorption spectrometry. For chemicals measured in urine, levels are expressed per volume of urine 
or per gram of creatinine. For lipophilic compounds such as dioxins, furans, PCBs, and organochlorine pesticides, serum levels are expressed per gram of total lipid and per whole weight of serum reflecting the amount of compounds that are stored in body fat. Blood serum and urinary samples collected during the MEC exam were stored at 4 degrees Celsius or frozen at -20 degrees Celsius and then shipped to the CDC's National Center for Environmental Health, Division of Environmental Health Laboratory Sciences for analysis. (CDC, 2013b).

Serum PCB, urinary BPA, and urinary phthalate metabolites. PCB levels were measured in serum from a random one-third subsample of people aged 12 years and older in the 1999-2000 and 2003-2004 survey cycles and people aged 20 years and older in the 2001-2002 survey cycle. Analytical results for PCBs are reported on a whole weight (ng/g or ppb) and a lipid-adjusted basis (ng/g or ppb). Urinary Bisphenol A (BPA) was measured in a random one-third subsample of participants aged 6 years and older in the 2003-2004, 2005-2006, 2007-2008, and 2009-2010 survey cycles. Urinary phthalate monoesters were measured in a random one-third subsample of participants aged 6 years and older in the 1999-2000, 2001-2002, 2003-2004, 2005-2006, and 2007-2008 survey cycles (CDC, 2012).

\section{Questionnaire Methods}

Demographic data was collected during the household interview in persons 16 years of age and older and emancipated minors. Reproductive health data was obtained during the Mobile Examination Center (MEC) private face-to-face interview in female participants aged 12 years and older. Medical health data was also obtained during the MEC interview from male and female participants, however, questions vary by age and 
gender. All interviewers completed a comprehensive two-week training program which included role-playing exercises and practice interviews, monitored by NCHS and contractor staff. In addition, MEC interviewers received extensive training on personal and audio-computer-assisted interview administration. Prior to implementing questionnaires a full pilot test was conducted as well as several types of quality control monitoring methods (CDC, 2012).

\section{Selection of Participants}

Inclusion criteria for the study included women, 20 years of age and older who completed a private face to face interview and provided a blood and/or urine sample in the mobile examination center. All subjects had to have available PCB, BPA, or phthalate measurements to be included in the study populations. In addition to available biological data, subjects in the 1999-2010 survey cycles had to complete the reproductive health and medical conditions questionnaires. To be included in the data for manuscript 1 and/or 3 , female participants had to provide a response to the medical question "Have you ever been told by a doctor or other health professional that you had cancer or a malignancy of any kind?" Participants with missing values for this question were deleted from the dataset. For manuscript 2, female participants had to provide a response to the reproductive health question "Has a doctor or other health professional ever told you that had endometriosis?" and/or "Has a doctor or other health professional ever told you that you had uterine fibroids?" Survey participants with missing values for these questions were deleted from the dataset (CDC, 2012). 


\section{Sample Weights and Limits of Detection}

Due to the complex survey design of NHANES, sample weights must be used to adjust for unequal probability of selection and possible bias resulting from non-response. Environmental chemicals are measured in subsamples of the study population and therefore must be weighted accordingly. PCBs, phthalates, and BPA were measured in a randomly selected $1 / 3$ subsample for each survey cycle. When merging data from multiple survey cycles, appropriate sampling weights must be created according to NHANES analytic guidelines (CDC, 2013b)

A detection limit variable is provided for all PCBs, phthalates, and BPA in the data sets. The variable LBD_LC has two values: the value " 0 " indicates that the result was below the limit of detection and the value " 1 " indicates that the result was at or above the limit of detection. Any participant with a serum PCB concentration below the limit of detection was assigned a serum level of the LOD divided by the square root of two. Limits of detection vary by individual PCB congener and survey cycle and can be found in the CDC's Fourth National Report on Human Exposure to Environmental Chemicals (CDC, 2013). LOD values may vary by survey year due to improvements in analytical methods. While most LODs are constant for each individual specimen analyzed, individual PCB samples have their own LODs because the sample volume used for analysis differed for each sample. For chemicals measured in urine, LOD calculations were performed using the chemical concentration expressed per volume of urine and for chemicals measured in serum, LOD calculations were performed using the chemical concentration expressed per amount of lipid because these concentrations determine the analytical sensitivity (CDC, 2013b). 


\section{EDC Exposure Assessment}

PCB Variables. NHANES sampled for 22 PCB congeners in the 1999-2000 survey cycle, 34 PCB congeners in the 2001-2002 survey cycle, and 38 PCB congeners in the 2003-2004 survey cycle. To avoid bias among those below the LOD, we selected 6 individual PCB congeners that were available in the 1999-2000, 2001-2002, and 20032004 survey cycles and had concentrations above the LOD in at least $60 \%$ of the study subjects. The data analysis explored the relationship between reproductive health variables in women using the following six individual PCB congeners: $2,4,4$ ',5tetrachlorobiphenly (74), 2,2’4,4',5-pentachlorobiphenyl (99), 2,3',4,4',5pentachlorobiphenyl (118), 2,2',3,4,4',5-hexachlorobiphenyl (138), 2,2',4,4',5,5'hexachlorobiphenyl (153), and 2,2',3,4,4,5,5'-heptachlorobiphenyl (180). Analysis was also conducted on the sum of non-dioxin-like PCBs $(99,138,153,180)$ and the sum of dioxin-like PCBs (74 and 118). We conducted analysis of PCBs and breast cancer and PCBs and other reproductive cancers (cervical, ovarian, and uterine) using 1999-2004 survey cycles with female participants 20 to 85 years of age. We conducted analysis of PCBs and endometriosis and uterine leiomyomata using the 1999-2004 survey cycles and women 20-54 years of age (CDC, 2012).

Phthalate Variables. NHANES sampled for 13 urinary phthalate metabolites in the 2003-2004 survey cycle, and 15 urinary phthalate metabolites in the 2005-2006, 20072008, and 2009-2010 survey cycles. We selected the following seven urinary phthalate metabolites for our analysis: mono-n-butyl phthalate (MnBP), mono-isobutyl phthalate (MiBP), mono-ethyl phthalate (MEP), mono-(3-caroxypropyl) phthalate (MCPP), monobenzyl phthalate (MZP), and three metabolites of di (2-ehtylhexyl) phthalate (DEHP): 
[mono-2-ethylhexyl phthalate (MEHP), mono-(2-ethyl-5-hydroxyhexyl) phthalate (MEHHP), and mono-(2-ethyl-5-oxohexyl) phthalate (MEOHP). These metabolites were chosen because they were consistently measured in the 2003-2010 survey cycles and their concentrations were above the LOD in $98 \%$ of the study subjects, with the exception of MEHP which was present in concentrations above the LOD for $68 \%$ of the study subjects. Data analysis was conducted using the 2003-2004, 2005-2006, 2007-2008 and 2009-2010 survey cycles and female participants, 20 years of age and older (CDC, 2012). BPA Variables. Urinary BPA measurements are available from the 2003-2004, 20052006, 2007-2008, and 2009-2010 survey cycles in survey participants aged 6 years and older. We conducted analysis of BPA and reproductive cancers using the 2005-2006, 2007-2008, and 2009-2010 survey cycles and female participants, 20 years of age and

older. We did not include the 2003-2004 survey participants because BPA samples were taken from a different subsample of participants (subsample A vs. subsample B) and the CDC does not recommend combining different subsamples across survey cycles (CDC, 2012).

\section{Reproductive and Medical Health Variables}

Data analysis explored the relationship between serum PCB, urinary BPA and urinary phthalate levels and self-reported health outcomes obtained from the reproductive and medical health questionnaires of female participants 20 years of age and older. Medical Health Questionnaire. Self-reported cancer status was obtained through the medical questionnaires in participants' 20 years of age and older who provided a response for "Have you ever been told by a doctor or other health professional that you had cancer or a malignancy of any kind?" Women who answered "yes" were 
subsequently asked "What kind of cancer was it?" and "What was your age at diagnosis?" Only women who reported no cancer diagnosis or a breast cancer diagnosis were included in our study population for manuscript 1. Participants who reported no cancer diagnosis and breast cancer, ovarian cancer, uterine cancer, or cervical cancer diagnosis were included in the analyses for manuscript 3. Cancer diagnosis (yes/no) was modeled as a categorical dependent variable for all analyses (CDC, 2012).

Reproductive Health Questionnaire. NHANES data was used to examine the relationship between serum PCB levels and endometriosis and uterine leiomyomata in manuscript 2. Self-reported endometriosis diagnosis was obtained through the reproductive health questionnaire in participants 20 to 54 years of age, who provided a response for "Have you ever been told by a doctor or other health professional that you have endometriosis?" Women who answered "yes" were subsequently asked "What was your age at diagnosis?" Self-reported uterine fibroid diagnosis was obtained through the reproductive health questionnaire in participants 20 to 54 years of age, who provided a response for "Have you ever been told by a doctor or other health professional that you have uterine fibroids?" Women who answered "yes" were subsequently asked "What was your age at diagnosis?" Endometriosis (yes/no) and uterine leiomyomas (yes/no) were modeled as categorical dependent variables in our analysis. Additionally, the following outcomes from the reproductive health questionnaire were evaluated using categorical data: having undergone a medical procedure (hysterectomy, oophorectomy, or both: yes/no), age at menarche ( $<12$ years, $12-14$ years, $\geq 15$ years), number of pregnancies resulting in live births $(0,1, \geq 2)$, oral contraceptive use (yes/no) and history of lactation (yes/no) (CDC, 2012). 


\section{Statistical Analysis}

Females, 20 years and older with PCB, BPA, and/or phthalate levels and available reproductive or medical health data were used in our analyses. Reproductive health outcomes are normally distributed and were modeled untransformed, while all PCBs, BPA, and phthalate metabolites are not normally distributed and were log transformed prior to statistical analyses. In addition, all urinary BPA and phthalate metabolites were creatinine corrected prior to analyses. All estimates were weighted according to the National Center for Health Statistics guidelines to produce accurate national estimates, adjusting for the oversampling of minority subgroups (CDC, 2013b). Variance estimation was conducted using the required stratum and PSU variables from the demographics data files. Geometric means (GM), geometric standard errors (GSE), and proportions of EDCs were calculated for demographic and reproductive health variables. GMs of EDCs were compared among reproductive health variables by means of Student's t-test or chi-square tests, depending on the type of variable. We used logistic regression models to calculate ORs and their 95\% CIs to investigate the risk between blood and urinary levels of EDCs and breast cancer, ovarian cancer, uterine cancer, and cervical cancer as well as PCBs and endometriosis and uterine leiomyomas. All statistical analyses were performed using SAS for windows (release 9.2; SAS Institute Inc. Cary, N.C.). These analyses used a 5\% significance level ( $\mathrm{p} \leq 0.05)$.

\section{Potential Confounding Variables}

Potential confounding variables from the demographics file include age, race/ethnicity, education and income. All potential confounding variables from the demographics file were inputted as categorical variables. For analysis of EDCs and 
reproductive cancers (manuscripts 1 and 3), age was categorized into three groups (20-59 years, $60-74$ years and $\geq 75$ years) due to a small number of reproductive cancer cases in the lower age range and race was categorized into two groups (non-Hispanic White and Other) due to a small number of reproductive cancer cases from races other than nonHispanic white. Women classified as 'Other' included non-Hispanic Blacks, Mexican Americans, Other Hispanic, and Other Races including Multi-Racial. For analysis of PCBs and endometriosis and uterine leiomyomas (manuscript 2), age was categorized into four groups (20-29 years, 30-39 years, 40-49 years, and 50-54 years) and race was categorized into three groups (non-Hispanic White, non-Hispanic Black, and Other). Women classified as 'Other' included Mexican Americans, Other Hispanic, and Other Races including Multi-Racial. Data on BMI was obtained through the examination component of the MEC exam and smoking status, alcohol consumption, education completed, and annual family income were obtained in the household interview. For all of our analyses, body mass index $\left(\mathrm{BMI}, \mathrm{kg} / \mathrm{m}^{2}\right)(>25,25-30$ and $\geq 30)$, smoking status [“Have you smoked at least 100 cigarettes in your entire life?" (yes/no)], alcohol consumption [In any one year, have you had at least 12 drinks of any type of alcoholic beverage?" (yes/no)], education completed $\left(<12^{\text {th }}\right.$ grade, $12^{\text {th }}$ grade and $>12^{\text {th }}$ grade $)$ and annual family income $(0-\$ 24,999, \$ 25,000-\$ 54,999, \$ 55,000-\$ 74,999$ and $\geq \$ 75,000)$ were evaluated as potential confounding variables, however smoking status, alcohol consumption, education completed, and annual family income were not retained in the final logistic regression models for manuscripts 1 and 3 because they were not found to be significant predictors of risk; manuscript 2 did not retain education and income in the final models. From the reproductive health questionnaire, additional covariates of age at 
menarche $(<12,12-14, \geq 15)$, parity, history of breastfeeding (yes/no), oral contraceptive use (yes/no) were evaluated for use in logistic regression models. Parity and oral contraceptive use were not retained in the final logistic regression models for manuscript 1 , breast feeding was not retained in the final logistic regression models for manuscript 2, and parity, breastfeeding, and oral contraceptive use were not retained in the final logistic regression models for manuscript 3 because of they contained a large number of missing values that significantly decreased the number of cancer cases in the model. 


\section{REFERENCES}

1. CDC (Centers for Disease Control and Prevention). 2012. National Health and Nutrition Examination Survey Questionnaires, Datasets, and Related Documentation. Available:

http://www.cdc.gov/nchs/nhanes/nhanes questionnaires.htm [last accessed June $112014]$

2. CDC (Centers for Disease Control and Prevention). 2013b. National Health and Nutrition Examination Survey: Analytic Guidelines, 1999-2010. Vital Health Stat 2(161). Available: http://www.cdc.gov/nchs/data/series/sr_02/sr02 161.pdf [last accessed June 112014$]$.

3. CDC (Centers for Disease Control and Prevention). 2013. Fourth National Report on Human Exposure to Environmental Chemicals. Available:

http://www.cdc.gov/exposurereport/pdf/FourthReport_UpdatedTables_Sep2013.p df [last accessed June 6 2014].

4. CDC (Centers for Disease Control and Prevention). 2014. National Health and Nutrition Examination Survey. Age Standardization and Population Counts. Available:

http://www.cdc.gov/nchs/tutorials/NHANES/NHANESAnalyses/agestandardizati on/age standardization intro.htm [last accessed June 16 2014]. 


\section{CHAPTER IV}

MANUSCRIPT 1

\section{EXPOSURE TO POLYCHLORINATED BIPHENYLS AND BREAST CANCER}

AMONG U.S. WOMEN: ANALYSES OF NHANES DATA 1999-2004

\section{ABSTRACT}

Background: Breast cancer is the most commonly diagnosed cancer among women worldwide. A number of chemicals are suspected to act as endocrine disruptors (EDs) by mimicking natural or synthetic estrogen resulting in an increased risk of breast cancer in women. Polychlorinated biphenyls (PCBs) have been recognized as endocrine disrupters due to their ability to interfere with reproductive function and development in animals and humans by either increasing estrogen activity or blocking estrogens from acting.

Objectives: The purpose of this study was to examine the cross-sectional relationship between exposure to PCBs and breast cancer among U.S. women.

Methods: We analyzed data from female participants (20 years of age and older) who provided blood samples for the Centers for Disease Control and Prevention's National Health and Nutrition Examination Survey (NHANES) between 1999 and 2004. Exposure was based on lipid adjusted serum levels of 6 individual PCB congeners (PCB 074, 099, $118,138,153$, and 180), the sum of dioxin-like PCBs $(074+118)$, and the sum of nondioxin-like PCBs $(099+138+153+187)$ in conjunction with data obtained from the medical and reproductive health questionnaires. We calculated geometric means to compare PCB concentrations in women who self-reported a breast cancer diagnosis vs. women who self-reported never being diagnosed with cancer. We used logistic regression models to estimate odds ratios (ORs) and 95\% confidence intervals (CIs) for the 
association between PCB measurements and breast cancer. We evaluated age,

race/ethnicity, age at menarche, body mass index $\left(\mathrm{BMI} ; \mathrm{kg} / \mathrm{m}^{2}\right)$, and lactation as potential confounders in our final models.

Results: Separate analyses showed weighted geometric mean levels of all 6 PCB congeners to be significantly higher among women with breast cancer when compared to the rest of the study population. After adjusting for age, race, and BMI we found breast cancer risk to be significantly associated with PCB 138 in the $50-75^{\text {th }}$ and $\geq 75^{\text {th }}$ percentile groups, [odds ratios of $2.93,95 \%$ confidence interval (CI): $1.04-8.26$ and $3.43,95 \% \mathrm{CI}$ : 1.12-10.4], respectively. After adjusting for age, race, BMI, lactation, and age at menarche we found that PCB 138 and 180 were significantly associated with breast cancer [ORs of $2.88 ; 95 \%$ CI: $1.14-7.30$ and $4.54,95 \%$ CI: 1.11-18.6, respectively] in women with higher body burdens of individual PCB congeners ( $>50^{\text {th }}$ percentile). After adjusting for age and race, we also found the sum of non-dioxin-like PCBs to be weakly associated with breast cancer [OR of 1.14; 95\% CI: 1.00-1.29].

Conclusions: Our results suggest a link between environmental exposures to PCBs and increased risk of breast cancer among U.S. women. Despite the ban on PCB production, environmental exposures appear to continue posing significant threats on the health of the general population.

Keywords: PCBs, NHANES, breast cancer 


\section{MANUSCRIPT 1}

\section{EXPOSURE TO POLYCHLORINATED BIPHENYLS AND BREAST CANCER \\ AMONG U.S. WOMEN: ANALYSES OF NHANES DATA 1999-2004 \\ INTRODUCTION}

Breast cancer is the most commonly diagnosed cancer among women in both developing and developed nations, representing $11.9 \%$ of all cancers diagnosed worldwide (SEER 2013, IARC 2012). Incidence rates of breast cancer vary greatly, with age standardized rates reaching 43.3 per 100,000 worldwide and 92.9 per 100,000 in North America (IARC 2012). The latest estimates released by the World Health Organization's (WHO) International Agency for Research on Cancer (IARC) GLOBOCAN 2012 database indicate that breast cancer incidence has increased 20\% while mortality has increased 14\% since 2008 (IARC 2012). While estimates vary, breast cancer cases cannot be solely attributed to risk factors such as family history, parity, prolonged exposure to endogenous estrogens (Bodicoat et al. 2014), physical inactivity, alcohol use, and obesity (Madigan et al 1995). A new recent report by the United Nations Environment Programme (UNEP) and WHO entitled "State of the Science: Endocrine Disrupting Chemicals - 2012" highlighted that approximately 800 chemicals are suspected to act as endocrine disruptors (EDs) or mimic natural hormones or disrupt hormone regulation (UNEP/WHO 2013, EU 2013). Some of these EDs mimic natural or synthetic estrogen. This recent UNEP/WHO report has renewed the concern by highlighting that there may be some associations between exposure to estrogen- 
mimicking EDs and an increased risk of breast cancer in women (UNEP/WHO 2013, EU 2013).

Polychlorinated biphenyls (PCBs) are a group of synthetic organic chemicals that were introduced into industry in the late 1920's and used primarily for heat exchange in transformers and capacitors, hydraulic and lubricating fluids, plasticizers, inks, paints, adhesives, flame retardants, and extenders for pesticides (ATSDR 2000). Despite the ban of PCBs in the late 1970's due to serious health concerns, environmental exposures are still possible due to a release from hazardous waste sites; illegal dumping; leaks from old transformers; and burning of PCB contaminated waste (Carpenter 2006, Johnson et al. 1999). Furthermore, PCBs bioaccumulate in the fatty tissues of fish and mammals, increasing the likelihood of dietary exposures. Elimination half-lives of PCBs vary substantially in humans for each PCB congener and range from a few months to a few decades depending on PCB chlorination, age, body fat, and breast feeding (Anderson et al. 1998, Phillips et al. 1989, Paris-Pombo et al. 2003, Tee et al. 2003, Milbrath et al. 2008).

PCBs have been recognized as endocrine disrupters due to their ability to interfere with reproductive function and development in animals and humans by either increasing estrogen activity or blocking estrogens from acting (Fielden et al. 2001, Aoki et al. 2001, Ma and Sassoon 2006, McLachlan et al. 2006). Estrogen is a contributing factor in the development of breast cancer (Lin et al. 2009). The increased risk of breast cancer among postmenopausal women may be due to an altered endogenous estrogen (Bertelsen et al. 2007, Roy et al. 1997, Roy et al. 1998). Furthermore, animal and limited human data suggest that exposure to PCBs may lead to a number of adverse reproductive effects such 
as decreased conception rates, prolonged time to pregnancy, irregular menstrual cycles, spontaneous abortion, preterm delivery, abnormal sperm morphology, decreased sperm motility, preterm delivery, low birth weight, reduced lactation time, and late miscarriages (Arisawa et al. 2005, Baibergenova et al. 2003, Buck et al. 2000, Kostyniak et al. 1999, Mendola et al. 1997, Rylander et al. 1998, Tsukimori et al. 2000, Yu et al. 2000, Yang et al. 2008).

Studies pertaining to PCBs and breast cancer are controversial. While some studies reported no significant associations (Gammon et al. 2002, Gatto et al. 2007, Wolff et al. 2000), or inverse associations (Pavuk et al. 2003, Itoh et al. 2009) other studies have found an increased breast cancer risk when analyzing total PCB exposure or specific individual PCB congeners (Charlier et al. 2004, Cohn et al. 2012, Demers et al. 2002, Millikan et al. 2013, Recio-Vega et al. 2001, Muscat et al. 2003). Charlier et al. (2004) found concentrations of PCB 138 (1.25 vs. 0.94 ppb; $\mathrm{p}=0.0068)$, PCB 153 (1.63 vs. $0.63 ; \mathrm{p}<0.0001)$, and total PCBs (7.08 vs. $5.10 \mathrm{ppb} ; \mathrm{p}=0.012)$ to be significantly higher in cases when compared to controls. After adjusting for confounding risk factors, PCB 153 was found to be significantly associated with an increased risk of breast cancer $(\mathrm{OR}=1.8 ; 95 \% \mathrm{CI}, 1.4-2.5)$ (Charlier et al. 2004). Cohn et al. (2012) did not find any associations between breast cancer risk and the sum of total PCBs or PCB groupings, however, a significant association was found for PCB 203 when comparing the highest vs. lowest quartiles of exposure (OR=6.3; 95\% CI, 1.9-21.7). Demers et al. (2002) found mean plasma lipid concentrations of individual PCB congeners 99, 118, and 156 and mean total concentrations of mono-ortho PCB congeners (nos. 105, 118, and 156) to be significantly higher in breast cancer cases than controls. Breast cancer risk was found to 
be significantly associated with the sum of mono-ortho congeners (nos. 105, 118, 156) $(\mathrm{OR}=2.02 ; 95 \% \mathrm{CI}, 1.24-3.28), \mathrm{PCB} 118(\mathrm{OR}=1.60 ; 95 \% \mathrm{CI}, 1.01-2.53)$ and PCB 156 $(\mathrm{OR}=1.80,95 \% \mathrm{CI} 1.11-2.94)$ when comparing the fourth vs. first quartiles (Demers et al. 2002). Millikan et al. (2013) did not find any associations with total PCBs and breast cancer among all participants $(\mathrm{OR}=1.09 ; 95 \% \mathrm{CI}, 0.79-1.52)$ or white women $(\mathrm{OR}=1.03$; 95\% CI, 0.68-1.56), but did find a slightly elevated risk for African-American women $(\mathrm{OR}=1.74 ; 95 \% \mathrm{CI}, 1.00-3.01)$. Recio-Vega et al. (2001) found the GM of total PCBs to be significantly higher in cases than controls (5.26 vs. $3.33 \mathrm{ppb})(\mathrm{OR}=1.09 ; 95 \% \mathrm{CI}$, 1.01-1.14) as well as an increased risk of breast cancer among PCBs grouped by structure-activity relationships and 8 individual PCB congeners (nos. 118, 128, 138, 170, 180, 195, 206, and 209) and Muscat et al. (2003) found that PCB concentrations in the highest tertile for PCB congener $118(\mathrm{RR}=4.0 ; 95 \%$, CI 1.32-4.9) and total PCBs $(\mathrm{RR}=2.9 ; 95 \% \mathrm{CI}, 1.02-8.2)$ were related to an increased risk of breast cancer recurrence in women with nonmetastatic breast cancer. Stronger associations were reported between PCB exposure and breast cancer risk in studies that considered genetic polymorphism of the CYP 1A1 enzyme and menopausal status (Zhang et al. 2004, Li et al. 2005, Moysich et al. 1998, Moysich et al. 1999). CYP1A1-M2 genetic variants were found to modify the association between PCB exposure and breast cancer in postmenopausal Caucasian women, while CYP1A1-M3 genotypes were found to modify this association in African American women (Zhang et al. 2004, Li et al. 2005).

In this study, we examined the relationship between 6 individual PCB congeners, the sum of dioxin-like PCBs and the sum of non-dioxin-like PCBs with self-reported breast cancer in female subjects participating in the National Health and Nutrition 
Examination Survey (NHANES) between the years 1999-2004. The objectives of this study were to: 1) describe the mean PCB levels in women ( $\geq 20$ years of age) diagnosed with breast cancer compared to women not diagnosed with cancer; and 2) assess the association between higher body burdens of PCBs and increased risk of breast cancer.

\section{METHODS}

Study design and population. NHANES is an ongoing cross-sectional survey designed to be nationally representative of the non-institutionalized U.S. civilian population. Conducted annually since 1999 by the National Center for Health Statistics of the Centers for Disease Control and Prevention (CDC), NHANES uses a complex multi-stage sampling design where approximately 5,000 survey participants a year complete in-home interviews and physical examinations in mobile examination units (CDC 2012). All participants provided written informed consent and all procedures were approved by the National Center for Health Statistics (NCHS) Institutional Review Board (CDC 2012). We merged data from the 1999-2000, 20012-2002, and 2003-2004 survey cycles. We limited our analysis to women 20 to 85 years of age who completed the reproductive and medical health questionnaires in a face-to-face interview at a mobile examination center. PCB measurements. Blood serum concentrations of individual PCB congeners were measured in a representative, random one-third subsample of people 12 years of age and older in the 1999-2000, 2001-2002, and 2003-2004 survey cycles. PCB congeners were measured in serum by high-resolution gas chromatography/isotope-dilution highresolution mass spectrometry (HRGS/ID-HRMS). NHANES provides both wet-weight and lipid adjusted values for each sample, corrected for sample weight and analyte recovery; we used lipid adjusted values in our analyses. Detailed laboratory methods 
were consistent among survey cycles and are available online (CDC 2013b). A detection limit variable is provided for all PCB congeners in the data set. The variable LBD_LC has two values: the value "0" indicates that the result was below the limit of detection and the value " 1 " indicates that the result was at or above the limit of detection. Any participant with a serum PCB concentration below the limit of detection was assigned a serum level of the LOD divided by the square root of two. Limits of detection vary by individual PCB congener and survey cycle and can be found in the CDC's Fourth National Report on Human Exposure to Environmental Chemicals (CDC 2013). Lipidadjusted serum concentrations (ng/g) for 6 individual PCB congeners as well as the sum of the dioxin-like PCBs $(74+118)$ and the sum of non-dioxin-like PCBs $(118+138$ $+153+170)$ were used in this study. PCB congeners $74,99,118,138,153$, and 180 were selected because they were available in all three survey cycles and concentrations were above the LOD in $>60 \%$ of the survey participants.

Breast cancer diagnosis. We included female 1999-2004 NHANES participants 20 to 85 years of age who completed the self-reported medical health questionnaire and provided a response for "Have you ever been told by a doctor or other health professional that you had cancer or a malignancy of any kind?" Women who answered "yes" were subsequently asked "What kind of cancer was it?" 8,315 women 20 to 85 years of age provided a response in the 1999-2004 survey cycles. After deleting observations that were missing PCB data and 25 additional observations that were missing values for PCB99, our study population consisted of 2,007 participants: 43 who reported a breast cancer diagnosis and 1,964 who reported no cancer diagnosis. There were 43 breast cancer cases for all six PCB congeners and 1959 non cancer cases for PCBs 74, 99, 118, 
and 138; 1960 non cases in PCB153; and 1954 noncases in PCB 180. The sum of dioxinlike PCBs and non-dioxin-like PCBs were available in 1,996 and 1,984 subjects, respectively (CDC 2012).

Statistical analysis. All statistical analyses were performed using SAS system software (release 9.2; SAS Institute Inc. Cary, N.C.). A six year subsample weight was calculated according to the National Center for Health Statistics guidelines to adjust for oversampling of minority groups in the merged 1999-2004 NHANES data cycles (CDC 2013b). Nonmissing values for serum concentrations below the LOD were assigned a serum level of the LOD divided by the square root of two. In our analysis, all lipidadjusted serum PCB concentrations were log transformed to satisfy normality assumptions. Due to a small number of breast cancer cases, participants were categorized the following ways depending on data analysis: $<$ LOD vs. $\geq$ LOD; $<$ LOD to $50^{\text {th }}$ percentile vs. $\geq 50^{\text {th }}$ percentile; and $<$ LOD to $50^{\text {th }}$ percentile vs. $50^{\text {th }}$ percentile to $75^{\text {th }}$ percentile vs. $\geq 75^{\text {th }}$ percentile. We also conducted separate analyses on all females with serum PCB levels > LOD where breast cancer cases were compared with non-cancer cases. Significance was set at $p<0.05$ for all analyses.

We used PROC SURVEYMEANS to account for the complex sampling design of NHANES and to obtain weighted means, 95\% confidence intervals, and standard errors of individual PCB congeners, the sum of dioxin-like PCBs, and the sum of non-dioxinlike PCBs. We used the Taylor Series (linearization) method to estimate standard errors. A two-sided student t-test was calculated using PROC SURVEYREG to test whether the mean PCB levels between women who reported a breast cancer diagnosis and women who reported no cancer diagnosis were significantly different. Geometric mean (GM) 
PCB levels and geometric standard errors (GSE) were reported for breast cancer status, age at interview, and race/ethnicity for all participants with individual serum PCB levels above the LOD. Arithmetic mean serum levels of dioxin-like and non-dioxin-like PCBs and 95\% CIs were reported for breast cancer status and select confounding variables (age, race, BMI, lactation, age at menarche, lactation, oral contraceptive use, smoking status, alcohol consumption, education completed and annual family income). Age was divided into three groups (20-59 years, $60-74$ years, and $\geq 75$ years) that were selected based on the age distribution of breast cancer cases and noncases in our data set. Race/ethnicity was divided into two groups (non-Hispanic White and 'Other') due to a very small number of breast cancer cases from races/ethnicities other than non-Hispanic White. The category of 'Other' includes Mexican American, Non-Hispanic Black, Other Hispanic and Other Race - Including Multi-Racial. To account for the different age structures among non-Hispanic whites and 'Other' ethnicities in our study population, we presented age standardized GM PCB levels for individual PCB congeners and age standardized arithmetic mean dioxin-like and non-dioxin-like PCB levels for race/ethnicity. We also calculated both crude and age standardized GMs for breast cancer cases and noncases in women with PCB levels above the LOD. We used the direct method for age standardization provided by the CDC (CDC 2014).

Using PROC SURVEYLOGISTIC, we derived unadjusted and adjusted ORs and their $95 \%$ CIs to evaluate the association between exposure to PCBs and breast cancer. We conducted separate analyses for the sum of dioxin-like and non-dioxin-like PCBs and individual PCB congeners and breast cancer. Due to a small number of breast cancer cases, ORs and $95 \%$ CIs were calculated using the following groups: $<$ LOD to $50^{\text {th }}$ 
percentile vs. $\geq 50^{\text {th }}$ percentile; and $<$ LOD to $50^{\text {th }}$ percentile vs. $50^{\text {th }}$ percentile to $75^{\text {th }}$ percentile vs. $\geq 75^{\text {th }}$ percentile. The reference group for each PCB congener is defined as those participants whose serum concentrations were $<$ LOD to $50^{\text {th }}$ percentile. We conducted further analyses which included participants (breast cancer cases vs. noncases) with only PCB levels $>$ LOD. ORs and 95\% CIs were reported for each group in the model.

Covariates. We considered a number of potential confounders based on previous literature and well-established risk factors for breast cancer. The following potential confounders were either self-reported in the questionnaire interviews or taken as a laboratory measurement. The demographic variables of age at interview (20-59 years, 60-74 years, and $\geq 75$ years), race (white vs. other), education completed $\left(<12^{\text {th }}\right.$ grade, $12^{\text {th }}$ grade, $>12^{\text {th }}$ grade $)$ and income $(0-\$ 24,999, \$ 25,000-\$ 54,999, \$ 55,000-\$ 74,999)$ were obtained during the NHANES home interview (CDC 2012). Reproductive variables including age at menarche ( $<12$ years, $12-14$ years, $\geq 15$ years), history of regular periods (yes/no), parity $(0,1, \geq 2)$, oral contraceptive use (yes/no) and breast-feeding (yes/no) as well as lifestyle variables including smoking (yes/no) and alcohol use (yes/no) were obtained from health questionnaires completed in the mobile examination center. Body mass index $\left(<25 \mathrm{~kg} / \mathrm{m}^{2}, 25\right.$ to $<30 \mathrm{~kg} / \mathrm{m}^{2}$, and $\left.\geq 30 \mathrm{~kg} / \mathrm{m}^{2}\right)$ was obtained through the body measurement component in the mobile examination center (CDC 2013b). For individual PCB congeners, ORs and 95\% CIs are reported for three models: unadjusted; age, race/ethnicity and BMI adjusted; and age, race/ethnicity, BMI, lactation, and age at menarche adjusted. For the sum of dioxin-like and non-dioxin-like PCBs, ORs and 95\% CIs are reported for four models: unadjusted; race/ethnicity adjusted; age and 
race/ethnicity adjusted; and age, race/ethnicity, BMI, lactation, and age at menarche adjusted. Parity and oral contraceptive use were not included in the models because of the extent of missing data. Smoking history, alcohol use, education, and income were not significant predictors of breast cancer risk and therefore were also not presented in the final logistic regression models.

\section{RESULTS}

Descriptive Statistics. The study population included 2,007 female participants 20 years of age and older with available PCB data and who completed the medical conditions questionnaire and provided a response for "Have you ever been told by a doctor or other health professional that you had cancer or a malignancy of any kind?" Women who answered "yes" were subsequently asked, "What kind of cancer was it?" Among the 2,007 participants, 1,964 (97.9\%) reported never being diagnosed with cancer and 43 (2.14\%) reported being diagnosed with breast cancer (Table 1.1). Participants were fairly evenly distributed over the two races: $48.6 \%$ were of non-Hispanic white ethnicity and $51.4 \%$ were classified as 'Other', however the majority of breast cancer cases were in non-Hispanic white women (81.5\%). The majority of participants were 20-59 years of age at the time of interview $(68.6 \%)$ (Table 1.1). The mean age at time of interview was 45.5 years for women who reported never being diagnosed with cancer and 65.2 years for women who reported being diagnosed with cancer with a mean age at breast cancer diagnosis of 55.3 years (Table 1.1). BMI was normal $\left(<25 \mathrm{~kg} / \mathrm{m}^{2}\right)$ for $39.6 \%$, overweight $\left(25\right.$ to $\left.<30 \mathrm{~kg} / \mathrm{m}^{2}\right)$ for $30.6 \%$, and obese $\left(\geq 30 \mathrm{~kg} / \mathrm{m}^{2}\right)$ for $35.1 \%$ of study participants. Age of menarche was $<12$ years of age for $19.4 \%, 12-14$ years for $66.2 \%$, and $\geq 15$ years for $14.3 \%$ of study participants. The majority of study participants 
reported $\geq 2$ live births (73.9\%), responded yes to breastfeeding (59.4\%), responded yes to oral contraceptive use $(60.8 \%)$, responded no to a history of smoking $(69.3 \%)$, yes to alcohol consumption (56.4\%), completed more than $12^{\text {th }}$ grade $(45.2 \%)$, and reported a yearly family income of $0-\$ 24,999$ (37.1\%) (Table 1.1). 
Table 1.1. Descriptive statistics for breast cancer status and selected covariates among women $\geq 20$ years of age, NHANES 1999-2004.

\begin{tabular}{|c|c|c|}
\hline Variable & $\begin{array}{c}\text { Breast Cancer } \\
\text { n(\%) }\end{array}$ & $\begin{array}{c}\text { No Breast Cancer } \\
\text { n (\%) }\end{array}$ \\
\hline Total Population (n,\%) & $43(2.14 \%)$ & 1964(97.9\%) \\
\hline Age at interview (years; mean $\pm \mathrm{se}$ ) & $65.2 \pm 2.10$ & $45.5 \pm .43$ \\
\hline Age at diagnosis (years; mean \pm se) & $55.3 \pm 3.11$ & \\
\hline \multicolumn{3}{|l|}{ Race/Ethnicity } \\
\hline Non-Hispanic white & $35(1.74 \%)$ & $940(46.8 \%)$ \\
\hline Other & $8(0.40 \%)$ & $1024(51.0 \%)$ \\
\hline \multicolumn{3}{|l|}{ Age at time of interview (years) } \\
\hline $20-59$ & $7(0.35 \%)$ & $1368(68.2 \%)$ \\
\hline $60-74$ & $26(1.30 \%)$ & $384(19.1 \%)$ \\
\hline$\geq 75$ & $10(0.50 \%)$ & $212(10.6 \%)$ \\
\hline \multicolumn{3}{|l|}{ Age at menarche (years) } \\
\hline$<12$ years & $6(0.33 \%)$ & $344(19.1 \%)$ \\
\hline $12-14$ years & $30(1.67 \%)$ & $1160(64.5 \%)$ \\
\hline$\geq 15$ years & $4(0.22 \%)$ & $254(14.1 \%)$ \\
\hline \multicolumn{3}{|l|}{ Parity (no. of live births) } \\
\hline 0 & $0(0.00 \%)$ & $82(5.27 \%)$ \\
\hline 1 & $5(0.32 \%)$ & $319(20.5 \%)$ \\
\hline$>2$ & $29(1.86 \%)$ & $1120(72.0 \%)$ \\
\hline \multicolumn{3}{|l|}{$\operatorname{BMI}\left(\mathrm{kg} / \mathrm{m}^{2}\right)$} \\
\hline Normal weight $(18.5$ to $<25)$ & $12(0.62 \%)$ & $655(33.7 \%)$ \\
\hline Overweight $(25$ to $<30)$ & $18(0.93 \%)$ & $578(29.7 \%)$ \\
\hline Obese $(\geq 30)$ & $12(0.62 \%)$ & $670(34.5 \%)$ \\
\hline \multicolumn{3}{|l|}{ Breastfed } \\
\hline Yes & $19(1.33 \%)$ & $835(58.1 \%)$ \\
\hline No & $15(1.05 \%)$ & $558(39.1 \%)$ \\
\hline \multicolumn{3}{|l|}{ Oral Contraceptive Use } \\
\hline Yes & $19(1.03 \%)$ & $1103(59.8 \%)$ \\
\hline No & $21(1.14 \%)$ & $701(38.0 \%)$ \\
\hline \multicolumn{3}{|l|}{ Ever Smoked } \\
\hline Yes & $23(1.15 \%)$ & $773(38.5 \%)$ \\
\hline No & $20(1.00 \%)$ & $1190(59.3 \%)$ \\
\hline \multicolumn{3}{|l|}{ Alcohol Use } \\
\hline Yes & $24(1.30 \%)$ & $1018(55.1 \%)$ \\
\hline No & $16(0.87 \%)$ & $790(42.8 \%)$ \\
\hline \multicolumn{3}{|l|}{ Education } \\
\hline$<12$ th grade & $15(0.75 \%)$ & $445(22.2 \%)$ \\
\hline $12^{\text {th }}$ grade & $15(0.75 \%)$ & $626(31.2 \%)$ \\
\hline$>12^{\text {th }}$ grade & $13(0.65 \%)$ & $893(44.5 \%)$ \\
\hline \multicolumn{3}{|l|}{ Income (yearly family income) } \\
\hline $0-\$ 24,999$ & $17(0.96 \%)$ & $642(36.1 \%)$ \\
\hline$\$ 25,000-\$ 54,999$ & $13(0.73 \%)$ & $566(31.8 \%)$ \\
\hline$\$ 55,000-\$ 74,999$ & $1(0.06 \%)$ & $208(11.7 \%)$ \\
\hline$\geq \$ 75,000$ & $7(0.39 \%)$ & $326(18.3 \%)$ \\
\hline
\end{tabular}

Estimated percent distribution after applying NHANES sampling weights. 
Table 1.2 presents GMs and GSEs of lipid adjusted PCBs by breast cancer status in participants with individual PCB concentrations above the LOD. Crude GM PCB levels were significantly higher for all 6 PCB congeners in women who reported a breast cancer diagnosis compared to women who reported no cancer diagnosis (Table 1.2). Overall GM levels of individual blood PCBs ranged from $7.24 \mathrm{ng} / \mathrm{g}$ lipid to $31.8 \mathrm{ng} / \mathrm{g}$ lipid in women who reported never being diagnosed with cancer and from $9.87 \mathrm{ng} / \mathrm{g}$ lipid to $55.1 \mathrm{ng} / \mathrm{g}$ lipid in women who reported being diagnosed with breast cancer, with the lowest levels observed for PCB congener 99 and the highest levels observed for PCB 153 (Table 1. 2; Figure 1.1). After adjusting for age, GM PCB levels in women with breast cancer remained significantly higher in breast cancer cases for PCB congeners 99, 138, 153, and 180. Age standardized GM PCB levels ranged from $7.03 \mathrm{ng} / \mathrm{g}$ lipid to $31.5 \mathrm{ng} / \mathrm{g}$ lipid in women who reported never being diagnosed with cancer and from $10.4 \mathrm{ng} / \mathrm{g}$ lipid to 47.5 $\mathrm{ng} / \mathrm{g}$ lipid in women who reported being diagnosed with breast cancer. These results are consistent with crude GM PCB levels with the lowest and highest blood levels being observed for PCB congeners 99 and 153, respectively.

Table 1.2. Geometric Mean PCB levels (ng/g) by breast cancer status among women $\geq 20$ years of age with PCB concentrations above the LOD, NHANES 1999-2004.

\begin{tabular}{|c|c|c|c|c|c|}
\hline \multirow[b]{2}{*}{ Analyte $^{1}$} & \multirow[b]{2}{*}{$\begin{array}{c}\text { Noncases/ } \\
\text { Cases }\end{array}$} & \multirow[b]{2}{*}{$\begin{array}{c}\text { No } \\
\text { Cancer }\end{array}$} & \multicolumn{3}{|c|}{ Geometric $\operatorname{mean}^{2}(\mathrm{ng} / \mathrm{g})(\mathrm{GSE})$} \\
\hline & & & $\begin{array}{c}\text { Breast } \\
\text { Cancer }\end{array}$ & $\begin{array}{c}\text { No } \\
\text { Cancer }^{3}\end{array}$ & $\begin{array}{l}\text { Breast } \\
\text { Cancer }^{3}\end{array}$ \\
\hline PCB 074 & $1483 / 43$ & $9.87(1.07)$ & $16.0(1.07)^{b}$ & $9.58(1.03)$ & $10.8(1.23)$ \\
\hline PCB 099 & $1334 / 41$ & $7.24(1.09)$ & $9.87(1.03)^{b}$ & $7.03(1.04)$ & $10.4(1.11)^{b}$ \\
\hline PCB 118 & $1533 / 43$ & $11.7(1.06)$ & $17.5(1.16)^{b}$ & $11.4(1.03)$ & $10.9(1.23)$ \\
\hline PCB 138 & $1594 / 43$ & $23.6(1.06)$ & $39.6(1.07)^{\mathrm{a}}$ & $23.1(1.03)$ & $33.8(1.19)^{b}$ \\
\hline PCB 153 & $1651 / 43$ & $31.8(1.06)$ & $56.3(1.08)^{\mathrm{a}}$ & $31.5(1.03)$ & $47.5(1.16)^{\mathrm{b}}$ \\
\hline PCB 180 & $1599 / 43$ & $23.3(1.63)$ & $44.3(1.05)^{\mathrm{a}}$ & $22.9(1.02)$ & $36.2(1.12)^{\mathrm{a}}$ \\
\hline
\end{tabular}

${ }^{1}$ Lipid adjusted and log transformed polychlorinated biphenyls (ng/g).

${ }^{2}$ Geometric means calculated after applying NHANES sampling weights.

${ }^{3}$ Age Standardized: $20-59$ years, 60-74 years, $\geq 75$ years.

PCB levels significantly higher in women with breast cancer vs. women without cancer; ${ }^{\mathrm{a}} \mathrm{p}<0.0001,{ }^{\mathrm{b}} \mathrm{p}<0.05$ 


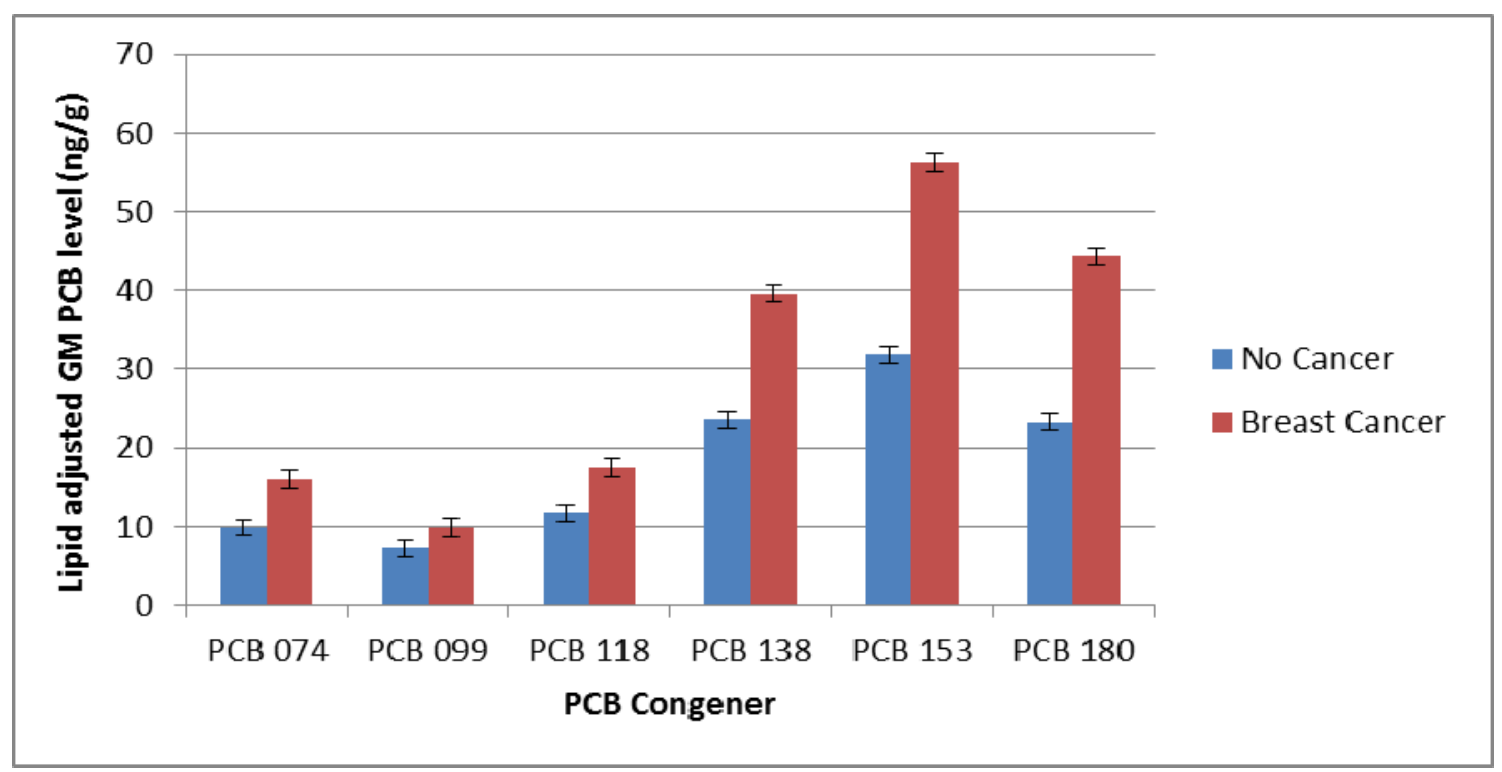

Figure 1.1. Geometric mean PCB levels (ng/g) by cancer status for women $\geq 20$ years of age with PCB concentrations above the LOD, NHANES 1999-2004.

GM PCB levels were also examined by age group in women with individual PCB concentrations above the LOD (Table 1.3). The overall GM levels of PCBs in blood significantly increased with age for each individual PCB congener measured with the exception of PCB 99, which decreased slightly for women diagnosed with breast cancer in the 60-74 year old age group. In the first age group (20-59 years), women diagnosed with breast cancer had significantly higher GM PCB levels of congeners 99, 138, 153, and 180 when compared to women never diagnosed with cancer (Table 1.3). Significant differences in GM PCB levels were not found in the other two age groups between women who reported being diagnosed with breast cancer and women who reported never being diagnosed with cancer (Table1. 3). 
Table 1.3 Geometric Mean PCB levels (ng/g) by age group and breast cancer status among women with PCB concentrations above the LOD, NHANES 1999-2004.

\begin{tabular}{|c|c|c|c|c|c|c|}
\hline \multirow[b]{3}{*}{ Analyte } & \multicolumn{6}{|c|}{ Geometric mean $^{2}$ (ng/g) (GSE, n) } \\
\hline & \multicolumn{2}{|c|}{ Age: $20-59$ years } & \multicolumn{2}{|c|}{ Age: $60-74$ years } & \multicolumn{2}{|c|}{ Age: $\geq 75$ years } \\
\hline & $\begin{array}{c}\overline{\text { No }} \\
\text { Cancer }\end{array}$ & $\begin{array}{l}\text { Breast } \\
\text { Cancer }\end{array}$ & $\begin{array}{c}\overline{\text { No }} \\
\text { Cancer }\end{array}$ & $\begin{array}{l}\text { Breast } \\
\text { Cancer }\end{array}$ & $\begin{array}{c}\overline{\text { No }} \\
\text { Cancer }\end{array}$ & $\begin{array}{l}\text { Breast } \\
\text { Cancer }\end{array}$ \\
\hline PCB 074 & $7.54(1.04,902)$ & $8.85(1.30,7)$ & $18.0(1.04,372)$ & $18.2(1.11,28)$ & $28.2(1.05,209)$ & $25.8(1.09,10)$ \\
\hline PCB 099 & $5.99(1.04,796)$ & $10.6(1.13,6)^{\mathrm{b}}$ & $10.5(1.04,341)$ & $9.49(1.14,25)$ & $14.6(1.07,197)$ & $10.5(1.21,10)$ \\
\hline PCB 118 & $9.03(1.04,952)$ & $8.76(1.30,7)$ & $21.8(1.04,371)$ & $20.9(1.17,27)$ & $32.1(1.06,210)$ & $27.4(1.15,10)$ \\
\hline PCB 138 & $18.9(1.03,1019)$ & $31.2(1.23,7)^{\mathrm{b}}$ & $40.9(1.04,370)$ & $42.1(1.11,28)$ & $58.0(1.04,205)$ & $48.4(1.11,10)$ \\
\hline PCB 153 & $25.0(1.03,1072)$ & $43.4(1.21,7)^{\mathrm{b}}$ & $59.1(1.03,371)$ & $58.6(1.11,28)$ & $83.1(1.04,208)$ & $74.4(1.09,10)$ \\
\hline PCB 180 & $18.0(1.03,1016)$ & $32.8(1.15,7)^{\mathrm{a}}$ & $44.3(1.03,375)$ & $45.6(1.09,28)$ & $61.6(1.03,208)$ & $61.6(1.12,10)$ \\
\hline
\end{tabular}

${ }^{\mathrm{P}}$ Lipid adjusted and log transformed polychlorinated biphenyls (ng/g).

${ }^{2}$ Geometric means calculated after applying NHANES sampling weights.

GM PCB levels significantly higher in women with breast cancer vs. women without cancer; ${ }^{\mathrm{a}} \mathrm{p}<0.0001,{ }^{\mathrm{b}} \mathrm{p}<0.05$.

Table 1.4 presents age standardized GMs and GSEs of lipid adjusted PCBs by race/ethnicity in participants with individual PCB concentrations above the LOD. For women who reported being diagnosed with breast cancer, women classified as 'Other' had significantly higher GM PCB levels for PCB congeners $74,99,118,138,153$, and 180 compared to non-Hispanic white women (Table 1.4). In women who reported never being diagnosed with cancer, only PCBs 74,153 , and 180 were found to be significantly higher in non-Hispanic white women compared to classified as 'Other' (Table 1.4). 
Table 1.4. Age standardized geometric mean PCB levels ( $\mathrm{ng} / \mathrm{g})$ by racelethnicity amongwomen $\geq 20$ years of age with PCB concentrations above the LOD, NHANES 1999-2004.

\begin{tabular}{lcccc}
\hline & \multicolumn{2}{c}{ Geometric mean $^{2}(\mathbf{n g} / \mathbf{g})(\mathbf{G S E}, \mathbf{n})$} \\
\hline & \multicolumn{2}{c}{ No Cancer } & \multicolumn{2}{c}{ Breast Cancer } \\
\hline Analyte $^{1}$ & $\begin{array}{c}\text { Non-Hispanic } \\
\text { White }\end{array}$ & Other & $\begin{array}{c}\text { Non-Hispanic } \\
\text { White }\end{array}$ & Other \\
\hline PCB 074 & $10.4(1.08,772)^{\mathrm{e}}$ & $8.67(1.07,711)$ & $15.3(1.07,35)^{\mathrm{d}}$ & $27.4(1.05,8)^{\mathrm{b}, \mathrm{c}}$ \\
PCB 099 & $7.17(1.11,679)$ & $7.39(1.08,655)$ & $9.12(1.08,34)^{\mathrm{d}}$ & $23.1(1.00,7)^{\mathrm{a}, \mathrm{c}}$ \\
PCB 118 & $12.2(1.06,779)$ & $11.8(1.07,754)$ & $16.4(1.21,35)$ & $32.8(1.01,8)^{\mathrm{b}, \mathrm{c}}$ \\
PCB 138 & $24.0(1.06,800)$ & $22.6(1.07,794)$ & $37.7(1.11,35)^{\mathrm{d}}$ & $69.4(1.12,8)^{\mathrm{b}, \mathrm{c}}$ \\
PCB 153 & $33.1(1.06,826)^{\mathrm{e}}$ & $29.1(1.06,825)$ & $54.1(1.09,35)^{\mathrm{c}}$ & $90.9(1.12,8)^{\mathrm{b}, \mathrm{c}}$ \\
PCB 180 & $24.8(1.05,809)^{\mathrm{e}}$ & $20.3(1.04,790)$ & $43.4(1.05,35)^{\mathrm{c}}$ & $52.5(1.17,8)^{\mathrm{c}}$ \\
\hline
\end{tabular}

${ }^{\mathrm{L}}$ Lipid adjusted and log transformed polychlorinated biphenyls (ng/g).

${ }^{2}$ Geometric means calculated after applying NHANES sampling weights.

PCB levels significantly higher in 'Other' women with breast cancer vs. non-Hispanic white women with breast cancer; ${ }^{a} \mathrm{p}<0.0001,{ }^{\mathrm{b}} \mathrm{p}<0.05$

PCB levels significantly higher in women with breast cancer vs. women without breast cancer; ${ }^{\mathrm{c}} \mathrm{p}<0.0001,{ }_{\mathrm{d}}^{\mathrm{p}}<0.05$

PCB levels significantly higher in non-Hispanic white women without cancer vs. 'Other' women without cancer, ${ }^{\mathrm{e}} \mathrm{p}<0.0001$.

Table 1.5 shows the arithmetic means and $95 \%$ CIs of serum levels of dioxin-like PCBs for breast cancer status and selected variables in the study population. Arithmetic means of dioxin-like PCBs were significantly higher in women who reported being diagnosed with breast cancer $(5.64 \mathrm{ng} / \mathrm{g}$ ) compared to women who reported never being diagnosed with cancer $(4.33 \mathrm{ng} / \mathrm{g})$, however mean dioxin-like PCBs did not remain significant after adjusting for age (Table 1.5). Mean dioxin-like PCBs increased with age, however there were no significant differences in the three age groups for women who reported being diagnosed with breast cancer compared to women who reported never being diagnosed with cancer. Age standardized dioxin-like PCBs were found to be significantly higher for breast cancer cases in both races (non-Hispanic white and 'Other') but were not found to significantly different from each other. With the exception of age at menarche ( $<12$ years $)$ and education $\left(<12^{\text {th }}\right.$ grade completed $)$, dioxin-like PCBs were found to be significantly higher in women who reported a breast 
cancer diagnosis compared to women who reported no cancer diagnosis (Table 1.5) for all covariates in the study population (Table 1.5). Table 1.6 shows the arithmetic means and 95\% CIs of serum levels of non-dioxin-like PCBs for breast cancer status and selected variables in the study population. Crude arithmetic means of non-dioxin-like PCBs were significantly higher in women who reported being diagnosed with breast cancer $(13.7 \mathrm{ng} / \mathrm{g})$ compared to women who reported never being diagnosed with cancer $(11.1 \mathrm{ng} / \mathrm{g})$, and remained significant after adjusting for age (13.2 ng/g vs $11.2 \mathrm{ng} / \mathrm{g})$ (Table 1.6). Mean non-dioxin-like PCBs increased with age, however only the women diagnosed with breast cancer in the first age group (20-59 years) had significantly higher non-dioxin-like PCBs compared to women never diagnosed with cancer. Age standardized non-dioxin-like PCBs were found to be significantly higher for breast cancer cases in both races (non-Hispanic white and 'Other') but were not found to significantly different from each other. With the exception of age at menarche, nondioxin-like PCBs were found to be significantly higher in women who reported a breast cancer diagnosis compared to women who reported no cancer diagnosis for all covariates in the study population (Table 1.6). 
Table 1.5. Serum Levels of dioxin-like PCBs ( $\mathrm{g} / \mathrm{g}$ ) in the study population, women $\geq 20$ years of age, NHANES 1999-2004.

\begin{tabular}{|c|c|c|c|}
\hline \multirow[b]{2}{*}{ Variable } & \multirow[b]{2}{*}{ Noncases/Cases } & \multicolumn{2}{|c|}{$\operatorname{Mean}^{1}(\mathrm{ng} / \mathrm{g})(95 \% \mathrm{CI})$} \\
\hline & & No Cancer & Breast Cancer \\
\hline Dioxin-like PCBs ${ }^{2}$ & $1953 / 43$ & $4.33(4.21-4.54)$ & $5.64(5.09-6.18)^{\mathrm{a}}$ \\
\hline Dioxin-like PCBs ${ }^{3}$ & $1752 / 45$ & $4.38(4.28-4.48)$ & $4.77(3.97-5.57)$ \\
\hline \multicolumn{4}{|l|}{ Dioxin-like PCBs_50 ${ }^{4}$} \\
\hline$<$ LOD to $50 \%$ & $973 / 4$ & $2.96(2.89-3.03)$ & $3.27(3.02-3.51)$ \\
\hline$\geq 50 \%$ & $979 / 39$ & $5.76(5.67-5.84)$ & $6.11(5.80-6.44)^{b}$ \\
\hline \multicolumn{4}{|l|}{ Age } \\
\hline $20-59$ years & $1362 / 7$ & $3.82(3.71-3.95)$ & $4.35(3.29-5.41)$ \\
\hline $60-74$ years & $379 / 26$ & $5.92(5.76-6.08)$ & $5.94(5.45-6.43)$ \\
\hline$\geq 75$ years & $212 / 10$ & $6.73(6.48-6.98)$ & $6.56(6.11-7.00)$ \\
\hline \multicolumn{4}{|l|}{ Race/Ethnicity ${ }^{3}$} \\
\hline Non-Hispanic White & $933 / 35$ & $4.43(3.98-4.26)$ & $5.53(4.94-6.12)^{b}$ \\
\hline Other & $1020 / 8$ & $4.12(4.28-4.58)$ & $6.80(6.60-7.00)^{\mathrm{a}}$ \\
\hline \multicolumn{4}{|l|}{ Age at Menarche (years) } \\
\hline$<12$ years & $342 / 6$ & $4.35(4.06-4.63)$ & $5.77(3.45-8.09)$ \\
\hline $12-14$ years & $1154 / 30$ & $4.34(4.19-4.50)$ & $5.65(5.12-6.19)^{\mathrm{a}}$ \\
\hline$\geq 15$ years & $252 / 4$ & $4.34(4.12-4.57)$ & $6.11(5.44-6.78)^{\mathrm{a}}$ \\
\hline \multicolumn{4}{|l|}{ BMI $\left(\mathrm{kg} / \mathbf{m}^{2}\right)$} \\
\hline Normal weight $(<25)$ & $651 / 12$ & $4.14(3.98-4.31)$ & $5.34(4.40-6.28)^{\mathrm{b}}$ \\
\hline Overweight $(25$ to $<30)$ & $573 / 18$ & $4.45(4.25-4.65)$ & $5.76(4.91-6.60)^{\mathrm{b}}$ \\
\hline Obese $(\geq 30)$ & $668 / 12$ & $4.41(4.27-4.55)$ & $5.70(4.73-6.67)^{\mathrm{b}}$ \\
\hline \multicolumn{4}{|l|}{ Breastfed } \\
\hline No & $554 / 15$ & $4.71(4.54-4.88)$ & $6.03(5.36-6.70)^{\mathrm{b}}$ \\
\hline Yes & $831 / 19$ & $4.43(4.27-4.58)$ & $5.34(4.58-6.10)^{\mathrm{b}}$ \\
\hline \multicolumn{4}{|l|}{ Oral Contraceptive Use } \\
\hline No & $698 / 21$ & $4.87(4.68-5.05)$ & $5.98(5.38-6.58)^{\mathrm{b}}$ \\
\hline Yes & $1095 / 19$ & $4.12(3.99-4.26)$ & $5.49(4.65-6.33)^{\mathrm{b}}$ \\
\hline \multicolumn{4}{|l|}{ Ever Smoked } \\
\hline No & $1184 / 20$ & $4.37(4.24-4.51)$ & $5.78(5.20-6.35)^{\mathrm{a}}$ \\
\hline Yes & $768 / 23$ & $4.28(4.10-4.46)$ & $5.52(4.77-6.26)^{b}$ \\
\hline \multicolumn{4}{|l|}{ Alcohol Use } \\
\hline No & 784/16 & $4.47(4.28-4.66)$ & $6.16(5.73-6.60)^{\mathrm{a}}$ \\
\hline Yes & $1013 / 24$ & $4.28(4.15-4.42)$ & $5.49(4.69-6.29)^{\mathrm{b}}$ \\
\hline \multicolumn{4}{|l|}{ Education } \\
\hline$<12$ th grade & $441 / 15$ & $4.46(4.26-4.67)$ & $5.31(4.38-6.25)$ \\
\hline $12^{\text {th }}$ grade & $624 / 15$ & $4.67(4.42-4.91)$ & $5.95(5.52-6.39)^{\mathrm{a}}$ \\
\hline$>12^{\text {th }}$ grade & $888 / 13$ & $4.16(4.02-4.29)$ & $5.72(4.51-6.92)^{\mathrm{b}}$ \\
\hline \multicolumn{4}{|c|}{ Income (yearly family income) } \\
\hline $0-\$ 24,999$ & $639 / 17$ & $4.60(4.41-4.80)$ & $6.31(5.80-6.82)^{\mathrm{a}}$ \\
\hline$\$ 25,000-\$ 74,999$ & $772 / 14$ & $4.19(4.05-4.33)$ & $5.14(4.33-5.94)^{b}$ \\
\hline$\geq \$ 75,000$ & $323 / 7$ & $4.23(3.99-4.46)$ & $5.30(4.11-6.50)$ \\
\hline
\end{tabular}

${ }^{\mathrm{T}}$ Means calculated after applying NHANES sampling weights.

${ }^{2}$ Sum of Dioxin-like PCBs $=(074+118)$; Lipid adjusted and log transformed PCBs.

${ }^{3}$ Age Standardized Dioxin-like- PCBs

${ }^{4}$ Serum Dioxin-like Levels: $<50^{\text {th }}$ percentile vs $\geq 50^{\text {th }}$ percentile

PCB levels significantly higher in women with breast cancer vs. women without breast cancer; ${ }^{\mathrm{a}} \mathrm{p}<0.0001$, ${ }^{\mathrm{b}} \mathrm{p}<0.05$ 
Table 1.6. Serum Levels of non-dioxin-like PCBs ( $\mathrm{ng} / \mathrm{g})$ in the study population, women $\geq 20$ years of age, NHANES 1999-2004.

\begin{tabular}{|c|c|c|c|}
\hline \multirow[b]{2}{*}{ Variable } & \multirow[b]{2}{*}{ Noncases/Cases } & \multicolumn{2}{|c|}{$\operatorname{Mean}^{1}(\mathrm{ng} / \mathrm{g})(95 \% \mathrm{CI})$} \\
\hline & & No Cancer & Breast Cancer \\
\hline Non-Dioxin-like PCBs ${ }^{2}$ & $1941 / 43$ & $11.1(11.0-11.3)$ & $13.7(13.0-14.5)^{\mathrm{a}}$ \\
\hline Non-Dioxin-like PCBs ${ }^{3}$ & $1941 / 43$ & $11.2(11.0-11.4)$ & $13.2(12.0-14.3)^{\mathrm{b}}$ \\
\hline \multicolumn{4}{|l|}{ Non-Dioxin-like PCBs 50 ${ }^{4}$} \\
\hline$<$ LOD to $50 \%$ & $967 / 2$ & $8.56(8.41-8.71)$ & $9.62(8.86-10.4)^{b}$ \\
\hline$\geq 50 \%$ & $974 / 41$ & $13.8(13.7-13.9)$ & $14.1(13.6-14.6)$ \\
\hline \multicolumn{4}{|l|}{ Age } \\
\hline $20-59$ years & $1354 / 7$ & $10.3(10.1-10.5)$ & $12.9(11.4-14.3)^{\mathrm{b}}$ \\
\hline $60-74$ years & $380 / 26$ & $13.8(13.5-14.1)$ & $13.9(13.1-14.6)$ \\
\hline$\geq 75$ years & $207 / 10$ & $15.1(14.6-15.5)$ & $14.7(13.9-15.4)$ \\
\hline \multicolumn{4}{|l|}{ Race/Ethnicity ${ }^{3}$} \\
\hline Non-Hispanic White & $926 / 35$ & $11.3(11.1-11.5)$ & $13.5(12.8-14.3)^{\mathrm{a}}$ \\
\hline Other & $1015 / 8$ & $10.8(10.5-11.1)$ & $15.8(14.8-16.8)^{\mathrm{a}}$ \\
\hline \multicolumn{4}{|l|}{ Age at Menarche (years) } \\
\hline$<12$ years & $340 / 6$ & $11.0(10.5-11.5)$ & $13.4(9.50-17.3)$ \\
\hline $12-14$ years & $1145 / 30$ & $11.1(10.9-11.4)$ & $13.8(13.1-14.4)^{\mathrm{a}}$ \\
\hline$\geq 15$ years & $252 / 4$ & $11.5(11.1-11.9)$ & $14.0(12.0-16.0)^{\mathrm{b}}$ \\
\hline \multicolumn{4}{|l|}{ BMI $\left(\mathbf{k g} / \mathbf{m}^{2}\right)$} \\
\hline Normal weight $(<25)$ & $649 / 12$ & $11.1(10.8-11.3)$ & $13.8(12.7-14.9)^{\mathrm{a}}$ \\
\hline Overweight $(25$ to $<30)$ & $570 / 18$ & $11.3(11.0-11.6)$ & $13.9(13.0-14.8)^{\mathrm{a}}$ \\
\hline Obese $(\geq 30)$ & $664 / 12$ & $10.9(10.7-11.2)$ & $13.4(11.8-15.0)^{\mathrm{b}}$ \\
\hline \multicolumn{4}{|l|}{ Breastfed } \\
\hline No & $551 / 15$ & $12.1(11.8-12.4)$ & $14.1(13.2-14.9)^{\mathrm{a}}$ \\
\hline Yes & $824 / 19$ & $11.3(11.1-11.6)$ & $13.2(12.1-14.3)^{\mathrm{b}}$ \\
\hline \multicolumn{4}{|l|}{ Oral Contraceptive Use } \\
\hline No & $693 / 21$ & $11.9(11.6-12.3)$ & $14.1(13.4-14.8)^{\mathrm{a}}$ \\
\hline Yes & $1090 / 19$ & $10.8(10.6-11.0)$ & $13.4(12.1-14.7)^{b}$ \\
\hline \multicolumn{4}{|l|}{ Ever Smoked } \\
\hline No & $1176 / 20$ & $11.0(10.7-11.2)$ & $13.5(12.4-14.5)^{\mathrm{a}}$ \\
\hline Yes & $764 / 23$ & $11.4(11.1-11.7)$ & $14.0(13.2-14.8)^{\mathrm{a}}$ \\
\hline \multicolumn{4}{|l|}{ Alcohol Use } \\
\hline No & $781 / 16$ & $11.3(11.0-11.6)$ & $14.3(13.4-15.1)^{\mathrm{a}}$ \\
\hline Yes & $1006 / 24$ & $11.1(10.8-11.3)$ & $13.5(12.3-14.6)^{\mathrm{b}}$ \\
\hline \multicolumn{4}{|l|}{ Education } \\
\hline$<12$ th grade & $435 / 15$ & $11.4(13.3-14.5)$ & $13.9(13.3-14.5)^{\mathrm{a}}$ \\
\hline $12^{\text {th }}$ grade & $621 / 15$ & $11.8(11.3-12.2)$ & $14.2(13.2-15.2)^{\mathrm{a}}$ \\
\hline$>12^{\text {th }}$ grade & $885 / 13$ & $10.8(10.6-11.0)$ & $13.1(11.0-15.2)^{\mathrm{b}}$ \\
\hline \multicolumn{4}{|c|}{ Income (vearly family income) } \\
\hline $0-\$ 24,999$ & $635 / 17$ & $11.5(11.2-11.8)$ & $14.5(13.5-15.4)^{\mathrm{a}}$ \\
\hline$\$ 25,000-\$ 74,999$ & $765 / 14$ & $10.9(10.6-11.1)$ & $12.4(11.0-13.9)^{\mathrm{a}}$ \\
\hline$>\$ 75,000$ & $323 / 7$ & $11.1(10.7-11.5)$ & $14.5(13.8-15.1)^{\mathrm{b}}$ \\
\hline
\end{tabular}

${ }^{1}$ Means calculated after applying NHANES sampling weights.

${ }^{2}$ Sum of non-Dioxin-like PCBs $=(099+138+153+180)$; Lipid adjusted and log transformed PCBs.

${ }^{3}$ Age Standardized Non-Dioxin-like PCBs.

${ }^{4}$ Serum Non-Dioxin-like Levels: $<50^{\text {th }}$ percentile vs $\geq 50^{\text {th }}$ percentile.

PCB levels significantly higher in women with breast cancer vs. women without breast cancer; ${ }^{\mathrm{a}} \mathrm{p}<0.0001$, ${ }_{\mathrm{b}}^{\mathrm{b}}<0.05$. 
GM and 95\% CI's of lipid-adjusted PCB levels are reported in table 1.7 for women with PCB levels $<$ LOD and $\geq$ LOD. PCB congeners 74, 118, 138, 153, and 180 did not have any breast cancer cases with PCB levels $<$ LOD. Women with PCB concentrations $\geq$ LOD who reported being diagnosed with breast cancer had significantly higher GM levels of PCB74 (16.0 ng/g vs 9.87 ng/g), PCB 99 (9.87 ng/g vs. 7.24 ng/g), PCB118 (17.5 ng/g vs 11.7 ng/g), PCB138 (39.6 ng/g vs. 23.6 ng/g), PCB153 (56.2 ng/g vs. $31.8 \mathrm{ng} / \mathrm{g}$ ), and PCB180 (44.3 ng/g vs. $23.3 \mathrm{ng} / \mathrm{g}$ ), compared to women who reported never being diagnosed with cancer (Table1.7).

Table 1.7. Geometric Mean PCB levels (ng/g) by cancer status among women $\geq 20$ years of age, NHANES 1999-2004

\begin{tabular}{|c|c|c|c|c|}
\hline \multirow[b]{2}{*}{ Analyte $^{1}$} & \multirow{2}{*}{$\begin{array}{c}\text { No. } \\
\text { Noncases }\end{array}$} & \multirow{2}{*}{$\begin{array}{l}\text { No. } \\
\text { Cases }\end{array}$} & \multicolumn{2}{|c|}{ Geometric mean $^{2}(\mathrm{ng} / \mathrm{g})(95 \% \mathrm{CI})$} \\
\hline & & & No Cancer & Breast Cancer \\
\hline \multicolumn{5}{|l|}{ PCB 074} \\
\hline$<\mathrm{LOD}$ & 476 & 0 & $4.01(3.90-4.13)$ & \\
\hline$\geq$ LOD & 1483 & 43 & $9.87(7.24-13.5)$ & $16.0(12.1-21.3)^{\mathrm{b}}$ \\
\hline \multicolumn{5}{|l|}{ РCB 099} \\
\hline$<\mathrm{LOD}$ & 625 & 2 & $3.94(3.82-4.01)$ & $3.13(3.03-3.25)$ \\
\hline$\geq \mathrm{LOD}$ & 1334 & 41 & $7.24(4.85-10.8)$ & $9.87(8.50-11.5)^{b}$ \\
\hline \multicolumn{5}{|l|}{ PCB 118} \\
\hline$<\mathrm{LOD}$ & 426 & 0 & $4.01(3.90-4.14)$ & \\
\hline$\geq \mathrm{LOD}$ & 1533 & 43 & $11.7(9.03-15.3)$ & $17.5(9.12-33.4)^{b}$ \\
\hline \multicolumn{5}{|l|}{ PCB 138} \\
\hline$<\mathrm{LOD}$ & 365 & 0 & $11.9(11.0-12.8)$ & \\
\hline$\geq \mathrm{LOD}$ & 1594 & 43 & $23.6(18.5-30.3$ & $39.6(28.8-55.1)^{\mathrm{a}}$ \\
\hline \multicolumn{5}{|l|}{ PCB 153} \\
\hline$<\mathrm{LOD}$ & 309 & 0 & $16.4(15.5-17.6)$ & \\
\hline$\geq \mathrm{LOD}$ & 1651 & 43 & $31.8(24.8-40.9)$ & $56.2(40.9-78.3)^{\mathrm{a}}$ \\
\hline \multicolumn{5}{|l|}{ PCB 180} \\
\hline$<\mathrm{LOD}$ & 355 & 0 & $7.69(7.24-8.17)$ & \\
\hline$\geq \mathrm{LOD}$ & 1599 & 43 & $23.3(18.4-29.7)$ & $44.3(35.9-54.1)^{\mathrm{a}}$ \\
\hline
\end{tabular}

${ }^{1}$ Lipid adjusted and log transformed polychlorinated biphenyls (ng/g).

${ }^{2}$ Geometric means calculated after applying NHANES sampling weights.

GM PCB levels significantly higher in women with breast cancer vs. women without cancer; ${ }^{\mathrm{a}} \mathrm{p}<0.0001$, ${ }_{\mathrm{b}}^{\mathrm{p}}<0.05$.

To account for the lack of breast cancer cases in women with low blood PCB levels and in women with blood PCB levels below the LOD, we divided lipid-adjusted PCB levels into the following two groups: $<$ LOD to $50^{\text {th }}$ percentile and $\geq 50^{\text {th }}$ percentile 
(Table 1.8). Women with PCB concentrations in first group $\left(<\right.$ LOD to $50^{\text {th }}$ percentile) who reported a breast cancer diagnosis had significantly higher GM PCB levels compared to women who reported never being diagnosed with cancer for PCB congeners 74 (5.58 ng/g vs. $4.26 \mathrm{ng} / \mathrm{g}), 138$ (15.0 ng/g vs. $11.4 \mathrm{ng} / \mathrm{g}), 153$ (23.3 ng/g vs. $15.3 \mathrm{ng} / \mathrm{g})$, and 180 (21.1 ng/g vs. $10.5 \mathrm{ng} / \mathrm{g})$ (Table 1.8). GM PCB concentrations did not significantly differ between any breast cancer cases and non-cases in the second group ( $\geq$ $50^{\text {th }}$ percentile) (Table 1.8).

Table 1.8. Geometric Mean PCB levels (ng/g) by cancer status among women $\geq 20$ years of age, NHANES 1999-2004.

\begin{tabular}{|c|c|c|c|c|}
\hline \multirow[b]{2}{*}{ Analyte $^{1}$} & \multirow[b]{2}{*}{$\begin{array}{c}\text { No. } \\
\text { Noncases }\end{array}$} & \multirow[b]{2}{*}{$\begin{array}{l}\text { No. } \\
\text { Cases }\end{array}$} & \multicolumn{2}{|c|}{ Geometric mean $^{2}(\mathrm{ng} / \mathrm{g})(95 \% \mathrm{CI})$} \\
\hline & & & No Cancer & Breast Cancer \\
\hline \multicolumn{5}{|l|}{ РCB 074} \\
\hline$<$ LOD to $50 \%$ & 1047 & 4 & $4.26(4.10-4.44)$ & $5.58(4.39-7.17)^{b}$ \\
\hline$\geq 50 \%$ & 912 & 39 & $17.3(16.6-18.0)$ & $19.9(17.1-23.1)$ \\
\hline \multicolumn{5}{|l|}{ РСВ 099} \\
\hline$<$ LOD to $50 \%$ & 1172 & 12 & $3.74(3.60-3.90)$ & $4.48(3.67-5.42)$ \\
\hline$\geq 50 \%$ & 787 & 31 & $13.1(12.4-13.6)$ & $14.0(11.7-16.6)$ \\
\hline \multicolumn{5}{|l|}{ РCB 118} \\
\hline$<\mathrm{LOD}$ to $50 \%$ & 999 & 6 & $4.71(4.53-4.85)$ & $5.26(4.48-6.23)$ \\
\hline$\geq 50 \%$ & 960 & 37 & $21.5(20.5-22.4)$ & $24.3(19.9-29.4)$ \\
\hline \multicolumn{5}{|l|}{ РСВ 138} \\
\hline$<\mathrm{LOD}$ to $50 \%$ & 1068 & 4 & $11.4(10.9-11.9)$ & $15.0(13.2-19.1)^{b}$ \\
\hline$\geq 50 \%$ & 891 & 39 & $45.6(43.8-47.5)$ & $47.5(41.3-54.1)$ \\
\hline \multicolumn{5}{|l|}{ PCB 153} \\
\hline$<$ LOD to $50 \%$ & 1078 & 4 & $15.3(14.7-16.0)$ & $23.3(18.4-30.0)^{b}$ \\
\hline$\geq 50 \%$ & 882 & 39 & $64.1(61.6-66.0)$ & $64.1(55.1-74.4)$ \\
\hline \multicolumn{5}{|l|}{ PCB 180} \\
\hline$<$ LOD to $50 \%$ & 1148 & 4 & $10.5(9.97-10.9)$ & $21.1(16.9-26.0)^{\mathrm{a}}$ \\
\hline$\geq 50 \%$ & 806 & 39 & $48.9(47.0-50.4)$ & $48.9(42.1-56.8)$ \\
\hline
\end{tabular}

We further divided lipid-adjusted GM PCB levels into the following three groups: $<$ LOD to $50^{\text {th }}$ percentile, $50^{\text {th }}$ percentile to $75^{\text {th }}$ percentile, and $\geq 75^{\text {th }}$ percentile (Table 1 . 9). Women in the first group ( $<$ LOD to $50^{\text {th }}$ percentile) who reported a breast cancer 
diagnosis had significantly higher GM levels of PCB 74 (5.58 ng/g vs. $4.26 \mathrm{ng} / \mathrm{g}$ ), PCB138 (16.0 ng/g vs. 11.5 ng/g), PCB153 (23.3 ng/g vs. 15.5 ng/g), PCB170 (8.08 ng/g vs. $5.00 \mathrm{ng} / \mathrm{g})$, PCB180 (21.1 ng/g vs. $10.5 \mathrm{ng} / \mathrm{g})$, and PCB187 (6.05 ng/g vs. $3.90 \mathrm{n} / \mathrm{g}$ ) compared to women who reported never being diagnosed with cancer (Table 1.9). GM PCB concentrations did not significantly differ between breast cancer cases and noncases in the second group $\left(50^{\text {th }}\right.$ percentile to $75^{\text {th }}$ percentile) or third group $\left(\geq 75^{\text {th }}\right.$ percentile). 
Table 1.9. Geometric Mean PCB levels (ng/g) by cancer status among women $\geq 20$ years of age, NHANES 1999-2004.

\begin{tabular}{|c|c|c|c|c|}
\hline \multirow[b]{2}{*}{ Analyte $^{1}$} & \multirow[b]{2}{*}{$\begin{array}{c}\text { No. } \\
\text { Noncases }\end{array}$} & \multirow[b]{2}{*}{$\begin{array}{l}\text { No. } \\
\text { Cases }\end{array}$} & \multicolumn{2}{|c|}{ Geometric mean $^{2}(\mathrm{ng} / \mathrm{g})(95 \% \mathrm{CI})$} \\
\hline & & & No Cancer & Breast Cancer \\
\hline \multicolumn{5}{|l|}{ PCB 074} \\
\hline$<$ LOD to $50 \%$ & 1047 & 4 & $4.26(4.10-4.44)$ & $5.58(4.39-7.17)^{b}$ \\
\hline $50-75 \%$ & 351 & 10 & $11.1(10.9-11.5)$ & $11.2(10.1-12.8)$ \\
\hline$\geq 75 \%$ & 561 & 29 & $24.5(23.6-25.5)$ & $25.3(22.4-28.5)$ \\
\hline \multicolumn{5}{|l|}{ РС̈В 099} \\
\hline$<$ LOD to $50 \%$ & 1172 & 12 & $3.74(3.60-3.90)$ & $4.48(3.67-5.42)$ \\
\hline $50-75 \%$ & 357 & 10 & $8.58(8.33-8.76)$ & $8.50(7.85-9.12)$ \\
\hline$\geq 75 \%$ & 430 & 21 & $19.3(18.5-20.3)$ & $18.0(15.5-20.7)$ \\
\hline \multicolumn{5}{|l|}{ PCB 118} \\
\hline$<\mathrm{LOD}$ to $50 \%$ & 999 & 6 & $4.71(4.53-4.85)$ & $5.26(4.48-6.23)$ \\
\hline $50-75 \%$ & 388 & 9 & $12.7(12.4-13.1)$ & $12.8(10.7-15.3)$ \\
\hline$\geq 75 \%$ & 572 & 28 & $33.1(31.5-34.8)$ & $32.1(27.4-37.7)$ \\
\hline \multicolumn{5}{|l|}{ PCВ 138} \\
\hline$<$ LOD to $50 \%$ & 1068 & 4 & $11.5(10.9-11.9)$ & $15.0(11.7-19.3)^{b}$ \\
\hline $50-75 \%$ & 394 & 14 & $30.0(29.7-30.6)$ & $31.5(28.8-34.8)$ \\
\hline$\geq 75 \%$ & 497 & 25 & $67.4(64.7-70.8)$ & $62.8(54.1-73.7)$ \\
\hline \multicolumn{5}{|l|}{ PCB 153} \\
\hline$<$ LOD to $50 \%$ & 1078 & 4 & $15.3(14.9-16.0)$ & $22.9(16.9-30.6)^{b}$ \\
\hline $50-75 \%$ & 383 & 14 & $43.8(42.5-44.7)$ & $44.3(42.1-47.0)$ \\
\hline$\geq 75 \%$ & 499 & 25 & $92.8(89.1-96.5)$ & $86.5(75.9-98.5)$ \\
\hline \multicolumn{5}{|l|}{ PC $\bar{C} 180$} \\
\hline$<$ LOD to $50 \%$ & 1148 & 4 & $10.5(9.97-10.9)$ & $21.1(16.9-26.0)^{\mathrm{a}}$ \\
\hline $50-75 \%$ & 386 & 19 & $35.2(34.5-35.9)$ & $38.1(34.8-41.3)$ \\
\hline$\geq 75 \%$ & 420 & 20 & $72.2(69.4-75.9)$ & $69.4(59.7-79.8)$ \\
\hline
\end{tabular}

Lipid adjusted and log transformed polychlorinated biphenyls (ng/g).

${ }^{2}$ Geometric means calculated after applying NHANES sampling weights.

GM PCB levels significantly higher in women with breast cancer vs. women without cancer; ${ }^{a} \mathrm{p}<0.0001$, ${ }_{\mathrm{b}}^{\mathrm{p}}<0.05$.

Estimated ORs and 95\% confidence intervals for the risk of having breast cancer and the six individual PCB congeners are shown in table 1.10. Due to the lack of breast cancer cases in women with low blood PCB levels and in women with blood PCB levels below the LOD, the following two groups were used to estimate breast cancer risk: < LOD to $50^{\text {th }}$ percentile (reference group) and $\geq 50^{\text {th }}$ percentile. Results are presented for three logistic regression models: unadjusted; age, race/ethnicity, and BMI adjusted; and age, race/ethnicity, BMI, lactation, and age at menarche adjusted. In unadjusted models, PCBs were significantly associated with breast cancer risk for subjects in the second 
group $\left(\geq 50^{\text {th }}\right.$ percentile) when compared to the reference group $\left(<\right.$ LOD to $50^{\text {th }}$ percentile) for PCB congeners 74, 99, 118, 138, 153, and 180 (Table 1.10). After adjusting for age, race/ethnicity and BMI, PCB138 was found to be significantly associated with breast cancer [OR of 3.16 (95\% CI: 1.14-8.76) (Table 1.10). After adjusting for age, race/ethnicity, BMI, lactation, and age at menarche, PCB138 and PCB180 were found to be significantly associated with breast cancer [OR of $2.88,95 \%$ CI: 1.14-7.30 and OR of 4.54, 95\% CI: 1.11-18.6], respectively (Table 1.10). Adjusting for lactation and age at menarche decreased the sample size to 34 breast cancer cases and 1324 and 1320 cancer noncases in PCB138 and PCB180, respectively.

Table 1.10. Estimated ORs (95\% CIs) of breast cancer by concentration of PCB levels among women $\geq 20$ years of age, NHANES 1999-2004.

\begin{tabular}{|c|c|c|c|c|c|}
\hline Analyte $^{1}$ & $\begin{array}{c}\text { No. } \\
\text { Cases }\end{array}$ & $\begin{array}{l}\text { No. } \\
\text { Noncases }\end{array}$ & $\begin{array}{l}\text { Unadjusted OR } \\
(95 \% \mathrm{CI})\end{array}$ & $\begin{array}{l}\text { Adjusted OR } \\
\qquad(95 \% \mathrm{CI})\end{array}$ & $\begin{array}{l}\text { Adjusted OR } \\
\quad(95 \% \mathrm{CI})\end{array}$ \\
\hline \multicolumn{6}{|l|}{ РCB 074} \\
\hline$<\mathrm{LOD}$ to $50 \%$ & 4 & 1047 & 1.00 & 1.00 & 1.00 \\
\hline$\geq 50 \%$ & 39 & 912 & $5.82(2.56-13.3)^{\mathrm{a}}$ & $1.55(0.46-5.24)$ & $2.64(0.59-12.0)$ \\
\hline \multicolumn{6}{|l|}{ РСВ 099} \\
\hline$<\mathrm{LOD}$ to $50 \%$ & 12 & 1172 & 1.00 & 1.00 & 1.00 \\
\hline$\geq 50 \%$ & 31 & 787 & $3.09(1.60-5.98)^{\mathrm{b}}$ & $1.39(0.66-2.92)$ & $1.67(0.60-3.43)$ \\
\hline \multicolumn{6}{|l|}{ РCB 118} \\
\hline$<$ LOD to $50 \%$ & 6 & 999 & 1.00 & 1.00 & 1.00 \\
\hline$\geq 50 \%$ & 37 & 960 & $4.34(1.95-9.67)^{\mathrm{b}}$ & $1.32(0.38-4.65)$ & $2.01(0.48-8.44)$ \\
\hline \multicolumn{6}{|l|}{ PCВ 138} \\
\hline$<$ LOD to $50 \%$ & 4 & 1068 & 1.00 & 1.00 & 1.00 \\
\hline$\geq 50 \%$ & 39 & 891 & $7.35(3.10-17.4)^{\mathrm{a}}$ & $3.16(1.14-8.76)^{b}$ & $2.88(1.14-7.30)^{\mathrm{b}}$ \\
\hline \multicolumn{6}{|l|}{ PCB 153} \\
\hline$<$ LOD to $50 \%$ & 4 & 1078 & 1.00 & 1.00 & 1.00 \\
\hline$\geq 50 \%$ & 39 & 882 & $9.20(2.30-36.7)^{\mathrm{b}}$ & $3.96(0.59-26.4)$ & $3.6(0.73-18.6)$ \\
\hline \multicolumn{6}{|l|}{ РCB 180} \\
\hline$<$ LOD to $50 \%$ & 4 & 1148 & 1.00 & 1.00 & 1.00 \\
\hline$\geq 50 \%$ & 39 & 806 & $10.6(3.03-37.1)^{\mathrm{b}}$ & $4.61(0.86-24.7)$ & $4.54(1.11-18.6)^{b}$ \\
\hline \multicolumn{6}{|c|}{ Lipid adjusted and log transformed polychlorinated biphenyls (ng/g). } \\
\hline \multicolumn{6}{|c|}{$\begin{array}{l}\text { Cases/Noncases: } 34 / 1323 \text { in } 74 ; 34 / 1326 \text { in } 99,118 ; 34 / 1324 \text { in } 138 ; 34 / 1325 \text { in } 153 ; 34 / 1320 \text { in } 180 \text {. } \\
\text { Significance }{ }^{\mathrm{a}} \mathrm{p}<0.0001,{ }_{\mathrm{b}}^{\mathrm{p}}<0.05 \text {. }\end{array}$} \\
\hline
\end{tabular}


ORs and 95\% confidence intervals for breast cancer were further explored for subjects with PCB concentrations divided into the following three groups: $<$ LOD to $50^{\text {th }}$ percentile, $50^{\text {th }}$ to $75^{\text {th }}$ percentile, and $\geq 75^{\text {th }}$ percentile (Table 1.11). Subjects with PCB concentrations in the first group $\left(<\mathrm{LOD}\right.$ to $50^{\text {th }}$ percentile $)$ were used as the reference group. In all of the unadjusted models, a significant risk of breast cancer was found for subjects with PCB concentrations in the second group $\left(50^{\text {th }}\right.$ to $75^{\text {th }}$ percentile $)$ for all six PCB congeners except PCB 99 and in the third group ( $\geq 75^{\text {th }}$ percentile) (Table 1.11). In unadjusted models, the strongest associations with breast cancer risk among subjects in the third group ( $\geq 75^{\text {th }}$ percentile) were found for PCB congeners $180,153,138$, and 74 [ORs of 10.0 (95\% CI: 3.20-31.4), 9.99 (95\% CI: 2.59-38.5), 8.49 (95\% CI: 3.41-21.1), and 7.30 (95\% CI: 3.08-17.3), respectively] (Table 1.11). In age, race/ethnicity and BMI adjusted models, we found PCB138 significantly associated with breast cancer for subjects in the second $\left(50^{\text {th }}\right.$ to $75^{\text {th }}$ percentile) and third $\left(\geq 75^{\text {th }}\right.$ percentile) groups: [ORs of 2.93, 95\% CI: $1.04-8.26$ and 3.43, 95\% CI: 1.13-10.4, respectively] (Table 1.11). However, this risk did not remain for either group after adjusting for age, race/ethnicity, BMI, lactation, and age at menarche. Race/ethnicity was significantly associated with breast cancer in models for all six PCB congeners, however, only BMI category four ( $\geq$ $30 \mathrm{~kg} / \mathrm{m}^{2}$ ) was significantly associated with breast cancer in models for PCB congener 180. The association between individual PCBs and breast cancer was also examined in multiple variable adjusted models that included the covariates parity, oral contraceptive use, smoking status, alcohol use, education, and yearly family income, however these variables were not included in the final model because they significantly decreased the sample size and were not found to be significant predictors of breast cancer risk. 
Table 1.11. Estimated ORs (95\% CIS) of breast cancer by concentration of PCB levels among women $\geq 20$ years of age, NHANES 1999-2004.

\begin{tabular}{|c|c|c|c|c|c|}
\hline Analyte $^{1}$ & $\begin{array}{c}\text { No. } \\
\text { Cases }\end{array}$ & $\begin{array}{c}\text { No. } \\
\text { Noncases }\end{array}$ & $\begin{array}{c}\text { Unadjusted OR } \\
(95 \% \mathrm{CI})\end{array}$ & $\begin{array}{l}\text { Adjusted OR } \\
\quad(95 \% \text { CI) }\end{array}$ & $\begin{array}{l}\text { Adjusted } \mathrm{OR}^{3} \\
(95 \% \mathrm{CI})\end{array}$ \\
\hline \multicolumn{6}{|l|}{$\overline{\text { PCB } 074}$} \\
\hline$<\operatorname{LOD}$ to $50 \%$ & 4 & 1047 & 1.00 & 1.00 & 1.00 \\
\hline $50 \%$ to $75 \%$ & 10 & 351 & $3.96(1.52-10.3)^{b}$ & $1.51(0.44-5.17)$ & $1.79(0.29-10.8)$ \\
\hline$\geq 75 \%$ & 29 & 561 & $7.30(3.08-17.3)^{\mathrm{a}}$ & $1.61(0.42-6.17)$ & $1.65(0.24-11.4)$ \\
\hline \multicolumn{6}{|l|}{ РC̈В 099} \\
\hline$<$ LOD to $50 \%$ & 12 & 1172 & 1.00 & 1.00 & 1.00 \\
\hline $50 \%$ to $75 \%$ & 10 & 357 & $2.12(0.77-5.80)$ & $1.12(0.39-3.25)$ & $1.26(0.36-4.49)$ \\
\hline$\geq 75 \%$ & 21 & 430 & $4.01(2.16-7.47)^{a}$ & $1.63(0.77-3.44)$ & $1.64(0.60-4.49)$ \\
\hline \multicolumn{6}{|l|}{ РCВ 118} \\
\hline$<$ LOD to $50 \%$ & 6 & 999 & 1.00 & 1.00 & 1.00 \\
\hline $50 \%$ to $75 \%$ & 9 & 388 & $2.98(1.29-6.85)^{b}$ & $1.19(0.31-4.58)$ & $1.27(0.21-7.79)$ \\
\hline$\geq 75 \%$ & 28 & 572 & $5.48(2.32-12.9)^{\mathrm{a}}$ & $1.45(0.40-5.24)$ & $1.45(0.26-7.92)$ \\
\hline \multicolumn{6}{|l|}{ РCВ 138} \\
\hline$<\mathrm{LOD}$ to $50 \%$ & 4 & 1068 & 1.00 & 1.00 & 1.00 \\
\hline $50 \%$ to $75 \%$ & 14 & 394 & $6.17(2.46-15.5)^{b}$ & $2.93(1.04-8.26)^{\mathrm{b}}$ & $1.93(0.76-4.86)$ \\
\hline$\geq 75 \%$ & 25 & 497 & $8.49(3.41-21.1)^{\mathrm{a}}$ & $3.43(1.13-10.4)^{b}$ & $2.70(0.90-8.09)$ \\
\hline \multicolumn{6}{|l|}{ РС 153} \\
\hline$<$ LOD to $50 \%$ & 4 & 1078 & 1.00 & 1.00 & 1.00 \\
\hline $50 \%$ to $75 \%$ & 14 & 383 & $8.40(1.75-40.3)^{b}$ & $3.82(0.47-31.1)$ & $2.57(0.39-16.8)$ \\
\hline$\geq 75 \%$ & 25 & 499 & $9.99(2.59-38.5)^{\mathrm{b}}$ & $4.14(0.73-23.4)$ & $3.28(0.62-17.4)$ \\
\hline \multicolumn{6}{|l|}{ PC̈ 180} \\
\hline$<$ LOD to $50 \%$ & 4 & 1148 & 1.00 & 1.00 & 1.00 \\
\hline $50 \%$ to $75 \%$ & 19 & 386 & $11.1(2.63-46.6)^{b}$ & $5.00(0.84-29.9)$ & $3.60(0.72-17.9)$ \\
\hline$\geq 75 \%$ & 20 & 420 & $10.0(3.20-31.4)^{\mathrm{a}}$ & $3.89(0.87-17.5)$ & $2.77(0.61-12.6)$ \\
\hline
\end{tabular}

${ }^{1}$ Lipid adjusted and log transformed polychlorinated biphenyls (ng/g).

${ }^{2}$ Adjusted for age, race/ethnicity, BMI; Breast Cancer Cases/Noncases:

42/1898 in 74, 138, 180; 42/1900 in 99; 42/1899 in 153; 42/1894 in 180.

${ }^{3}$ Adjusted for age, race/ethnicity, BMI, lactation, age at menarche; Breast Cancer Cases/Noncases:

$34 / 1323$ in $74 ; 34 / 1326$ in 99,$118 ; 34 / 1324$ in $138 ; 34 / 1325$ in $153 ; 34 / 1320$ in 180 .

Significance ${ }^{\mathrm{a}} \mathrm{p}<0.0001,{ }^{\mathrm{b}} \mathrm{p}<0.05$.

Estimated ORs and $95 \%$ confidence intervals for the risk of having breast cancer

and dioxin-like and non-dioxin-like PCBs are shown in table 1.12. In the unadjusted and race/ethnicity adjusted models, dioxin-like PCBs were significantly associated with breast cancer [ORs of $1.50,95 \%$ CI: $1.27-1.77$ and $1.49,95 \%$ CI: $1.24-1.79]$ as well as non-dioxin-like PCBs [ORs of 1.28, 95\% CI: 1.18-1.38 and 1.29, 95\% CI: 1.18-1.40], respectively. After adjusting for age, race/ethnicity, and BMI, non-dioxin-like PCBs remained significantly associated with breast cancer risk [OR of 1.14, 95\% CI: 1.00-1.29] 
(Table 1.12). Neither dioxin-like or non-dioxin-like PCBs remained significantly associated for breast cancer in the models after adjusting for age, race/ethnicity, BMI, lactation, and age at menarche (Table 1.12). We further analyzed breast cancer risk of dioxin-like and non-dioxin-like PCBs using the following two groups: $<$ LOD to $50^{\text {th }}$ percentile (reference group) and $\geq 50^{\text {th }}$ percentile. In subjects with PCB levels $\geq 50^{\text {th }}$ percentile, breast cancer was significantly associated with dioxin-like and non-dioxin-like PCBs in the unadjusted models [ORs of 4.95, 95\%CI: 2.36-10.4 and 11.6, 95\% CI: 2.37$57.2]$ and in the race/ethnicity adjusted models [ORs of $4.65,95 \%$ CI: $2.00-10.8$ and 11.1, 95\% CI: 2.24-55.1], respectively. The risk of breast cancer did not remain significant for these dioxin-like and non-dioxin-like PCBs after further adjustment for age, lactation, and age at menarche (Table 1.12). 
Table 1.12. Estimated ORs (95\% CIs) of breast cancer by concentrations of dioxin-like and non-dioxin-like PCBs among women $\geq 20$ years of age, NHANES 1999-2004.

\begin{tabular}{|c|c|c|c|c|c|}
\hline & Cases/Noncases & $\begin{array}{c}\text { Unadjusted OR } \\
(95 \% \mathrm{CI})\end{array}$ & $\begin{array}{c}\text { Adjusted OR }{ }^{1} \\
(95 \% \mathrm{CI})\end{array}$ & $\begin{array}{c}\text { Adjusted OR } \\
(95 \% \text { CI })\end{array}$ & $\begin{array}{l}\text { Adjusted OR } \\
\quad(95 \% \mathrm{CI})\end{array}$ \\
\hline Dioxin-like PCBs $^{4}$ & $43 / 1953$ & $1.50(1.27-1.77)^{\mathrm{a}}$ & $1.49(1.24-1.79)^{\mathrm{a}}$ & $1.08(0.84-1.40)$ & $1.07(0.78-1.49)^{+}$ \\
\hline \multicolumn{6}{|l|}{ Dioxin-like PCBs_50 $0^{4,6}$} \\
\hline$<$ LOD to $50 \%$ & $4 / 973$ & 1.00 & 1.00 & 1.00 & 1.00 \\
\hline$\geq 50 \%$ & $39 / 979$ & $4.95(2.36-10.4)^{\mathrm{a}}$ & $4.65(2.00-10.8)^{b}$ & $1.47(0.46-4.71)$ & $1.58(0.29-8.53)^{+}$ \\
\hline \multicolumn{6}{|l|}{ Dioxin-like PCBs_75 ${ }^{4,7}$} \\
\hline$<\operatorname{LOD}$ to $75 \%$ & $12 / 1404$ & 1.00 & 1.00 & 1.00 & 1.00 \\
\hline$\geq 75 \%$ & $31 / 543$ & $5.08(2.19-11.8)^{\mathrm{a}}$ & $4.63(2.17-9.89)^{\mathrm{a}}$ & $1.71(0.82-3.54)$ & $1.45(0.57-3.69)^{+}$ \\
\hline Non- Dioxin-like PCBs ${ }^{5}$ & $43 / 1941$ & $1.28(1.18-1.38)^{\mathrm{b}}$ & $1.29(1.18-1.40)^{\mathrm{a}}$ & $1.14(1.00-1.29)^{\mathrm{b}}$ & $1.10(0.94-1.29)^{++}$ \\
\hline \multicolumn{6}{|c|}{ Non-Dioxin-like PCBs $50^{5,6}$} \\
\hline$<$ LOD to $50 \%$ & $15 / 1274$ & 1.00 & 1.00 & 1.00 & 1.00 \\
\hline$\geq 50 \%$ & $45 / 1315$ & $11.6(2.37-57.2)^{\mathrm{a}}$ & $11.1(2.24-55.1)^{\mathrm{b}}$ & $4.73(0.92-4.50)$ & $3.97(0.52-22.3)^{++}$ \\
\hline \multicolumn{6}{|c|}{ Non-Dioxin-like PCBs_75 } \\
\hline$<\operatorname{LOD}$ to $75 \%$ & $2 / 967$ & 1.00 & 1.00 & 1.00 & 1.00 \\
\hline$\geq 75 \%$ & $41 / 974$ & $4.56(2.35-8.83)^{\mathrm{a}}$ & $4.43(2.25-8.72)^{\mathrm{a}}$ & $2.04(0.92-4.50)$ & $2.63(0.88-7.87)^{++}$ \\
\hline
\end{tabular}

${ }^{1}$ Adjusted for race/ethnicity.

${ }^{2}$ Adjusted for age and race/ethnicity.

${ }^{3}$ Adjusted for age, race/ethnicity, BMI, age at menarche, lactation.

${ }^{4}$ Dioxin-like PCBs: Sum of lipid adjusted and log transformed PCB Congeners $(074+118)$.

${ }^{+} 34$ breast cancer cases/1420 noncases.

${ }^{5}$ Non-Dioxin-like PCBs: Sum of lipid adjusted and log transformed PCB Congeners $(099+138+153+180)$.

34 breast cancer cases/1312 noncases.

${ }^{6}$ Serum PCB Levels $<50^{\text {th }}$ percentile vs $\geq 50^{\text {th }}$ percentile.

${ }^{7}$ Serum PCB Levels $<75^{\text {th }}$ percentile vs $\geq 75^{\text {th }}$ percentile.

Significance ${ }^{\mathrm{a}} \mathrm{p}<0.0001,{ }^{\mathrm{b}} \mathrm{p}<0.05$. 


\section{DISCUSSION}

This cross-sectional assessment of a representative sample of U.S. women demonstrated that higher body burdens of PCBs were significantly associated with breast cancer in the general population. We evaluated 6 individual PCB congeners, the sum of dioxin-like PCBs, and the sum of non-dioxin-like PCBs. Analysis of GM levels of PCBs by breast cancer status, age, and race was done to assess PCB concentrations in subpopulations. All PCB congeners and total PCBs showed an increasing trend with age. These results are supported by previously reported associations of PCB body burdens and age in women (Axelrad et al. 2009, Thompson et al. 2013). While this may be a result of lower levels of PCBs in the environment today, it may also be due to the persistent nature of PCBs and increased accumulations in the human body over time. In women who reported being diagnosed with breast cancer, women classified as 'Other' had significantly higher age standardized GMs of PCB than non-Hispanic white women. Higher PCB and DDE levels have been previously reported among African-American women compared with non-Hispanic white women by Millikan et al. (2013) and Zheng et al. (1999), respectively. While race was found to be a protective factor against the odds of breast cancer for all non-Hispanic white women, the small number of nonwhite breast cancer cases limits the interpretation of the findings in this study. Differences between races could be attributed to differences in diet and geographic locations. While these results do not provide any evidence of causal associations, it is noteworthy that women diagnosed with breast cancer have higher levels of dioxin-like, non-dioxin-like, and individual PCB congeners compared to women who reported never being diagnosed with cancer. 
A landmark UN report assessing effects of human exposure to hormonedisrupting chemicals acknowledges that approximately 800 chemicals are suspected to act as endocrine disruptors or mimic natural hormones or disrupt hormone regulation (UNEP/WHO 2013). This report highlights that there is some associations between exposures to many of the endocrine disruptors, particularly, estrogen-mimicking chemicals and an increased risk of breast cancer in women. Exposure to EDCs, such as PCBs, during early development of the breast can alter its development, and possibly contribute to the susceptibility to diseases through effects on stem cells.

For women with detectable levels of blood PCBs, age adjusted GMs for PCB congeners $(99,138,153$, and 180) were significantly higher among breast cancer cases compared to noncases. These findings are consistent with previously reported studies by Charlier et al. (2004) who found higher blood levels of PCB congeners 138 and 153, Demers et al. (2002) who found significantly greater concentrations of PCB congeners 99, 118, and 156, and Recio-Vega et al. (2001) who found significantly higher concentrations of $11 \mathrm{PCB}$ congeners $(8,105,118,126,128,138,170,180,195,206$, and 209) in breast cancer cases compared to controls. The sum of dioxin-like and nondioxin-like PCBs were also found to be significantly higher in breast cancer cases compared to noncases which is consistent with findings from Demers et al. (2002) (sum of 105, 118, and 156) and Recio-Vega et al. (2001) (sum of 20 PCB congeners), however significance only remained for non-dioxin-like PCBs after we adjusted for age. Our results for age adjusted total PCBs are fairly consistent with epidemiological studies by Cohn et al. (2012), Gammon et al. (2002), Gatto et al. (2007) and Wolff et al. (2000), 
however, these comparisons are limited due to the difference in PCB congeners used in the sum of total PCBs and adjustment for confounding variables in each study.

Breast cancer risk appeared to be highest in women with the highest PCB concentrations in unadjusted logistic regression models. Only PCB 138 was found to be significantly associated with increased breast cancer risk after adjusting for age, race/ethnicity, BMI, lactation, and age at menarche. There were no associations between the sum of dioxin-like and non-dioxin-like PCBs and breast cancer when models were adjusted for age, race/ethnicity, BMI, lactation, and age at menarche. While these results are consistent with previous studies reporting age and multivariate adjusted ORs for breast cancer risk and PCBs (Gammon et al. 2002, Gatto et al. 2007, Wolff et al. 2000), a few studies have reported significant associations for specific PCB congeners or subpopulations (Cohn et al. 2012, Millikan et al. 2103, Recio-Vega et al. 2001). Cohn et al. (2012) found a significant association with breast cancer in women diagnosed before 50 years of age for PCB 203 after adjusting for lipids, race, year, lactation, and body mass; Millikan et al. (2013) found a slightly elevated risk of breast cancer (OR=1.74, 95\% CI:1.00-3.01) in African American women after adjusting for age, age-squared, race, menopausal status, BMI, parity/lactation, HRT use, and income; and Recio-Vego et al. (2001) found the risk of breast cancer to be positively associated with eight PCB congeners: $118,128,138,170,180,195,206$, and 209 and total PCBs (OR=1.09, 95\% CI: 1.02-1.16) after adjusting for age, age at menarche, lactation, menopausal status, BMI, and family history.

There are a number of limitations to our study, the most important of which is its cross-sectional design with self-reported data. Self-reported data increases the risk of 
misclassification bias of cases and controls, particularly in analyses of associations between PCBs and reproductive outcomes. We also had a relatively small sample size for breast cancer cases resulting in decreased statistical power within subgroup analyses. Furthermore, observed associations could be potentially confounded by lack of information on geographical location of primary residence and family history of some of the variables. Strengths of this cross-sectional study design include the large sample survey size, availability of biological measurements of environmental contaminants, and oversampling of minority populations that make it highly representative and generalizable to the U.S. population.

\section{CONCLUSION}

Based on our analysis of serum blood lipid PCB levels in the 1999-2004 NHANES data cycles, biological levels of PCBs may contribute to breast cancer risk among U.S. women. Despite the ban on PCB production, environmental exposures appear to pose significant threats on the reproductive health of the general population. A single exposure to an internal or external environmental factor alone cannot explain the development of a complex chronic disease, such as breast cancer, rather it appears that exposure to multiple environmental and molecular factors across the lifespan and their interactions influence the development of these chronic diseases in an individual. Given the proven contribution of unopposed estrogens to the risk for breast cancer, it is biologically plausible that altered endogenous estrogen levels presumably from exposure to estrogen mimicking EDCs may contribute to the risk of disease. Findings of this study are based on the use of cross-sectional self-reported data. Thus, further research is needed to assess specific biological mechanisms of reproductive health outcomes and 
cancer development in relation to PCB biomarker levels among women in the general population. 


\section{REFERENCES}

1. National Cancer Institute: Surveillance, Epidemiology, and End Results Program (SEER). (2013). SEER Stat Fact Sheets: Breast Cancer. Available:

http://seer.cancer.gov/statfacts/html/breast.html [last accessed June 1 2014].

2. International Agency for Research on Cancer (IARC). (2012). GLOBOCAN 2012: Estimated Cancer Incidence, Mortality, and Prevalence Worldwide in 2012. Available: http://globocan.iarc.fr/pages/fact sheets cancer.aspx [last accessed June 12014$]$.

3. Bodicoat DH, Schoemaker MJ, Jones ME, McFadden E, Griffin J, Ashworth A, and Swerdlow AJ. 2014. Timing of pubertal stages and breast cancer risk: the Breakthrough Generations Study. Breast Cancer Research 16:R18.

4. Madigan MP, Ziegler RG, Benichou J, Byrne C, Hoover RN. 1995. Proportion of breast cancer cases in the United States explained by well-established risk factors. JNCI 87: 1681.

5. UNEP/ WHO Expert Advisory Group: State of the Science of Endcorine Disrupting Chemicals - 2012. Eds: Åke Bergman, Jerrold J. Heindel, Susan Jobling,Karen A. Kidd and R. Thomas Zoeller, WHO Press; 2013.

6. EU Commission Expert Advisory Group: Key scientific issues relevant to the identification and characterisation of endocrine disrupting substances. JRC Scientific and Policy Reports; 2013.

7. Agency for Toxic Substances and Disease Registry. 2000. Toxicological Profile for Polychlorinated Biphenyls (PCBs). Atlanta, GA.

8. Carpenter DO. 2006. Polychlorinated biphenyls (PCBs): routes of exposure and effects on human health. Rev Env Health 21(1): 1-23.

9. Johnson BL, Hicks HE, Cibulas W, et al. 1999. Public Health Implications of Exposure to Polychlorinated Biphenyls (PCBs), Agency for Toxic Substances and Disease Registry.

10. Anderson HA, Falk C, Hanrahan L, Olson J, Burse V, Needham L, Paschal D et al. 1998. Profiles of Great Lakes critical pollutants: A sentinel analysis of human blood and urine. Environ Health Perspect 106(5):279-289.

11. Phillips DL, Smith AB, Burse VW, Steele GK, Needham LL, Hannon WH. 1989. Half-life of polychlorinated biphenyls in occupationally exposed workers. Arch Environ Health 44(6):351-354. 
12. Paris-Pombo A, Aronson KJ, Woolcott CG, King WD. 2003. Dietary predictors of concentrations of polychlorinated biphenyls in breast adipose tissue of women living in Ontario, Canada. Arch Environ Health 58(1):48-54.

13. Tee PG, Sweeney AM, Symanski E, Gardiner JC, Gasior DM, Schantz SL. 2003. A longitudinal examination of factors related to changes in serum polychlorinated biphenyl levels. Environ Health Perspect 111(5):702-707.

14. Milbrath MO, Wenger Y, Chang CW, Emond C, Garabrant D, et al. 2008. Apparent half-lives of dioxins, furans, and polychlorinated biphenyls as a function of age, body fat, smoking status, and breast-feeding. Environ Health Perspect 117(30): doi:10.1289/ehp.11781

15. Fielden MR, Halgren RG, Tashiro C, Yeo BR, Chittim B, Chou K, Zacharewski, TR. 2001. Effects of gestational and lactational exposure to Aroclor 1242 on sperm quality and in vitro fertility in early adult and middle-aged mice. Reprod Toxicol 15:281-292.

16. Aoki Y. 2001. Polychlorinated Biphenyls, Polychlorinated Dibenzo-p-dioxins, and Polychlorinated Dibenzofurans as Endocrine Disrupters-What We have Learned from Yusho Disease. Env Research 85: 2-11.

17. Ma R. \& Sasoon DA. 2006. PCBs exert an estrogenic effect through repression of the Wnt7a signaling pathway in the female reproductive tract. Environ Health Perspect 114(6):898-904.

18. McLachlan JA, Simpson E, Martin M. 2006. Endocrine disrupters and female reproductive health. Best Pract Res Clin Endocrinol Metab 20(1):63-75.

19. Lin BC, Suzawa M, Blind RD, Tobias SC, Bulun SE, ScanlanTS, Ingraham HA. 2009. Stimulating the GPR30 Estrogen Receptor with a Novel Tamoxifen Analogue Activates SF-1 and Promotes Endometrial Cell Proliferation. Cancer Res 69:5415-5423.

20. Bertelsen L, Mellemkjaer L, Frederiksen K, Kjaer SK, Brinton LA, Sakoda LC, van Valkengoed I, Olsen JH. 2007. Risk for breast cancer among women with endometriosis. Int J Cancer 15:1372-1375.

21. Roy D, Palangat M, Chen CW, Thomas RD, Colerangle J, Atkinson A, Yan ZJ. 1997. Biochemical and molecular changes at the cellular level in response to exposure to environmental estrogen-like chemicals. J Tox Env Hlth 50:1-29.

22. Roy D, Colerangle J, Singh KP. 1998. Is exposure of environmental or industrial endocrine disrupting estrogen-like chemicals able to cause genomic instability? Front Biosci 3 (Suppl): d913-921. 
23. Arisawa K, Takeda H, Mikasa H. 2005. Background exposure to PCDDs/PCDFs/PCBs and its potential health effects: a review of epidemiologic studies. J Med Invest 52:10-21.

24. Baibergenova A, Kudyakov R, Zdeb M, Carpenter DO, et al. 2003. Low birth weight and residential proximity to PCB-contaminated waste sites. Environ Health Perspect 111(10):1352-1357.

25. Buck GM, Vena JE, Schisterman EF, Dmochowski J, Mendola P, et al. 2000. Parental consumption of contaminated sport fish from Lake Ontario and predicted fecundability. Epidemiology 11:388-393.

26. Kostyniak PJ, Stinson C, Greizerstein HB, et al. 1999. Relation of Lake Ontario fish consumption, lifetime lactation, and parity to break milk polychlorobiphenyl and pesticide concentrations. Environ Res 80:S166-S174.

27. Mendola P, Buck GM., Sever LE, Zielezny M, Vena JE, et al. 1997. Consumption of PCB-contaminated freshwater fish and shortened menstrual cycle length. Am J Epidemiol 146(11):955-960.

28. Rylander L, Strömberg U, Dyremark E, Ostman C, Nilsson-Ehle P, Hagmar L. 1998. Polychlorinated biphenyls in blood plasma among Swedish female fish consumers in relation to low birth weight. Am J Epidemiol 147(5):493-502.

29. Tsukimori K, Tokunaga S, Shibata S, Uchi H, Nakayama D, et al. 2008. Longterm effects of polychlorinated biphenyls and dioxins on pregnancy outcomes in women affected by the Yusho incident. Environ Health Perspect 116(5):626-631.

30. Yu M, Guo YL, Hsu CC, Rogan WJ. 2000. Menstruation and reproduction in women with polychlorinated biphenyl (PCB) poisoning: long-term follow-up interviews of the women from the Taiwan Yucheng cohort. Int J Epidemiol 29:672-677.

31. Yang CY, Ying-Jan W, Pau-Chung C, et al. 2008. Exposure to a mixture of polychlorinated biphenyls and polychlorinated dibenzofurans resulted in a prolonged time to pregnancy in women. Environ Health Perspect 116(5):599605.

32. Gammon MD, Wolff MS, Neugut AI, Eng SM, Teitelbaum SL, Britton JA et al. 2002. Environmental Toxins and Breast Cancer on Long Island. II. Organochlorine Compound Levels in Blood. Cancer Epidemiol Biomark Prev 11:686-697.

33. Gatto NM, Longnecker MP, Press MF, Sullivan-Halley J, McKean-Cowdin R, Bernstein L. 2007. Serum organochlorines and breast cancer: a case-control study among African-American women. Cancer Causes Control 18:29-39 
34. Wolff MS, Zeleniuch-Jacquotte A, Dubin N, Toniolo P. 2000. Risk of breast cancer and organochlorine exposure. Cancer Epidemiol Biomarkers Prev $9(3): 271-277$.

35. Pavuk M, Cerhan JR, Lynch CF, Kocan A, Petrik J, Chovancova J. 2003. Casecontrol study of PCBs, other organochlorines and breast cancer in Eastern Slovakia. J of Exp Ana Env Epidemiol 13: 267-275.

36. Itoh H, Iwasaki M, Hanaoka T, Kasuga Y, Yokoyama S, et al. 2009. Serum organochlorines and breast cancer risk in Japanese women: a case-control study. Cancer Causes Control 20:567-580.

37. Charlier CJ, Albert AI, Zhang L, Dubois NG, Phoenix GJ. 2004. Polychlorinated biphenyls contamination in women with breast cancer. Clinica Chimica Acta 347:177-181.

38. Cohn BA, Terry MB, Plumb M, Cirillo PM. 2012. Exposure to polychlorinated biphenyl (PCB) congeners measured shortly after giving birth and subsequent risk of maternal cancer before age 50. Breast Cancer Res Treat 136: 267-275.

39. Demers A, AYotte P, Brisson J, Dodin S, Robert J, Dewailly E. 2002. Plasma Concentrations of Polychlorinated Biphenyls and the Risk of Breast Cancer: A Congener-specific Analysis. Am J Epidemiol 2002, 155: 629-635.

40. Millikan R, DeVoto E, Duell EJ, Tse CK, Savitz DA, Beach J, Edmiston S, Jackson S, Newman B. 2013. Dichlorodiphenyldichloroethane, polychlorinated biphenyls, and breast cancer among African-American and white women in North Carolina. Cancer Epidemiol Biomark Prev 9:1233-1240.

41. Recio-Vega R, Velazco-Rodriguez V, Ocampo-Gomez G, Hernandez-Gonzalez S, Ruiz-Flores P, Lopez-Marquez F. 2001. Serum levels of polychlorinated biphenyls in Mexican women and breast cancer risk. J Appl Toxicol 31:270-278.

42. Muscat, JE, Britton, JA, Djordjevic, MV, Citron, ML, Kemeny M, BuschDevereauxE, Pittman, B., Stellman SD. 2003. Adipose concentrations of organochlorine compounds and breast cancer recurrence in Long Island, New York. Cancer Epidemiol Biomarkers Prev 12(12):1474-1478.

43. Zhang Y, Wise JP, Holford TR, Xie H, Boyle P, Zahm SH, Rusiecki J, Zoum K, et al. 2004. Serum polychlorinated biphenyls, cytochrome P-450 1A1 polymorphisms, and risk of breast cancer in Connecticut women. Am J Epidemiol 160(12):1177-83.

44. Li Y, Millikan RC, Bell DA, Cui L, Tse CK, Newman B, Conway K. 2005. Polychlorinated biphenyls, cytochrome P450 1A1 (CYP1A1) polymorphisms, and 
breast cancer risk among African American women and white women in North Carolina: a population-based case-control study. Breast Cancer Research 7(1):R12-18.

45. Moysich KB, Ambrosone CB, Vena JE, Shields PG, Mendola P, Kostyniak P, Greizerstein, H, et al. 1998. Environmental organochlorine exposure and postmenopausal breast cancer risk. Cancer Epidemiol Biomarkers Prev 7 (3): 181188.

46. Moysich KB, Shields PG, Freudenheim JL, Schisterman EF, Vena JE, Kostyniak P, Greizerstein H, et al. 1999. Polychlorinated biphenyls, cytochrome P4501A1 polymorphism, and postmenopausal breast cancer risk. Cancer Epidemiol Biomarkers Prev 8(1):41-44.

47. CDC (Centers for Disease Control and Prevention). 2012. National Health and Nutrition Examination Survey Questionnaires, Datasets, and Related Documentation. Available: http://www.cdc.gov/nchs/nhanes/nhanes questionnaires.htm [last accessed June $112014]$.

48. CDC (Centers for Disease Control and Prevention). 2013b. National Health and Nutrition Examination Survey: Analytic Guidelines, 1999-2010. Vital Health Stat 2(161). Available: http://www.cdc.gov/nchs/data/series/sr_02/sr02 161.pdf [last accessed June 11 2014].

49. CDC (Centers for Disease Control and Prevention). 2013. Fourth National Report on Human Exposure to Environmental Chemicals. Available: http://www.cdc.gov/exposurereport/pdf/FourthReport UpdatedTables Sep2013.p df [last accessed June 6 2014].

50. CDC (Centers for Disease Control and Prevention). 2014. National Health and Nutrition Examination Survey. Age Standardization and Population Counts. Available: http://www.cdc.gov/nchs/tutorials/NHANES/NHANESAnalyses/agestandardizati on/age standardization intro.htm [last accessed June 16 2014].

51. Axelrad DA, Goodman S, Woodruff T. 2009. PCB body burden in U.S. women of childbearing age 2001-2002; an evaluation of alternate summary metrics of NHANES data. Environ. Res. 109, 368-378.

52. Thompson MR, Boekelheide K. 2013. Multiple environmental chemical exposures to lead, mercury, polychlorinated biphenyls among childbearing-age women (NHANES 1999-2004): Body burden and risk factors. Environ Res. 121 (23-30). 
53. Zheng T, Holford T, Mayne S, Ward B, Carter D, Owens P, Dubrow R, Zahm S, Boyle P, Archibeque S, Tessari J. 1999. DDE and DDT in breast adipose tissue and risk of female breast cancer. Am. J. Epidemiol., 150: 453-458. 


\title{
CHAPTER V
}

\section{MANUSCRIPT 2}

\section{ASSOCIATION OF POLYCHLORINATED BIPHENYLS, ENDOMETRIOSIS AND UTERINE LEIOMYOMAS AMONG U.S. WOMEN: NHANES 1999-2004 \\ ABSTRACT}

\begin{abstract}
Background: It is estimated that endometriosis occurs in $10 \%$ of women and is the most common cause of infertility in the United States. Uterine leiomyomas are the most common benign tumors in women and leading cause of hysterectomies. There is considerable evidence that endometriosis and uterine leiomyomas are estrogen dependent diseases. The estrogenic activity of polychlorinated biphenyls (PCBs) may play a role in the development of these diseases.
\end{abstract}

Objectives: The purpose of this study was to examine the cross-sectional relationship between exposure to PCBs and endometriosis and uterine leiomyomas among U.S. women.

Methods: We analyzed data from female participants (20-54 years of age) who provided blood samples for the Centers for Disease Control and Prevention's National Health and Nutrition Examination Survey (NHANES) between 1999 and 2004. Exposure was based on lipid adjusted serum levels of 6 individual PCB congeners $(74,99,118,138,153$, and 180), the sum of dioxin-like PCBs $(074+118)$, and the sum of non-dioxin-like PCBs $(099+138+153+187)$ in conjunction with data obtained from the reproductive health questionnaire. We calculated geometric means to compare $\mathrm{PCB}$ concentrations in women who self-reported an endometriosis or uterine leiomyoma diagnosis vs. women who self-reported never being diagnosed with endometriosis or uterine leiomyomas. We 
used logistic regression models to estimate odds ratios (ORs) and 95\% confidence intervals (CIs) of endometriosis and uterine leiomyomas by concentration of lipidadjusted serum PCBs. We evaluated age, race/ethnicity, body mass index (BMI; $\mathrm{kg} / \mathrm{m}^{2}$ ), age at menarche, oral contraceptive use, parity, smoking status, and alcohol consumption as potential confounders.

Results: Separate analyses showed weighted geometric mean levels of PCB congeners 138,153 , and 180 to be significantly higher among women diagnosed with endometriosis and geometric mean levels of PCB congeners 74, 99, 118, 138, 153, and 180 to be significantly higher among women diagnosed with uterine leiomyomas compared to the rest of the study population. Dioxin-like PCBs were found to be significantly higher in women diagnosed with uterine leiomyomas and non-dioxin-like PCBs were found to be significantly higher in women diagnosed with endometriosis and uterine leiomyomas compared to women who were not diagnosed. After adjusting for age, race, BMI, parity, age at menarche, oral contraceptive use, alcohol, and smoking status we found that PCB 74 and 118 were significantly associated with uterine leiomyomas [ORs of $1.91 ; 95 \% \mathrm{CI}$ : 1.10-3.29 and 1.91, 95\% CI:1.13-3.22] in women with higher body burdens of individual PCB congeners ( $<$ LOD vs. $\geq$ LOD), respectively. PCB 180 was also found to be significantly associated with uterine leiomyomas for women in the second tertile ( $33^{\text {rd }}$ to $66^{\text {th }} \%$ ile) [OR of $1.87,95 \%$ CI: $1.15-3.02$ ]. We did not find endometriosis to be significantly associated with any PCBs in the adjusted logistic regression models. Conclusions: Our results suggest a link between environmental exposures to PCBs and increased risk of uterine leiomyomas among women in the general U.S. population. Keywords: PCBs, NHANES, endometriosis, uterine leiomyomas. 


\section{MANUSCRIPT 2}

\section{ASSOCIATION OF POLYCHLORINATED BIPHENYLS, ENDOMETRIOSIS, AND UTERINE LEIOMYOMAS AMONG U.S. WOMEN: NHANES DATA 1999-2004}

\section{INTRODUCTION}

Endometriosis and uterine leiomyomas are estrogen dependent disorders associated with pelvic pain, significant morbidity, and infertility (Borah et al. 2013, Parker et al. 2007, Buttram and Reiter 1981). They are both common disorders among reproductive women with prevalence estimates in premenopausal women of $10 \%$ and $30 \%$ for endometriosis and uterine leiomyomas, respectively (Baird et al. 2003, Ezkenazi and Warner 2008, Diamanti-Kandarakis et al. 2009). Endometriosis is characterized by growth of tissue outside the uterus and uterine leiomyomas, also known as uterine fibroids, are benign tumors of the smooth muscle cells found in the human uterus. Both are the leading indication of hysterectomy in the United States (Farquhar and Steiner 2002). Through research on hormone contraception, postmenopausal hormonal therapies and estrogen-receptor (ER)-based endocrine therapies, we know estrogens are a major risk factor for endometriosis and uterine leiomyomas (Evans et al. 2008, Lin et al. 2009, Bertelsen et al. 2007, Hodges et al. 2006).

There is a renewed concern that exposure to environmental chemicals that act as endocrine disruptors (EDs) and mimic natural hormones or disrupt hormone regulation are associated with an increased risk of endometriosis and reproductive dysfunction in women (UNEP/WHO 2013, EU 2013). Of particular concern are the estrogenmimicking EDs, such as polychlorinated biphenyls, that are persistent in the environment, 
highly lipophilic, and readily bio-accumulate and magnify within the food chain (Roy et al. 1997, Roy et al. 1998). Polychlorinated biphenyls (PCBs) are a group of synthetic organic chemicals with half-lives ranging from a few months to a few decades depending on PCB chlorination, age, body fat, and breast feeding (Calafat et al. 2008, Woodruff et al. 2011, Silva et al. 2004). PCBs have been shown to interfere with reproductive function and development in animals and humans by either increasing or blocking estrogen activity (Fielden et al. 2001, Ma and Sassoon 2006, McLachlan et al. 2006). Adverse reproductive health effects have been established in a number of animal studies and have linked PCB exposure to decreased sperm fertilizing ability in mice (Fielden et al. 2001), changes in the uterine myometrium and gland formation in mice (Ma and Sassoon 2006), and a significant dose-dependent relationship in the prevalence and severity of endometriosis in rhesus monkeys (Rier et al.2001).

Epidemiologic studies demonstrating the association between exposure to EDCs and endometriosis are limited and conflicting. Three case-control studies found significant associations between exposure to total PCBs and risk of endometriosis (Buck Louis et al. 2005, Porpora et al. 2009, Heiler et al.2005). Buck Louis et al. (2005) found a significant increased risk of endometriosis for the sum of anti-estrogenic PCBs for women in the third tertile ( $\mathrm{OR}=3.77,95 \%$ CI $1.12-12.68)$, however, the risk remained elevated but not significant when adjusted for all listed covariates. Porpora et al. (2009) found the GM of total PCBs to be significantly higher in cases than controls (301.3 vs. 203.0, $\mathrm{p}<0.01$ ) and the OR of endometriosis risk in the highest tertile of total PCBs compared with the lowest tertile, was 5.63 (95\% CI 2.25-14.10). Significant increased risk of endometriosis was also found for PCB congeners 118, 138, 153, and 170. In a 
case-control study conducted by Heiler et al. (2005) dioxin-like PCB concentrations were higher in women with deep endometriotic (DE) nodules compared to controls (12.4 vs. $8.5, \mathrm{p}=.026)$ but did not significantly differ for women with peritoneal endometriosis (PE) compared to controls (11.0 vs. 8.5) and for women with DE compared to women with PE (12.4 vs. 11.0).

In contrast, a number of case-control studies have failed to find significant associations between endometriosis and exposure to individual PCB congeners, total PCBs, or specific sub-groups (Niskar et al. 2009, Pauwels et al. 2001, Trabert et al. 2010, Tsukino et al. 2005). Niskar et al. (2009) conducted a case-control study with 60 confirmed endometriosis cases staged as I (minimal), II (mild), III (moderate), and IV (severe) and 30 controls. Mean lipid-adjusted PCB concentrations were not significantly different (179.98 vs. 217.33 vs. 194.76 vs. 193.37) between stage I-II cases, stage III cases, stage IV cases, and controls, respectively. In the largest case-control study, conducted by Trabert et al. (2010), total PCBs $(n=20)$, estrogenic PCBs $(n=6)$, and individual PCB congeners were measured in the serum from 251 cases and 538 controls, matched for age and reference year. Adjusted total and estrogenic PCBs in the highest quartiles were not associated with an increased risk of endometriosis (Total: $\mathrm{OR}=1.2$, 95\% CI 0.6-2.3, Estrogenic: OR=0.9, 95\% CI 0.5-1.4). In two case-control studies measuring median TEQ values (pg TEQ/g lipid) Pauwels et al. (2001) found no association between endometriosis and the median TEQ values (pg TEQ/g lipid) in cases and controls (29 vs. 27) and Tsukino et al. (2005) found no difference in median TEQ values for endometriosis cases (stage II-IV) and controls (stage $0-\mathrm{I}$ ) (cPCBs: 3.40 vs. 
3.59, PCBs: 4.61 vs. 5.14), respectively. The OR of endometriosis risk in the highest quartile of total PCBs compared with the lowest quartile was 0.41 (95\% CI 0.14-1.27).

Epidemiological studies pertaining to PCBs and uterine leiomyomas are limited. Trabert et al. (2014) found PCB 99 (OR of 1.64, 95\% CI: 1.08-2.49), PCB 138 (OR of 1.64, 95\% CI: 1.03-2.59), PCB 146 (OR of 1.54, 95\% CI: 1.01-2.37), PCB 153 (OR of 1.88, 95\% CI: 1.12-3.13), PCB 196 (OR of 1.60, 95\% CI: 1.02-2.51), and PCB 206 (OR of $1.52,95 \%$ CI: $1.01-2.29$ ) to be associated with fibroids but only in the absence of endometriosis.

In this study, we examined the relationship between 6 individual PCB congeners, the sum of dioxin-like PCBs, and the sum of non-dioxin-like PCBs with self-reported endometriosis and uterine leiomyomas in female subjects participating in the National Health and Nutrition Examination Survey (NHANES) between the years 1999-2004. The objectives of this study were to: 1) describe the mean PCB levels in women (20-54 years of age) diagnosed with endometriosis or uterine leiomyomas compared to women not diagnosed with endometriosis or uterine leiomyomas; and 2) assess the association between higher body burdens of PCBs and increased risk of endometriosis or uterine leiomyomas.

\section{METHODS}

Study design and population. NHANES is an ongoing cross-sectional survey designed to be nationally representative of the non-institutionalized U.S. civilian population. Conducted annually since 1999 by the National Center for Health Statistics of the Centers for Disease Control and Prevention (CDC), NHANES uses a complex multi-stage sampling design where approximately 5,000 survey participants a year complete in-home 
interviews and physical examinations in mobile examination units (CDC, 2012).

Sociodemographic information and medical histories were collected during the in-home interview and biological samples and reproductive health information was collected in the mobile examination component (MEC). All participants provided written informed consent and all procedures were approved by the National Center for Health Statistics (NCHS) Institutional Review Board (CDC, 2012). We merged data from the 1999-2000, 2001-2002 and 2003-2004 survey cycles. We limited our analysis to women 20 to 54 years of age who completed the reproductive questionnaire in a face-to-face interview at a mobile examination center.

PCB measurements. Blood serum concentrations of individual PCB congeners were measured in a representative, random one-third subsample of people 12 years of age and older in the 1999-2000, 2001-2002, and 2003-2004 survey cycles. PCB congeners were measured in serum by high-resolution gas chromatography/isotope-dilution highresolution mass spectrometry (HRGS/ID-HRMS). NHANES provides both wet-weight and lipid adjusted values for each sample, corrected for sample weight and analyte recovery; we used lipid adjusted values in our analyses. Detailed laboratory methods were consistent among survey cycles and are available online (CDC 2013b). A detection limit variable is provided for all PCB congeners in the data set. The variable LBD LC has two values: the value "0" indicates that the result was below the limit of detection and the value "1" indicates that the result was at or above the limit of detection. Any participant with a serum PCB concentration below the limit of detection was assigned a serum level of the LOD divided by the square root of two. Limits of detection vary by individual PCB congener and survey cycle and can be found in the CDC's Fourth 
National Report on Human Exposure to Environmental Chemicals (CDC 2103). Lipidadjusted serum concentrations (ng/g) for 6 individual PCB congeners as well as the sum of the dioxin-like PCBs $(74+118)$ and the sum of non-dioxin-like PCBs $(99+138+153$ +180 ) were used in this study. PCB congeners $74,99,118,138,153$, and 180 were selected because they were available in all three survey cycles and concentrations were above the limit of detection (LOD) in $>60 \%$ of the survey participants.

Diagnosis of endometriosis and uterine leiomyomas. We included female 1999-2004 NHANES participants 20 to 54 years of age who completed the self-reported medical health questionnaire and provided a response for "Have you ever been told by a doctor or other health professional that you had endometriosis?" and "Have you ever been told by a doctor or other health professional that you had uterine fibroids?". Women who answered "yes" were subsequently asked "How old were you when you were first told you had endometriosis?" Questions pertaining to endometriosis and uterine leiomyoma diagnosis were restricted to women 20 to 54 years of age in the NHANES datasets. PCB measurements were available in 80 women who reported an endometriosis diagnosis for PCB congeners 74, 99, 118, 138 and 153, and in 79 women for PCB 180. PCB measurements were available in 1073 women who reported never being diagnosed with endometriosis for PCBs 74, 153 and 180, and in 1,074 women for PCBs 99, 118, and 138. PCB measurements were available in 148 women who reported a diagnosis of uterine leiomyomas for PCB congeners 74, 118, and 180, and in 149 women for PCBs 99, 138, and 153. PCB measurements were available in 1004 women who reported never being diagnosed with uterine leiomyomas for PCBs 153 and 180, in 1005 women for PCBs 74, 99 and 138, and in 1,006 women for PCB 118. The sum of dioxin-like PCBs 
was available in 80 endometriosis cases and 1,071 endometriosis non-cases and in 147 uterine leiomyoma cases and 1004 uterine leiomyoma noncases. The sum of non-dioxinlike PCBs was available in 79 endometriosis cases and 1,067 endometriosis noncases and in 148 uterine leiomyoma cases and in 998 uterine leiomyoma noncases.

Statistical analysis. All statistical analyses were performed using SAS system software (release 9.2; SAS Institute Inc. Cary, N.C.). A six year subsample weight was calculated according to the National Center for Health Statistics guidelines to adjust for oversampling of minority groups in the merged 1999-2004 NHANES data cycles (CDC 2013b). Nonmissing values for serum concentrations below the LOD were assigned a serum level of the LOD divided by the square root of two. In our analysis, all lipidadjusted serum PCB concentrations were log transformed to satisfy normality assumptions. Participants were categorized the following ways depending on data analysis: $<$ LOD vs. $\geq$ LOD and tertiles: $<$ LOD to $<33^{\text {rd }}$ percentile, $\geq 33^{\text {rd }}$ percentile to $66^{\text {th }}$ percentile, and $\geq 66^{\text {th }}$ percentile. Significance was set at $p<0.05$ for all analyses.

We used PROC SURVEYMEANS to account for the complex sampling design of NHANES and to obtain weighted means, 95\% CIs, and standard errors of individual PCB congeners, the sum of dioxin-like PCBs, and the sum of non-dioxin-like PCBs. We used the Taylor Series (linearization) method to estimate standard errors. A two-sided student t-test was calculated using PROC SURVEYREG to test whether the mean PCB levels between women who reported an endometriosis or uterine leiomyoma diagnosis and women who reported no endometriosis or uterine leiomyoma diagnosis were significantly different. Geometric mean (GM) PCB levels and geometric standard errors (GSE) were reported for endometriosis and uterine leiomyoma status, age at time of interview (years), 
and race/ethnicity for all participants. Serum levels of dioxin-like and non-dioxin-like PCBs and their 95\% CIs were reported for endometriosis and uterine leiomyoma status and select confounding variables (age, race, BMI, parity, age at menarche, alcohol consumption and smoking status). Age was divided into four groups (20-29 years, 30-39 years, 40-49 years, and 50-54 years), race/ethnicity was divided into three groups (nonHispanic White, non-Hispanic Black and 'Other'). The category of 'Other' includes Mexican American, Other Hispanic and Other Race - Including Multi-Racial. To account for the different age structures among ethnicities in our study population, we presented age standardized GM PCB levels for race/ethnicity in individual PCB congeners and age standardized arithmetic mean dioxin-like and non-dioxin-like PCB levels for race/ethnicity. We used the direct method for age standardization provided by the CDC (CDC 2014).

Using PROC SURVEYLOGISTIC, we derived unadjusted and adjusted ORs and their 95\% CIs to evaluate the association between exposure to PCBs and endometriosis and uterine leiomyomas. We conducted separate analyses for the sum of dioxin-like and non-dioxin-like PCBs and individual PCB congeners and endometriosis and uterine leiomyomas. ORs were calculated using the following groups: $<$ LOD vs. $>$ LOD and tertiles $\left(<\right.$ LOD to $33^{\text {rd }}$ percentile vs. $33^{\text {rd }}$ percentile to $66^{\text {th }}$ percentile vs. $\geq 66^{\text {th }}$ percentile). The reference group for each PCB congener is defined as those participants whose serum concentrations were $<$ LOD or $<$ LOD to $33^{\text {rd }}$ percentile depending on the analysis.

Covariates. We considered a number of potential confounders based on previous literature and well-established risk factors for endometriosis. The following potential 
confounders were either self-reported in the questionnaire interviews or taken as a laboratory measurement. The demographic variables of age at interview (20-29, 30-39, 40-49, and 50-54 years) and race (non-Hispanic White, non-Hispanic Black, Other) were obtained during the NHANES home interview (CDC 2012). Reproductive variables including age at menarche ( $<12$ years, $12-14$ years, $\geq 15$ years), parity $(0,1, \geq 2)$, number of live births $(0,1, \geq 2)$, oral contraceptive use (yes/no), having undergone a hysterectomy (yes/no), having undergone a oophorectomy (yes/no) as well as lifestyle variables including smoking (yes/no) and alcohol use (yes/no) were obtained from health questionnaires completed in the mobile examination center. Body mass index $(<25$ $\mathrm{kg} / \mathrm{m}^{2}, 25$ to $<30 \mathrm{~kg} / \mathrm{m}^{2}$, and $\geq 30 \mathrm{~kg} / \mathrm{m}^{2}$ ) was obtained through the body measurement component in the mobile examination center (CDC 2012). For individual PCB congeners, the sum of dioxin-like PCBs and the sum of non-dioxin-like PCBs, ORs and 95\% CIs are reported for three models: unadjusted; age and race/ethnicity adjusted; and age, race/ethnicity, BMI, parity, age at menarche, oral contraceptive use, smoking, and alcohol adjusted.

\section{RESULTS}

Descriptive statistics. The study population included 1,154 female participants 2054years of age and older who completed the medical questionnaire and provided a response for "Have you ever been told by a doctor or other health professional that you had endometriosis?" and "Have you ever been told by a doctor or other health professional that you had uterine fibroids?" Women who answered "yes" were subsequently asked, "What was your age at diagnosis?" Among the 1,154 female participants who responded to those two questions and had available PCB data, 1,074 
reported never being diagnosed with endometriosis, 80 reported being diagnosed with endometriosis, 1,005 reported never being diagnosed with uterine leiomyomas, and 149 reported being diagnosed with uterine leiomyomas (Table 2.1). The majority of participants were of non-Hispanic white ethnicity (44.9\%). A diagnosis of endometriosis occurred in $4.59 \%$ of non-Hispanic white women, $1.13 \%$ of non-Hispanic black women, and $1.21 \%$ of women from 'Other' races. A diagnosis of uterine leiomyomas occurred in $5.11 \%$ of non-Hispanic white women, $4.59 \%$ of non-Hispanic black women, and $3.21 \%$ of women from 'Other' races (Table 2.1). The mean age at time of interview was 37.2 years for the overall population, 41.0 and 44.3 years for women who an endometriosis or uterine leiomyoma diagnosis and 36.8 and 35.9 years for women who reported never being diagnosed with endometriosis or uterine leiomyoma, respectively. The mean age at endometriosis diagnosis was 29.0 years and the mean age at uterine leiomyoma diagnosis was 38.8 years (Table 2.1). The majority of endometriosis and uterine leiomyoma cases were reported from women in the 30-39 and 40-49 year old age groups. BMI was normal $\left(<25 \mathrm{~kg} / \mathrm{m}^{2}\right)$ for $37.5 \%$, overweight $\left(25\right.$ to $\left.<30 \mathrm{~kg} / \mathrm{m}^{2}\right)$ for $26.3 \%$, and obese $(\geq 30$ $\mathrm{kg} / \mathrm{m}^{2}$ ) for $36.2 \%$ of study participants. Age of menarche was $<12$ years of age for $22.9 \%, 12-14$ years for $65.5 \%$, and $\geq 15$ years for $11.6 \%$ of study participants. The majority of study participants reported $\geq 2$ live births (67.9\%), responded yes to oral contraceptive use $(72.7 \%)$, responded no to having a hysterectomy $(81.2 \%)$, responded no to having a oophorectomy $(93.1 \%)$, responded no to a history of smoking $(61.1 \%)$ and yes to alcohol consumption (61.7\%) (Table 2.1). 
Table 2.1. Descriptive statistics for endometriosis and uterine leiomyomas in the study population, women 20-54years of age, NHANES 1999-2004.

\begin{tabular}{|c|c|c|c|c|c|}
\hline Variable & $\begin{array}{r}\text { Overall } \\
\mathbf{n}(\%) \\
\end{array}$ & $\begin{array}{c}\text { Endometriosis } \\
n(\%)\end{array}$ & $\begin{array}{c}\text { No } \\
\text { Endometriosis } \\
\text { n (\%) } \\
\end{array}$ & $\begin{array}{c}\text { Uterine } \\
\text { Leiomyomas } \\
\text { n(\%) } \\
\end{array}$ & $\begin{array}{c}\text { No Uterine } \\
\text { Leiomyomas } \\
n(\%) \\
\end{array}$ \\
\hline Total Population (n,\%) & $1154(100 \%)$ & $80(6.93 \%)$ & $1074(93.1 \%)$ & $149(12.9 \%)$ & $1005(87.1 \%)$ \\
\hline Age at interview ( mean $\pm \mathrm{sd}$ ) & $37.2 \pm 0.40$ & $41.0 \pm .89$ & $36.8 \pm .43$ & $44.3 \pm .65$ & $35.9 \pm .42$ \\
\hline Age at diagnosis (mean \pm sd) & & $29.0 \pm .62$ & & $38.8 \pm .79$ & \\
\hline \multicolumn{6}{|l|}{ Race/Ethnicity } \\
\hline Non-Hispanic white & $518(44.9 \%)$ & $53(4.59 \%)$ & $465(40.3 \%)$ & $59(5.11 \%)$ & $460(39.8 \%)$ \\
\hline Non-Hispanic black & $221(19.2 \%)$ & $13(1.13 \%)$ & $208(18.0 \%)$ & $53(4.59 \%)$ & $168(14.6 \%)$ \\
\hline Other & $415(36.0 \%)$ & $14(1.21 \%)$ & $401(34.8 \%)$ & $37(3.21 \%)$ & $378(32.8 \%)$ \\
\hline \multicolumn{6}{|l|}{ Age at interview (years) } \\
\hline $20-29$ & $386(33.5 \%)$ & $12(1.04 \%)$ & $374(32.4 \%)$ & $10(0.87 \%)$ & $376(32.6 \%)$ \\
\hline $30-39$ & $354(30.7 \%)$ & $25(2.17 \%)$ & $329(28.5 \%)$ & $32(2.77 \%)$ & $323(27.9 \%)$ \\
\hline $40-49$ & $283(24.5 \%)$ & $30(2.60 \%)$ & $253(21.9 \%)$ & $67(5.81 \%)$ & $216(18.7 \%)$ \\
\hline $50-54$ & $131(11.4 \%)$ & $13(1.13 \%)$ & $118(10.2 \%)$ & $40(3.47 \%)$ & $91(7.89 \%)$ \\
\hline \multicolumn{6}{|l|}{ BMI $\left(\mathrm{kg} / \mathrm{m}^{2}\right)$} \\
\hline Normal weight $(<25)$ & $428(37.5 \%)$ & $24(2.11 \%)$ & $404(35.4 \%)$ & $43(3.77 \%)$ & $385(33.8 \%)$ \\
\hline Overweight $(25$ to $<30)$ & $300(26.3 \%)$ & $23(2.02 \%)$ & $277(24.3 \%)$ & $38(3.33 \%)$ & $263(23.0 \%)$ \\
\hline Obese $(\geq 30)$ & $412(36.2 \%)$ & $32(2.81 \%)$ & $380(33.3 \%)$ & $68(5.96 \%)$ & $344(30.2 \%)$ \\
\hline \multicolumn{6}{|l|}{ Parity (no. of live births) } \\
\hline 0 & $64(5.94 \%)$ & $9(0.84 \%)$ & $55(5.11 \%)$ & $10(0.93 \%)$ & $54(5.01 \%)$ \\
\hline 1 & $282(26.2 \%)$ & $28(2.60 \%)$ & $254(23.6 \%)$ & $25(2.32 \%)$ & $257(23.9 \%)$ \\
\hline$\geq 2$ & $731(67.9 \%)$ & $41(3.81 \%)$ & $690(64.1 \%)$ & $112(10.4 \%)$ & $619(57.5 \%)$ \\
\hline \multicolumn{6}{|l|}{ Age at menarche (years) } \\
\hline$<12$ & $258(22.9 \%)$ & $22(1.95 \%)$ & $236(20.9 \%)$ & $45(3.99 \%)$ & $213(18.9 \%)$ \\
\hline $12-14$ & $740(65.5 \%)$ & $52(4.61 \%)$ & $688(60.9 \%)$ & $87(7.71 \%)$ & $653(57.8 \%)$ \\
\hline$\geq 15$ & $131(11.6 \%)$ & $5(0.44 \%)$ & $126(11.2 \%)$ & $14(1.24 \%)$ & $117(10.4 \%)$ \\
\hline \multicolumn{6}{|l|}{ Oral contraceptive use } \\
\hline Yes & $837(72.7 \%)$ & $72(6.24 \%)$ & $765(66.4 \%)$ & $125(10.9 \%)$ & $712(61.8 \%)$ \\
\hline No & $315(27.3 \%)$ & $8(0.69 \%)$ & $307(26.7 \%)$ & $24(2.08 \%)$ & $291(25.3 \%)$ \\
\hline \multicolumn{6}{|l|}{ Hysterectomy } \\
\hline Yes & $102(18.9 \%)$ & $29(5.36 \%)$ & $73(13.5 \%)$ & $49(9.06 \%)$ & $53(9.80 \%)$ \\
\hline No & $439(81.2 \%)$ & $27(4.99 \%)$ & $412(76.2 \%)$ & $37(6.84 \%)$ & $402(74.3 \%)$ \\
\hline \multicolumn{6}{|c|}{ Oophorectomy - at least one ovary removed. } \\
\hline Yes & $79(6.86 \%)$ & $25(2.17 \%)$ & $54(4.69 \%)$ & $34(2.95 \%)$ & $34(2.95 \%)$ \\
\hline No & $1072(93.1 \%)$ & $55(4.78 \%)$ & $1017(88.4 \%)$ & $113(9.82 \%)$ & $113(9.82 \%)$ \\
\hline \multicolumn{6}{|l|}{ Alcohol Use } \\
\hline Yes & $712(61.7 \%)$ & $24(2.08 \%)$ & $418(36.2 \%)$ & $52(4.51 \%)$ & $390(33.8 \%)$ \\
\hline No & $442(38.3 \%)$ & $56(4.85 \%)$ & $656(56.9 \%)$ & $97(8.41 \%)$ & $615(53.3 \%)$ \\
\hline \multicolumn{6}{|l|}{ Ever Smoked } \\
\hline Yes & $449(38.9 \%)$ & $44(3.82 \%)$ & $660(57.2 \%)$ & $88(7.63 \%)$ & $616(53.4 \%)$ \\
\hline No & $704(61.1 \%)$ & $36(3.12 \%)$ & $413(35.8 \%)$ & $61(5.29 \%)$ & $388(33.7 \%)$ \\
\hline
\end{tabular}

Estimated percent distribution after applying NHANES sampling weights.

Table 2.2 presents GMs and GSEs of lipid adjusted PCBs by endometriosis and uterine leiomyoma diagnosis for all study participants. GM PCB levels were significantly higher for PCB congeners 138, 153, and 180 in women who reported a diagnosis of endometriosis compared to women who reported no diagnosis (Table 2.2). Overall GM 
levels of individual blood PCBs ranged from $4.90 \mathrm{ng} / \mathrm{g}$ lipid to $21.3 \mathrm{ng} / \mathrm{g}$ lipid in women who reported never being diagnosed with endometriosis and from $5.31 \mathrm{ng} / \mathrm{g}$ lipid to 27.1 $\mathrm{ng} / \mathrm{g}$ lipid in women who reported being diagnosed with endometriosis, with the lowest levels observed for PCB 99 and the highest levels observed for PCB 153 (Table 2.2;

Figure 2.1). GM PCB levels were significantly higher for all 6 PCB congeners in women who reported a diagnosis of uterine leiomyomas compared to women who reported no diagnosis (Table 2.2). Overall GM levels of individual blood PCBs ranged from 4.81 $\mathrm{ng} / \mathrm{g}$ lipid to $20.3 \mathrm{ng} / \mathrm{g}$ lipid in women who reported never being diagnosed with uterine leiomyomas and from $5.99 \mathrm{ng} / \mathrm{g}$ lipid to $33.1 \mathrm{ng} / \mathrm{g}$ lipid in women who reported no diagnosis, with the lowest levels observed for PCB 99 and the highest levels observed for PCB 153 (Table 2.2; Figure 2.2).

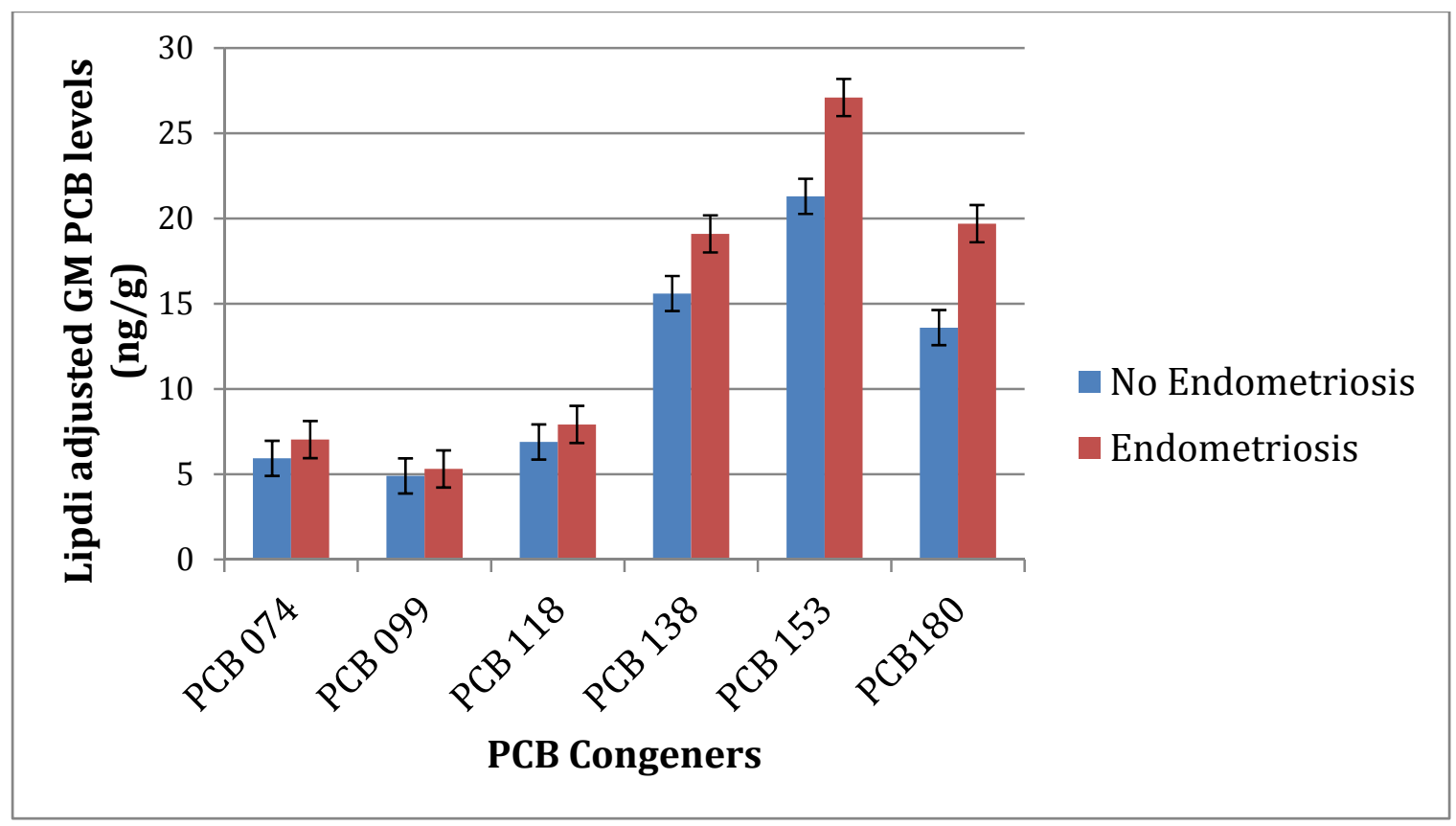

Figure 2.1. Lipid adjusted geometric mean PCB levels (ng/g) by endometriosis status among women 20-54 years of age, NHANES 1999-2004. 


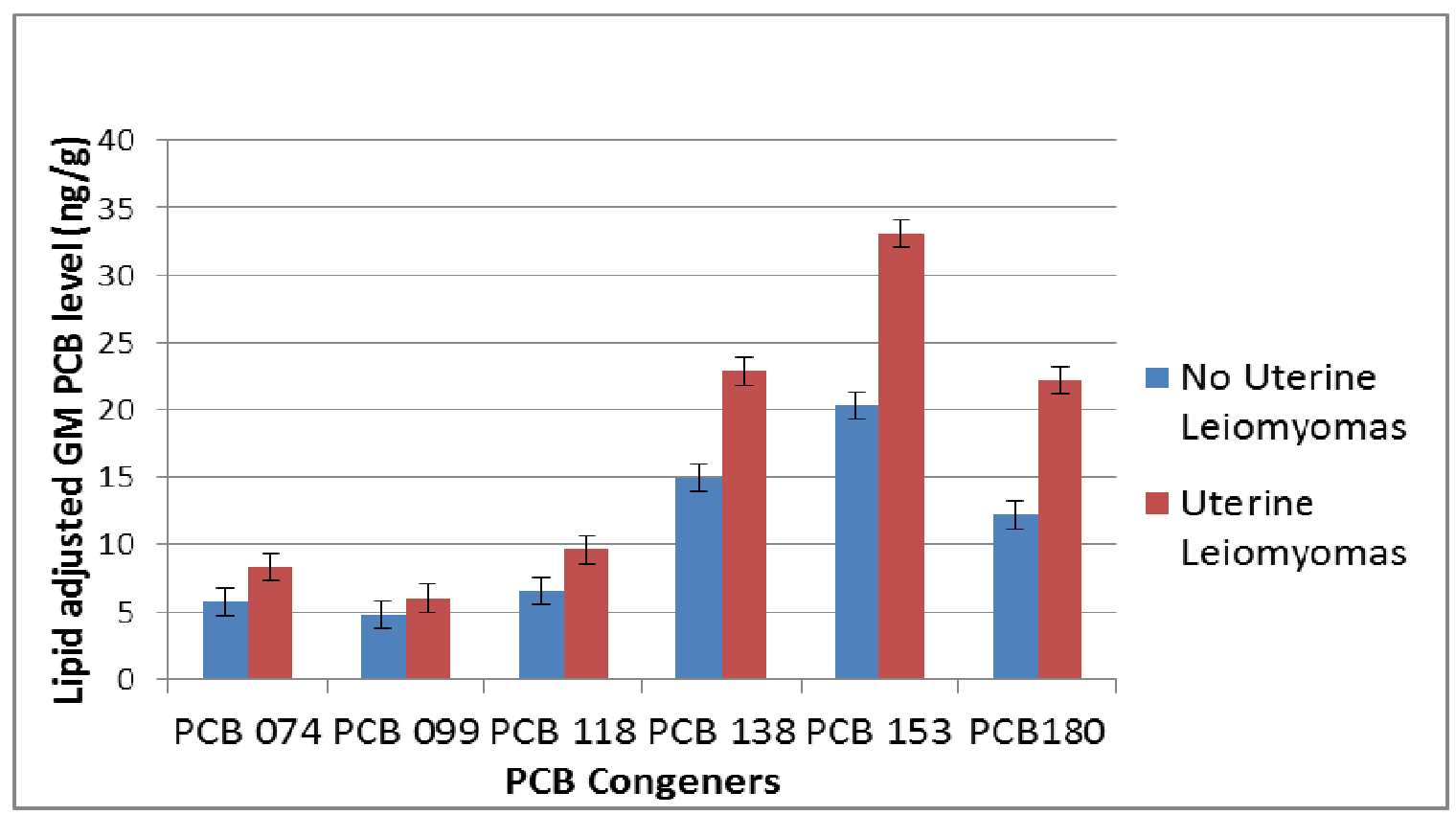

Figure 2.2. Lipid adjusted geometric mean PCB levels (ng/g) by uterine leiomyoma status among women 20-54 years of age, NHANES 1999-2004.

Table 2.3 presents age standardized GMs and GSEs of lipid adjusted PCBs by race/ethnicity in participants with endometriosis data. Non-Hispanic black women who reported being diagnosed with endometriosis had significantly higher GM PCB levels for PCB 138 and 180 compared to non-Hispanic White women (Table 2.3). In women who reported never being diagnosed with endometriosis, non-Hispanic black women had significantly higher levels of PCB congeners 99, 118, 138, 153, and 180 compared to non-Hispanic white women and significantly higher levels of all 6 PCB congeners compared to women classified as 'Other' (Table 2.3). Non-Hispanic white women not diagnosed with endometriosis had significantly higher levels of PCB 74, 118, 138, 153, and 180 compared to women classified as 'Other' (Table 2.3). 
Table 2.3. Age standardized geometric mean PCB levels (ng/g) for race by endometriosis diagnosis among women 20-54 years of age, NHANES 1999-2004.

\begin{tabular}{|c|c|c|c|c|c|c|}
\hline \multirow[b]{3}{*}{ Analyte $^{1}$} & & \multicolumn{5}{|c|}{ Geometric mean $^{2}$ (ng/g) (GSE, n) } \\
\hline & \multicolumn{2}{|c|}{ Non-Hispanic Black } & \multicolumn{2}{|c|}{ Non-Hispanic White } & \multicolumn{2}{|c|}{ Other Races } \\
\hline & $\begin{array}{c}\text { No } \\
\text { Endometriosis }\end{array}$ & Endometriosis & $\begin{array}{c}\text { No } \\
\text { Endometriosis }\end{array}$ & Endometriosis & $\begin{array}{c}\text { No } \\
\text { Endometriosis }\end{array}$ & Endometriosis \\
\hline$\overline{\mathrm{PCB} 074}$ & $6.89(1.05,207)^{\mathrm{e}}$ & $6.42(1.14,13)$ & $6.17(1.04,464)^{\mathrm{f}}$ & $5.87(1.08,53)$ & $5.16(1.04,402)$ & $6.42(1.14,14)$ \\
\hline PCB 099 & $6.82(1.05,207)^{\mathrm{c}, \mathrm{e}}$ & $5.53(1.07,13)$ & $4.90(1.04,466)^{\mathrm{f}}$ & $4.66(1.08,53)$ & $4.44(1.04,401)$ & $5.16(1.13,14)$ \\
\hline PCB 118 & $8.67(1.06,208)^{\mathrm{d}, \mathrm{f}}$ & $6.96(1.15,13)$ & $6.75(1.04,465)$ & $6.75(1.11,53)$ & $6.69(1.06,401)$ & $8.17(1.15,14)$ \\
\hline PCB 138 & $22.0(1.05,208)^{\mathrm{c}, \mathrm{e}}$ & $19.9(1.09,13)^{\mathrm{d}}$ & $15.6(1.04,465)^{\mathrm{f}}$ & $14.9(1.09,53)$ & $14.0(1.04,401)$ & $20.3(1.16,14)$ \\
\hline PCB 153 & $29.1(1.05,208)^{\mathrm{d}, \mathrm{e}}$ & $27.7(1.08,13)$ & $21.9(1.04,465)^{\mathrm{f}}$ & $21.3(1.09,53)$ & $18.5(1.04,400)$ & $27.7(1.15,14)$ \\
\hline PCB 180 & $16.8(1.04,208)^{\mathrm{d}, \mathrm{e}}$ & $16.6(1.11,13)^{\mathrm{d},}$ & $14.3(1.04,463)^{f}$ & $14.9(1.11,52)$ & $11.8(1.04,402)$ & $18.0(1.14,14)$ \\
\hline
\end{tabular}

${ }^{1}$ Lipid adjusted and log transformed polychlorinated biphenyls (ng/g).

${ }^{2}$ Geometric means calculated after applying NHANES sampling weights.

GM PCB levels significantly higher in women with endometriosis vs. women without endometriosis;

${ }^{\mathrm{a}} \mathrm{p}<0.0001,{ }^{\mathrm{b}} \mathrm{p}<0.05$.

GM PCB levels significantly higher in non-Hispanic black women compared to non-Hispanic white women;

${ }_{\mathrm{p}}^{\mathrm{p}}<0.0001,{ }^{\mathrm{d}} \mathrm{p}<0.05$.

GM PCB levels significantly higher in non-Hispanic black or non-Hispanic white women compared to 'Other' women; ${ }^{\mathrm{e}} \mathrm{p}<0.0001,{ }^{\mathrm{f}} \mathrm{p}<0.05$.

Table 2.4 presents age standardized GMs and GSEs of lipid adjusted PCBs by

race/ethnicity in participants with uterine leiomyoma data. Non-Hispanic black women

who reported being diagnosed with uterine leiomyomas had significantly higher GM

PCB levels for PCB 99, 118, 138, 153, and 180 compared to non-Hispanic White women and higher levels of PCB 99 compared to women classified as 'Other' (Table 2.4). In women who reported never being diagnosed with uterine leiomyomas, non-Hispanic black women had significantly higher levels of PCB congeners 99, 118, 138, 153, and 180 compared to non-Hispanic white women and significantly higher levels of all 6 PCB congeners compared to women classified as 'Other' (Table 2.4). Non-Hispanic white women not diagnosed with uterine leiomyomas had significantly higher levels of PCB $74,99,118,138,153$, and 180 compared to women classified as 'Other' (Table 2.4). 
Table 2.4. Age standardized geometric mean PCB levels $(\mathrm{ng} / \mathrm{g})$ for race by uterine leiomyoma diagnosis among women 20-54 years of age, NHANES 1999-2004.

\begin{tabular}{|c|c|c|c|c|c|c|}
\hline \multirow[b]{3}{*}{ Analyte $^{1}$} & \multicolumn{6}{|c|}{ Geometric mean $^{2}$ (ng/g) (GSE, n) } \\
\hline & \multicolumn{2}{|c|}{$\underline{\text { Non-Hispanic Black }}$} & \multicolumn{2}{|c|}{$\underline{\text { Non-Hispanic White }}$} & \multicolumn{2}{|c|}{ Other Races } \\
\hline & $\begin{array}{l}\text { No Uterine } \\
\text { Leiomyomas }\end{array}$ & $\begin{array}{c}\text { Uterine } \\
\text { Leiomyomas }\end{array}$ & $\begin{array}{l}\text { No Uterine } \\
\text { Leiomyomas }\end{array}$ & $\begin{array}{c}\text { Uterine } \\
\text { Leiomyomas }\end{array}$ & $\begin{array}{l}\text { No Uterine } \\
\text { Leiomyomas }\end{array}$ & $\begin{array}{c}\text { Uterine } \\
\text { Leiomyomas }\end{array}$ \\
\hline PCB 074 & $6.69(1.05,168)^{\mathrm{e}}$ & $6.96(1.09,52)$ & $6.17(1.04,458)^{\mathrm{e}}$ & $5.81(1.09,26)$ & $5.00(1.04,379)$ & $5.87(1.05,37)$ \\
\hline PCB 099 & $6.69(1.05,167)^{\mathrm{c}, \mathrm{e}}$ & $6.89(1.09,53)^{\mathrm{c}, \mathrm{d}}$ & $4.90(1.04,460)^{\mathrm{f}}$ & $4.10(1.08,25)$ & $4.39(1.04,378)$ & $4.66(1.08,37)$ \\
\hline PCB 118 & $8.58(1.06,168)^{\mathrm{d}, \mathrm{f}}$ & $8.76(1.08,53)^{\mathrm{c}}$ & $6.75(1.04,460)$ & $5.99(1.08,26)$ & $6.49(1.05,378)$ & $7.77(1.07,37)$ \\
\hline PCB 138 & $22.2(1.05,168)^{\mathrm{c}, \mathrm{e}}$ & $22.2(1.09,53)^{\mathrm{c}}$ & $15.6(1.04,459)^{\mathrm{f}}$ & $14.7(1.09,26)$ & $13.9(1.04,378)$ & $18.4(1.13,37)$ \\
\hline PCB 153 & $29.1(1.05,168)^{\mathrm{c}, \mathrm{e}}$ & $30.3(1.11,53)^{\mathrm{c}}$ & $21.5(1.04,459)^{\mathrm{f}}$ & $20.9(1.11,26)$ & $18.4(1.04,377)$ & $23.6(1.12,37)$ \\
\hline PCB 180 & $17.1(1.05,168)^{\mathrm{d}, \mathrm{e}}$ & $17.1(1.09,53)^{\mathrm{c}}$ & $14.4(1.04,457)^{\mathrm{f}}$ & $12.8(1.11,26)$ & $11.6(1.04,379)$ & $15.0(1.12,37)$ \\
\hline
\end{tabular}

${ }^{1}$ Lipid adjusted and log transformed polychlorinated biphenyls (ng/g).

${ }^{2}$ Geometric means calculated after applying NHANES sampling weights.

GM PCB levels significantly higher in women with uterine leiomyomas vs. women without uterine leiomyomas; ${ }^{\mathrm{a}} \mathrm{p}<0.0001,{ }^{\mathrm{b}} \mathrm{p}<0.05$.

GM PCB levels significantly higher in non-Hispanic black women compared to non-Hispanic white women; ${ }^{\mathrm{c}} \mathrm{p}<0.0001,{ }^{\mathrm{d}} \mathrm{p}<0.05$.

GM PCB levels significantly higher in non-Hispanic black or non-Hispanic white women compared to 'Other' women; ${ }^{\mathrm{e}}<0.0001,{ }_{\mathrm{f}}^{\mathrm{p}}<0.05$.

Table 2.5 shows the arithmetic means and $95 \%$ CIs of serum levels of dioxin-like PCBs for endometriosis and uterine leiomyoma status and selected variables in the study population. Arithmetic means of dioxin-like PCBs were not significantly higher in women who reported being diagnosed with endometriosis $(4.02 \mathrm{ng} / \mathrm{g})$ compared to women who reported never being diagnosed with endometriosis $(3.70 \mathrm{ng} / \mathrm{g})$ but were significantly higher in women who reported being diagnosed with uterine leiomyomas (4.36 ng/g) compared to women who reported never being diagnosed with uterine leiomyomas (3.62 ng/g) (Table 2.5). Mean dioxin-like PCBs increased with age, however there were no significant differences in the four age groups for endometriosis or uterine leiomyoma diagnosis with the exception of the 20-29 year old age group that had significantly higher dioxin-like PCB levels in the women not diagnosed with uterine leiomyomas compared to women diagnosed with uterine leiomyomas (Table 2.5). Age standardized dioxin-like PCBs were not found to be significantly different among races for women diagnosed with endometriosis but were found to significantly different among races for women not diagnosed with endometriosis. Non-Hispanic black women had 
significantly higher dioxin-like PCBs compared to non-Hispanic white women and women classified as 'Other' (Table 2.5). Dioxin-like PCBs were also found to be significantly higher in non-Hispanic black women with uterine leiomyomas compared to non-Hispanic white women with uterine leiomyomas and in non-Hispanic black women without uterine leiomyomas compared to non-Hispanic white women and women classified as 'Other' (Table 2.5). Dioxin-like PCBs were not found to be different among covariates for women with an endometriosis diagnosis but were found to be significantly higher in women with a uterine leiomyoma diagnosis compared to women without a uterine leiomyoma diagnosis for age at menarche, alcohol consumption and smoking status (Table 2.5). 
Table 2.5. Arithmetic mean dioxin-like PCB levels in the study population, women 20 -54 years of age, NHANES 1999-2004.

\begin{tabular}{|c|c|c|c|c|}
\hline Variable & $\begin{array}{r}\text { Endometriosis } \\
\text { Mean (SE,n) }\end{array}$ & $\begin{array}{c}\text { No } \\
\text { Endometriosis } \\
\text { Mean (SE,n) }\end{array}$ & $\begin{array}{l}\text { Leiomyomas } \\
\text { Mean (SE,n) }\end{array}$ & $\begin{array}{c}\text { No } \\
\text { Leiomyomas } \\
\text { Mean (SE,n) }\end{array}$ \\
\hline Dioxin-like PCBs & $4.02(0.19,80)$ & $3.70(0.06,1071)$ & $4.36(0.14,147)^{\mathrm{a}}$ & $3.62(0.07,1004)$ \\
\hline \multicolumn{5}{|l|}{ Race/Ethnicity ${ }^{3}$} \\
\hline Non-Hispanic white & $3.68(0.17,53)$ & $3.74(0.07,463)^{\mathrm{e}}$ & $3.54(0.16,58)^{b}$ & $3.73(0.07,458)^{\mathrm{e}}$ \\
\hline Non-Hispanic black & $3.67(0.20,13)$ & $4.08(0.11,207)^{\mathrm{c}, \mathrm{e}}$ & $4.11(0.16,52)^{\mathrm{b}, \mathrm{c}}$ & $4.04(0.11,168)^{\mathrm{c}, \mathrm{e}}$ \\
\hline Other & $3.96(0.26,14)$ & $3.54(0.08,401)$ & $3.82(0.10,37)^{\mathrm{a}}$ & $3.47(0.09,378)$ \\
\hline \multicolumn{5}{|l|}{ Age at interview (years) } \\
\hline $20-29$ & $2.85(0.13,12)$ & $2.87(0.07,375)$ & $2.19(0.10,10)$ & $2.89(0.07,377)^{\mathrm{a}}$ \\
\hline $30-39$ & $3.37(0.24,25)$ & $2.54(0.09,327)$ & $3.80(0.23,32)$ & $3.49(0.08,320)$ \\
\hline $40-49$ & $4.27(0.25,30)$ & $4.20(0.08,252)$ & $4.42(0.22,66)$ & $4.15(0.09,216)$ \\
\hline $50-54$ & $5.11(0.62,13)$ & $4.77(0.14,117)$ & $5.02(0.22,39)$ & $4.70(0.16,91)$ \\
\hline \multicolumn{5}{|l|}{ BMI $\left(\mathrm{kg} / \mathrm{m}^{2}\right)$} \\
\hline Normal weight $(<25)$ & $4.18(0.32,24)$ & $3.70(0.08,403)$ & $4.38(0.26,42)$ & $3.65(0.08,385)$ \\
\hline Overweight $(25$ to $<30)$ & $3.99(0.37,23)$ & $3.55(0.12,277)$ & $4.13(0.27,38)$ & $3.48(0.12,262)$ \\
\hline Obese $(\geq 30)$ & $3.88(0.21,32)$ & $3.82(0.09,378)$ & $4.51(0.14,67)$ & $3.67(0.10,343)$ \\
\hline \multicolumn{5}{|l|}{ Parity (no. of live births) } \\
\hline 0 & $4.47(0.50,9)$ & $3.65(0.20,54)$ & $4.60(0.56,9)^{b}$ & $3.62(0.21,54)$ \\
\hline 1 & $4.26(0.37,27)$ & $3.66(0.13,224)$ & $4.50(0.43,25)$ & $3.64(0.13,258)$ \\
\hline$\geq 2$ & $3.81(0.25,34)$ & $3.82(0.08,573)$ & $4.34,(0.14,111)$ & $3.71(0.07,618)$ \\
\hline \multicolumn{5}{|l|}{ Age at menarche (years) } \\
\hline$<12$ & $3.92(0.18,52)$ & $3.68(0.08,688)$ & $4.57(0.31,45)^{\mathrm{b}}$ & $3.75(0.13,212)$ \\
\hline $12-14$ & $4.05(0.47,22)$ & $3.91(0.14,235)$ & $4.30(0.16,86)^{b}$ & $3.61(0.09,654)$ \\
\hline$\geq 15$ & $4.70(0.41,5)^{\mathrm{b}}$ & $3.42(0.09,125)$ & $4.11(0.34,14)^{b}$ & $3.38(0.10,116)$ \\
\hline \multicolumn{5}{|l|}{ Alcohol Use } \\
\hline No & $3.90(0.23,24)$ & $3.56(0.09,415)$ & $4.11(0.25,51)^{b}$ & $3.51(0.08,388)$ \\
\hline Yes & $4.07(0.22,56)$ & $3.77(0.07,656)$ & $4.47(0.16,96)^{\mathrm{a}}$ & $3.67(0.08,616)$ \\
\hline \multicolumn{5}{|l|}{ Ever Smoked } \\
\hline No & $3.88(0.25,44)$ & $3.67(0.08,657)$ & $4.35,(0.18,87)^{b}$ & $3.58(0.08,614)$ \\
\hline Yes & $4.17(0.28,36)$ & $3.74(0.08,413)$ & $4.37(0.20,60)^{\mathrm{b}}$ & $3.68(0.08,389)$ \\
\hline
\end{tabular}

${ }^{1}$ Means calculated after applying NHANES sampling weights.

${ }^{2}$ Sum of Dioxin-like PCBs $=(074+118)$; Lipid adjusted and $\log$ transformed PCBs $(\mathrm{ng} / \mathrm{g})$.

${ }^{3}$ Age standardized.

PCB levels significantly higher in women with endometriosis or uterine leiomyomas vs. women without endometriosis or uterine leiomyomas; ${ }^{\mathrm{a}} \mathrm{p}<0.0001,{ }^{\mathrm{b}} \mathrm{p}<0.05$.

PCB levels significantly higher in non-Hispanic black women compared to non-Hispanic white women; ${ }^{c} \mathrm{p}<0.0001,{ }^{\mathrm{d}} \mathrm{p}<0.05$.

PCB levels significantly higher in non-Hispanic black or non-Hispanic white women compared to 'Other' women; ${ }^{\mathrm{e}} \mathrm{p}<0.0001,{ }_{\mathrm{p}}^{\mathrm{p}}<0.05$.

Table 2.6 shows the arithmetic means and 95\% CIs of serum levels of nondioxin-like PCBs for endometriosis and uterine leiomyoma status and selected variables in the study population. Arithmetic means of non-dioxin-like PCBs were significantly higher in women who reported being diagnosed with endometriosis (10.9 ng/g) compared to women who reported no endometriosis diagnosis $(10.0 \mathrm{ng} / \mathrm{g})$ and in women who 
reported a uterine leiomyoma diagnosis $(11.5 \mathrm{ng} / \mathrm{g})$ compared women who reported no uterine leiomyoma diagnosis $(9.84 \mathrm{ng} / \mathrm{g})$ (Table 2.6). Mean non-dioxin-like PCBs increased with age, however there were only significant differences among women in the 20-29 year old age group for both endometriosis diagnosis and uterine leiomyoma diagnosis (Table 2.6). In women diagnosed with endometriosis, age standardized nondioxin-like PCBs were found to be significantly higher in non-Hispanic black women compared to non-Hispanic white women and in women not diagnosed with endometriosis, age-standardized non-dioxin-like PCBs were significantly higher in nonHispanic black women compared to non-Hispanic white women and women classified as 'Other'. In women diagnosed with uterine leiomyomas, age standardized non-dioxin-like PCBs were found to be significantly higher in non-Hispanic black women compared to non-Hispanic white women and women classified as 'Other' and in women not diagnosed with uterine leiomyomas, age-standardized non-dioxin-like PCBs were significantly higher in non-Hispanic black women compared to non-Hispanic white women and women classified as 'Other' (Table 2.5). Non-dioxin-like PCBs were found to be significantly higher in women with a uterine leiomyoma diagnosis compared to women without a uterine leiomyoma diagnosis for BMI, parity, age at menarche, alcohol consumption and smoking status (Table 2.6). 
Table 2.6. Arithmetic mean non-dioxin-like PCB levels in the study population, women 20 -54years of age, NHANES 1999-2004.

\begin{tabular}{|c|c|c|c|c|}
\hline Variable & $\begin{array}{l}\text { Endometriosis } \\
\text { Mean (SE,n) }\end{array}$ & $\begin{array}{c}\text { No } \\
\text { Endometriosis } \\
\text { Mean (SE,n) }\end{array}$ & $\begin{array}{l}\text { Leiomyomas } \\
\text { Mean (SE,n) }\end{array}$ & $\begin{array}{c}\text { No } \\
\text { Leiomyomas } \\
\text { Mean (SE,n) }\end{array}$ \\
\hline Non-Dioxin-like PCBs & $10.9(0.34,79)^{b}$ & $10.0(0.12,1067)$ & $11.5(0.19,148)^{\mathrm{a}}$ & $9.84(0.13,998)$ \\
\hline \multicolumn{5}{|l|}{ Race/Ethnicity ${ }^{3}$} \\
\hline Non-Hispanic white & $10.0(0.34,52)$ & $10.1(0.15,461)^{\mathrm{e}}$ & $9.70(0.34,53)^{\mathrm{a}}$ & $10.1(0.15,455)^{\mathrm{e}}$ \\
\hline Non-Hispanic black & $10.8(0.29,13)^{\mathrm{c}}$ & $11.2(0.17,207)^{\mathrm{d}, \mathrm{e}}$ & $11.3(0.33,58)^{\mathrm{b}, \mathrm{d}}$ & $11.2(0.19,167)^{\mathrm{c}, \mathrm{e}}$ \\
\hline Other & $10.9(0.51,14)$ & $9.52(0.14,399)$ & $10.3(0.38,37)^{\mathrm{a}}$ & $9.48(0.15,376)$ \\
\hline \multicolumn{5}{|l|}{ Age at interview (years) } \\
\hline $20-29$ & $8.07(0.44,12)^{\mathrm{b}}$ & $7.78(0.014372)$ & $7.22(0.55,10)$ & $7.81(0.14,374)^{\mathrm{a}}$ \\
\hline $30-39$ & $9.74(0.46,25)$ & $9.77(0.19,327)$ & $10.5(0.37,32)$ & $9.69(0.18,320)$ \\
\hline $40-49$ & $11.4(0.39,30)$ & $11.4(0.14,252)$ & $11.4(0.33,67)$ & $11.4(0.16,215)$ \\
\hline $50-54$ & $13.6(1.18,12)$ & $12.3(0.25,116)$ & $13.1(0.41,39)$ & $12.1(0.33,89)$ \\
\hline \multicolumn{5}{|l|}{ BMI $\left(\mathrm{kg} / \mathrm{m}^{2}\right)$} \\
\hline Normal weight $(<25)$ & $11.8(0.53,24)$ & $10.2(0.16,402)$ & $12.5(0.37,43)^{\mathrm{a}}$ & $10.1(0.17,383)$ \\
\hline Overweight $(25$ to $<30)$ & $11.0(0.67,22)$ & $9.72(0.21,276)$ & $10.9(0.48,37)^{\mathrm{b}}$ & $9.63(0.20,261)$ \\
\hline Obese $(\geq 30)$ & $9.94(0.39,32)$ & $9.93(0.20,377)$ & $11.4(0.23,68)^{\mathrm{a}}$ & $9.60(0.21,341)$ \\
\hline \multicolumn{5}{|l|}{ Parity (no. of live births) } \\
\hline 0 & $11.2(1.04,9)$ & $9.97(0.54,55)$ & $11.2(0.56,10)^{\mathrm{a}}$ & $9.91(0.56,54)$ \\
\hline 1 & $11.1(0.66,28)$ & $9.81(0.28,252)$ & $12.2(0.79,25)^{\mathrm{b}}$ & $9.72(0.26,255)$ \\
\hline$\geq 2$ & $10.8(0.44,40)$ & $10.4(0.13,685)$ & $11.5(0.66,111)$ & $10.2(0.14,614)$ \\
\hline \multicolumn{5}{|l|}{ Age at menarche (years) } \\
\hline$<12$ & $10.7(0.38,52)$ & $9.96(0.15,682)$ & $11.5(0.57,44)^{b}$ & $9.92(0.29,213)$ \\
\hline $12-14$ & $10.8(0.86,21)$ & $10.2(0.29,236)$ & $11.5(0.26,87)^{b}$ & $9.81(0.17,647)$ \\
\hline$\geq 15$ & $12.7(1.20,5)^{\mathrm{b}}$ & $10.1(0.20,125)$ & $11.8(0.69,14)^{b}$ & $9.93(0.20,116)$ \\
\hline \multicolumn{5}{|l|}{ Alcohol Use } \\
\hline No & $10.6(0.23,24)$ & $9.77(0.17,417)$ & $11.0(0.40,52)^{\mathrm{b}}$ & $9.65(0.17,389)$ \\
\hline Yes & $11.0(0.38,55)^{\mathrm{b}}$ & $10.1(0.15,650)$ & $11.7(0.23,96)^{\mathrm{a}}$ & $9.94(0.16,609)$ \\
\hline \multicolumn{5}{|l|}{ Ever Smoked } \\
\hline No & $10.2(0.47,43)$ & $9.74(0.16,656)$ & $11.2(0.26,87)^{\mathrm{a}}$ & $9.54(0.16,612)$ \\
\hline Yes & $11.6(0.55,36)$ & $10.4(0.15,410)$ & $11.9(0.32,61)^{\mathrm{a}}$ & $10.3(0.16,385)$ \\
\hline
\end{tabular}

${ }^{\mathrm{T}}$ Means calculated after applying NHANES sampling weights.

${ }^{2}$ Sum of Dioxin-like PCBs $=(099+138+153+180)$; Lipid adjusted and log transformed PCBs (ng/g). ${ }^{3}$ Age Standardizd Mean.

PCB levels significantly higher in women with endometriosis or uterine leiomyomas vs. women without endometriosis or uterine leiomyomas; ${ }^{\mathrm{a}} \mathrm{p}<0.0001,{ }^{\mathrm{b}} \mathrm{p}<0.05$.

PCB levels significantly higher in non-Hispanic black women compared to non-Hispanic white women; ${ }^{\mathrm{c}} \mathrm{p}<0.0001,{ }^{\mathrm{d}} \mathrm{p}<0.05$.

PCB levels significantly higher in non-Hispanic black or non-Hispanic white women compared to 'Other' women; ${ }^{\mathrm{e}} \mathrm{p}<0.0001,{ }_{\mathrm{f}}^{\mathrm{p}}<0.05$.

GM and 95\% CI's of lipid-adjusted PCB levels are reported in table 2.7 for women with PCB levels $<$ LOD and $\geq$ LOD. Women with PCB concentrations $\geq$ LOD who reported being diagnosed with endometriosis had significantly higher GM levels of PCB 138 (22.0 ng/g vs 17.3 ng/g), PCB 153 (29.7 ng/g vs. 23.8 ng/g), and PCB 180 (24.0 $\mathrm{ng} / \mathrm{g}$ vs. $16.3 \mathrm{ng} / \mathrm{g})$, compared to women who reported never being diagnosed with 
endometriosis (Table 2.7). Women with PCB concentrations $\geq$ LOD who reported being diagnosed with uterine leiomyomas had significantly higher GM levels of all 6 PCB congeners 74 (9.39 ng/g vs.6.75 ng/g), PCB 99 (1.70 ng/g vs. 5.70 ng/g), PCB 118 (10.9 ng/g vs. $8.08 \mathrm{ng} / \mathrm{g}$ ), PCB 138 (25.3 ng/g vs. $16.4 \mathrm{ng} / \mathrm{g}$ ), PCB 153 (35.9 ng/g vs. 21.5 ng/g), and PCB 180 (25.5 ng/g vs. $15.5 \mathrm{ng} / \mathrm{g})$, compared to women who reported never being diagnosed with uterine leiomyomas (Table 2.7). 
Table 2.7. Geometric mean PCB levels (ng/g) by diagnosis of endometriosis or uterine leiomyomas among women 20 to 54 years of age, NHANES 1999-2004.

\begin{tabular}{|c|c|c|c|c|}
\hline \multirow[b]{2}{*}{ Analyte $^{1}$} & \multirow[b]{2}{*}{$\begin{array}{c}\text { No. } \\
\text { Noncases }\end{array}$} & \multirow[b]{2}{*}{$\begin{array}{c}\text { No. } \\
\text { Cases }\end{array}$} & \multicolumn{2}{|c|}{ Geometric mean $^{2}(\mathrm{ng} / \mathrm{g})(95 \% \mathrm{CI})$} \\
\hline & & & $\begin{array}{c}\text { No } \\
\text { Endometriosis } \\
\end{array}$ & Endometriosis \\
\hline \multicolumn{5}{|l|}{$\overline{\text { PCB } 074}$} \\
\hline$<$ LOD & 396 & 23 & $4.01(3.90-4.18)$ & $3.74(3.39-4.10)$ \\
\hline$\geq$ LOD & 677 & 57 & $7.10(6.49-7.69)$ & $8.24(6.69-10.2)$ \\
\hline \multicolumn{5}{|l|}{ РCB 099} \\
\hline$<\mathrm{LOD}$ & 475 & 35 & $3.97(3.86-4.10)$ & $3.49(3.25-3.78)^{\mathrm{b}}$ \\
\hline$\geq$ LOD & 599 & 45 & $5.70(5.16-6.30)$ & $7.03(5.26-9.39)$ \\
\hline \multicolumn{5}{|l|}{ PCB 118} \\
\hline$<\mathrm{LOD}$ & 350 & 24 & $4.01(3.90-4.18)$ & $3.82(3.42-4.26)$ \\
\hline$\geq$ LOD & 724 & 56 & $8.41(7.77-9.12)$ & $9.87(7.92-12.4)$ \\
\hline \multicolumn{5}{|l|}{ РCB 138} \\
\hline$<$ LOD & 293 & 21 & $11.8(10.9-12.7)$ & $11.5(9.21-14.4)$ \\
\hline$\geq$ LOD & 781 & 59 & $17.3(16.0-18.7)$ & $22.0(18.2-26.3)^{\mathrm{b}}$ \\
\hline \multicolumn{5}{|l|}{ PCB 153} \\
\hline$<\mathrm{LOD}$ & 247 & 16 & $16.3(15.2-17.6)$ & $17.5(16.4-18.5)$ \\
\hline$\geq$ LOD & 826 & 64 & $23.8(21.1-25.0)$ & $29.7(23.8-36.6)^{\mathrm{b}}$ \\
\hline \multicolumn{5}{|l|}{ PCB 180} \\
\hline$<\mathrm{LOD}$ & 298 & 18 & $7.61(7.17-8.17)$ & $7.39(5.93-9.21)$ \\
\hline$\geq \mathrm{LOD}$ & 775 & 61 & $16.3(15.0-17.6)$ & $24.0(19.5-56.8)^{b}$ \\
\hline Analyte ${ }^{1}$ & $\begin{array}{l}\text { No. } \\
\text { Noncases }\end{array}$ & $\begin{array}{l}\text { No. } \\
\text { Cases }\end{array}$ & $\begin{array}{c}\text { No } \\
\text { Uterine Leiomyomas }\end{array}$ & Uterine Leiomyomas \\
\hline \multicolumn{5}{|l|}{ PCB 074} \\
\hline$<\mathrm{LOD}$ & 396 & 23 & $4.01(3.90-4.18)$ & $3.67(3.22-7.39)$ \\
\hline$\geq$ LOD & 609 & 125 & $6.75(6.17-7.39)$ & $9.39(8.08-10.8)^{\mathrm{b}}$ \\
\hline \multicolumn{5}{|l|}{ РCВ 099} \\
\hline$<$ LOD & 472 & 38 & $3.97(3.86-4.10)$ & $3.60(3.28-3.90)^{\mathrm{b}}$ \\
\hline$\geq$ LOD & 533 & 111 & $5.70(4.90-6.17)$ & $7.10(6.11-8.33)^{b}$ \\
\hline \multicolumn{5}{|l|}{ PCB 118} \\
\hline$<$ LOD & 355 & 19 & $4.06(3.89-4.22)$ & $3.49(3.03-3.97$ \\
\hline$\geq \mathrm{LOD}$ & 651 & 129 & $8.08(7.39-8.85)$ & $10.9(9.39-12.7)^{b}$ \\
\hline \multicolumn{5}{|l|}{ PCB 138} \\
\hline$<$ LOD & 295 & 19 & $11.7(10.7-12.8)$ & $12.4(11.0-13.9)$ \\
\hline$\geq$ LOD & 710 & 130 & $16.4(15.2-17.8)$ & $25.3(22.4-28.8)^{\mathrm{a}}$ \\
\hline \multicolumn{5}{|l|}{ PCB 153} \\
\hline$<$ LOD & 247 & 16 & $16.4(15.2-17.8)$ & $16.0(13.7-18.5)$ \\
\hline$\geq$ LOD & 757 & 133 & $21.5(19.7-23.6)$ & $35.9(31.8-40.4)^{\mathrm{a}}$ \\
\hline \multicolumn{5}{|l|}{ PCB 180} \\
\hline$<$ LOD & 299 & 17 & 7.69 (7.17-8.17) & $6.89(5.10-9.21)$ \\
\hline$\geq$ LOD & 705 & 131 & $15.5(14.3-16.8)$ & $25.5(22.9-28.5)^{\mathrm{a}}$ \\
\hline
\end{tabular}

${ }^{\mathrm{L}}$ Lipid adjusted and log transformed polychlorinated biphenyls (ng/g).

${ }^{2}$ Geometric means calculated after applying NHANES sampling weights.

GM PCB levels significantly higher in women diagnosed with endometriosis or uterine leiomyomas vs. women not diagnosed with endometriosis or uterine leiomyomas; ${ }^{\mathrm{a}} \mathrm{p}<0.0001,{ }^{\mathrm{b}}<0.05$.

We further explored endometriosis and uterine leiomyoma diagnosis with exposure to PCBs in tertiles (Table 2.8 and 2.9) For women with data on endometriosis, 
only non-dioxin-like PCBs were found to be significantly higher in women diagnosed with endometriosis compared to women not diagnosed with endometriosis $(8.19 \mathrm{ng} / \mathrm{g}$ vs. $7.60 \mathrm{ng} / \mathrm{g}$ ) for subjects in the first tertile (Table 2.8). For women with uterine leiomyomas, PCB 138 was significantly higher for women in the first tertile $(10.1 \mathrm{ng} / \mathrm{g}$ vs. $8.25 \mathrm{ng} / \mathrm{g})$, PCB 153 was significantly higher for women in the first tertile $(13.1 \mathrm{ng} / \mathrm{g}$ vs. $10.8 \mathrm{ng} / \mathrm{g}$ ) and second tertile (30.3 ng/g vs. $26.8 \mathrm{ng} / \mathrm{g}$ ), and non-dioxin-like PCBs were significantly higher for women in the first tertile $(8.36 \mathrm{ng} / \mathrm{g}$ vs $7.58 \mathrm{ng} / \mathrm{g})$ and second tertile (11.2 ng/g vs. $10.8 \mathrm{ng} / \mathrm{g})$ (Table 2.9$)$. 
Table 2.8. Geometric Mean PCB levels (ng/g) by endometriosis status among women 20 to 54 years of age, NHANES 1999-2004.

\begin{tabular}{|c|c|c|c|c|}
\hline \multirow[b]{2}{*}{ PCB Percentiles ${ }^{1}$} & \multirow[b]{2}{*}{$\begin{array}{c}\text { No. } \\
\text { Noncases }\end{array}$} & \multirow[b]{2}{*}{$\begin{array}{l}\text { No. } \\
\text { Cases }\end{array}$} & \multicolumn{2}{|c|}{ Geometric mean $^{2}(\mathrm{ng} / \mathrm{g})(95 \% \mathrm{CI})$} \\
\hline & & & No Endometriosis & Endometrios is \\
\hline \multicolumn{5}{|l|}{ PCB 074} \\
\hline$<33^{\text {rd }}$ & 576 & 28 & $3.39(3.25-3.49)$ & $3.35(3.03-3.71)$ \\
\hline $33^{\text {rd }}$ to $66^{\text {th }}$ & 345 & 38 & $7.39(7.03-7.69)$ & $7.17(6.62-7.77)$ \\
\hline$\geq 66^{\text {th }}$ & 151 & 14 & $17.5(16.4-18.5)$ & $20.3(15.2-27.1)$ \\
\hline \multicolumn{5}{|l|}{ РCB 099} \\
\hline$<33^{\text {rd }}$ & 494 & 36 & $2.83(2.69-2.94)$ & $2.92(1.10-3.16)$ \\
\hline $33^{\text {rd }}$ to $66^{\text {th }}$ & 372 & 23 & $5.21(5.10-5.31)$ & $5.21(4.85-5.58)$ \\
\hline$\geq 66^{\text {th }}$ & 208 & 21 & $12.2(11.4-13.1)$ & $14.4(10.9-18.9)$ \\
\hline \multicolumn{5}{|l|}{ PCB 118} \\
\hline$<33^{\text {rd }}$ & 544 & 33 & $3.71(3.60-3.82)$ & $3.74(3.42-4.18)$ \\
\hline $33^{\text {rd }}$ to $66^{\text {th }}$ & 348 & 29 & $8.05(7.85-8.33)$ & $7.92(7.03-8.94)$ \\
\hline$\geq 66^{\text {th }}$ & 180 & 18 & $22.4(20.7-24.5)$ & $22.4(16.4-30.6)$ \\
\hline \multicolumn{5}{|l|}{ PCB 138} \\
\hline$<33^{\text {rd }}$ & 562 & 32 & $8.33(7.85-8.76)$ & $9.30(7.92-11.0)$ \\
\hline $33^{\text {rd }}$ to $66^{\text {th }}$ & 333 & 27 & $19.7(18.9-19.9)$ & $18.2(16.6-19.7)$ \\
\hline$\geq 66^{\text {th }}$ & 179 & 21 & $47.9(44.7-51.4)$ & $48.9(37.7-63.4)$ \\
\hline \multicolumn{5}{|l|}{ PCB 153} \\
\hline$<33^{\text {rd }}$ & 576 & 30 & $10.8(10.3-11.4)$ & $12.7(10.8-14.9)$ \\
\hline $33^{\text {rd }}$ to $66^{\text {th }}$ & 326 & 29 & $27.7(26.8-28.5)$ & $26.8(24.3-29.7)$ \\
\hline$\geq 66^{\text {th }}$ & 171 & 21 & $66.7(62.2-68.7)$ & $68.0(51.9-88.2)$ \\
\hline \multicolumn{5}{|l|}{ PCB 180} \\
\hline$<33^{\text {rd }}$ & 615 & 27 & $6.69(6.30-7.03)$ & $7.39(6.23-8.67)$ \\
\hline $33^{\text {rd }}$ to $66^{\text {th }}$ & 308 & 33 & $19.9(19.5-20.5)$ & $18.5(16.6-20.9)$ \\
\hline$\geq 66^{\text {th }}$ & 149 & 19 & $48.9(45.2-53.0)$ & $49.4(40.4-59.7)$ \\
\hline \multicolumn{5}{|l|}{ Dioxin-like $\mathbf{P C B s}^{3}$} \\
\hline$<33^{\text {rd }}$ & 556 & 29 & $2.56(2.48-2.63)$ & $2.59(2.38-2.80)$ \\
\hline $33^{\text {rd }}$ to $66^{\text {th }}$ & 260 & 27 & $3.83(3.76-3.89)$ & $3.79(3.59-3.99)$ \\
\hline$\geq 66^{\text {th }}$ & 254 & 24 & $5.41(5.31-5.52)$ & $5.42(4.89-5.96)$ \\
\hline \multicolumn{5}{|c|}{ Non-Dioxin-like $\mathrm{PCBs}^{4}$} \\
\hline$<33^{\text {rd }}$ & 575 & 30 & $7.60(7.44-7.76)$ & $8.19(7.73-8.66)^{\mathrm{b}}$ \\
\hline $33^{\text {rd }}$ to $66^{\text {th }}$ & 317 & 28 & $10.9(10.8-11.0)$ & $10.7(10.4-11.1)$ \\
\hline$\geq 66^{\text {th }}$ & 175 & 27 & $14.2(14.0-14.5)$ & $14.4(13.4-15.4)$ \\
\hline \multirow{2}{*}{\multicolumn{5}{|c|}{$\begin{array}{l}\text { } 2 \text { Lipid adjusted and log transformed polychlorinated biphenyls (ng/g). } \\
{ }^{2} \text { Geometric means calculated after applying NHANES sampling weight }\end{array}$}} \\
\hline & & & & \\
\hline \multicolumn{5}{|c|}{$\begin{array}{l}{ }^{2} \text { Geometric means calculated after applying NHANES sampling weight } \\
{ }^{3} \text { Arithmetic Mean Dioxin-like PCBs: Sum of PCB } 074+118 \text {. }\end{array}$} \\
\hline \multicolumn{5}{|c|}{${ }^{4}$ Arithmetic Mean Non-Dioxin-like-PCBs: Sum of PCB $099+138+153+180$. } \\
\hline 3 levels sig & gher in & & th endometriosis vs & t diagnos \\
\hline
\end{tabular}


Table 2.9. Geometric Mean PCB levels (ng/g) by uterine leiomyoma status among women 20 to 54 years of age, NHANES 1999-2004.

\begin{tabular}{|c|c|c|c|c|}
\hline \multirow[b]{2}{*}{ PCB Percentiles ${ }^{1}$} & \multirow[b]{2}{*}{$\begin{array}{c}\text { No. } \\
\text { Noncases } \\
\end{array}$} & \multirow[b]{2}{*}{$\begin{array}{l}\text { No. } \\
\text { Cases }\end{array}$} & \multicolumn{2}{|c|}{ Geometric mean $^{2}(\mathrm{ng} / \mathrm{g})(95 \% \mathrm{CI})$} \\
\hline & & & $\begin{array}{c}\text { No } \\
\text { Uterine Leiomyomas }\end{array}$ & Uterine Leiomyomas \\
\hline \multicolumn{5}{|l|}{$\overline{\text { PCB } 074}$} \\
\hline$<33^{\text {rd }}$ & 565 & 39 & $3.35(3.25-3.49)$ & $3.49(3.19-3.82)$ \\
\hline $33^{\text {rd }}$ to $66^{\text {th }}$ & 319 & 64 & $7.24(7.03-7.54)$ & $7.61(7.03-8.25)$ \\
\hline$\geq 66^{\text {th }}$ & 120 & 45 & $17.5(16.4-18.5)$ & $18.2(16.6-20.1)$ \\
\hline \multicolumn{5}{|l|}{ PCB 099} \\
\hline$<33^{\text {rd }}$ & 489 & 41 & $2.80(2.69-2.94)$ & $2.94(2.69-3.22)$ \\
\hline $33^{\text {rd }}$ to $66^{\text {th }}$ & 340 & 55 & $5.16(5.10-5.26)$ & $5.26(5.05-5.53)$ \\
\hline$\geq 66^{\text {th }}$ & 176 & 53 & $12.2(11.4-12.9)$ & $13.2(11.5-15.0)$ \\
\hline \multicolumn{5}{|l|}{ РCB 118} \\
\hline$<33^{\text {rd }}$ & 543 & 34 & $3.74(3.60-3.86)$ & $3.53(3.16-3.90)$ \\
\hline $33^{\text {rd }}$ to $66^{\text {th }}$ & 313 & 64 & $8.00(7.77-8.25)$ & $8.33(7.85-8.94)$ \\
\hline$\geq 66^{\text {th }}$ & 148 & 50 & $22.2(20.3-24.3)$ & $23.1(20.1-26.6)$ \\
\hline \multicolumn{5}{|l|}{ PCB 138} \\
\hline$<33^{\text {rd }}$ & 559 & 35 & $8.25(7.77-8.67)$ & $10.1(9.03-11.4)^{\mathrm{b}}$ \\
\hline $33^{\text {rd }}$ to $66^{\text {th }}$ & 298 & 62 & $19.1(18.5-19.9)$ & $20.1(18.9-21.1)$ \\
\hline$\geq 66^{\text {th }}$ & 148 & 52 & $48.4(44.7-53.0)$ & $46.5(41.3-52.5)$ \\
\hline \multicolumn{5}{|l|}{ РCB 153} \\
\hline$<33^{\text {rd }}$ & 572 & 34 & $10.8(10.3-11.2)$ & $13.1(11.1-15.3)^{\mathrm{b}}$ \\
\hline $33^{\text {rd }}$ to $66^{\text {th }}$ & 291 & 64 & $26.8(26.0-27.9)$ & $30.3(27.9-32.8)^{\mathrm{b}}$ \\
\hline$\geq 66^{\text {th }}$ & 141 & 51 & $67.4(62.1-73.0)$ & $64.7(57.4-73.0)$ \\
\hline \multicolumn{5}{|l|}{ PCB 180} \\
\hline$<33^{\text {rd }}$ & 607 & 35 & $6.69(6.30-7.03)$ & $6.96(5.64-8.50)$ \\
\hline $33^{\text {rd }}$ to $66^{\text {th }}$ & 270 & 71 & $19.3(18.7-19.9)$ & $21.5(19.9-23.3)^{\mathrm{b}}$ \\
\hline$\geq 66^{\text {th }}$ & 126 & 42 & $49.4(45.2-55.1)$ & $47.5(43.4-51.9)$ \\
\hline \multicolumn{5}{|l|}{ Dioxin-like PCBs ${ }^{3}$} \\
\hline$<33^{\text {rd }}$ & 550 & 35 & $2.56(2.49-2.64)$ & $2.55(2.37-2.74)$ \\
\hline $33^{\text {rd }}$ to $66^{\text {th }}$ & 243 & 44 & $3.81(3.75-3.86)$ & $3.91(3.77-4.04)$ \\
\hline$\geq 66^{\text {th }}$ & 210 & 68 & $5.38(5.25-5.52)$ & $5.51(5.27-5.74)$ \\
\hline \multicolumn{5}{|c|}{ Non-Dioxin-like PCBs ${ }^{4}$} \\
\hline$<33^{\text {rd }}$ & 569 & 36 & $7.58(7.41-7.74)$ & $8.36(7.81-8.90)^{\mathrm{b}}$ \\
\hline $33^{\text {rd }}$ to $66^{\text {th }}$ & 282 & 63 & $10.8(10.6-10.9)$ & $11.2(11.1-11.4)^{\mathrm{b}}$ \\
\hline$\geq 66^{\text {th }}$ & 147 & 49 & $14.2(13.9-14.5)$ & $14.3(13.9-14.8)$ \\
\hline
\end{tabular}

${ }^{1}$ Lipid adjusted and log transformed polychlorinated biphenyls (ng/g).

${ }^{2}$ Geometric means calculated after applying NHANES sampling weights.

${ }^{3}$ Arithmetic Mean Dioxin-like PCBs: Sum of PCB $074+118$.

${ }^{4}$ Arithmetic Mean Non-Dioxin-like-PCBs: Sum of PCB $099+138+153+180$.

GM PCB levels significantly higher in women diagnosed with uterine leiomyomas vs. women not diagnosed with uterine leiomyomas; ${ }^{\mathrm{a}} \mathrm{p}<0.0001,{ }^{\mathrm{b}}<0.05$. 
Estimated ORs and 95\% confidence intervals for the risk of having breast cancer and the six individual PCB congeners are shown in table 2.10. We estimated endometriosis and uterine leiomyoma risk for subjects with PCB levels $<$ LOD (reference group) and $\geq$ LOD. Results are presented for three logistic regression models: unadjusted; age and race/ethnicity adjusted; and age, race/ethnicity, BMI, parity, age at menarche, oral contraceptive use, smoking, and alcohol consumption adjusted. In unadjusted models, PCBs were significantly associated with endometriosis for PCB 74 (OR of 1.71, 95\% CI: 1.07-2.21). PCBs were not significantly associated with endometriosis in any of the adjusted models (Table 2.10). In unadjusted models, all six PCB congeners were significantly associated with uterine leiomyomas. After adjusting final models for age, race/ethnicity, BMI, parity, age at menarche, oral contraceptive use, smoking, and alcohol, PCB 74 and 118 remained significantly associated with uterine leiomyomas ORs of 1.91 (95\% CI: 1.10-3.29) and 1.91 (95\% CI: 1.13-3.22), respectively (Table 2.10). 
Table 2.10. Estimated ORs (95\% CIs) of endometriosis or uterine leiomyomas by concentrations of PCBs among women 20-54 years of age, NHANES 1999-2004.

\begin{tabular}{|c|c|c|c|c|c|}
\hline Analyte $^{1}$ & $\begin{array}{c}\text { No. } \\
\text { Cases }\end{array}$ & $\begin{array}{c}\text { No. } \\
\text { Noncases }\end{array}$ & $\begin{array}{c}\text { Unadjusted OR } \\
(95 \% \mathrm{CI})\end{array}$ & $\begin{array}{c}\text { Adjusted OR }{ }^{2} \\
(95 \% \text { CI })\end{array}$ & $\begin{array}{c}\text { Adjusted OR } \mathrm{OR}^{3, \mathrm{a}} \\
(95 \% \mathrm{CI})\end{array}$ \\
\hline \multicolumn{6}{|c|}{ ENDOMETRIOSIS } \\
\hline \multicolumn{6}{|l|}{ PCB 074} \\
\hline$<$ LOD & 23 & 396 & 1.00 & 1.00 & 1.00 \\
\hline$\geq$ LOD & 57 & 677 & $1.71(1.07-2.71)^{\mathrm{b}}$ & $1.15(0.66-2.01)$ & $1.18(0.59-2.38)$ \\
\hline \multicolumn{6}{|l|}{ РCB 099} \\
\hline$<$ LOD & 35 & 475 & 1.00 & 1.00 & 1.00 \\
\hline$\geq$ LOD & 45 & 599 & $1.02(0.58-1.80)$ & $0.84(0.44-1.60)$ & $0.83(0.40-1.73)$ \\
\hline \multicolumn{6}{|l|}{ PCB 118} \\
\hline$<$ LOD & 24 & 350 & 1.00 & 1.00 & 1.00 \\
\hline$\geq$ LOD & 56 & 724 & $1.26(0.72-2.20)$ & $0.93(0.49-1.77)$ & $0.86(0.40-1.85)$ \\
\hline \multicolumn{6}{|l|}{ PCB 138} \\
\hline$<$ LOD & 21 & 293 & 1.00 & 1.00 & 1.00 \\
\hline$\geq$ LOD & 59 & 781 & $1.24(0.76-2.03)$ & $0.97(0.56-1.68)$ & $1.02(0.63-1.63)$ \\
\hline \multicolumn{6}{|l|}{ PCB 153} \\
\hline$<$ LOD & 16 & 247 & 1.00 & 1.00 & 1.00 \\
\hline$\geq$ LOD & 64 & 826 & $1.35(0.76-2.39)$ & $0.97(0.97-1.72)$ & $1.13(0.68-1.87)$ \\
\hline \multicolumn{6}{|l|}{ PCB 180} \\
\hline$<\mathrm{LOD}$ & 18 & 298 & 1.00 & 1.00 & 1.00 \\
\hline$\geq$ LOD & 61 & 775 & $1.49(0.94-2.37)$ & $0.97(0.62-1.50)$ & $1.07(0.74-1.55)$ \\
\hline Analyte $^{1}$ & $\begin{array}{c}\text { No. } \\
\text { Cases }\end{array}$ & $\begin{array}{c}\text { No. } \\
\text { Noncases }\end{array}$ & $\begin{array}{c}\text { Unadjusted OR } \\
(95 \% \mathrm{CI})\end{array}$ & $\begin{array}{c}\text { Adjusted OR }{ }^{2} \\
(95 \% \mathrm{CI})\end{array}$ & $\begin{array}{c}\text { Adjusted OR } \mathrm{OR}^{3, \mathrm{~b}} \\
(\mathbf{9 5 \%} \mathrm{CI})\end{array}$ \\
\hline \multicolumn{6}{|c|}{ UTERINE LEIOMYOMAS } \\
\hline \multicolumn{6}{|l|}{ РCB 074} \\
\hline$<$ LOD & 23 & 396 & 1.00 & 1.00 & 1.00 \\
\hline$\geq$ LOD & 125 & 609 & $3.63(2.10-6.29)^{\mathrm{a}}$ & $1.96(1.15-3.35)^{\mathrm{b}}$ & $1.91(1.10-3.29)^{\mathrm{b}}$ \\
\hline \multicolumn{6}{|l|}{ РCB 099} \\
\hline$<$ LOD & 38 & 472 & 1.00 & 1.00 & 1.00 \\
\hline$\geq$ LOD & 111 & 533 & $2.25(1.38-3.68)^{b}$ & $1.47(0.87-2.48)$ & $1.60(0.95-2.72)$ \\
\hline \multicolumn{6}{|l|}{ PCB 118} \\
\hline$<\mathrm{LOD}$ & 19 & 355 & 1.00 & 1.00 & 1.00 \\
\hline$\geq$ LOD & 129 & 651 & $3.35(1.87-6.03)^{\mathrm{a}}$ & $2.00(1.17-3.42)^{\mathrm{b}}$ & $1.91(1.13-3.22)^{\mathrm{b}}$ \\
\hline \multicolumn{6}{|l|}{ PCB 138} \\
\hline$<\mathrm{LOD}$ & 19 & 295 & 1.00 & 1.00 & 1.00 \\
\hline$\geq$ LOD & 130 & 710 & $2.24(1.22-4.12)^{\mathrm{b}}$ & $1.31(0.63-2.74)$ & $1.63(0.86-3.10)$ \\
\hline \multicolumn{6}{|l|}{ РС̄ 153} \\
\hline$<$ LOD & 16 & 247 & 1.00 & 1.00 & 1.00 \\
\hline$\geq$ LOD & 133 & 757 & $2.42(1.55-3.78)^{\mathrm{a}}$ & $1.32(0.78-2.23)$ & $1.45(0.83-2.54)$ \\
\hline \multicolumn{6}{|l|}{ PCB 180} \\
\hline$<\mathrm{LOD}$ & 17 & 299 & 1.00 & 1.00 & 1.00 \\
\hline$\geq \mathrm{LOD}$ & 131 & 705 & $2.78(1.64-4.74)^{\mathrm{b}}$ & $1.28(0.72-2.28)$ & $1.38(0.70-2.74)$ \\
\hline
\end{tabular}

Lipid adjusted and log transformed polychlorinated biphenyls (ng/g).

${ }^{2}$ Adjusted for age, race/ethnicity .

${ }^{3}$ Adjusted for age, race/ethnicity, BMI, parity, age at menarche, oral contraceptive use, smoking, alcohol use.

${ }^{\mathrm{a} C}$ Cases/noncases: 77/962 in PCB 074, 153, 180; 77/963 in PCB 138; 77/964 in PCB 099; $77 / 965$ in PCB 118.

${ }^{\mathrm{b}}$ Cases/noncases: 143/896 in PCB 074; 144/897 in PCB 099;144/898 in PCB 118; 144/896 in PCB 138; 144/895 in PCB 153, 180.

Significance: ${ }^{\mathrm{a}} \mathrm{p}<0.0001,{ }^{\mathrm{b}} \mathrm{p}<0.05$. 
ORs and 95\% confidence intervals for risk of endometriosis and uterine leiomyomas were further analyzed for subjects with PCB concentrations divided into tertiles (Tables 2.11 and 2.12). Subjects with PCB concentrations in the first tertile $(<$ 33 rd percentile) were used as the reference group. In the unadjusted models, risk of endometriosis was significantly associated with PCB 74 for subjects in the second tertile (OR of 2.32, 95\% CI: 1.27-4.24) and PCB 180 for subjects in the second and third tertiles [ORs of 2.38 (95\% CI: 1.38-4.09) and 3.44 (95\% CI: 1.46-8.11)], respectively (Table 2.11). Endometriosis did not remain significantly associated with any PCBs in the adjusted models. In the unadjusted models, risk of uterine leiomyomas were significantly associated with PCB 99 in the third tertile and PCBs 74, 118, 138, and 180 for subjects in the second and third tertiles (Table 2.12). After adjusting for age and race/ethnicity, PCB 180 remained significantly associated with uterine leiomyoma for subjects in the second tertile (OR of 1.64, 95\% CI: 1.07-2.51). After adjusting for all variables in the final model, PCB 180 continued to remain significantly associated with uterine leiomyomas for subjects in the second tertile (OR of 1.87, 95\% CI: 1.15-3.02) (Table 2.12). 
Table 2.11. Estimated ORs (95\% CIs) of endometriosis by concentrations of PCBs among women 20-54 years of age, NHANES 1999-2004.

\begin{tabular}{|c|c|c|c|c|c|}
\hline Percentiles $^{1}$ & $\begin{array}{c}\text { No. } \\
\text { Cases }\end{array}$ & $\begin{array}{c}\text { No. } \\
\text { Noncases }\end{array}$ & $\begin{array}{c}\text { Unadjusted OR } \\
(95 \% \mathrm{CI})\end{array}$ & $\begin{array}{c}\text { Adjusted OR }{ }^{2} \\
(95 \% \mathrm{CI})\end{array}$ & $\begin{array}{c}\text { Adjusted OR }{ }^{3, \mathrm{a}} \\
(95 \% \mathrm{CI})\end{array}$ \\
\hline \multicolumn{6}{|l|}{ РCВ 074} \\
\hline$<33^{\text {rd }}$ & 28 & 576 & 1.00 & 1.00 & 1.00 \\
\hline $33^{\text {rd }}$ to $66^{\text {th }}$ & 38 & 345 & $2.32(1.27-4.24)^{\mathrm{b}}$ & $1.64(0.85-3.18)$ & $1.80(0.90-3.57)$ \\
\hline$\geq 66^{\text {th }}$ & 14 & 151 & $1.75(0.73-4.23)$ & $1.04(0.45-2.38)$ & $1.00(0.46-2.16)$ \\
\hline \multicolumn{6}{|l|}{ PCB 099} \\
\hline$<33^{\text {rd }}$ & 36 & 494 & 1.00 & 1.00 & 1.00 \\
\hline $33^{\text {rd }}$ to $66^{\text {th }}$ & 23 & 372 & $0.72(0.36-1.44)$ & $0.64(0.31-1.32)$ & $0.74(0.36-1.50)$ \\
\hline$\geq 66^{\text {th }}$ & 21 & 208 & $1.12(0.66-1.89)$ & $0.79(0.44-1.40)$ & $0.83(0.42-1.63)$ \\
\hline \multicolumn{6}{|l|}{ РСВ 118} \\
\hline$<33^{\text {rd }}$ & 33 & 544 & 1.00 & 1.00 & 1.00 \\
\hline $33^{\text {rd }}$ to $66^{\text {th }}$ & 29 & 348 & $1.22(0.63-2.37)$ & $0.94(0.46-1.95)$ & $0.96(0.44-2.09)$ \\
\hline$\geq 66^{\text {th }}$ & 18 & 180 & $1.75(0.82-3.74)$ & $1.19(0.55-2.59)$ & $1.09(0.47-2.51)$ \\
\hline \multicolumn{6}{|l|}{ PCB 138} \\
\hline$<33^{\text {rd }}$ & 32 & 562 & 1.00 & 1.00 & 1.00 \\
\hline $33^{\text {rd }}$ to $66^{\text {th }}$ & 27 & 333 & $1.39(0.65-2.98)$ & $0.98(0.43-2.25)$ & $1.13(0.49-2.58)$ \\
\hline$\geq 66^{\text {th }}$ & 21 & 179 & $1.97(0.95-4.11)$ & $1.25(0.58-2.70)$ & $1.33(0.56-3.16)$ \\
\hline \multicolumn{6}{|l|}{ PCB 153} \\
\hline$<33^{\text {rd }}$ & 30 & 576 & 1.00 & 1.00 & 1.00 \\
\hline $33^{\text {rd }}$ to $66^{\text {th }}$ & 29 & 326 & $1.52(0.90-2.57)$ & $1.04(0.55-1.98)$ & $1.25(0.63-2.45)$ \\
\hline$\geq 66^{\text {th }}$ & 21 & 172 & $2.02(0.91-4.47)$ & $1.18(0.50-2.78)$ & $1.43(0.54-3.83)$ \\
\hline \multicolumn{6}{|l|}{ PCB 180} \\
\hline$<33^{\text {rd }}$ & 27 & 615 & 1.00 & 1.00 & 1.00 \\
\hline $33^{\text {rd }}$ to $66^{\text {th }}$ & 33 & 308 & $2.38(1.38-4.09)^{\mathrm{b}}$ & $1.59(0.83-3.04)$ & $1.69(0.78-3.65)$ \\
\hline$\geq 66^{\text {th }}$ & 19 & 149 & $3.44(1.46-8.11)^{b}$ & $2.20(0.82-5.96)$ & $2.70(0.93-7.81)$ \\
\hline
\end{tabular}

${ }^{\mathrm{C}}$ Lipid adjusted and log transformed polychlorinated biphenyls (ng/g).

${ }^{2}$ Adjusted for age, race/ethnicity.

${ }^{3}$ Adjusted for age, race/ethnicity, BMI, parity, age at menarche, oral contraceptive use, smoking, alcohol.

${ }^{a}$ Cases/Noncases: 79/1034 in PCB 074; 79/1037 in PCB 099, 79/1035 in PCB 118 and 153;

79/1036 in PCB 138; 78/1034 in PCB 180.

Significance: ${ }^{\mathrm{a}} \mathrm{p}<0.0001,{ }^{\mathrm{b}} \mathrm{p}<0.05$. 
Table 2.12. Estimated ORs $(95 \%$ CIs) of uterine leiomyomas by concentrations of PCBs among women 2054 years of age, NHANES 1999-2004.

\begin{tabular}{|c|c|c|c|c|c|}
\hline Percentiles $^{1}$ & $\begin{array}{r}\text { No. } \\
\text { Cases }\end{array}$ & $\begin{array}{c}\text { No. } \\
\text { Noncases }\end{array}$ & $\begin{array}{c}\text { Unadjusted OR } \\
(95 \% \mathrm{CI})\end{array}$ & $\begin{array}{c}\text { Adjusted OR }{ }^{2} \\
(95 \% \text { CI })\end{array}$ & $\begin{array}{l}\text { Adjusted OR } \mathrm{OR}^{3, \mathrm{a}} \\
(95 \% \mathrm{CI})\end{array}$ \\
\hline \multicolumn{6}{|l|}{$\overline{\text { PCB } 074}$} \\
\hline$<33^{\text {rd }}$ & 39 & 565 & 1.00 & 1.00 & 1.00 \\
\hline $33^{\text {rd }}$ to $66^{\text {th }}$ & 64 & 319 & $2.24(1.36-3.70)^{\mathrm{b}}$ & $1.29(0.72-2.34)$ & $1.30(0.72-2.35)$ \\
\hline$\geq 66^{\text {th }}$ & 45 & 120 & $4.39(2.42-7.97)^{\mathrm{a}}$ & $1.68(0.84-3.34)$ & $1.56(0.81-3.02)$ \\
\hline \multicolumn{6}{|l|}{ PCB 099} \\
\hline$<33^{\text {rd }}$ & 41 & 489 & 1.00 & 1.00 & 1.00 \\
\hline $33^{\text {rd }}$ to $66^{\text {th }}$ & 55 & 340 & $1.32(0.75-2.30)$ & $1.04(0.56-1.91)$ & $1.06(0.58-1.95)$ \\
\hline$\geq 66^{\text {th }}$ & 53 & 176 & $2.25(1.32-3.86)^{b}$ & $1.00(0.57-1.76)$ & $1.04(0.61-1.78)$ \\
\hline \multicolumn{6}{|l|}{ РCB 118} \\
\hline$<33^{\text {rd }}$ & 34 & 543 & 1.00 & 1.00 & 1.00 \\
\hline $33^{\text {rd }}$ to $66^{\text {th }}$ & 64 & 313 & $1.54(1.43-4.53)^{b}$ & $1.61(0.88-2.95)$ & $1.62(0.90-2.91)$ \\
\hline$\geq 66^{\text {th }}$ & 50 & 148 & $4.11(2.34-7.08)^{\mathrm{a}}$ & $1.66(0.91-3.05)$ & $1.57(0.88-2.79)$ \\
\hline \multicolumn{6}{|l|}{ РCB 138} \\
\hline$<33^{\text {rd }}$ & 35 & 559 & 1.00 & 1.00 & 1.00 \\
\hline $33^{\text {rd }}$ to $66^{\text {th }}$ & 62 & 298 & $2.16(1.23-3.77)^{\mathrm{b}}$ & $1.14(0.60-2.16)$ & $1.28(0.67-2.46)$ \\
\hline$\geq 66^{\text {th }}$ & 52 & 148 & $4.12(2.42-7.03)^{\mathrm{a}}$ & $1.39(0.75-2.59)$ & $1.61(0.89-2.88)$ \\
\hline \multicolumn{6}{|l|}{ PCB 153} \\
\hline$<33^{\mathrm{rd}}$ & 34 & 572 & 1.00 & 1.00 & 1.00 \\
\hline $33^{\text {rd }}$ to $66^{\text {th }}$ & 64 & 291 & $2.69(1.64-4.42)$ & $1.41(0.79-2.52)$ & $1.61(0.89-2.89)$ \\
\hline$\geq 66^{\text {th }}$ & 51 & 141 & $4.65(2.61-8.29)$ & $1.54(0.77-3.09)$ & $1.71(0.86-3.39)$ \\
\hline \multicolumn{6}{|l|}{ PCB 180} \\
\hline$<33^{\text {rd }}$ & 35 & 607 & 1.00 & 1.00 & 1.00 \\
\hline $33^{\text {rd }}$ to $66^{\text {th }}$ & 71 & 270 & $3.80(2.56-5.64)^{\mathrm{a}}$ & $1.64(1.07-2.51)^{\mathrm{b}}$ & $1.87(1.15-3.02)^{b}$ \\
\hline$\geq 66^{\text {th }}$ & 42 & 126 & $5.47(3.38-8.86)^{\mathrm{a}}$ & $1.60(0.87-2.97)$ & $1.70(0.84-3.45)$ \\
\hline
\end{tabular}

${ }^{1}$ Lipid adjusted and log transformed polychlorinated biphenyls (ng/g).

${ }^{2}$ Adjusted for age, race/ethnicity.

${ }^{3}$ Adjusted for age, race/ethnicity, BMI, parity, age at menarche, oral contraceptive use, smoking, alcohol.

${ }^{\text {a }}$ Cases/Noncases: 145/968 in PCB 074; 146/968 in PCB 118 and 153; 146/969 in PCB 118,

146/970 in PCB 099; 145/967 in PCB 180.

Significance: ${ }^{\mathrm{a}} \mathrm{p}<0.0001,{ }^{\mathrm{b}} \mathrm{p}<0.05$.

Estimated ORs and 95\% CIs of endometriosis and uterine leiomyomas by dioxin-

like and non-dioxin-like PCBs are shown in table 2.13. In the unadjusted models, non-

dioxin-like PCBs were significantly associated with endometriosis (OR of $1.11,95 \% \mathrm{CI}$ :

1.02-1.21). Dioxin and non-dioxin-like PCBs did not remain significantly associated

with endometriosis in the adjusted models (Table 2.13). In all of the unadjusted models, 
dioxin-like and non-dioxin-like PCBs were significantly associated with uterine leiomyomas, however, none of the models remained significant after adjusting for age, race/ethnicity, BMI, parity, age at menarche, oral contraceptive use, smoking status, and alcohol consumption (Table 2.13).

Table 2.13. Estimated ORs (95\% CIs) of endometriosis and uterine leiomyomas by concentration of lipid adjusted dioxin-like and non-dioxin-like PCBs in women 20 to 54 years of age, NHANES 1999-2004.

\begin{tabular}{|c|c|c|c|c|}
\hline & $\begin{array}{c}\text { Cases/ } \\
\text { Noncases }\end{array}$ & $\begin{array}{c}\text { Unadjusted OR } \\
(95 \% \mathrm{CI})\end{array}$ & $\begin{array}{l}\text { Adjusted OR }{ }^{1} \\
(95 \% \text { CI) }\end{array}$ & $\begin{array}{l}\text { Adjusted } \mathrm{OR}^{2} \\
\quad(95 \% \mathrm{CI})\end{array}$ \\
\hline \multicolumn{5}{|l|}{ Endometriosis } \\
\hline Dioxin-like PCBs ${ }^{4}$ & $80 / 1071$ & $1.18(0.96-1.41)$ & $1.03(0.84-1.27)$ & $0.97(0.76-1.23)^{+}$ \\
\hline \multicolumn{5}{|l|}{ Dioxin-like PCBs ${ }^{4,7}$} \\
\hline$<33^{\text {rd }}$ & $29 / 566$ & 1.00 & 1.00 & 1.00 \\
\hline $33^{\text {rd }}$ to $66^{\text {th }}$ & $27 / 260$ & $1.75(0.82-3.73)$ & $1.35(0.62-3.04)$ & $1.48(0.62-3.51)$ \\
\hline$\geq 66^{\text {th }}$ & $24 / 254$ & $1.89(0.88-4.07)$ & $1.20(0.54-2.68)$ & $1.04(0.46-2.38)$ \\
\hline Non- Dioxin-like PCBs ${ }^{5}$ & $79 / 1067$ & $1.11(1.02-1.21)^{\mathrm{b}}$ & $1.04(0.93-1.16)$ & $1.04(0.91-1.18)^{*}$ \\
\hline \multicolumn{5}{|l|}{ Non-Dioxin-like PCBs ${ }^{4,7}$} \\
\hline$<33^{\text {rd }}$ & $30 / 575$ & 1.00 & 1.00 & 1.00 \\
\hline $33^{\text {rd }}$ to $66^{\text {th }}$ & $28 / 317$ & $1.37(0.77-2.44)$ & $0.92(0.47-1.77)$ & $1.08(0.50-2.34)$ \\
\hline$\geq 66^{\text {th }}$ & $27 / 175$ & $2.01(0.98-4.14)$ & $1.22(0.53-2.79)$ & $1.23(0.46-3.30)$ \\
\hline \multicolumn{5}{|l|}{ Uterine Leiomyomas } \\
\hline Dioxin-like PCBs ${ }^{4}$ & $80 / 1071$ & $1.47(1.27-1.71)^{\mathrm{a}}$ & $1.12(0.94-1.33)$ & $1.11(0.94-1.30)^{++}$ \\
\hline \multicolumn{5}{|l|}{ Dioxin-like PCBs ${ }^{4,7}$} \\
\hline$<33^{\text {rd }}$ & $35 / 550$ & 1.00 & 1.00 & 1.00 \\
\hline $33^{\text {rd }}$ to $66^{\text {th }}$ & $71 / 270$ & $1.99(1.14-3.49)^{\mathrm{b}}$ & $1.22(0.65-2.28)$ & $1.24(0.65-2.39)$ \\
\hline$\geq 66^{\text {th }}$ & $42 / 126$ & $3.81(2.22-6.54)^{\mathrm{a}}$ & $1.59(0.84-3.02)$ & $1.56(0.87-2.80)$ \\
\hline Non- Dioxin-like PCBs ${ }^{5}$ & $79 / 1067$ & $1.23(1.15-1.31)^{\mathrm{a}}$ & $1.05(0.96-1.14)$ & $1.06(0.97-1.15)^{* *}$ \\
\hline \multicolumn{5}{|l|}{ Non-Dioxin-like PCBs ${ }^{4,7}$} \\
\hline$<33^{\text {rd }}$ & $36 / 569$ & 1.00 & 1.00 & 1.00 \\
\hline $33^{\text {rd }}$ to $66^{\text {th }}$ & $63 / 282$ & $2.45(1.55-3.85)^{\mathrm{b}}$ & $1.20(0.70-2.05)$ & $1.39(0.78-2.45)$ \\
\hline$\geq 66^{\text {th }}$ & $49 / 147$ & $3.62(2.05-6.39)^{\mathrm{a}}$ & $1.08(0.70-2.05)$ & $1.23(0.63-2.38)$ \\
\hline \multicolumn{5}{|c|}{$\begin{array}{l}{ }^{2} \text { Adjusted for age and race/ethnicity. } \\
{ }^{2} \text { Adjusted for age, race/ethnicity, BMI, parity, age at menarche, oral contraceptive use, smoking, alcohol. } \\
\text { ADioxin-like PCBs: Sum of lipid adjusted and log transformed PCB Congeners }(074+118) \text {. } \\
{ }^{+} \text {Cases/noncases: } 77 / 962 ;{ }^{++} \text {Cases/noncases: } 143 / 896 . \\
{ }^{5} \text { Non-Dioxin-like PCBs: Sum of lipid adjusted and log transformed PCB Congeners }(099+138+153+180) \text {. } \\
{ }^{*} \text { Cases/noncases: } 76 / 957 ;{ }^{* *} \text { Cases/noncases: } 143 / 890 . \\
\text { Significance: }{ }^{\mathrm{a} p}<0.0001,{ }^{\mathrm{b}}<<0.05 \text {. }\end{array}$} \\
\hline
\end{tabular}




\section{DISCUSSION}

Evidence supporting the role of PCBs in endometriosis and uterine leiomyoma is conflicting and inconclusive. Experimental animal studies have linked PCB exposure to prolonged estrus and decreased sexual receptivity in rats, decreased sperm fertilizing ability in mice (Fielden et al. 2001), decreased conception in mice, changes in the uterine myometrium and gland formation in mice (Ma and Sassoon 2006), prolonged menstruation, decreased birth weights, and decreased conception rates in rhesus monkeys (ASTDR 2000), and a significant dose-dependent relationship in the prevalence and severity of endometriosis in rhesus monkeys (Rier et al. 2001). Although these animal studies have shown the have potential endocrine disrupting activities of PCBs, the data on their endocrine disrupting effects in humans is inconsistent (Buck Louis et al. 2005, Porpora et al. 2009, Heiler et al. 2005, Trabert et al. 2010, Pauwels et al. 2001). In this cross-sectional study of U.S. women, we evaluated the concentrations of 6 PCB congeners, dioxin-like PCBs, and non-dioxin-like PCBs and explored the association between PCB exposure and diagnosis of endometriosis and uterine leiomyomas.

Analysis of dioxin-like PCBs and non-dioxin-like PCBs by endometriosis and uterine leiomyoma status and age and race/ethnicity was done to assess PCB concentrations in subpopulations. Dioxin-like and non-dioxin-like PCBs showed an increasing trend with age. These results are supported by previously reported associations of PCB body burdens and age in women (Axelrad et al. 2009, Thompson et al. 2013). While this may be a result of lower levels of PCBs in the environment today, it may also be due to the persistent nature of PCBs and increased accumulations in the human body over time. Although not significant, women diagnosed with uterine leiomyomas had the 
highest dioxin-like PCB levels in the 30-39, 40-49 and 50-54 year old age groups. NonHispanic black women had significantly higher mean PCB levels compared to nonHispanic white women and women classified as 'Other'. This finding is consistent with higher PCB and DDE levels that have been previously reported among African-American women compared with non-Hispanic white women by Millikan et al. (2013) and Zheng et al. (1999), respectively. While these results do not provide any evidence of causal associations, it is noteworthy that women diagnosed with uterine leiomyomas have higher levels of dioxin-like and non-dioxin-like PCBs and all six PCB congeners compared to women who reported never being diagnosed with uterine leiomyomas.

Our results show that women diagnosed with endometriosis have slightly higher body burdens of PCB congeners 138, 153, and 180 compared to women never diagnosed with endometriosis. Our findings of the association between endometriosis and higher body burdens of PCB congeners 138, 153, 180, and the sum of non-dioxin-like PCBs are consistent with a two previously reported case-control studies by Porpora et al. (2006 and 2009). Porpora et al. (2006) reported higher levels of total PCBs in endometriosis cases vs. controls (410 ng/g vs. $250 \mathrm{ng} / \mathrm{g}$ ), as well as an increased risk in involving both dioxin-like $(105,118,156,167)$ and non-dioxin-like $(101,138,153,170,180)$ congeners, after adjusting for age and smoking. Porpora et al. (2009) found the GM of total PCBs to be significantly higher in cases than controls (301.3 vs. 203.0, p < 0.01). In contrast, Niskar et al. (2009) did not find mean lipid-adjusted PCB concentrations to be significantly different (179.98 vs. 217.33 vs. 194.76 vs. 193.37) between stage I-II cases, stage III cases, stage IV cases, and controls, respectively. Pauwels et al. (2001) found no association between endometriosis and the median TEQ values (pg TEQ/g lipid) in cases 
and controls (29 vs. 27) and Tsukino et al.(2005) found no difference in median TEQ values for endometriosis cases (stage II-IV) and controls (stage $0-\mathrm{I}$ ) (cPCBs: 3.40 vs. 3.59, PCBs: 4.61 vs. 5.14), respectively.

Risk of endometriosis was only present for PCB 74 and non-dioxin-like PCBs in unadjusted logistic regression models and did not remain in any of the adjusted models. These findings are consistent with Trabert et al. (2005), who reported no association between adjusted total and estrogenic PCBs in the highest quartiles and an increased risk of endometriosis (Total PCBs: OR=1.2, 95\% CI: 0.6-2.3, Estrogenic PCBs: $\mathrm{OR}=0.9$, 95\% CI: 0.5-1.4) after adjusting for age, lipids, income, alcohol consumption, and DDE exposure. Our findings do not agree with Buck Louis et al. (2005) who reported a significant increased risk of endometriosis for the sum of anti-estrogenic PCBs for women in the third tertile ( $\mathrm{OR}=3.77,95 \% \mathrm{CI}: 1.12-12.68)$, however, the risk remained elevated but not significant when adjusted for all listed covariates and Porpora et al. (2009) who reported the OR of endometriosis risk in the highest tertile of total PCBs compared with the lowest tertile to be 5.63 (95\% CI: 2.25-14.10).

We observed significantly higher body burdens of PCBs in women diagnosed with uterine leiomyomas and an increased risk of uterine leiomyomas in association with PCB 180 after adjusting for age, race/ethnicity, BMI, parity, age at menarche, oral contraceptive use, smoking status, and alcohol consumption. Epidemiological studies demonstrating the association between PCBs and uterine leiomyomas are lacking. Our findings are difficult to compare due to differences in the study population and methods. Findings from Lambertino et al. (2011) reported that uterine leiomyomas were significantly associated with exposure to dioxin-like- PCBs in women who never 
breastfed (OR=8.6, 95\% CI: 2.0-36.6) but not in women who breastfed (OR=0.80, 95\%

CI: .023-2.8). Qin et al. (2009) et al. found significantly higher concentrations of PCB $123(17.8 \mathrm{ng} / \mathrm{g}$ vs. $11.7 \mathrm{ng} / \mathrm{g}, \mathrm{p}<0.01), 126$ (21.0 ng/g vs. $10.4 \mathrm{ng} / \mathrm{g}, \mathrm{p}<0.01)$, and 180 (13.9 ng/g vs. $6.99 \mathrm{ng} / \mathrm{g}, \mathrm{p}<0.05)$ in the subcutaneous fat of patients compared to controls. While these results are consistent with our findings for PCB 180, they are difficult to compare because they assessed PCB concentrations in adipose tissue as opposed to serum blood.

There are a number of limitations to our study, the most important of which is its cross-sectional design with self-reported data. Self-reported data increases the risk of misclassification bias of cases and controls. It is possible that false reports or undiagnosed endometriosis or uterine leiomyoma cases may have occurred. Furthermore, observed associations could be potentially confounded by lack of information on geographical location of primary residence and family history of some of the variables. Strengths of this cross-sectional study design include the large sample survey size, availability of biological measurements of environmental contaminants, and oversampling of minority populations that make it highly representative and generalizable to the U.S. population.

\section{CONCLUSION}

Based on our analysis of serum blood lipid PCB levels in the 1999-2004 NHANES data cycles, biological levels of PCBs may contribute to reproductive dysfunction among U.S. women. Given the proven contribution of unopposed estrogens to the risk for endometriosis or endometrial neoplasia, it is biologically plausible that an altered endogenous estrogen levels presumably from exposure to estrogen mimicking 
EDCs may contribute to the risk of these diseases. In conclusion, we have identified preliminary evidence suggesting that exposure to PCBs may be associated with uterine leiomyomas. Thus, further research with an epidemiologic approach is warranted to investigate reproductive health outcomes in relation to PCB exposure among women in the general population. 


\section{REFERENCES}

1. Borah BJ, Nicholson WK, Bradley L, Steward EA. 2013. The impact of uterine leiomyomas: a national survey of affected women. Am J Obstet Gynecol 209: 319-322.

2. Parker WH. 2007. Etiology, symptomatology, and diagnosis of uterine myomas. Fertil Steril 87(4):725-36.

3. Buttram Jr VC, Reiter RC. 1981. Uterine leiomyomata: etiology, symptomoatology, and manangement. Fertil Steril 36:433-445.

4. Baird DD, Dunson DB, Hill MC, Cousins D, Schectman JM. 2003. High cumulative incidence of uterine leiomyoma black and white women: ultrasound evidence. Am J ObstetGenecol 188: 100-107.

5. Eskenazi B, Warner ML. 1997. Epidemiology of endometriosis. Obstet Gynecol Clin North Am 24:235-258.

6. Diamanti-Kandarakis E, Bourguignon JP, Giudice LC, Hauser R, Prins GS. et al. 2009. Endocrine-disrupting chemicals: an Endocrine Society scientific statement. Endocr Rev 30: 293-342.

7. Farquhar CM, Steiner CA. 2002. Hysterectomy rates in the United States 19901997. Obstet Gynecol 99(2):229-234.

8. Evans JM. 2008. An Integrative Approach to Fibroids, Endometriosis, and Breast Cancer Prevention. Integrative Medicine 7: 28-31.

9. Lin BC, Suzawa M, Blind RD, Tobias SC, Bulun SE, ScanlanTS, Ingraham HA. 2009. Stimulating the GPR30 Estrogen Receptor with a Novel Tamoxifen Analogue Activates SF-1 and Promotes Endometrial Cell Proliferation. Cancer Res 69:5415-5423.

10. Bertelsen L, Mellemkjaer L, Frederiksen K, Kjaer SK, Brinton LA, Sakoda LC, van Valkengoed I, Olsen JH. 2007. Risk for breast cancer among women with endometriosis. Int J Cancer 15:1372-1375.

11. Hodges LC, Hunter DS, Bergerson JL, Fuchs-Young R, Walker CL. 2006. An In vivo/in vitro Model to Assess Endocrine Disrupting Activity of Xenoestrogens in Uterine Leiomyoma. Annals of the New York Academy of Sciences, 948:100111.

12. UNEP/ WHO Expert Advisory Group. 2013. State of the Science of Endcorine Disrupting Chemicals - 2012. Eds: Åke Bergman, Jerrold J. Heindel, Susan Jobling,Karen A. Kidd and R. Thomas Zoeller, WHO Press. 
13. EU Commission Expert Advisory Group. 2013. Key scientific issues relevant to the identification and characterisation of endocrine disrupting substances. JRC Scientific and Policy Reports.

14. Roy D, Palangat M, Chen CW, Thomas RD, Colerangle J, Atkinson A, Yan ZJ. 1997. Biochemical and molecular changes at the cellular level in response to exposure to environmental estrogen-like chemicals. J Tox Env Hlth 50:1-29.

15. RoyD, Colerangle J, Singh KP. 1998. Is exposure of environmental or industrial endocrine disrupting estrogen-like chemicals able to cause genomic instability? Front Biosci 3: d913-921.

16. Calafat AM, Xiaoyun X, Wong LY, Reidy JA, Needham LL. 2008. Exposure of the U.S. Population to Bisphenol A and 4-tertiary-Octylphenol: 2003-2204. Env Health Perspect 116: 39-44.

17. Woodruff TJ, Zota AR, Schwartz JM. 2011. Environmental chemicals in pregnant women in the US: NHANES 2003-2004. Env Health Perspect 119:878-885.

18. Silva MJ, Barr DB, Reidy JA, Malek NA, Hodge CC, Caudill AP, Brock JW, Needham LL, Calafat AM. 2004. Urinary levels of seven phthalate metabolites in the U.S. population from the National Health and Nutrition Examination Survey (NHANES) 1999-2000. Env Health Perspect 112:331-338.

19. Fielden MR, Halgren RG, Tashiro C, Yeo BR, Chittim B, Chou K, Zacharewski TR. 2001. Effects of gestational and lactational exposure to Aroclor 1242 on sperm quality and in vitro fertility in early adult and middle-aged mice. Reprod Toxicol 15:281-92.

20. Ma R, Sassoon D. 2006. PCBs Exert and Estrogenic Effect through Repression of the Wnt7a Signaling Pathway in the Female Reproductive Tract. Environ Health Perspect 114: 898-904.

21. McLachlan JA, Simpson E, Martin M. 2006. Endocrine disrupters and female reproductive health. Best Pract Res Clin Endocrinol Metab 20(1):63-75.

22. Rier SE, Turner WE, Martin DC, Morris R, Lucier GW, Clark GC. 2001. Serum levels of TCDD and dioxin-like chemicals in rhesus monkeys chronically exposed to dioxin: correlation of increased serum PCB levels with endometriosis. Toxicol Sci 59:147-159.

23. Buck Louis GM, Weiner JM, Whitcomb BW, Sperrazza R, Schisterman EF, Lobdell DT, Crickard K, Greizerstein H, Kostyniak PJ. 2005. Environmental PCB exposure and risk of endometriosis. Human Reprod 20: 279-285. 
24. Porpora MG, MeddaE, Abballe A, Bolli S, De Angelis I, di Domenico A, Ferro A, Ingelido AM, Maggi A, Panici PB, De Felip E. 2009. Endometriosis and organochlorinated environmental pollutants: A case-control study on Italian women of reproductive age. Env Health Perspect 117:1070-1075.

25. Heiler JF, Nackers F, Verougstraete V, Tonglet R, Lison D, Donnez J. 2005. Increased dioxin-like compounds in the serum of women with peritoneal endometriosis and deep endometriotic (adenomyotic) nodules. Fertil Steril 84: 305-312.

26. Niskar AS, Needham LL, Rubin C, Turner WE, Martin CA, Patterson DG, Hasty L, Wong LY, Marcus M. 2009. Serum dioxins, polychlorinated biphenyls, and endometriosis: A case-control study in Atlanta. Chemosphere 74:944-949.

27. Pauwels A, Schepens PJ, Hooghe TD, Delbeke I, Dhont M, Brouwer A, Weyler J. 2001. The risk of endometriosis and exposure to dioxins and polychlorinated biphenyls: a case-control study of infertile women. Human Reprod 16: 20502055.

28. Trabert B, De Roos AJ, Schwartz SM, Peters U, Scholes D, Barr DB, Holt VL. 2010. Non-dioxin-like polychlorinated biphenyls and risk of endometriosis. Env Health Perspect 118:1280-1285.

29. Tsukino H, Hanaoka T, Sasaki H, Motoyama H, Hiroshima M, Tanaka T, Kabuto M, Niskar AS, Rubin C, Patterson Jr, DG, Turner W, Needham L, Tsugane S. 2005. Associations between serum levels of selected organochlorine compunds and endometriosis in infertile Japanese women. Environ Res 99:118-125.

30. Trabert B, Chen Z, Kannan K, Peterson CM, Pollack AZ, et al. 2014. Persistent organic pollutants (POPs) and fibroids: results from the ENDO study. Journal of Exposure Science and Environmental Epidemiology

31. CDC (Centers for Disease Control and Prevention). 2012. National Health and Nutrition Examination Survey Questionnaires, Datasets, and Related Documentation. Available: http://www.cdc.gov/nchs/nhanes/nhanes questionnaires.htm [last accessed June 11 2014].

32. CDC (Centers for Disease Control and Prevention). 2013b. National Health and Nutrition Examination Survey: Analytic Guidelines, 1999-2010. Vital Health Stat 2(161). Available: http://www.cdc.gov/nchs/data/series/sr 02/sr02 161.pdf [last accessed June 11 2014].

33. CDC (Centers for Disease Control and Prevention). 2013. Fourth National Report on Human Exposure to Environmental Chemicals. Available: 
http://www.cdc.gov/exposurereport/pdf/FourthReport UpdatedTables_Sep2013.p df [last accessed June 6 2014].

34. CDC (Centers for Disease Control and Prevention). 2014. National Health and Nutrition Examination Survey. Age Standardization and Population Counts. Available: http://www.cdc.gov/nchs/tutorials/NHANES/NHANESAnalyses/agestandardizati on/age_standardization_intro.htm [last accessed June 16 2014].

35. Agency for Toxic Substances and Disease Registry. 2000. Toxicological Profile for Polychlorinated Biphenyls (PCBs). Atlanta, GA.

36. Millikan R, DeVoto E, Duell EJ, Tse CK, Savitz DA, Beach J, Edmiston S, Jackson S, Newman B. 2013. Dichlorodiphenyldichloroethane, polychlorinated biphenyls, and breast cancer among African-American and white women in North Carolina. Cancer Epidemiol Biomark Prev 9:1233-1240.

37. Recio-Vega R, Velazco-Rodriguez V, Ocampo-Gomez G, Hernandez-Gonzalez S, Ruiz-Flores P, Lopez-Marquez F. 2001. Serum levels of polychlorinated biphenyls in Mexican women and breast cancer risk. J Appl Toxicol 31:270-278.

38. Zheng T, Holford T, Mayne S, Ward B, Carter D, Owens P, Dubrow R, Zahm S, Boyle P, Archibeque S, Tessari J. 1999. DDE and DDT in breast adipose tissue and risk of female breast cancer. Am. J. Epidemiol., 150: 453-458.

39. Axelrad DA, Goodman S, Woodruff T. 2009. PCB body burden in U.S. women of childbearing age 2001-2002; an evaluation of alternate summary metrics of NHANES data. Environ. Res. 109, 368-378.

40. Thompson MR, Boekelheide K. 2013. Multiple environmental chemical exposures to lead, mercury, polychlorinated biphenyls among childbearing-age women. (NHANES 1999-2004): Body burden and risk factors. Environ Res. 121 (23-30).

41. Lambertino A, Turyk M, Anderson H, Freels S, Persky V. 2011. Uterine Leiomyomata in a Cohort of Great Lakes Sport Fish Consumers. Environ Res . 111 (4): 565-572.

42. Qin YY, Leung CKM, Leung AOW, Wu SC, Zheng JS, Wong MH. 2010. Persistent organic pollutants and heavy metals in adipose tissues of patients with uterine leiomyomas and the association of these pollutants with seafood diet, BMI, and age. Environ Sci Pollut Res. 17:229-240. 


\title{
CHAPTER VI
}

MANUSCRIPT 3

\section{ENDOCRINE DISRUPTING COMPOUNDS AND REPRODUCTIVE CANCERS}

\section{AMONG U.S. WOMEN: NHANES 1999-2010}

\begin{abstract}
Background. A number of chemicals are suspected to act as endocrine disruptors (EDs) by mimicking natural or synthetic estrogen resulting in an increased risk of hormonal cancer in women. Polychlorinated biphenyls (PCBs), phthalates and bisphenol A (BPA) have been recognized as endocrine disrupters due to their ability to interfere with reproductive function and development in animals and humans by either increasing estrogen activity or blocking estrogens from acting.
\end{abstract}

Objectives: The purpose of this study was to explore the cross-sectional relationship between exposure to PCBs, phthalates, and BPA and reproductive cancers (breast, cervical, ovarian, and uterine) among U.S. women.

Methods: We analyzed data from female participants (20 years of age and older) who provided blood and urine samples for the Centers for Disease Control and Prevention's National Health and Nutrition Examination Survey (NHANES) between 1999 and 2010. Exposure was based on lipid adjusted serum levels of 6 individual PCB congeners (74, $99,118,138,153$, and 180$)$, the sum of dioxin-like PCBs $(074+118)$, the sum of nondioxin-like PCBs $(099+138+153+187), 8$ urinary phthalate metabolites (MNP, MEP, MEHP, MBzP, MCPP, MEHHP, MEOHP, and MIB), the sum of DEHP metabolites $(\mathrm{MHP}+\mathrm{MHH}+\mathrm{MOH})$, the sum of total phthalates, and urinary BPA in conjunction with data obtained from the medical and reproductive health questionnaires. We 
calculated geometric means to compare EDCs concentrations in women who selfreported a breast, cervical, ovarian, or uterine cancer diagnosis vs. women who selfreported never being diagnosed with cancer. We used logistic regression models to estimate odds ratios (ORs) and 95\% confidence intervals (CIs) for the association between exposure to EDCs and reproductive cancers. We evaluated age, race/ethnicity, body mass index (BMI; $\mathrm{kg} / \mathrm{m}^{2}$ ), and age at menarche as potential confounding variables in our final models.

Results: Separate analyses showed weighted geometric mean levels of individual PCB congeners to be significantly higher among women with breast cancer, ovarian cancer, and uterine cancer when compared to the rest of the study population. Mono-(2-ethyl-5hydroxyhexyl) phthalate (MEHHP) was found to be significantly higher among women with ovarian cancer compared to women never diagnosed with cancer and BPA was significantly higher in women never diagnosed with cancer compared to women diagnosed with breast cancer. After adjusting for age, race, BMI, and age at menarche we found PCB 138 to be significantly associated with breast cancer, cervical cancer, and uterine cancer [odds ratios of 2.52.; 95\% confidence interval (CI): 1.06-5.99; 3.05, 95\% CI: 1.21-7.69; and 5.83, 95\% CI: 1.63-20.9], respectively, and PCB 74 and 118 to be significantly associated with ovarian cancer [odds ratios of $6.47,95 \%$ CI: $1.23-3.41$ and 6.68, 95\% CI: 1.39-32.3), respectively. We also found the sum of non-dioxin-like PCBs to be significantly associated with ovarian cancer (OR of 1.12, 95\% CI: 1.03-1.23) and the sum of dioxin-like PCBs to be significantly associated with ovarian cancer (OR of 2.02, 95\% CI: 1.06-3.85). We found null associations between urinary phthalates and BPA and reproductive cancers. 
Conclusions: Our results suggest a link between environmental exposures to PCBs and an increased risk of reproductive cancers (breast, cervix, ovarian and uterine) among U.S. women.

Keywords: NHANES, PCBs, phthalates, BPA, EDC, reproductive cancers. 


\section{MANUSCRIPT 3}

\section{ENDOCRINE DISRUPTING COMPOUNDS AND REPRODUCTIVE CANCERS \\ AMONG U.S. WOMEN: NHANES 1999-2010 \\ INTRODUCTION}

Human populations are continually exposed to a wide variety of environmental estrogen-like chemicals. A recent report by the United Nations Environment Programme (UNEP) and WHO highlighted the increasing rates of endocrine-related cancers over the past 40-50 years in conjunction with approximately 800 chemicals that are suspected to act as endocrine disruptors (EDs) (UNEP/WHO 2013, EU 2013). Many of these chemicals are used in a variety of consumer products; therefore exposure to EDCs among the general population is widespread. Human exposure to EDCs may result from inhalation through the air, absorption through the skin, and most commonly through the ingestion of contaminated food and water (Balabanic et al. 2001). In the last decade, exposure to multiple EDCs such as polychlorinated biphenyls (PCBs), phthalates, and bisphenol A (BPA) have been detected in $>90 \%$ of blood and urine samples collected (Calafat et a. 2008, Woodruff et al. 2011, Silva et al. 2004)

Although a number of experimental animal studies have shown many chemicals have potential endocrine disrupting activities, the data on their endocrine disrupting effects in humans is limited. The role of EDC's in the etiology of some of the human cancers and reproductive health hazards has been implicated, although the linkage between these two processes is highly controversial (Burantrevedh and Roy 2001). PCBs have been shown to interfere with reproductive function and development in animals and humans by either increasing or blocking estrogen activity (Fielden et al. 2001, Ma and 
Sassoon 2006, McLachlan et al. 2006, Roy et al. 1997, Roy et al. 1998). Animal studies have linked PCB exposure to decreased sperm fertilizing ability in mice (Fielden et al. 2001), changes in the uterine myometrium and gland formation in mice (Ma and Sassoon 2006), and a significant dose-dependent relationship in the prevalence and severity of endometriosis in rhesus monkeys (Rier et al. 2001). Among various phthalates, di (2ethylhexyl) phthalate (DEHP), di-butyl phthalate (DBP) and butylbenzyl phthalate (BBP) have been studied for their endocrine disrupting effects. Phthalates have been shown to produce anti-androgenic effects by suppressing testosterone and estrogen production. Reproductive abnormalities reported in rodent females include increased uterine and ovarian weights and malformations at very high phthalate levels, delayed onset of puberty and modified morphology of the mammary gland (Moral et al. 2008). We have shown that bisphenol A (BPA) is oxidized to bisphenol-o-quinone by cytochrome P450 activation system. Administration of a single dose or multiple doses of $200 \mathrm{mg} / \mathrm{kg}$ of BPA to CD1 male rats produces in vivo DNA adducts matching the profile of dGMP-bisphenol-o-quinone. Covalent modifications in DNA by in vivo exposure of BPA are suspected to be a factor in the induction of endocrine toxicity (Atkinson and Roy 1995). In rodent females, BPA exposure has shown to cause alterations in the mammary gland development, changes in gene expression of the mammary gland, cystic ovaries, endometrial hyperplasia, adenomyosis, leiomyomas, atypical hyperplasia, stromal polyps, ductal hyperplasias and carcinoma, a decline in fertility and fecundity, decreased wet weight of the vagina, decreased volume of the endometrial lamina propria, and an increased expression of estrogen receptor- $\alpha(\mathrm{ER} \alpha)$ and progesterone receptors (Moral et al. 2008, Atkinson et al. 1995, Colerangle and Roy 1997, Munoz-de-Toro et al. 2005, 
Newbold et al. 2007, Murray et al. 2007, Signorile et al. 2010, Cabaton et al. 2011). In summary, exposure to EDCs - PCBs, BPA, or phthalates during early development of the breast, endometrium, and prostate can alter their development, possibly contributing to the susceptibility to complex chronic diseases through effects on stem cells. Through research on hormone contraception, postmenopausal hormonal therapies and estrogenreceptor (ER)-based endocrine therapies, we know estrogens are a major risk factor of both breast cancer and endometriosis (Evans 2008, Lin et al. 2009, Bertelsen et al. 2007). Given the proven contribution of unopposed estrogens to the risk for hormonal cancer, renewed health concerns have aroused about estrogen mimicking EDCs found in food, personal care products or as environmental contaminants. PCBs, BPA, and phthalates are the most extensively studied EDCs, and therefore, our objective of this study was to use the National Health and Nutrition Examination Survey (NHANES) data to assess the association of reproductive cancers (breast, cervix, ovarian, and uterine) with exposure to these three selected classes of EDCs: PCBs, BPA, and phthalates, commonly found in the environment today.

\section{METHODS}

Study design and population. NHANES is an ongoing cross-sectional survey designed to be nationally representative of the non-institutionalized U.S. civilian population.

Conducted annually since 1999 by the National Center for Health Statistics of the Centers for Disease Control and Prevention (CDC), NHANES uses a complex multi-stage sampling design where approximately 5,000 survey participants a year complete in-home interviews and physical examinations in mobile examination units (CDC, 2012). Sociodemographic information and medical histories were collected during the in-home 
interview and biological samples and reproductive health information was collected in the mobile examination component (MEC). All participants provided written informed consent and all procedures were approved by the National Center for Health Statistics (NCHS) Institutional Review Board (CDC, 2012). We merged data from the 2003-2004, 2005-2006, 2007-2008, and 2009-2010 survey years to analyze phthalate metabolites and from the 2005-2006, 2007-2008, and 2009-2010 survey years to analyze bisphenol A. During the 2003-2004 survey years, NHANES sampled urinary phenols and phthalates from two separate one-third subsets, therefore we did not include the 2003-2004 survey years in our analysis of bisphenol A. We conducted a separate analysis of PCBs with data merged from the 1999-2000, 2001-2002, and 2003-2004 survey years. We were not able to analyze PCBs from the 2005-2006 and 2007-2008 survey years because the datasets were withdrawn due to a quality control issue (CDC 2014). In each survey year, subsets are a representative one-third sample of NHANES participants. We limited our analysis to women 20 to 85 years of age who completed the reproductive and medical condition questionnaires in a face-to-face interview at a mobile examination center.

Measurement of PCBs. Blood serum concentrations of individual PCB congeners were measured in a representative, random one-third subsample of people 12 years of age and older in the 1999-2000, 2001-2002, and 2003-2004 survey cycles. PCB congeners were measured in serum by high-resolution gas chromatography/isotope-dilution highresolution mass spectrometry (HRGS/ID-HRMS). NHANES provides both wet-weight and lipid adjusted values for each sample, corrected for sample weight and analyte recovery; we used lipid adjusted values in our analyses. Detailed laboratory methods were consistent among survey cycles and are available online (CDC, 2013b). Lipid- 
adjusted serum concentrations (ng/g) for 6 individual PCB congeners as well as the sum of the dioxin-like PCBs $(74+118)$ and the sum of non-dioxin-like PCBs $(118+138$ $+153+170$ ) were used in this study. PCB congeners $74,99,118,138,153$, and 180 were selected because they were available in all three survey cycles and concentrations were above the LOD in $>60 \%$ of the survey participants.

Measurement of urinary phthalates and phenols. Bisphenol A and phthalate metabolites were quantified in urine by the use of solid phase extraction (SPE) coupled to reverse phase high performance liquid chromatography-tandem mass spectrometry (HPLCMS/MS). Laboratory methods and quality control were consistent across survey years and documentation in available online (CDC, 2012). We examined 8 phthalate metabolites measured in the 4 consecutive NHANES cycles: mono-n-butyl phthalate (MBP), mono-ethyl phthalate (MEP), mono-(2-ethyl)-hexyl phthalate (MEHP), monobenzyl phthalate (MBzP), mono-(3-carboxypropyl) phthalate (MCPP), mono-(2-ethyl-5hydroxyhexyl) phthalate (MEHHP), mono-(2-ethyl-5-oxohexyl) phthalate (MEOHP), and mono-isobutyl phthalate (MIB). We summed MEHP, MEHHP, and MEOHP to represent the sum of di (2-ethylhexyl) phthalate (DEHP) and we summed all 8 phthalate metabolites (MBP $+\mathrm{MEP}+\mathrm{MEHP}+\mathrm{MBz}+\mathrm{MCPP}+\mathrm{MEHHP}+\mathrm{MEOHP}+\mathrm{MIB})$ to represent total phthalate exposure. Bisphenol A (BPA) was the only phenol included in this study. To correct for urine dilution, we divided all phthalate metabolites and BPA concentrations by urinary creatinine concentration and used the resulting creatinine corrected concentrations $(\mathrm{mg} / \mathrm{g})$ for all of our analyses. Urine samples with creatinine levels $>300 \mathrm{mg} / \mathrm{dL}$ or $<30 \mathrm{mg} / \mathrm{dL}$ were excluded because they were too dilute or too concentrated for accurate analysis (Sata et al. 1995). 
Limit of detection. A detection limit variable is provided for each PCB congener, phthalate metabolite and BPA in the data sets. The variable LBD_LC has two values: the value " 0 " indicates that the result was below the limit of detection and the value " 1 " indicates that the result was at or above the limit of detection. Any participant with a serum PCB concentration below the limit of detection was assigned a serum level of the LOD divided by the square root of two. Limits of detection vary by metabolite and survey cycle and can be found in the CDC's Fourth National Report on Human Exposure to Environmental Chemicals (CDC, 2013b).

Data analysis. We included female NHANES participants 20 to 85 years of age who completed the physical exam, reproductive questionnaire, and medical health questionnaire and provided a response for "Have you ever been told by a doctor or other health professional that you had cancer or a malignancy of any kind?" Women who answered "yes" were subsequently asked "What kind of cancer was it?" and "What was your age at diagnosis?"

PCB data analysis. 8,315 women 20 to 85 years of age provided a response in the 19992004 survey cycles to for "Have you ever been told by a doctor or other health professional that you had cancer or a malignancy of any kind?” After deleting observations that were missing PCB data our PCB study population consisted of 2,072 participants: 43 reported a breast cancer diagnosis, 27 reported a cervical cancer diagnosis, 11 reported an ovarian cancer diagnosis, 26 reported a uterine cancer diagnosis and women who reported never being diagnosed with cancer ranged from 1955 to 1962 participants depending on the PCB congener being evaluated. 
Phthalate data analysis. Our phthalate study population consisted of women 20 to 85 years of age who provided a response in the 2003-2010 survey years to "Have you ever been told by a doctor or other health professional that you had cancer or a malignancy of any kind?" After deleting creatinine observations that were $<30 \mathrm{mg} / \mathrm{dL}$ and $>300$ $\mathrm{mg} / \mathrm{dL}$ our study populations consisted of 3,003 participants of whom 97 reported a breast cancer diagnosis, 28 reported a cervical cancer diagnosis, 20 reported an ovarian cancer diagnosis, 27 reported a uterine cancer diagnosis, and 2,731reported never being diagnosed with cancer.

BPA data analysis. Our BPA study population consisted of women 20 to 85 years of age provided a response in the 2005-2010 survey cycles to for "Have you ever been told by a doctor or other health professional that you had cancer or a malignancy of any kind?" After deleting creatinine observations that were $<30 \mathrm{mg} / \mathrm{dL}$ and $>300 \mathrm{mg} / \mathrm{dL}$ our study populations consisted of 2,202 participants of whom 78 reported a breast cancer diagnosis, 16 reported a cervical cancer diagnosis, 16 reported an ovarian cancer diagnosis, 22 reported a uterine cancer diagnosis, and 2,070 reported never being diagnosed with cancer.

Statistical analysis. All statistical analyses were performed using SAS system software (release 9.2; SAS Institute Inc. Cary, N.C.). Appropriate subsample weights were calculated according to the National Center for Health Statistics guidelines to adjust for oversampling of minority groups (CDC, 2013b). Nonmissing values for serum concentrations below the LOD were assigned a serum level of the LOD divided by the square root of two. In our PCB analysis, all lipid-adjusted serum PCB concentrations were $\log$ transformed to satisfy normality assumptions. In our phthalate and BPA 
analyses, all urinary compounds and metabolites were log transformed and creatinine corrected. Due to a small number of cervical, ovarian and uterine cancer cases, we conducted logistic regression analyses using the following two groups: $<$ LOD to $50^{\text {th }}$ percentile (reference) vs. $\geq 50^{\text {th }}$ percentile. We also conducted separate analyses on females with serum PCB, phthalate, and BPA levels $>$ LOD where cancer cases were compared with non-cancer cases. Significance was set at $p<0.05$.

We used PROC SURVEYMEANS to account for the complex sampling design of NHANES and to obtain weighted means, $95 \%$ confidence intervals, and standard errors of individual PCB congeners, the sum of dioxin-like PCBs, the sum of non-dioxin-like PCBs, individual phthalate metabolites, the sum of DEHP (MHH+MOH+MHP), and BPA. We used the Taylor Series (linearization) method to estimate standard errors. A two-sided student t-test was calculated using PROC SURVEYREG to test whether the mean $\mathrm{EDC}$ (PCB, phthalate, or BPA) levels between women who reported a breast, cervical, ovarian, or uterine cancer diagnosis and women who reported no cancer diagnosis were significantly different. Age was divided into three groups (20-59 years, $60-74$ years, and $\geq 75$ years) that were selected based on the age distribution of reproductive cancer cases and noncases in our data set. Race/ethnicity was divided into two groups (non-Hispanic White and 'Other') due to a very small number of reproductive cancer cases from races/ethnicities other than non-Hispanic White. The category of 'Other' includes Mexican American, Non-Hispanic Black, Other Hispanic and Other Race - Including Multi-Racial. We also calculated GMs for reproductive cancer cases and noncases in women with PCB, phthalate, and BPA levels above the LOD. 
Using PROC SURVEYLOGISTIC, we derived unadjusted and adjusted ORs and their 95\% CIs to evaluate the association between exposure to EDCs and breast cancer, cervical cancer, ovarian cancer, or uterine cancer. We conducted separate analyses for the sum of dioxin-like and non-dioxin-like PCBs and individual PCB congeners and reproductive cancers. Due to a small number of cervical, ovarian, and uterine cancer cases, ORs and $95 \%$ CIs were calculated using the following group: $<$ LOD to $50^{\text {th }}$ percentile vs. $\geq 50^{\text {th }}$ percentile. The reference group for each PCB congener is defined as those participants whose serum concentrations were $<$ LOD to $50^{\text {th }}$ percentile. Covariates. We considered a number of potential confounders based on previous literature and well-established risk factors for reproductive cancers. The following potential confounders were either self-reported in the questionnaire interviews or taken as a laboratory measurement. The demographic variables of age at interview (20-59 years, 60-74 years, and $\geq 75$ years), race (white vs. other) were obtained during the NHANES home interview (CDC 2012). Reproductive variables including age at menarche $(<12$ years, $12-14$ years, $\geq 15$ years), parity $(0,1, \geq 2)$, oral contraceptive use (yes/no) and lactation (yes/no) as well as lifestyle variables including smoking (yes/no) and alcohol use (yes/no) were obtained from health questionnaires completed in the mobile examination center. Body mass index $\left(<25 \mathrm{~kg} / \mathrm{m}^{2}, 25\right.$ to $<30 \mathrm{~kg} / \mathrm{m}^{2}$, and $\left.\geq 30 \mathrm{~kg} / \mathrm{m}^{2}\right)$ was obtained through the body measurement component in the mobile examination center (CDC 2013b). For all EDCs, ORs and 95\% CIs are reported for three models: unadjusted; age and race/ethnicity adjusted; and age, race/ethnicity, BMI, and age at menarche adjusted. Parity, oral contraceptive use and lactation were not included in the models because of the extent of missing data. Smoking history and alcohol consumption 
were not significant predictors of breast cancer risk and therefore were also not presented in the final models.

\section{RESULTS}

PCB descriptive statistics. The study population included 2,008 female participants 20 years of age and older with available PCB data and who completed the medical conditions questionnaire and provided a response for "Have you ever been told by a doctor or other health professional that you had cancer or a malignancy of any kind?" Women who answered "yes" were subsequently asked, "What kind of cancer was it?" and "What was your age at diagnosis?" Among the women who responded to the questions stated above and had available PCB data, 1,965 (91.5\%) reported never being diagnosed with cancer, 43 (2.14\%) reported being diagnosed with breast cancer, 27 $(1.36 \%)$ reported being diagnosed with cervical cancer, $11(0.56 \%)$ reported being diagnosed with ovarian cancer, and $26(1.31 \%)$ reported being diagnosed with uterine cancer (Table 3.1). Participants were fairly evenly distributed over the two races: $48.6 \%$ were of non-Hispanic white ethnicity and $51.4 \%$ were classified as 'Other', however the majority of breast cancer cases were in non-Hispanic white women $(81.5 \%)$. The majority of participants were 20-59 years of age at the time of interview (65.9\%) (Table 3.1). The mean age at time of interview was 45.6 years for women who reported never being diagnosed with cancer, 65.7 years, 47.5 years, 52.0 years, and 52.4 years for women who reported being diagnosed with breast cancer, cervical cancer, ovarian cancer, and uterine cancer, respectively. The mean age at diagnosis was 54.9 years, 30.6 years, 41.9 years, and 53.2 years for women diagnosed with breast cancer, cervical cancer, ovarian cancer, and uterine cancer, respectively (Table 3.1). BMI was normal $(<25$ 
$\mathrm{kg} / \mathrm{m}^{2}$ ) for $35.5 \%$, overweight $\left(25 \mathrm{to}<30 \mathrm{~kg} / \mathrm{m}^{2}\right)$ for $28.6 \%$, and obese $\left(\geq 30 \mathrm{~kg} / \mathrm{m}^{2}\right)$ for $39.0 \%$ of study participants. The majority of study participants reported and an age of menarche of $12-14$ years $(64 \%), \geq 2$ live births $(71.4 \%)$, responded yes to breastfeeding (57.6\%), responded yes to oral contraceptive use (58.8\%), responded no to a history of smoking (57.8\%), and yes to alcohol consumption (54.5\%) (Table 3.1).

Table 3.1. Descriptive statistics for cancer diagnosis and selected covariates among women $\geq 20$ years of age with serum PCB measurements, NHANES 1999-2004.

\begin{tabular}{|c|c|c|c|c|c|}
\hline Variable & $\begin{array}{c}\text { No Cancer } \\
\mathbf{n}(\%) \\
\end{array}$ & $\begin{array}{r}\text { Breast } \\
\text { Cancer } \\
\text { n(\%) }\end{array}$ & $\begin{array}{c}\text { Cervical } \\
\text { Cancer } \\
\text { n( } \%) \\
\end{array}$ & $\begin{array}{r}\text { Ovarian } \\
\text { Cancer } \\
n(\%) \\
\end{array}$ & $\begin{array}{r}\text { Uterine } \\
\text { Cancer } \\
n(\%) \\
\end{array}$ \\
\hline Total Population (n,\%) & $1965(91.5 \%)$ & $43(2.14 \%)$ & $27(1.36 \%)$ & $11(0.56 \%)$ & $26(1.31 \%)$ \\
\hline Age at interview (years; mean \pm se) & $45.6 \pm .42$ & $65.7 \pm 2.12$ & $47.5 \pm 2.61$ & $52.0 \pm 3.75$ & $52.4 \pm 5.17$ \\
\hline Age at diagnosis (years; mean \pm se) & & $54.9 \pm 3.91$ & $30.6 \pm 1.14$ & $41.9 \pm .1 .97$ & $53.2 \pm 1.52$ \\
\hline \multicolumn{6}{|l|}{ Race/Ethnicity 1} \\
\hline Non-Hispanic white & $942(44.0 \%)$ & $35(1.74 \%)$ & $19(0.95 \%)$ & $6(0.30 \%)$ & $17(0.85 \%)$ \\
\hline Other & $1023(47.6 \%)$ & $8(0.40 \%)$ & $8(0.40 \%)$ & $5(0.25 \%)$ & $9(0.45 \%)$ \\
\hline \multicolumn{6}{|l|}{ Age (years) } \\
\hline $20-59$ & $1369(63.7 \%)$ & $7(0.35 \%)$ & $18(0.90 \%)$ & $7(0.35 \%)$ & $11(0.55 \%)$ \\
\hline $60-74$ & $384(17.8 \%)$ & $26(1.29 \%)$ & $6(0.30 \%)$ & $3(0.15 \%)$ & $11(0.55 \%)$ \\
\hline$\geq 75$ & $212(9.87 \%)$ & $10(0.50 \%)$ & $3(0.15 \%)$ & $1(0.05 \%)$ & $4(0.20 \%)$ \\
\hline \multicolumn{6}{|l|}{ Age at menarche (years) } \\
\hline$<12$ years & $344(17.9 \%)$ & $6(0.33 \%)$ & $10(0.56 \%)$ & $2(0.11 \%)$ & $7(0.39)$ \\
\hline $12-14$ years & $1161(60.4 \%)$ & $30(1.67 \%)$ & $14(0.79 \%)$ & $6(0.34 \%)$ & $14(0.78 \%)$ \\
\hline$\geq 15$ years & $254(13.2 \%)$ & $4(0.22 \%)$ & $0(0.00 \%)$ & $2(0.11 \%)$ & $4(0.22 \%)$ \\
\hline \multicolumn{6}{|l|}{ Parity (no. of live births) } \\
\hline 0 & $82(4.89 \%)$ & $0(0.00 \%)$ & $3(0.19 \%)$ & $1(0.07 \%)$ & $1(0.06 \%)$ \\
\hline 1 & $319(19.0 \%)$ & $5(0.32 \%)$ & $4(0.26 \%)$ & $2(0.13 \%)$ & $5(0.32 \%)$ \\
\hline$>2$ & $1121(66.9 \%)$ & $29(1.86) \%$ & $16(1.04 \%)$ & $6(0.39 \%)$ & $18(1.16 \%)$ \\
\hline \multicolumn{6}{|l|}{ BMI $\left(\mathrm{kg} / \mathrm{m}^{2}\right)$} \\
\hline Normal weight $(18.5$ to $<25)$ & $715(33.3 \%)$ & $13(0.65 \%)$ & $16(0.80 \%)$ & $4(0.20 \%)$ & $12(0.60 \%)$ \\
\hline Overweight $(25$ to $<30)$ & $580(27.0 \%)$ & $18(0.90 \%)$ & $2(0.10 \%)$ & $4(0.20 \%)$ & $8(0.40 \%)$ \\
\hline Obese $(\geq 30)$ & $670(31.2 \%)$ & $12(0.60 \%)$ & $9(0.45 \%)$ & $3(0.15 \%)$ & $6(0.30 \%)$ \\
\hline \multicolumn{6}{|l|}{ Breastfed } \\
\hline Yes & $835(54.1 \%)$ & $19(1.33 \%)$ & $12(0.85 \%)$ & $5(0.36 \%)$ & $13(0.92 \%)$ \\
\hline No & $559(36.2 \%)$ & $15(1.05 \%)$ & $8(0.57 \%)$ & $3(0.21 \%)$ & $10(0.71 \%)$ \\
\hline \multicolumn{6}{|l|}{ Oral Contraceptive Use } \\
\hline Yes & $1101(55.9 \%)$ & $22(0.91 \%)$ & $18(0.98 \%)$ & $6(0.33 \%)$ & $12(0.66 \%)$ \\
\hline No & $701(35.5 \%)$ & $30(1.25 \%)$ & $6(0.33 \%)$ & $4(0.22 \%)$ & $14(0.76 \%)$ \\
\hline \multicolumn{6}{|l|}{ Ever Smoked } \\
\hline Yes & $775(36.1 \%)$ & $21(1.14 \%)$ & $13(0.65 \%)$ & $7(0.35 \%)$ & $16(0.80 \%)$ \\
\hline No & $1189(55.4 \%)$ & $19(1.03 \%)$ & $14(0.70 \%)$ & $4(0.20 \%)$ & $10(0.50 \%)$ \\
\hline \multicolumn{6}{|l|}{ Alcohol Use } \\
\hline Yes & $1019(51.5 \%)$ & $23(1.15 \%)$ & $10(0.55 \%)$ & $7(0.38 \%)$ & $17(0.93 \%)$ \\
\hline No & $790(39.9 \%)$ & $20(1.00 \%)$ & $15(0.85 \%)$ & $3(0.16 \%)$ & $9(0.49 \%)$ \\
\hline
\end{tabular}

Estimated percent distribution after applying NHANES sampling weights. 
Phthalate and BPA descriptive statistics. The study population included 3,003 female participants 20 years of age and older with available phthalate and/or BPA data and who completed the medical conditions questionnaire and provided a response for "Have you ever been told by a doctor or other health professional that you had cancer or a malignancy of any kind?" Women who answered "yes" were subsequently asked, "What kind of cancer was it?" and "What was your age at diagnosis?" Among the 3,003 participants, 2,731 (90.4\%) reported never being diagnosed with cancer, 97 (2.22\%) reported being diagnosed with breast cancer, $28(0.65 \%)$ reported being diagnosed with cervical cancer, $20(0.47 \%)$ reported being diagnosed with ovarian cancer, and 27 $(0.63 \%)$ reported being diagnosed with uterine cancer (Table 3.2). Of the women who reported a reproductive cancer or no cancer, $43.5 \%$ of the participants were of nonHispanic white ethnicity and $52.6 \%$ were classified as 'Other'. The majority of participants were 20-59 years of age at the time of interview (67.7\%) (Table 3.2). The mean age at time of interview was 45.3 years for women who reported never being diagnosed with cancer, 65.1 years, 48.1 years, 56.1 years, and 58.3 years for women who reported being diagnosed with breast cancer, cervical cancer, ovarian cancer, and uterine cancer, respectively. The mean age at diagnosis was 56.0 years, 30.5 years, 46.3 years, and 52.3 years for women diagnosed with breast cancer, cervical cancer, ovarian cancer, and uterine cancer, respectively (Table 3.2). BMI was normal $\left(<25 \mathrm{~kg} / \mathrm{m}^{2}\right.$ ) for $28.3 \%$, overweight $\left(25\right.$ to $\left.<30 \mathrm{~kg} / \mathrm{m}^{2}\right)$ for $28.6 \%$, and obese $\left(\geq 30 \mathrm{~kg} / \mathrm{m}^{2}\right)$ for $39.3 \%$ of study participants. The majority of study participants reported and an age of menarche of 1214 years $(62.1 \%), \geq 2$ live births $(74.0 \%)$, responded yes to breastfeeding $(54.9 \%)$, and 
responded yes to oral contraceptive use $(63.4 \%)$, responded no to a history of smoking

(58.4\%), and yes to alcohol consumption (57.1\%) (Table 3.2).

Table 3.2. Descriptive statistics for cancer diagnosis and selected covariates among women $\geq 20$ years of age with urinary phthalate and bisphenol A measurements, NHANES 2003-2010.

\begin{tabular}{|c|c|c|c|c|c|}
\hline Variable & $\begin{array}{c}\text { No Cancer } \\
\text { n(\%) }\end{array}$ & $\begin{array}{c}\text { Breast } \\
\text { Cancer } \\
\text { n(\%) }\end{array}$ & $\begin{array}{c}\text { Cervical } \\
\text { Cancer } \\
\text { n(\%) }\end{array}$ & $\begin{array}{c}\text { Ovarian } \\
\text { Cancer } \\
\text { n( }(\%)\end{array}$ & $\begin{array}{c}\text { Uterine } \\
\text { Cancer } \\
\text { n(\%) }\end{array}$ \\
\hline Total Population (n,\%) & $2731(90.4 \%)$ & $97(2.22 \%)$ & $28(0.65 \%)$ & $20(0.47 \%)$ & $27(0.63 \%)$ \\
\hline Age at interview (years; mean \pm se) & $45.3 \pm .40$ & $65.1 \pm 2.40$ & $48.1 \pm 2.71$ & $56.1 \pm 5.09$ & $58.3 \pm 3.10$ \\
\hline Age at diagnosis (years; mean \pm se) & & $56.0 \pm 2.27$ & $30.5 \pm 0.76$ & $46.3 \pm 1.42$ & $52.3 \pm 2.04$ \\
\hline \multicolumn{6}{|l|}{ Race/Ethnicity } \\
\hline Non-Hispanic white & $1202(39.6 \%)$ & $63(2.23 \%)$ & $18(0.65 \%)$ & $9(0.33 \%)$ & $20(0.73 \%)$ \\
\hline Other & $1529(50.4 \%)$ & $34(1.20 \%)$ & $10(0.36 \%)$ & $11(0.40 \%)$ & $7(0.25 \%)$ \\
\hline \multicolumn{6}{|l|}{ Age (years) } \\
\hline $20-59$ & $1971(65.0 \%)$ & $22(0.78 \%)$ & $24(0.87 \%)$ & $9(0.33 \%)$ & $8(0.29 \%)$ \\
\hline $60-74$ & $504(16.6 \%)$ & $38(1.34 \%)$ & $3(0.11 \%)$ & $6(0.22 \%)$ & $11(0.40 \%)$ \\
\hline$\geq 75$ & $256(8.44 \%)$ & $37(1.31 \%)$ & $1(0.04 \%)$ & $5(0.18 \%)$ & $8(0.29 \%)$ \\
\hline \multicolumn{6}{|l|}{ Age at menarche (years) } \\
\hline$<12$ years & $517(19.0 \%)$ & $18(0.71 \%)$ & $5(0.20 \%)$ & $4(0.16 \%)$ & $5(0.20 \%)$ \\
\hline $12-14$ years & $1574(58.0 \%)$ & $57(2.26 \%)$ & $18(0.73 \%)$ & $10(0.41 \%)$ & $17(0.69 \%)$ \\
\hline$\geq 15$ years & $343(12.6 \%)$ & $16(0.63 \%)$ & $3(0.12 \%)$ & $3(0.12 \%)$ & $5(0.20 \%)$ \\
\hline \multicolumn{6}{|l|}{ Parity (no. of live births) } \\
\hline 0 & $54(2.42 \%)$ & $2(0.10 \%)$ & $1(0.05 \%)$ & $0(0.00 \%)$ & $0(0.00 \%)$ \\
\hline 1 & $400(17.9 \%)$ & $13(0.63 \%)$ & $4(0.20 \%)$ & $4(0.20 \%)$ & $1(0.21 \%)$ \\
\hline$>2$ & $1531(68.5 \%)$ & $63(3.05 \%)$ & $21(1.04 \%)$ & $11(0.55 \%)$ & $4(0.82 \%)$ \\
\hline \multicolumn{6}{|l|}{ BMI $\left(\mathrm{kg} / \mathrm{m}^{2}\right)$} \\
\hline Normal weight $(18.5$ to $<25)$ & $800(26.6 \%)$ & $32(1.14 \%)$ & $7(0.26 \%)$ & $3(0.11 \%)$ & $6(0.22 \%)$ \\
\hline Overweight $(25$ to $<30)$ & $803(26.7 \%)$ & $26(0.93 \%)$ & $7(0.26 \%)$ & $12(0.44 \%)$ & $6(0.22 \%)$ \\
\hline Obese $(\geq 30)$ & $1102(36.7 \%)$ & $38(1.36 \%)$ & $14(0.51 \%)$ & $5(0.18 \%)$ & $15(0.55 \%)$ \\
\hline \multicolumn{6}{|l|}{ Breastfed } \\
\hline Yes & $1117(51.1 \%)$ & $42(2.09 \%)$ & $15(0.77 \%)$ & $7(0.36 \%)$ & $11(0.56 \%)$ \\
\hline No & $816(37.4 \%)$ & $35(1.74 \%)$ & $10(0.51 \%)$ & $8(0.41 \%)$ & $15(0.77 \%)$ \\
\hline \multicolumn{6}{|l|}{ Oral Contraceptive Use } \\
\hline Yes & $1650(60.0 \%)$ & $42(1.64 \%)$ & $21(0.84 \%)$ & $7(0.28 \%)$ & $15(0.60 \%)$ \\
\hline No & $827(30 . \%)$ & $49(1.91 \%)$ & $5(0.20 \%)$ & $10(0.40 \%)$ & $12(0.48 \%)$ \\
\hline \multicolumn{6}{|l|}{ Ever Smoked } \\
\hline Yes & $1060(35.0 \%)$ & $39(1.38 \%)$ & $21(0.76 \%)$ & $6(0.22 \%)$ & $13(0.47 \%)$ \\
\hline No & $1669(55.1 \%)$ & $58(2.05 \%)$ & $7(0.25 \%)$ & $14(0.51 \%)$ & $14(0.51 \%)$ \\
\hline \multicolumn{6}{|l|}{ Alcohol Use } \\
\hline Yes & $1480(53.6 \%)$ & $50(1.95 \%)$ & $19(0.76 \%)$ & $6(0.24 \%)$ & $14(0.56 \%)$ \\
\hline No & $998(36.1 \%)$ & $41(1.60 \%)$ & $7(0.28 \%)$ & $11(0.44 \%)$ & $13(0.52 \%)$ \\
\hline
\end{tabular}

Estimated percent distribution after applying NHANES sampling weights.

Table 3.3 presents GMs and GSEs of EDCs by reproductive cancer status. GM

PCB levels were significantly higher for all 6 PCB congeners in women diagnosed with

breast cancer, PCB 74, 99, 118, 138, and 153 were significantly higher in women

diagnosed with uterine cancer and PCB 138, 153, and 180 were significantly higher in

women diagnosed with uterine cancer compared to women never diagnosed with cancer. 
None of the PCB congeners were significantly higher in women diagnosed with cervical cancer (Table 3.3, Figure 3.1). MEHHP was significantly higher in women diagnosed with ovarian cancer and MEP was significantly higher in women diagnosed with uterine cancer compared to women never diagnosed with cancer (Table 3.3, Figure 3.2). MBzP was found to be significantly higher in women without cancer compared to women with breast cancer. Women diagnosed with a reproductive cancer did not have significantly higher levels of BPA compared to women never diagnosed with cancer. In contrast, women never diagnosed with cancer had significantly higher levels of BPA than women diagnosed with breast cancer (Table 3.3). 
Table 3.3. Geometric Mean serum PCB, urinary phthalate and urinary BPA levelsby cancer diagnosis for women $\geq 20$ years of age.

\begin{tabular}{|c|c|c|c|c|c|}
\hline & \multicolumn{5}{|c|}{ Geometric mean $^{1}(\mathrm{ng} / \mathrm{g})(\mathrm{GSE}, \mathrm{n})$} \\
\hline & No & Breast & Cervical & Ovarian & Uterine \\
\hline & Cancer & Cancer & Cancer & Cancer & Cancer \\
\hline \multicolumn{6}{|l|}{ PCB Metabolites ${ }^{2}$} \\
\hline PCB 074 & $8.08(1.03,1960)$ & $15.6(1.14,43)^{\mathrm{a}}$ & $9.58(1.21,27)$ & $30.0(1.32,11)^{\mathrm{b}}$ & $10.8(1.21,26)$ \\
\hline РCB 099 & $5.99(1.03,1958)$ & $9.39(1.12,43)^{b}$ & $6.82(1.16,26)$ & $51.9(1.32,11)^{\mathrm{b}}$ & $7.24(1.21,25)$ \\
\hline PCB 118 & $9.49(1.03,1960)$ & $17.5(1.16,43)^{b}$ & $12.2(1.25,27)$ & $38.9(1.38,11)^{\mathrm{b}}$ & $11.1(1.32,26)$ \\
\hline PCB 138 & $20.9(1.03,1961)$ & $39.6(1.11,43)^{\mathrm{a}}$ & $25.3(1.20,27)$ & $22.3(1.36,11)^{\mathrm{b}}$ & $30.9(1.14,26)^{\mathrm{b}}$ \\
\hline PCB 153 & $28.8(1.02,1962)$ & $56.2(1.11,43)^{\mathrm{a}}$ & $33.8(1.20,27)$ & $12.2(1.42,11)^{\mathrm{b}}$ & $40.9(1.15,26)^{b}$ \\
\hline PCB 180 & $19.5(1.02,1955)$ & $44.3(1.10,43)^{\mathrm{a}}$ & $23.8(1.17,27)$ & $16.6(1.28,11)$ & $30.3(1.20,26)_{\mathrm{b}}$ \\
\hline \multicolumn{6}{|c|}{ Phthalate Metabolites ${ }^{3}$} \\
\hline MBP & $1.93(1.01,2723)$ & $1.90(1.04,97)$ & $1.92(1.04,28)$ & $1.93(1.04,20)$ & $2.03(1.07,27)$ \\
\hline MEP & $2.83(1.01,2723)$ & $2.66(1.05,97)$ & $2.86(1.04,28)$ & $2.64(1.05,20)$ & $3.10(1.16,27)^{\mathrm{b}}$ \\
\hline MEHP & $1.19(1.01,2723)$ & $1.14(1.05,97)$ & $1.20(1.05,28)$ & $1.36(1.05,20)$ & $1.07(1.07,27)$ \\
\hline $\mathrm{MBzP}$ & $1.54(1.01,2723)^{\mathrm{d}}$ & $1.45(1.04,97)$ & $1.51(1.05,28)$ & $1.68(1.07,20)$ & $1.46(1.08,27)$ \\
\hline МCCP & $1.21(1.01,2723)$ & $1.19(1.03,97)$ & $1.18(1.05,28)$ & $1.26(1.09,20)$ & $1.20(1.04,27)$ \\
\hline МEHHP & $1.90(1.01,2723)$ & $1.92(1.03,97)$ & $1.88(1.05,28)$ & $2.32(1.25,20)^{\mathrm{b}}$ & $1.93(1.08,27)$ \\
\hline MEOHP & $1.72(1.01,2723)$ & $1.73(1.04,97)$ & $1.77(1.05,28)$ & $2.03(1.28,20)$ & $1.72(1.08,27)$ \\
\hline MIB & $1.46(1.01,2723)$ & $1.39(1.05,97)$ & $1.39(1.04,28)$ & $1.46(1.06,20)$ & $1.46(1.09,27)$ \\
\hline DEHP $^{4}$ & $3.86(1.03,2723)$ & $3.78(1.13,97)$ & $3.34(1.17,28)$ & $6.55(2.08,20)$ & $3.53(1.23,27)$ \\
\hline Total Phthalates ${ }^{5}$ & $58.0(1.04,2723)$ & $46.5(1.15,97)$ & $54.6(1.31,28)$ & $102(1.54,20)$ & $56.8(1.22,27)$ \\
\hline \multicolumn{6}{|l|}{ Bisphenol $\mathrm{A}^{6}$} \\
\hline BPA & $1.16(1.01,2070)^{\mathrm{c}}$ & $1.06(1.03,78)$ & $1.17(1.08,16)$ & $1.23(1.08,16)$ & $1.09(1.06,22)$ \\
\hline
\end{tabular}

${ }^{\mathrm{C}}$ Geometric means calculated after applying NHANES sampling weights.

${ }^{2}$ Lipid adjusted and log transformed polychlorinated biphenyls (ng/g); NHANES 1999-2004.

${ }^{3} \log$ transformed and creatinine corrected urinary phthalate metabolites (ng/mg); NHANES 2003-2010.

${ }^{4}$ DEHP $=$ Sum of MEHP, MEHHP and MEOHP.

${ }^{5}$ Total Phthalates $=$ Sum of MBP, MEP, MEHP, MBzP, MCCP, MEHHP, MEOHP and MIB.

${ }^{6} \mathrm{Log}$ transformed and creatinine corrected urinary BPA measurements (ng/g); NHANES 2005-1010.

PCB or phthalate levels significantly higher in women with cancer vs. women without cancer; ${ }^{\mathrm{a}} \mathrm{p}<0.0001,{ }^{\mathrm{b}} \mathrm{p}<0.05$.

BPA significantly higher in women without cancer vs. women with breast cancer, ${ }^{c} p<0.05$.

MBzP is significantly higher in women without cancer vs. women diagnosed with breast cancer, ${ }^{d} p<0.05$. 


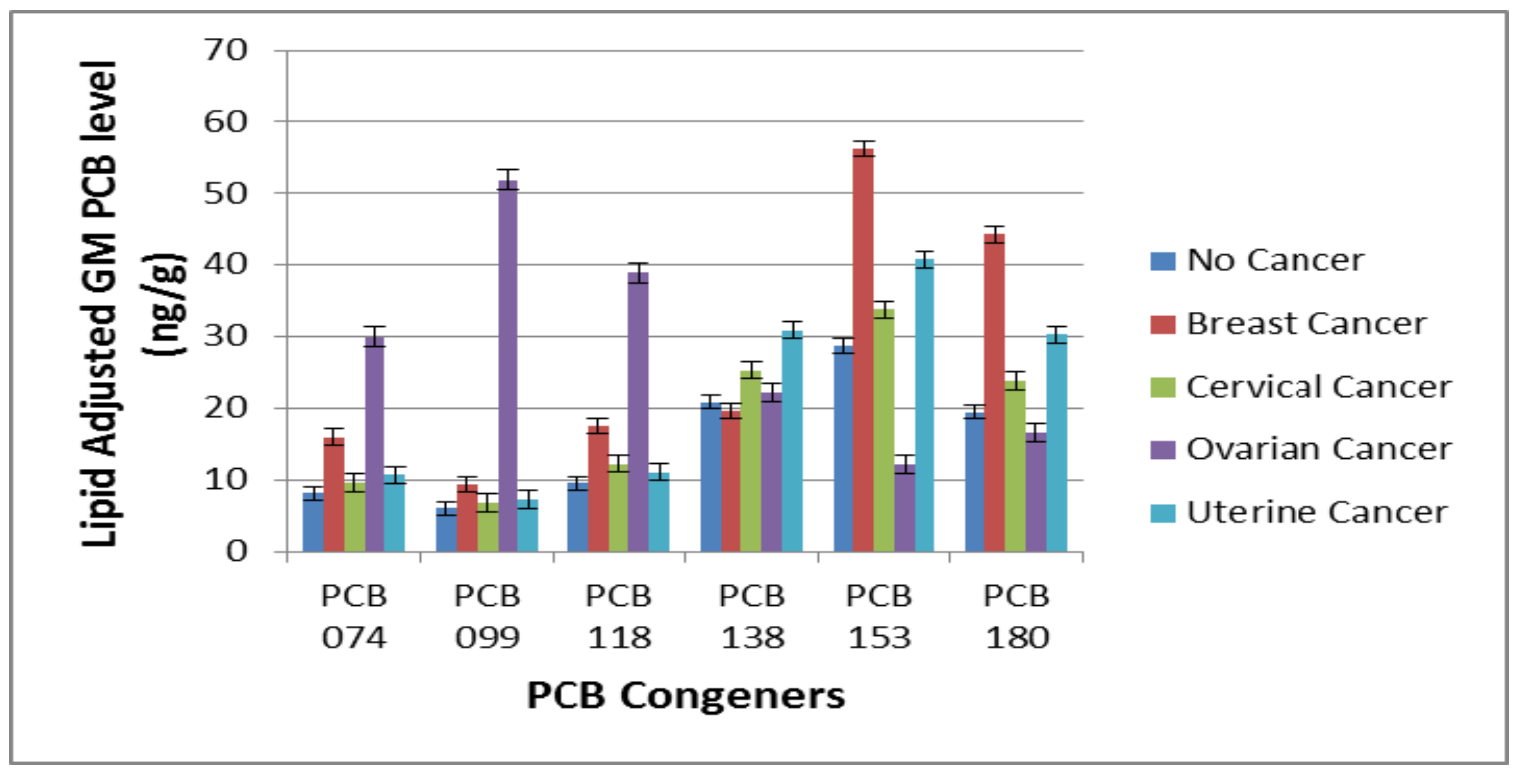

Figure 3.1. Geometric Mean PCB levels (ng/g) by cancer diagnosis among women $\geq 20$ years of age, NHANES 1999-2004.

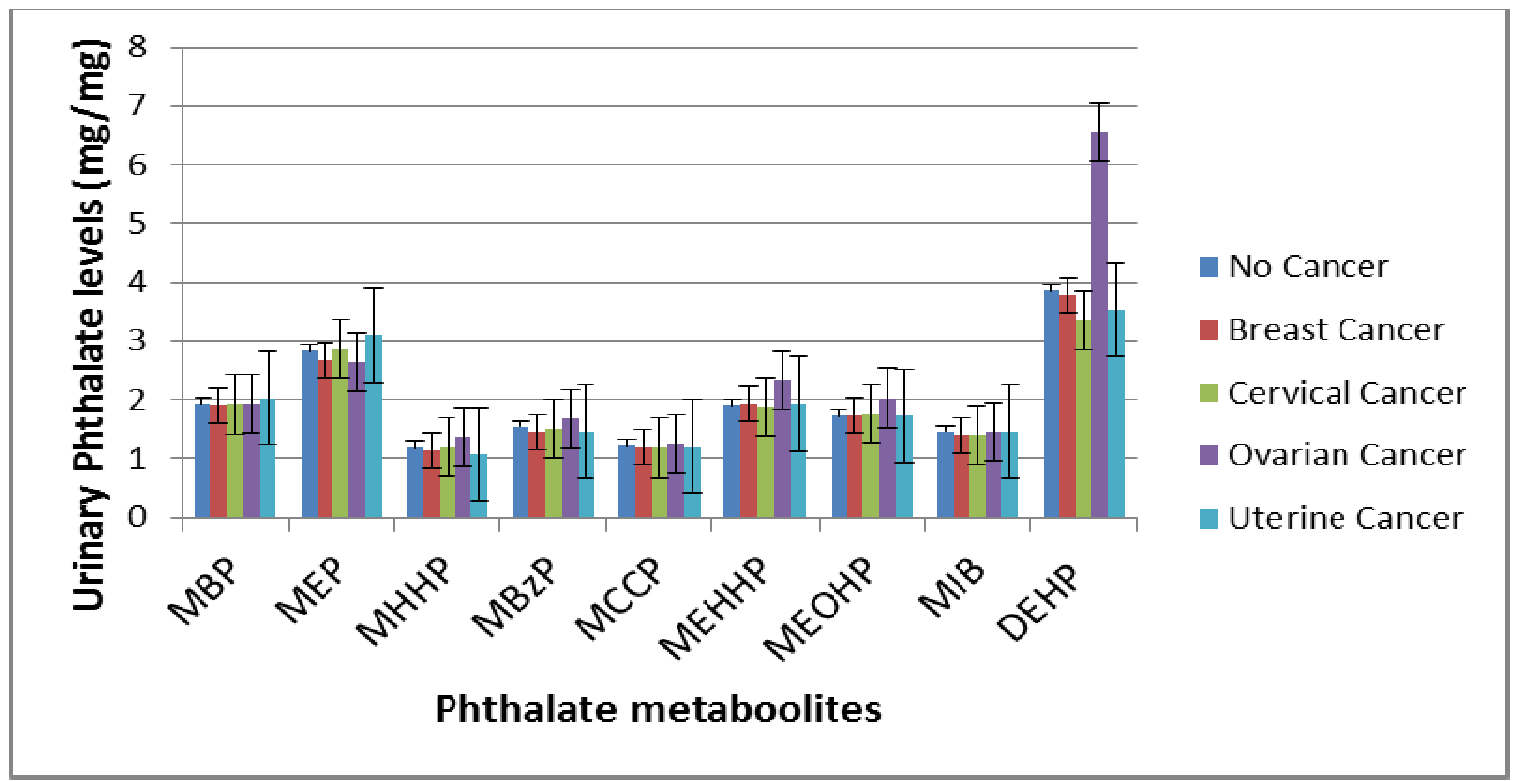

Figure 3.2. Geometric mean urinary phthalate levels $(\mathrm{ng} / \mathrm{mg})$ by cancer diagnosis among women $\geq 20$ years of age, NHANES 2003-2010.

GM EDC levels were also examined by cancer status in women with individual PCB concentrations above the LOD (Table 3.4). All 6 PCB congeners remained significantly higher in women diagnosed with breast cancer, PCB 74, 99, 118, 138, and 
153 were significantly higher in women diagnosed with ovarian cancer, and PCB 138 was significantly higher in women diagnosed with uterine cancer compared to women never diagnosed with cancer. For women with phthalate concentrations above the LOD, GM levels did not differ between women diagnosed with a reproductive cancer and women never diagnosed with cancer (Table 3.4). When observations below the LOD were removed BPA became significantly higher in women diagnosed with cervical cancer compared to women never diagnosed with cancer (Table 3.4).

Table 3.4. Geometric Mean PCB, urinary phthalate and urinary BPA levels by cancer diagnosis among women $\geq 20$ years of age with concentrations above the LOD.

\begin{tabular}{|c|c|c|c|c|c|}
\hline & \multicolumn{5}{|c|}{ Geometric mean $^{1}$ (GSE,n) } \\
\hline & $\begin{array}{c}\text { No } \\
\text { Cancer }\end{array}$ & $\begin{array}{r}\text { Breast } \\
\text { Cancer }\end{array}$ & $\begin{array}{c}\text { Cervical } \\
\text { Cancer }\end{array}$ & $\begin{array}{l}\text { Ovarian } \\
\text { Cancer }\end{array}$ & $\begin{array}{l}\text { Uterine } \\
\text { Cancer }\end{array}$ \\
\hline \multicolumn{6}{|c|}{ PCB Metabolites $^{2}$} \\
\hline PCB 074 & $9.87(1.03,1484)$ & $16.0(1.07,43)^{b}$ & $10.7(1.25,24)$ & $21.8(1.19,9)^{\mathrm{a}}$ & $10.9(1.21,23)$ \\
\hline PCB 099 & $7.24(1.02,1334)$ & $9.87(1.08,43)^{\mathrm{b}}$ & $7.61(1.21,21)$ & $20.1(1.21,8)^{\mathrm{b}}$ & $8.50(1.22,19)$ \\
\hline PCB 118 & $11.7(1.03,1534)$ & $17.5(1.16,43)^{\mathrm{b}}$ & $14.4(1.29,24)$ & $30.9(1.25,9)^{\mathrm{a}}$ & $12.9(1.25,23)$ \\
\hline PCB 138 & $23.6(1.03,1594)$ & $39.6(1.11,43)^{\mathrm{a}}$ & $28.2(1.22,24)$ & $47.5(1.38,9)^{b}$ & $31.5(1.14,25)^{\mathrm{b}}$ \\
\hline PCB 153 & $31.8(1.03,1651)$ & $56.2(1.11,43)^{\mathrm{a}}$ & $37.7(1.21,25)$ & $63.4(1.35,9)^{\mathrm{b}}$ & $41.3(1.15,25)$ \\
\hline PCB 180 & $23.3(1.03,1600)$ & $44.3(1.10,43)^{\mathrm{a}}$ & $25.0(1.17,25)$ & $37.7(1.36,9)$ & $30.9(1.21,24)$ \\
\hline \multicolumn{6}{|c|}{ Phthalate Metabolites ${ }^{3}$} \\
\hline MBP & $1.93(1.01,2718)$ & $1.93(1.03,97)$ & $1.92(1.04,27)$ & $1.93(1.04,20)$ & $2.03(1.08,27)$ \\
\hline MEP & $2.83(1.01,2722)$ & $2.66(1.04,97)$ & $2.86(1.06,28)$ & $2.64(1.05,20)$ & $3.10(1.06,27)$ \\
\hline MEHP & $1.34(1.01,1913)$ & $1.28(1.04,64)$ & $1.45(1.06,18)$ & $1.55(1.27,16)$ & $1.16(1.04,19)$ \\
\hline MBzP & $1.55(1.01,2704)$ & $1.46(1.03,96)$ & $1.51(1.05,28)$ & $1.68(1.07,20)$ & $1.46(1.05,27)$ \\
\hline MCCP & $1.22(1.01,2677)$ & $1.22(1.03,95)$ & $1.19(1.05,28)$ & $1.26(1.09,20)$ & $1.20(1.05,27)$ \\
\hline MEHHP & $1.90(1.01,2719)$ & $1.92(1.03,97)$ & $1.88(1.06,28)$ & $2.32(1.25,20)$ & $1.93(1.04,27)$ \\
\hline MEOHP & $1.72(1.01,2714)$ & $1.73(1.03,97)$ & $1.77(1.05,28)$ & $2.03(1.28,20)$ & $1.72(1.03,27)$ \\
\hline MIB & $1.48(1.01,2695)$ & $1.42(1.03,95)$ & $1.43(1.04,27)$ & $1.46(1.06,20)$ & $1.46(1.06,27)$ \\
\hline \multicolumn{6}{|c|}{ Bisphenol $\mathrm{A}^{4}$} \\
\hline BPA & $1.18(1.01,1959)$ & $1.11(1.03,71)$ & $1.27(1.05,14)^{\mathrm{a}}$ & $1.30(1.08,15)$ & $1.16(1.05,20)$ \\
\hline
\end{tabular}

${ }^{1}$ Geometric means calculated after applying NHANES sampling weights.

${ }^{2}$ Lipid adjusted and log transformed polychlorinated biphenyls (ng/g); NHANES 1999-2004.

${ }^{3} \mathrm{Log}$ transformed and creatinine corrected phthalate metabolites (ng/mg); NHANES 2003-2010.

${ }^{4} \mathrm{Log}$ transformed and creatinine corrected urinary BPA measurements (ng/g); NHANES 2005-1010.

PCB, BPA, or phthalate levels significantly higher in women with cancer vs. women without cancer; ${ }^{\mathrm{a}} \mathrm{p}<0.0001,{ }^{\mathrm{b}} \mathrm{p}<0.05$

Estimated ORs and $95 \%$ confidence intervals for the risk of having breast, cervical, ovarian, or uterine cancers cancer and the six individual PCB congeners are shown in tables 3.5-3.8. Due to the lack of breast cancer cases in women with low blood PCB levels and in women with blood PCB levels below the LOD, the following two 
groups were used to estimate breast cancer risk: $<$ LOD to $50^{\text {th }}$ percentile (reference group) and $\geq 50^{\text {th }}$ percentile. Results are presented for three logistic regression models: unadjusted; age and race/ethnicity adjusted; and age, race/ethnicity, BMI, and age at menarche adjusted. In unadjusted models, PCBs were significantly associated with breast cancer risk for subjects in the second group ( $\geq 50^{\text {th }}$ percentile) when compared to the reference group ( $<$ LOD to $50^{\text {th }}$ percentile) for PCB congeners $74,99,118,138,153$, and 180 (Table 3.5). After adjusting for age and race/ethnicity, PCB138 was the only congener found to be significantly associated with breast cancer [OR of 3.16;95\% CI: 1.14-8.76] (Table 3.5)After adjusting for age, race/ethnicity, BMI, lactation, and age at menarche, PCB138 remained significantly associated with breast cancer (OR of 2.88, 95\% CI) (Table 3.5). 
Table 3.5. Estimated ORs (95\% CIs) of breast cancer by concentration of PCBs, among women $\geq 20$ years of age, NHANES 1999-2004.

\begin{tabular}{|c|c|c|c|c|c|}
\hline Analyte $^{1}$ & $\begin{array}{c}\text { No. } \\
\text { Cases } \\
\end{array}$ & $\begin{array}{c}\text { No. } \\
\text { Noncases }\end{array}$ & $\begin{array}{c}\text { Unadjusted OR } \\
(95 \% \text { CI })\end{array}$ & $\begin{array}{c}\text { Adjusted OR } \\
(95 \% \text { CI })\end{array}$ & $\begin{array}{c}\text { Adjusted OR }{ }^{3} \\
(95 \% \text { CI })\end{array}$ \\
\hline \multicolumn{6}{|l|}{$\overline{\text { PCB } 074}$} \\
\hline$<$ LOD to $50 \%$ & 4 & 1047 & 1.00 & 1.00 & 1.00 \\
\hline$\geq 50 \%$ & 39 & 912 & $5.82(2.56-13.1)^{\mathrm{a}}$ & $1.62(0.48-5.38)$ & $1.95(0.31-12.4)$ \\
\hline \multicolumn{6}{|l|}{ РCB 099} \\
\hline$<$ LOD to $50 \%$ & 12 & 1172 & 1.00 & 1.00 & 1.00 \\
\hline$\geq 50 \%$ & 31 & 787 & $3.09(1.60-5.98)^{b}$ & $1.40(0.66-2.94)$ & $1.52(0.62-3.74)$ \\
\hline \multicolumn{6}{|l|}{ PCB 118} \\
\hline$<\mathrm{LOD}$ to $50 \%$ & 6 & 999 & 1.00 & 1.00 & 1.00 \\
\hline$\geq 50 \%$ & 37 & 960 & $4.34(1.95-9.70)^{b}$ & $1.38(0.40-4.78)$ & $1.54(0.29-8.35)$ \\
\hline \multicolumn{6}{|l|}{ PCB 138} \\
\hline$<$ LOD to $50 \%$ & 4 & 1068 & 1.00 & 1.00 & 1.00 \\
\hline$\geq 50 \%$ & 39 & 891 & $7.35(3.10-17.5)^{\mathrm{a}}$ & $3.14(1.14-8.62)^{b}$ & $2.52(1.06-5.99)^{b}$ \\
\hline \multicolumn{6}{|l|}{ PCB 153} \\
\hline$<$ LOD to $50 \%$ & 4 & 1078 & 1.00 & 1.00 & 1.00 \\
\hline$\geq 50 \%$ & 39 & 882 & $9.20(2.30-36.8)^{\mathrm{b}}$ & $3.94(0.58-26.6)$ & $3.15(0.53-18.6)$ \\
\hline \multicolumn{6}{|l|}{ PCB 180} \\
\hline$<\mathrm{LOD}$ to $50 \%$ & 4 & 1148 & 1.00 & 1.00 & 1.00 \\
\hline$\geqq 50 \%$ & 39 & 806 & $10.6(3.03-37.1)^{\mathrm{b}}$ & $4.33(0.79-23.6)$ & $3.45(0.76-15.6)$ \\
\hline
\end{tabular}

${ }^{\mathrm{I}}$ Lipid adjusted and log transformed polychlorinated biphenyls (ng/g).

${ }^{2}$ Adjusted for age and race/ethnicity.

${ }^{3}$ Adjusted for age, race/ethnicity, BMI, age at menarche; Cases/Noncases: 40/1754 in 074; 40/1753 in099; $40 / 1755$ in $118 ; 40 / 1756$ in 138 and $153 ; 40 / 1749$ in 180 .

Significance ${ }^{\mathrm{a}} \mathrm{p}<0.0001,{ }^{\mathrm{b}} \mathrm{p}<0.05$.

Estimated ORs and 95\% confidence intervals for the risk of having cervical and the six individual PCB congeners are shown in table 3.6. In unadjusted models, PCBs were significantly associated with cervical cancer risk for subjects in the second group ( $\geq 50^{\text {th }}$ percentile) when compared to the reference group ( $<$ LOD to $50^{\text {th }}$ percentile) for PCB congeners 138 and 153 (Table 3.6). After adjusting for age and race/ethnicity, PCB138 was the only congener found to be significantly associated with cervical cancer (OR of 3.12; 95\% CI: 1.32-8.74) (Table 3.6). After adjusting for age, race/ethnicity, BMI, lactation, and age at menarche, PCB138 remained significantly associated with cervical cancer (OR of 3.05, 95\% CI: 1.21-7.69) (Table 3.6). 
Table 3.6. Estimated ORs ( $95 \%$ CIs) of cervical cancer by concentration of PCBs, among women $\geq 20$ years of age, NHANES 1999-2004.

\begin{tabular}{|c|c|c|c|c|c|}
\hline Analyte $^{1}$ & $\begin{array}{r}\text { No. } \\
\text { Cases } \\
\end{array}$ & $\begin{array}{c}\text { No. } \\
\text { Noncases }\end{array}$ & $\begin{array}{c}\text { Unadjusted OR } \\
(95 \% \text { CI })\end{array}$ & $\begin{array}{c}\text { Adjusted OR }{ }^{2} \\
(95 \% \text { CI) }\end{array}$ & $\begin{array}{c}\text { Adjusted } \mathrm{OR}^{3} \\
(95 \% \mathrm{CI})\end{array}$ \\
\hline \multicolumn{6}{|l|}{ PCB 074} \\
\hline$<$ LOD to $50 \%$ & 12 & 1048 & 1.00 & 1.00 & 1.00 \\
\hline$\geq 50 \%$ & 15 & 912 & $1.26(0.55-2.87)$ & $1.01(0.37-2.77)$ & $0.87(0.28-2.70)$ \\
\hline \multicolumn{6}{|l|}{ РCB 099} \\
\hline$<$ LOD to $50 \%$ & 13 & 1172 & 1.00 & 1.00 & 1.00 \\
\hline$\geq 50 \%$ & 13 & 787 & $1.52(0.81-2.83)$ & $1.53(0.81-2.88)$ & $1.40(0.72-2.74)$ \\
\hline \multicolumn{6}{|l|}{ РCВ 118} \\
\hline$<$ LOD to $50 \%$ & 11 & 1000 & 1.00 & 1.00 & 1.00 \\
\hline$\geq 50 \%$ & 16 & 960 & $1.47(0.57-3.77)$ & $1.39(0.48-3.96)$ & $1.28(0.40-4.04)$ \\
\hline \multicolumn{6}{|l|}{ PCB 138} \\
\hline$<\mathrm{LOD}$ to $50 \%$ & 9 & 1070 & 1.00 & 1.00 & 1.00 \\
\hline$\geq 50 \%$ & 18 & 891 & $2.96(1.45-6.06)^{\mathrm{b}}$ & $3.12(1.32-87.40)^{b}$ & $3.05(1.21-7.69)^{\mathrm{b}}$ \\
\hline \multicolumn{6}{|l|}{ PCB 153} \\
\hline$<\operatorname{LOD}$ to $50 \%$ & 11 & 1080 & 1.00 & 1.00 & 1.00 \\
\hline$\geq 50 \%$ & 16 & 882 & $2.17(1.04-4.53)^{\mathrm{b}}$ & $2.18(0.86-5.53)$ & $2.46(0.90-6.67)$ \\
\hline \multicolumn{6}{|l|}{ PCB 180} \\
\hline$<\mathrm{LOD}$ to $50 \%$ & 14 & 1149 & 1.00 & 1.00 & 1.00 \\
\hline$\geqq 50 \%$ & 13 & 806 & $1.75(0.95-3.23)$ & $1.61(074-3.50)$ & $1.58(0.70-3.56)$ \\
\hline \multirow{2}{*}{\multicolumn{6}{|c|}{$\begin{array}{l}{ }^{1} \text { Lipid adjusted and log transformed polychlorinated biphenyls (ng/g). } \\
{ }^{2} \text { Adjusted for age and race/ethnicity. }\end{array}$}} \\
\hline & & & & & \\
\hline \multicolumn{6}{|c|}{${ }^{3}$ Adjusted for age, race/ethnicity, BMI, age at menarche; Cases/Noncases: $24 / 1754$ in $074 ; 23 / 1753$ in 099 ; } \\
\hline
\end{tabular}

Estimated ORs and 95\% confidence intervals for the risk of having ovarian cancer and the six individual PCB congeners are shown in table 3.7. In unadjusted models, PCBs were significantly associated with ovarian cancer risk for subjects in the second group ( $\geq$ $50^{\text {th }}$ percentile) when compared to the reference group $\left(<\mathrm{LOD}\right.$ to $50^{\text {th }}$ percentile) for PCB congeners 74 and 118 (Table 3.7). After adjusting for age, race/ethnicity, BMI, lactation, and age at menarche, PCB 74 and 118 remained significantly associated with ovarian cancer [ORs of 6.47 (95\% CI: 1.23-34.1) and 6.68 (95\% CI: 1.39-32.3)] (Table 3.7). 
Table 3.7. Estimated ORs ( $95 \%$ CIs) of ovarian cancer by concentration of PCBs among women $\geq 20$ years of age, NHANES 1999-2004,

\begin{tabular}{|c|c|c|c|c|c|}
\hline Analyte $^{1}$ & $\begin{array}{c}\text { No. } \\
\text { Cases }\end{array}$ & $\begin{array}{c}\text { No. } \\
\text { Noncases }\end{array}$ & $\begin{array}{l}\text { Unadjusted OR } \\
(95 \% \mathrm{CI})\end{array}$ & $\begin{array}{l}\text { Adjusted OR } \\
(95 \% \text { CI })\end{array}$ & $\begin{array}{l}\text { Adjusted OR }{ }^{3} \\
(95 \% \mathrm{CI})\end{array}$ \\
\hline \multicolumn{6}{|l|}{ PCB 074} \\
\hline$<$ LOD to $50 \%$ & 2 & 1048 & 1.00 & 1.00 & 1.00 \\
\hline$\geq 50 \%$ & 9 & 912 & $5.88(1.67-207)^{\mathrm{b}}$ & $7.31(1.62-32.9)^{b}$ & $6.47(1.23-34.1)^{b}$ \\
\hline \multicolumn{6}{|l|}{ РCB 099} \\
\hline$<$ LOD to $50 \%$ & 3 & 1171 & 1.00 & 1.00 & 1.00 \\
\hline$\geq 50 \%$ & 8 & 787 & $3.67(0.65-20.9)$ & $4.15(0.55-31.3)$ & $3.69(0.43-31.7)$ \\
\hline \multicolumn{6}{|l|}{ PCB 118} \\
\hline$<\mathrm{LOD}$ to $50 \%$ & 2 & 1000 & 1.00 & 1.00 & 1.00 \\
\hline$\geq 50 \%$ & 9 & 960 & $5.81(1.66-20.4)^{\mathrm{b}}$ & $7.17(1.64-31.3)^{\mathrm{b}}$ & $6.68(1.39-32.3)^{b}$ \\
\hline \multicolumn{6}{|l|}{ PCB 138} \\
\hline$<$ LOD to $50 \%$ & 4 & 1070 & 1.00 & 1.00 & 1.00 \\
\hline$\geq 50 \%$ & 7 & 891 & $1.22(0.24-6.28)$ & $1.23(0.15-9.81)$ & $0.97(0.12-7.63)$ \\
\hline \multicolumn{6}{|l|}{ PCB 153} \\
\hline$<$ LOD to $50 \%$ & 3 & 1080 & 1.00 & 1.00 & 1.00 \\
\hline$\geq 50 \%$ & 8 & 882 & $2.12(0.49-9.13)$ & $2.36(0.46-12.0)$ & $2.05(0.50-8.41)$ \\
\hline \multicolumn{6}{|l|}{ PCB 180} \\
\hline$<$ LOD to $50 \%$ & 3 & 1149 & 1.00 & 1.00 & 1.00 \\
\hline$\geq 50 \%$ & 8 & 806 & $2.49(0.58-10.7)$ & $2.88(0.53-15.6)$ & $2.55(0.66-9.85)$ \\
\hline
\end{tabular}

${ }^{2}$ Lipid adjusted and log transformed polychlorinated biphenyls (ng/g).

${ }^{2}$ Adjusted for age and race/ethnicity.

${ }^{3}$ Adjusted for age, race/ethnicity, BMI, age at menarche; Cases/Noncases: 10/1754in 074; 10/1753 in 099; $10 / 1755$ in $118 ; 10 / 1756$ in 138 and 153; 10/1749 in 180.

Significance ${ }^{\mathrm{a}} \mathrm{p}<0.0001,{ }^{\mathrm{b}} \mathrm{p}<0.05$.

Estimated ORs and 95\% confidence intervals for the risk of having uterine cancer and the six individual PCB congeners are shown in table 3.8. In unadjusted models, PCBs were significantly associated with uterine cancer risk for subjects in the second group ( $\geq$ $50^{\text {th }}$ percentile) when compared to the reference group ( $<$ LOD to $50^{\text {th }}$ percentile) for PCB congeners 138 and 153 (Table 3.8). After adjusting for age, race/ethnicity, BMI, lactation, and age at menarche, PCB 138 remained significantly associated with ovarian cancer [OR of 5.83 (95\% CI: 1.63-20.9)] (Table 3.8). 
Table 3.8. Estimated ORs $(95 \%$ CIs) of uterine cancer by concentration of PCBs among women $\geq 20$ years of age, NHANES 1999-2004.

\begin{tabular}{|c|c|c|c|c|c|}
\hline Analyte $^{1}$ & $\begin{array}{c}\text { No. } \\
\text { Cases }\end{array}$ & $\begin{array}{c}\text { No. } \\
\text { Noncases }\end{array}$ & $\begin{array}{l}\text { Unadjusted OR } \\
(95 \% \mathrm{CI})\end{array}$ & $\begin{array}{c}\text { Adjusted OR }{ }^{2} \\
(95 \% \mathrm{CI})\end{array}$ & $\begin{array}{c}\text { Adjusted OR }{ }^{3} \\
(95 \% \text { CI })\end{array}$ \\
\hline \multicolumn{6}{|l|}{ РCB 074} \\
\hline$<$ LOD to $50 \%$ & 8 & 1048 & 1.00 & 1.00 & 1.00 \\
\hline$\geq 50 \%$ & 18 & 912 & $2.13(0.63-7.15)$ & $1.41(0.36-5.55)$ & $1.55(0.34-7.06)$ \\
\hline \multicolumn{6}{|l|}{ РС̄ В 099} \\
\hline$<$ LOD to $50 \%$ & 13 & 1171 & 1.00 & 1.00 & 1.00 \\
\hline$\geq 50 \%$ & 12 & 787 & $1.55(0.46-5.27)$ & $1.19(0.28-4.97)$ & $1.43(0.34-6.06)$ \\
\hline \multicolumn{6}{|l|}{ PCB 118} \\
\hline$<$ LOD to $50 \%$ & 10 & 1000 & 1.00 & 1.00 & 1.00 \\
\hline$\geq 50 \%$ & 16 & 960 & $1.60(0.55-4.63)$ & $1.07(0.24-4.76)$ & $1.52(0.39-5.92)$ \\
\hline \multicolumn{6}{|l|}{ PCВ 138} \\
\hline$<$ LOD to $50 \%$ & 7 & 1070 & 1.00 & 1.00 & 1.00 \\
\hline$\geq 50 \%$ & 19 & 891 & $4.84(1.68-13.9)^{\mathrm{b}}$ & $4.29(1.21-15.2)^{\mathrm{b}}$ & $5.83(1.63-20.9)^{\mathrm{b}}$ \\
\hline \multicolumn{6}{|l|}{ РCB 153} \\
\hline$<$ LOD to $50 \%$ & 8 & 1080 & 1.00 & 1.00 & 1.00 \\
\hline$\geq 50 \%$ & 18 & 882 & $3.71(1.39-9.89)^{b}$ & $3.14(0.89-11.0)$ & $4.07(1.19-14.0)$ \\
\hline \multicolumn{6}{|l|}{ PC $\bar{C} 180$} \\
\hline$<$ LOD to $50 \%$ & 8 & 1149 & 1.00 & 1.00 & 1.00 \\
\hline$\geq 50 \%$ & 18 & 806 & $2.64(0.79-8.87)$ & $2.00(0.60-6.61)$ & $1.70(0.53-5.45)$ \\
\hline
\end{tabular}

${ }^{1}$ Lipid adjusted and log transformed polychlorinated biphenyls (ng/g).

${ }^{2}$ Adjusted for age and race/ethnicity.

${ }^{3}$ Adjusted for age, race/ethnicity, BMI, age at menarche; Cases/Noncases: 24/1754 in 074; 24/1753in 099; $25 / 1755$ in $118 ; 25 / 1756$ in 138 and $153 ; 25 / 1749$ in 180 .

Significance ${ }^{\mathrm{a}} \mathrm{p}<0.0001,{ }^{\mathrm{b}} \mathrm{p}<0.05$.

Estimated ORs and 95\% confidence intervals for the risk of having a reproductive cancer and dioxin-like and non-dioxin-like PCBs are shown in table 3.9. In the unadjusted models, dioxin-like and non-dioxin-like PCBs were significantly associated with breast cancer, ovarian cancer and uterine cancer. In the age and race/ethnicity adjusted models, dioxin-like PCBs were significantly associated with breast cancer (OR of $1.50,95 \%$ CI: $1.27-1.77$ ) and ovarian cancer (OR of $1.95,95 \%$ CI: $1.25-3.05)$ and non-dioxin-like PCBs were significantly associated with breast cancer (OR of 1.14, 95\% CI: 1.00-1.29), cervical cancer (OR of 1.29, 95\% CI: 1.18-1.40), ovarian cancer (OR of 1.32, 95\% CI: 1.02-1.69), and uterine cancer (OR of 1.11, 95\% CI: 1.01-1.22). After adjusting for age, race/ethnicity, BMI, and age at menarche dioxin-like PCBs remained 
significantly associated with ovarian cancer risk (OR of 2.02, 95\% CI: 1.06-3.85) and non-dioxin-like PCBs remained significantly associated with uterine cancer risk (OR of 1.12, 95\% CI: 1.03-1.23) (Table 3.9). We further analyzed reproductive cancer risk of dioxin-like and non-dioxin-like PCBs using the following two groups: $<$ LOD to $50^{\text {th }}$ percentile (reference group) and $\geq 50^{\text {th }}$ percentile. In subjects with PCB levels $\geq 50^{\text {th }}$ percentile, breast cancer, ovarian cancer, and uterine cancer were associated with dioxinlike and non-dioxin-like PCBs in the unadjusted models. Non-dioxin-like PCBs were significantly associated with cervical cancer risk and ovarian cancer risk in the age and race/ethnicity adjusted models [ORs of 2.59, (95\% CI: 1.04-6.42) and 6.62, )95\% CI: 1.50-29.2)], respectively. Dioxin-like PCBs were associated with the risk of ovarian cancer in the age and race/ethnicity adjusted models [OR of 6.32 (95\% CI: 1.44-27.7)]. In the final adjusted models (age, race/ethnicity, BMI, age at menarche) the risk of ovarian cancer remained significant for dioxin-like PCBs [OR of 5.71 (95\% CI: 1.1229.2)] and non-dioxin-like PCBs [OR of 5.99 (95\% CI: 1.20-29.9)] and the risk of uterine cancer remained significant for non-dioxin-like PCBs [OR of 4.85 (95\% CI: 1.32-17.8)] (Table 3.9). 
Table 3.9. Estimated ORs (95\% CIs) of a reproductive cancer by concentrations of dioxin-like and nondioxin-like PCBs among women $\geq 20$ years of age, NHANES 1999-2004.

\begin{tabular}{|c|c|c|c|c|}
\hline & Cases/Noncases & $\begin{array}{c}\text { Unadjusted OR } \\
(95 \% \mathrm{CI})\end{array}$ & $\begin{array}{l}\text { Adjusted OR }{ }^{1} \\
(95 \% \mathrm{CI})\end{array}$ & $\begin{array}{l}\text { Adjusted OR } \\
(95 \% \text { CI })\end{array}$ \\
\hline \multicolumn{5}{|l|}{ Breast Cancer } \\
\hline $\begin{array}{l}\text { Dioxin-like PCBs } \\
\text { Dioxin-like PCBs } 50^{3,5}\end{array}$ & $43 / 1953$ & $1.50(1.27-1.78)^{\mathrm{a}}$ & $1.50(1.27-1.77)^{\mathrm{a}}$ & $1.08(0.80-1.45)$ \\
\hline $\begin{array}{l}<\text { LOD to } 50 \% \\
\geq 50 \%\end{array}$ & $\begin{array}{r}4 / 985 \\
39 / 968\end{array}$ & $\begin{array}{l}1.00 \\
5.23(2.25-12.2)^{\mathrm{a}}\end{array}$ & $\begin{array}{l}1.00 \\
1.55(0.49-4.90)\end{array}$ & $\begin{array}{l}1.00 \\
1.90(0.33-10.8)\end{array}$ \\
\hline Non- Dioxin-like PCBs ${ }^{4}$ & $43 / 1941$ & $1.28(1.18-1.38)^{\mathrm{a}}$ & $1.14(1.00-1.29)^{b}$ & $1.12(0.98-1.28)$ \\
\hline $\begin{array}{l}\text { Non-Dioxin-like PCBs_50 } 4,5 \\
<\text { LOD to } 50 \% \\
>50 \%\end{array}$ & $\begin{array}{r}2 / 997 \\
41 / 944\end{array}$ & $\begin{array}{l}1.00 \\
12.7(2.58-62.2)^{\mathrm{b}}\end{array}$ & $\begin{array}{l}1.00 \\
5.40(0.87-33.5)\end{array}$ & $\begin{array}{l}1.00 \\
4.27(0.68-26.8)\end{array}$ \\
\hline Cervical Cancer & & & & \\
\hline $\begin{array}{l}\text { Dioxin-like PCBs } \\
\text { Dioxin-like PCBs } 50^{3,5}\end{array}$ & $27 / 1954$ & $1.15(0.91-1.45)$ & $1.13(0.82-1.56)$ & $1.10(0.78-1.55)$ \\
\hline $\begin{array}{l}<\text { LOD to } 50 \% \\
\geq 50 \%\end{array}$ & $\begin{array}{r}12 / 985 \\
15 / 968\end{array}$ & $\begin{array}{l}1.00 \\
1.13(0.50-2.58)\end{array}$ & $\begin{array}{l}1.00 \\
1.04(0.90-1.20)\end{array}$ & $\begin{array}{l}1.00 \\
0.80(0.27-2.38)\end{array}$ \\
\hline $\begin{array}{l}\text { Non- Dioxin-like PCBs }{ }^{4} \\
\text { Non-Dioxin-like PCBs } 50^{4,5}\end{array}$ & $26 / 1941$ & $1.05(0.94-1.16)$ & $1.29(1.18-1.40)^{\mathrm{a}}$ & $1.02(0.87-1.19)$ \\
\hline $\begin{array}{l}<\text { LOD to } 50 \% \\
\geq 50 \%\end{array}$ & $\begin{array}{r}9 / 997 \\
17 / 944\end{array}$ & $\begin{array}{l}1.00 \\
2.38(1.14-4.94)^{\mathrm{b}}\end{array}$ & $\begin{array}{l}1.00 \\
2.59(1.04-6.42)^{\mathrm{b}}\end{array}$ & $\begin{array}{l}1.00 \\
2.51(0.94-6.68)\end{array}$ \\
\hline Ovarian Cancer & & & & \\
\hline $\begin{array}{l}\text { Dioxin-like PCBs } \\
\text { Dioxin-like PCBs } 50^{3,5}\end{array}$ & $11 / 1954$ & $1.61(1.19-2.17)^{\mathrm{a}}$ & $1.95(1.25-3.05)^{b}$ & $2.02(1.06-3.85)^{b}$ \\
\hline $\begin{array}{l}<\text { LOD to } 50 \% \\
\geq 50 \%\end{array}$ & $\begin{array}{l}2 / 985 \\
9 / 968\end{array}$ & $\begin{array}{l}1.00 \\
5.26(1.51-18.4)^{\mathrm{b}}\end{array}$ & $\begin{array}{l}1.00 \\
6.32(1.44-27.7)^{\mathrm{b}}\end{array}$ & $\begin{array}{l}1.00 \\
5.71(1.12-29.2)^{\mathrm{b}}\end{array}$ \\
\hline $\begin{array}{l}\text { Non- Dioxin-like PCBs } \\
\text { Non-Dioxin-like PCBs } 50^{4,5}\end{array}$ & $11 / 1941$ & $1.24(1.01-1.53)^{b}$ & $1.32(1.02-1.69)^{b}$ & $1.30(0.98-1.72)$ \\
\hline $\begin{array}{l}<\text { LOD to } 50 \% \\
\geq 50 \%\end{array}$ & $\begin{array}{l}2 / 997 \\
9 / 994\end{array}$ & $\begin{array}{l}1.00 \\
5.51(1.56-19.5)^{\mathrm{b}}\end{array}$ & $\begin{array}{l}1.00 \\
6.62(1.50-29.2)^{\mathrm{b}}\end{array}$ & $\begin{array}{l}1.00 \\
5.99(1.20-29.9)^{\mathrm{b}}\end{array}$ \\
\hline Uterine Cancer & & & & \\
\hline $\begin{array}{l}\text { Dioxin-like PCBs } \\
\text { Dioxin-like PCBs } 50^{3,5}\end{array}$ & $26 / 1954$ & $1.16(0.88-1.52)$ & $1.02(0.76-1.37)$ & $1.10(0.83-1.46)$ \\
\hline $\begin{array}{l}<\text { LOD to } 50 \% \\
\geq 50 \%\end{array}$ & $\begin{array}{l}10 / 985 \\
16 / 968\end{array}$ & $\begin{array}{l}1.00 \\
1.14(1.04-1.25)^{\mathrm{b}}\end{array}$ & $\begin{array}{l}1.00 \\
0.87(0.18-4.21)\end{array}$ & $\begin{array}{l}1.00 \\
1.24(0.29-5.28)\end{array}$ \\
\hline $\begin{array}{l}\text { Non- Dioxin-like PCBs } \\
\text { Non-Dioxin-like PCBs } 50^{4}=\end{array}$ & $25 / 1941$ & $1.28(1.18-1.38)^{b}$ & $1.11(1.01-1.22)^{b}$ & $1.12(1.03-1.23)^{b}$ \\
\hline $\begin{array}{l}<\text { LOD to } 50 \% \\
\geq 50 \%\end{array}$ & $\begin{array}{r}7 / 997 \\
18 / 944\end{array}$ & $\begin{array}{l}1.00 \\
4.14(1.44-11.3)^{\mathrm{b}}\end{array}$ & $\begin{array}{l}1.00 \\
3.53(0.96-13.1)\end{array}$ & $\begin{array}{l}1.00 \\
4.85(1.32-17.8)^{\mathrm{b}}\end{array}$ \\
\hline
\end{tabular}


${ }^{1}$ Adjusted for age and race/ethnicity.

${ }^{2}$ Adjusted for age, race/ethnicity, BMI, age at menarche.

${ }^{a}$ Cases/Noncases in dioxin-like PCBs : 40/1749 for breast cancer, 24/1749 for cervical cancer, 10/1749 for ovarian cancer, $25 / 1749$ for uterine cancer.

${ }^{\mathrm{b}}$ Cases/Noncases in non-dioxin-like PCBs: $40 / 1737$ for breast cancer, 23/1737 for cervical cancer, 10/1737 for ovarian cancer, $24 / 1737$ for uterine cancer.

${ }^{3}$ Dioxin-like PCBs: Sum of lipid adjusted and log transformed PCB Congeners $(074+118)$.

${ }^{4}$ Non-Dioxin-like PCBs: Sum of lipid adjusted \& $\log$ transformed PCB Congeners $(099+138+153+180)$.

${ }^{5}$ Serum PCB Levels $<50^{\text {th }}$ percentile vs $\geq 50^{\text {th }}$ percentile.

Significance ${ }^{\mathrm{a}} \mathrm{p}<0.0001,{ }^{\mathrm{b}} \mathrm{p}<0.05$.

Estimated ORs and 95\% CIs for the risk of having breast, cervical, ovarian, or uterine cancer and the eight phthalate metabolites, the sum of DEHP, and total phthalates are shown in tables 3.10-3.13. We analyzed the phthalate levels the in the following group: $<$ LOD to $50^{\text {th }}$ percentile (reference group) and $\geq 50^{\text {th }}$ percentile. Results are presented for two logistic regression models: age and race adjusted; and age, race/ethnicity, BMI, and age at menarche adjusted. Results were not presented for unadjusted models because the derived ORs and 95\% CIs did not differ from the models presented. A significant association between breast cancer or cervical cancer and phthalates was not found in any of the models (Table 3.10 and 3.11). 
Table 3.10. Estimated ORs (95\% CIS) of breast cancer by concentration of creatinine corrected urinary phthalate metabolite among women $\geq 20$ years of age, NHANES 2003-2010.

\begin{tabular}{|c|c|c|c|c|}
\hline Metabolite $^{1}$ & $\begin{array}{r}\text { No. } \\
\text { Cases }\end{array}$ & $\begin{array}{c}\text { No. } \\
\text { Noncases }\end{array}$ & $\begin{array}{l}\text { Adjusted } \mathrm{OR}^{2} \\
(95 \% \mathrm{CI})\end{array}$ & $\begin{array}{c}\text { Adjusted } \mathrm{OR}^{3} \\
(95 \% \mathrm{CI})\end{array}$ \\
\hline \multicolumn{5}{|l|}{$\overline{\mathrm{MBP}}$} \\
\hline$<$ LOD to $50 \%$ & 41 & 1045 & 1.00 & 1.00 \\
\hline$\geq 50 \%$ & 56 & 1678 & $0.89(0.49-1.64)$ & $0.85(0.47-1.55)$ \\
\hline \multicolumn{5}{|l|}{ MEP } \\
\hline$<\mathrm{LOD}$ to $50 \%$ & 47 & 1106 & 1.00 & 1.00 \\
\hline$\geq 50 \%$ & 50 & 21616 & $0.66(0.38-1.15)$ & $0.63(0.36-1.10)$ \\
\hline \multicolumn{5}{|l|}{ МЕНР } \\
\hline$<$ LOD to $50 \%$ & 57 & 1339 & 1.00 & 1.00 \\
\hline$\geq 50 \%$ & 40 & 1376 & $0.94(0.50-1.76)$ & $0.92(0.48-1.74)$ \\
\hline \multicolumn{5}{|l|}{ MBzP } \\
\hline$<\mathrm{LOD}$ to $50 \%$ & 52 & 1205 & 1.00 & 1.00 \\
\hline$\geq 50 \%$ & 45 & 1517 & $0.75(0.44-1.29)$ & $0.72(0.42-1.23)$ \\
\hline \multicolumn{5}{|l|}{ МССР } \\
\hline$<\mathrm{LOD}$ to $50 \%$ & 51 & 1396 & 1.00 & 1.00 \\
\hline$\geq 50 \%$ & 46 & 1326 & $0.86(0.51-1.43)$ & $0.83(0.49-1.40)$ \\
\hline \multicolumn{5}{|l|}{ МЕННР } \\
\hline$<\mathrm{LOD}$ to $50 \%$ & 40 & 1280 & 1.00 & 1.00 \\
\hline$\geq 50 \%$ & 57 & 1443 & $1.23(0.74-2.03)$ & $1.15(0.71-1.86)$ \\
\hline \multicolumn{5}{|l|}{ МЕОНР } \\
\hline$<\mathrm{LOD}$ to $50 \%$ & 39 & 1267 & 1.00 & 1.00 \\
\hline$\geq 50 \%$ & 58 & 1456 & $1.27(0.75-2.17)$ & $1.19(0.71-1.99)$ \\
\hline \multicolumn{5}{|l|}{ MIB } \\
\hline$<$ LOD to $50 \%$ & 57 & 1260 & 1.00 & 1.00 \\
\hline$\geq 50 \%$ & 40 & 1457 & $0.69(0.42-1.14)$ & $0.71(0.42-1.18)$ \\
\hline \multicolumn{5}{|l|}{ DEHP } \\
\hline$<$ LOD to $50 \%$ & 50 & 1301 & 1.00 & 1.00 \\
\hline$\geq 50 \%$ & 47 & 1422 & $0.91(0.50-1.64)$ & $0.85(0.46-1.55)$ \\
\hline \multicolumn{5}{|l|}{ Total } \\
\hline$<\mathrm{LOD}$ to $50 \%$ & 55 & 1423 & 1.00 & 1.00 \\
\hline$\geq 50 \%$ & 42 & 1300 & $0.84(0.48-1.48)$ & $0.81(0.40-1.63)$ \\
\hline
\end{tabular}

${ }^{\mathrm{I}}$ Log transformed and creatinine adjusted urinary phthalates (ng/mg).

${ }^{2}$ Adusted for age and race/ethnicity .

${ }^{3}$ Adjusted for age, race/ethnicity, BMI, age at menarche; Cases/Noncases: 91/2410 in MBP, MEHHP, MEOHP, MIB, DEHP; 91/2409 in MEP, MCCP, MBzP; 91/2403 in MEHP.

Significance ${ }^{\mathrm{a}} \mathrm{p}<0.001,{ }^{\mathrm{b}} \mathrm{p}<0.05$. 
Table 3.11. Estimated ORs (95\% CIs) of cervical cancer by concentration of creatinine corrected urinary phthalate metabolite among women $\geq 20$ years of age, NHANES 2003-2010.

\begin{tabular}{|c|c|c|c|c|}
\hline Metabolite $^{1}$ & $\begin{array}{c}\text { No. } \\
\text { Cases }\end{array}$ & $\begin{array}{c}\text { No. } \\
\text { Noncases }\end{array}$ & $\begin{array}{c}\text { Adjusted OR } \\
(95 \% \text { CI) }\end{array}$ & $\begin{array}{l}\text { Adjusted } \mathrm{OR}^{3} \\
(95 \% \mathrm{CI})\end{array}$ \\
\hline \multicolumn{5}{|l|}{ MBP } \\
\hline$<$ LOD to $50 \%$ & 10 & 1045 & 1.00 & 1.00 \\
\hline$\geq 50 \%$ & 18 & 1678 & $0.70(0.25-1.97)$ & $0.64(0.22-1.85)$ \\
\hline \multicolumn{5}{|l|}{ MEP } \\
\hline$<$ LOD to $50 \%$ & 14 & 1106 & 1.00 & 1.00 \\
\hline$\geq 50 \%$ & 14 & 1616 & $0.91(0.39-2.14)$ & $0.80(0.33-1.97)$ \\
\hline \multicolumn{5}{|l|}{ МЕНР } \\
\hline$<$ LOD to $50 \%$ & 12 & 1339 & 1.00 & 1.00 \\
\hline$\geq 50 \%$ & 16 & 1376 & $0.95(0.46-1.96)$ & $0.91(0.44-1.88)$ \\
\hline \multicolumn{5}{|l|}{ MBzP } \\
\hline$<\mathrm{LOD}$ to $50 \%$ & 10 & 1205 & 1.00 & 1.00 \\
\hline$\geq 50 \%$ & 18 & 1517 & $1.07(0.51-2.22)$ & $1.04(0.49-2.21)$ \\
\hline \multicolumn{5}{|l|}{ МССР } \\
\hline$<$ LOD to $50 \%$ & 16 & 1396 & 1.00 & 1.00 \\
\hline$\geq 50 \%$ & 12 & 1326 & $0.73(0.38-1.38)$ & $0.77(0.41-1.47)$ \\
\hline \multicolumn{5}{|l|}{ МЕННР } \\
\hline$<\mathrm{LOD}$ to $50 \%$ & 10 & 1280 & 1.00 & 1.00 \\
\hline$\geq 50 \%$ & 18 & 1443 & $1.10(0.39-3.11)$ & $1.00(0.36-2.77)$ \\
\hline \multicolumn{5}{|l|}{ МЕОНР } \\
\hline$<$ LOD to $50 \%$ & 11 & 1267 & 1.00 & 1.00 \\
\hline$\geq 50 \%$ & 17 & 1456 & $0.77(0.31-1.87)$ & $0.68(0.28-1.65)$ \\
\hline \multicolumn{5}{|l|}{ MIB } \\
\hline$<\mathrm{LOD}$ to $50 \%$ & 14 & 1260 & 1.00 & 1.00 \\
\hline$\geq 50 \%$ & 14 & 1457 & $0.81(0.35-1.87)$ & $0.85(0.35-2.03)$ \\
\hline \multicolumn{5}{|l|}{ DEHP } \\
\hline$<\mathrm{LOD}$ to $50 \%$ & 12 & 1301 & 1.00 & 1.00 \\
\hline$\geq 50 \%$ & 16 & 1422 & $0.79(0.33-1.92)$ & $0.73(0.30-1.76)$ \\
\hline \multicolumn{5}{|l|}{ Total } \\
\hline$<$ LOD to $50 \%$ & 12 & 1423 & 1.00 & 1.00 \\
\hline$\geq 50 \%$ & 16 & 1300 & $0.98(0.44-2.17)$ & $0.81(0.38-1.74)$ \\
\hline
\end{tabular}

${ }_{\mathrm{I}}$ Log transformed and creatinine adjusted urinary phthalates $(\mathrm{ng} / \mathrm{mg})$.

${ }^{2}$ Adjusted for age and race/ethnicity.

${ }^{3}$ Adjusted for age, race/ethnicity, BMI, age at menarche; Cases/Noncases: 26/2410 in MBP, MEHHP, MEOHP, MIB, DEHP; 26/2409 in MEP, MBzP, MCCP; 26/2403 in MEHP.

Significance ${ }^{\mathrm{a}} \mathrm{p}<0.0001,{ }^{\mathrm{b}} \mathrm{p}<0.05$.

Estimated ORs and 95\% CIs for the risk of ovarian cancer and uterine cancer by concentration of the eight phthalate metabolites, the sum of DEHP, and total phthalates are shown in table 3.12 and 3.13. In the age and race adjusted model, MEHHP showed a weak association with ovarian cancer [OR of 3.63 (95\%CI: 1.00-13.2), p=.0497], however this association did remain significant after adjusting for age, race/ethnicity, 
BMI, and age at menarche (Table 3.12). None of the phthalates were significantly associated with the risk of uterine cancer (Table 3.13).

Table 3.12. Estimated ORs (95\% CIs) of ovarian cancer by concentration of creatinine corrected urinary phthalate metabolite among women $\geq 20$ years of age, NHANES 2003-2010.

\begin{tabular}{|c|c|c|c|c|}
\hline Metabolite $^{1}$ & $\begin{array}{c}\text { No. } \\
\text { Cases }\end{array}$ & $\begin{array}{c}\text { No. } \\
\text { Noncases }\end{array}$ & $\begin{array}{c}\text { Adjusted OR } \\
(95 \% \text { CI })\end{array}$ & $\begin{array}{c}\text { Adjusted OR } \\
(95 \% \text { CI })\end{array}$ \\
\hline \multicolumn{5}{|l|}{$\overline{\mathrm{MBP}}$} \\
\hline$<\mathrm{LOD}$ to $50 \%$ & 6 & 1045 & 1.00 & 1.00 \\
\hline$\geq 50 \%$ & 14 & 1678 & $1.96(0.61-6.31)$ & $1.48(0.42-5.19)$ \\
\hline \multicolumn{5}{|l|}{ МЕР } \\
\hline$<\mathrm{LOD}$ to $50 \%$ & 11 & 1106 & 1.00 & 1.00 \\
\hline$\geq 50 \%$ & 9 & 1616 & $0.43(0.17-1.12)$ & $0.38(0.11-1.30)$ \\
\hline \multicolumn{5}{|l|}{ МЕНР } \\
\hline$<$ LOD to $50 \%$ & 7 & 1339 & 1.00 & 1.00 \\
\hline$\geq 50 \%$ & 13 & 1376 & $2.56(0.92-7.10)$ & $1.91(0.61-5.94)$ \\
\hline \multicolumn{5}{|l|}{ MBzP } \\
\hline$<\mathrm{LOD}$ to $50 \%$ & 10 & 1205 & 1.00 & 1.00 \\
\hline$\geq 50 \%$ & 10 & 1517 & $1.65(0.56-4.83)$ & $1.59(0.50-5.11)$ \\
\hline \multicolumn{5}{|l|}{ МССР } \\
\hline$<\mathrm{LOD}$ to $50 \%$ & 12 & 1396 & 1.00 & 1.00 \\
\hline$\geq 50 \%$ & 8 & 1326 & $1.13(0.35-3.60)$ & $1.24(0.36-4.25)$ \\
\hline \multicolumn{5}{|l|}{ МЕННР } \\
\hline$<$ LOD to $50 \%$ & 4 & 1280 & 1.00 & 1.00 \\
\hline$\geq 50 \%$ & 16 & 1443 & $3.63(1.00-13.2)^{\mathrm{b}}$ & $2.73(0.67-11.1)$ \\
\hline \multicolumn{5}{|l|}{ МЕОНР } \\
\hline$<$ LOD to $50 \%$ & 4 & 1267 & 1.00 & 1.00 \\
\hline$\geq 50 \%$ & 16 & 1456 & $3.58(0.98-13.1)$ & $2.67(0.678-10.6)$ \\
\hline \multicolumn{5}{|l|}{ MIB } \\
\hline$<$ LOD to $50 \%$ & 11 & 1260 & 1.00 & 1.00 \\
\hline$\geq 50 \%$ & 9 & 1457 & $0.57(0.16-1.99)$ & $0.61(0.13-2.83)$ \\
\hline \multicolumn{5}{|l|}{ DEHP } \\
\hline$<$ LOD to $50 \%$ & 6 & 1301 & 1.00 & 1.00 \\
\hline$\geq 50 \%$ & 14 & 1422 & $2.88(0.95-8.76)$ & $2.29(0.64-8.23)$ \\
\hline \multicolumn{5}{|l|}{ Total } \\
\hline$<$ LOD to $50 \%$ & 9 & 1423 & 1.00 & 1.00 \\
\hline$\geq 50 \%$ & 11 & 1300 & $1.21(0.46-3.17)$ & $1.38(0.46-4.17)$ \\
\hline
\end{tabular}

${ }^{1}$ Log transformed and creatinine adjusted urinary phthalates (ng/mg).

${ }^{2}$ Adjusted for age and race/ethnicity.

${ }^{3}$ Adjusted for age, race/ethnicity, BMI, age at menarche; Cases/Noncases: 17/2410 in MBP, MEHHP, MEOHP, MIB, DEHP; 17/2409 in MEP, MBzP, MCCP; 17/2403 in MEHP.

Significance ${ }^{\mathrm{a}} \mathrm{p}<0.0001,{ }^{\mathrm{b}} \mathrm{p}<0.05$. 
Table 3.13. Estimated ORs ( $95 \%$ CIs) of uterine cancer by concentration of creatinine corrected urinary phthalate metabolite among women $\geq 20$ years of age, NHANES 2003-2010.

\begin{tabular}{|c|c|c|c|c|}
\hline Metabolite $^{1}$ & $\begin{array}{c}\text { No. } \\
\text { Cases }\end{array}$ & $\begin{array}{c}\text { No. } \\
\text { Noncases }\end{array}$ & $\begin{array}{c}\text { Adjusted OR }{ }^{2} \\
(95 \% \mathrm{CI})\end{array}$ & $\begin{array}{c}\text { Adjusted } \mathrm{OR}^{3} \\
(95 \% \mathrm{CI})\end{array}$ \\
\hline \multicolumn{5}{|l|}{ MBP } \\
\hline$<$ LOD to $50 \%$ & 10 & 1045 & 1.00 & 1.00 \\
\hline$\geq 50 \%$ & 17 & 1678 & $1.17(0.36-3.78)$ & $1.11(0.33-3.68)$ \\
\hline \multicolumn{5}{|l|}{ MEP } \\
\hline$<$ LOD to $50 \%$ & 12 & 1106 & 1.00 & 1.00 \\
\hline$\geq 50 \%$ & 15 & 1616 & $1.02(0.47-2.20)$ & $0.99(0.46-2.12)$ \\
\hline \multicolumn{5}{|l|}{ МЕНР } \\
\hline$<$ LOD to $50 \%$ & 21 & 1339 & 1.00 & 1.00 \\
\hline$\geq 50 \%$ & 6 & 1376 & $0.34(0.11-1.03)$ & $0.34(0.11-1.09)$ \\
\hline \multicolumn{5}{|l|}{ MBzP } \\
\hline$<\mathrm{LOD}$ to $50 \%$ & 16 & 1205 & 1.00 & 1.00 \\
\hline$\geq 50 \%$ & 11 & 1517 & $0.59(0.23-1.48)$ & $0.55(0.21-1.43)$ \\
\hline \multicolumn{5}{|l|}{ МССР } \\
\hline$<$ LOD to $50 \%$ & 14 & 1396 & 1.00 & 1.00 \\
\hline$\geq 50 \%$ & 13 & 1326 & $0.88(0.32-2.45)$ & $0.85(0.31-2.32)$ \\
\hline \multicolumn{5}{|l|}{ МЕННР } \\
\hline$<$ LOD to $50 \%$ & 10 & 1280 & 1.00 & 1.00 \\
\hline$\geq 50 \%$ & 17 & 1443 & $1.55(0.65-3.70)$ & $1.43(0.61-3.34)$ \\
\hline \multicolumn{5}{|l|}{ МЕОНР } \\
\hline$<\mathrm{LOD}$ to $50 \%$ & 11 & 1267 & 1.00 & 1.00 \\
\hline$\geq 50 \%$ & 16 & 1450 & $1.02(0.46-2.23)$ & $0.95(0.45-2.02)$ \\
\hline \multicolumn{5}{|l|}{ MIB } \\
\hline$<$ LOD to $50 \%$ & 12 & 1260 & 1.00 & 1.00 \\
\hline$\geq 50 \%$ & 15 & 2337 & $1.20(0.45-3.17)$ & $1.21(0.45-3.20)$ \\
\hline \multicolumn{5}{|l|}{ DEHP } \\
\hline$<\mathrm{LOD}$ to $50 \%$ & 15 & 1301 & 1.00 & 1.00 \\
\hline$\geq 50 \%$ & 12 & 1422 & $0.92(0.40-2.12)$ & $0.87(0.39-1.93)$ \\
\hline \multicolumn{5}{|l|}{ Total } \\
\hline$<\mathrm{LOD}$ to $50 \%$ & 13 & 1423 & 1.00 & 1.00 \\
\hline$\geq 50 \%$ & 14 & 1300 & $0.98(0.34-2.84)$ & $0.92(0.30-2.79)$ \\
\hline
\end{tabular}

${ }^{\mathrm{1}}$ Log transformed and creatinine adjusted urinary phthalates (ng/mg).

${ }^{2}$ Adjusted for age and race/ethnicity

${ }^{3}$ Adjusted for age, race/ethnicity, BMI, age at menarche; Cases/Noncases: 27/2410 in MBP, MEHHP, MEOHP, MIB, DEHP; 27/2409 in MEP, MBzP, MCCP; 27/2403 in MEHP

Significance ${ }^{\mathrm{a}} \mathrm{p}<0.0001,{ }^{\mathrm{b}} \mathrm{p}<0.05$.

Estimated ORs and 95\% confidence intervals for the risk of having breast, cervical, ovarian, or uterine cancers cancer by concentration of BPA are shown in table 3.14. The following two groups were used to estimate reproductive cancer risk: < LOD to $50^{\text {th }}$ percentile (reference group) and $\geq 50^{\text {th }}$ percentile. Results are presented for three logistic regression models: unadjusted; age and race/ethnicity adjusted; and age, race/ethnicity, BMI, and age at menarche adjusted. None of the models showed a 
significant association between BPA and breast cancer, cervical cancer, ovarian cancer, or uterine cancer (Table 3.14).

Table 3.14. Estimated ORs $(95 \%$ CIs) of a reproductive cancer by concentration of creatinine adjusted urinary BPA among women $\geq 20$ years of age, NHANES 2005-2010.

\begin{tabular}{|c|c|c|c|c|c|}
\hline & $\begin{array}{l}\text { No. } \\
\text { Cases }\end{array}$ & $\begin{array}{l}\text { No. } \\
\text { Noncases }\end{array}$ & $\begin{array}{l}\text { Unadjusted OR } \\
(95 \% \mathrm{CI})\end{array}$ & $\begin{array}{l}\text { Adjusted OR } \\
\quad(95 \% \mathrm{CI})\end{array}$ & $\begin{array}{l}\text { Adjusted OR }{ }^{2} \\
\quad(95 \% \mathrm{CI})\end{array}$ \\
\hline \multicolumn{6}{|l|}{ Breast Cancer } \\
\hline$<$ LOD to $50 \%$ & 44 & 985 & 1.00 & 1.00 & 1.00 \\
\hline$\geq 50 \%$ & 34 & 1082 & $0.67(0.40-1.14)$ & $0.76(0.45-1.30)$ & $0.73(0.42-1.23)$ \\
\hline \multicolumn{6}{|l|}{ Cervical Cancer } \\
\hline$<$ LOD to $50 \%$ & 6 & 985 & 1.00 & 1.00 & 1.00 \\
\hline$\geq 50 \%$ & 9 & 1082 & $1.34(0.37-4.81)$ & $1.39(0.39-4.91)$ & $1.33(0.42-4.18)$ \\
\hline \multicolumn{6}{|l|}{ Ovarian Cancer } \\
\hline$<\mathrm{LOD}$ to $50 \%$ & 6 & 985 & 1.00 & 1.00 & 1.00 \\
\hline$\geq 50 \%$ & 10 & 1082 & $1.57(0.43-5.76)$ & $1.64(0.43-6.25)$ & $1.41(0.30-6.70)$ \\
\hline \multicolumn{6}{|l|}{ Uterine Cancer } \\
\hline$<\mathrm{LOD}$ to $50 \%$ & 13 & 985 & 1.00 & 1.00 & 1.00 \\
\hline$\geq 50 \%$ & 9 & 1082 & $0.58(0.27-1.28)$ & $0.65(0.30-1.41)$ & $0.57(0.25-1.29)$ \\
\hline \multicolumn{6}{|c|}{$\begin{array}{l}\text { Log -transformed and creatinine adjusted BPA measurements (ng/mg); NHANES 2005-2010. } \\
{ }^{1} \text { Adjusted for age and race/ethnicity. }\end{array}$} \\
\hline
\end{tabular}

\section{DISCUSSION}

In this cross-sectional study of women 20-85 years of age, we separately evaluated 6 individual PCB congeners, the sum of dioxin-like PCBs, the sum of nondioxin-like PCBs, eight phthalate metabolites, the sum of DEHP, the sum of total phthalates, and BPA in association with reproductive cancers (breast, cervical, ovarian, and uterine) in women. In women with detectable PCB levels, higher exposures were found in women diagnosed with breast cancer, ovarian cancer, and cervical cancer compared to women never diagnosed with cancer. Epidemiological studies on the association of PCBs with cervical cancer, ovarian cancer, and uterine cancer are lacking but our findings are consistent with breast cancer studies that have reported higher PCB levels in breast cancer cases compared to controls (Charlier et al. 2004 and Recio-Vega et al. 2001) Charlier et al. 2004found total PCBs and PCB 153 to be significantly higher in 
cases compared to controls [7.08 ppb vs. $5.10 \mathrm{ppb}(\mathrm{p}=0.012)]$ and $[1.63 \mathrm{ppb}$ vs. $0.63 \mathrm{ppb}$ ( $\mathrm{p}<0.0001)$ ] respectively, and Recio-Vega et al. (2001) found total PCBs to be significantly higher in cases vs. controls (5.26 ppb vs. $3.33 \mathrm{ppb)} \mathrm{as} \mathrm{well} \mathrm{as} \mathrm{an} \mathrm{increased}$ risk of breast cancer among $8 \mathrm{PCB}$ congeners. While these results do not provide any evidence of causal associations, it is noteworthy that women diagnosed with breast cancer, ovarian cancer, and uterine cancer have higher body burdens of PCBs compared to women never diagnosed with cancer.

Significant higher MEHHP levels were found in women diagnosed with ovarian cancer and significantly higher MEP levels were found in women diagnosed with uterine cancer compared between to women never diagnosed with cancer. However, when comparing phthalate levels only among women with concentrations above the LOD, GM levels of phthalate metabolites did not differ in the study population. In women with detectable levels of BPA, higher exposure was found in women with cervical cancer only. Epidemiological studies on the association with phthalates and BPA with breast, cervical, ovarian, and uterine cancers are lacking or limited. Our findings are not consistent with findings by Lopez-Carillo et al. 2010, who reported significantly higher concentrations of MEP in breast cancer cases compared to controls when comparing the highest vs. lowest tertile of exposure (169.58 vs $106.78 \mathrm{ug} / \mathrm{g}$ creatinine) and significant negative associations for $\mathrm{MBzP}(\mathrm{OR}=0.46,95 \% \mathrm{CI} 0.27-0.79)$ and $\mathrm{MCPP}(\mathrm{OR}=0.44$, 95\% CI 0.24-0.80). Yang et al. (2008) measured median blood BPA levels in 70 cases and 80 controls and reported higher median BPA levels in cases compared to controls ( 0.61 vs. $0.03 \mathrm{ug} / \mathrm{L}$ ), however, the differences were not found to be statistically significant $(\mathrm{p}=0.42)$. 
Risk of a reproductive cancer (breast, cervix, ovarian, or uterine) was not found to be significantly associated with BPA in unadjusted or adjusted logistic regression models. Mono-(2-ethyl-5-hydroxyhexyl) phthalate (MEHHP) was weakly associated ( $\mathrm{p}=0.0497)$ with ovarian cancer risk in the model adjusted for age and race but did not remain significantly associated when the additional variables of BMI and age at menarche were added. PCBs showed the most significant associations with all reproductive cancers. After adjusting for all confounding variables, women with ovarian cancer had significant associations with PCB 74 and 118, and therefore the dioxin-like PCBs. PCB 138 had the strongest associations and was found to significantly increase the risk of breast, cervical, and uterine cancers. Epidemiological data is lacking on the associations between PCBs and cervical, ovarian, and uterine cancers, however significant associations have been found between individual PCB congeners and breast cancer risk (Charlier et al. 2004, Cohn et al. 2012, Demers et al. 2002). Dioxin-like PCBs were significantly associated with ovarian cancer and non-dioxin-like PCBs were significantly associated with ovarian and uterine cancers, after adjusting for age, race, BMI, and age at menarche. In contrast to our findings, Gammon et al. (2002) failed to find any association between PCB exposure and breast cancer risk when comparing the highest quintile of serum Peak-4 (nos. $118,153,138$, and 180) PCB levels to the lowest quintile (OR=0.83, 95\% CI 0.541.29).

There are a number of limitations to our study, the most important of which is its cross-sectional design with self-reported data that does not allow for causal inferences to be made. Self-reported data increases the risk of misclassification bias of cases and controls with the possibility of undiagnosed or incorrectly reported cancer cases. In the 
PCB data analysis, we had relatively small sample sizes for cervical cancer $(\mathrm{n}=27)$, ovarian cancer $(\mathrm{n}=11)$, and uterine cancer $(\mathrm{n}=26)$, resulting in decreased statistical power. Breast cancer cases were larger in the phthalate and BPA data analysis ( $\mathrm{n}=97$ and 78 , respectively), however cervical, ovarian, and uterine cancer cases were still limited. Missing data on reproductive confounding variables such as parity and lactation also limits the findings of our study. Furthermore, observed associations could be potentially confounded by lack of information on family history of hormonal cancers. Strengths of this cross-sectional study design include the large sample survey size, availability of biological measurements of environmental contaminants, and oversampling of minority populations that make it highly representative and generalizable to the U.S. population. In addition, this study has the ability to analyze the combined effect of EDCs within a class or across classes. Since chemicals may have an additive, synergistic, or antagonistic effect when combined, it is important to investigate associations for combined chemical exposures in addition to single chemical exposures.

\section{CONCLUSION}

Based on our analysis of urinary phthalates and BPA from the 2003-2010 and 2003-2008 NHANES data cycles, biological levels of phthalates and BPA did not contribute to the risk of reproductive cancers in women. In contrast, our analysis of serum blood lipid PCB levels in the 1999-2004 NHANES data cycles, showed a significantly increased risk of breast, ovarian, and uterine cancers in women with higher body burdens of PCBs. Due to their lipophilic nature, exposures to environmental PCBs appear to continue to pose significant threats on the reproductive health of women. Given the proven contribution of unopposed estrogens to the risk for hormonal cancers, it 
is biologically plausible that altered endogenous estrogen levels presumably from exposure to estrogen mimicking EDCs may contribute to the risk of disease. Exposure to EDCs, such as PCBs, during early development of the breast and endometrium can alter its development, and possibly contribute to the susceptibility to diseases through effects on stem cells. Although we did not find significant associations between phthalates, BPA, and reproductive cancers, our research is based on the use of cross-sectional self-reported data thus further research is needed. Our findings, coupled with the lack of available epidemiological evidence concerning EDCs and cervical, ovarian, and uterine cancers warrants the need for future prospective studies. 


\section{REFERENCES}

1. UNEP/ WHO Expert Advisory Group: State of the Science of Endcorine Disrupting Chemicals - 2012. Eds: Åke Bergman, Jerrold J. Heindel, Susan Jobling,Karen A. Kidd and R. Thomas Zoeller, WHO Press; 2013.

2. EU Commission Expert Advisory Group: Key scientific issues relevant to the identification and characterisation of endocrine disrupting substances. JRC Scientific and Policy Reports; 2013.

3. Balabanic D, Rupnik M, Klemencic A. 2011. Negative impact of endocrinedisrupting compounds on human reproductive health. Reproduction, Fertility, and Development 23:403-416.

4. Burantrevedh S \& Roy D. 2001. Occupational exposure to endocrine disrupting pesticides and the potential of developing hormonal cancers. J Env Health 64:1730 .

5. Calafat AM, Xiaoyun X, Wong LY, Reidy JA, Needham LL. 2008. Exposure of the U.S. Population to Bisphenol A and 4-tertiary-Octylphenol: 2003-2204. Env Health Perspect 116: 39-44.

6. Woodruff TJ, Zota AR, Schwartz JM. 2011. Environmental chemicals in pregnant women in the US: NHANES 2003-2004. Env Health Perspect 119:878-885.

7. Silva MJ, Barr DB, Reidy JA, Malek NA, Hodge CC, Caudill AP, Brock JW, Needham LL, Calafat AM. 2004. Urinary levels of seven phthalate metabolites in the U.S. population from the National Health and Nutrition Examination Survey (NHANES) 1999-2000. Env Health Perspect 112:331-338.

8. Roy D, Palangat M, Chen CW, Thomas RD, Colerangle J, Atkinson A, Yan ZJ. 1997. Biochemical and molecular changes at the cellular level in response to exposure to environmental estrogen-like chemicals. J Tox Env Hlth 50:1-29.

9. Roy D, Colerangle J, Singh KP. 1998. Is exposure of environmental or industrial endocrine disrupting estrogen-like chemicals able to cause genomic instability? Front Biosci 3 (Suppl): d913-921.

10. Fielden MR, Halgren RG, Tashiro C, Yeo BR, Chittim B, Chou K, Zacharewski, TR. 2001. Effects of gestational and lactational exposure to Aroclor 1242 on sperm quality and in vitro fertility in early adult and middle-aged mice. Reprod Toxicol 15:281-292. 
11. Ma R. \& Sasoon DA. 2006. PCBs exert an estrogenic effect through repression of the Wnt7a signaling pathway in the female reproductive tract. Environ Health Perspect 114(6):898-904.

12. Rier SE, Turner WE, Martin DC, Morris R, Lucier GW, Clark GC. 2001. Serum levels of TCDD and dioxin-like chemicals in rhesus monkeys chronically exposed to dioxin: correlation of increased serum PCB levels with endometriosis. Toxicol Sci 59:147-159.

13. Moral R, Wang R, Russo IH, Lamartiniere CA, Pereira J, Russo J. 2008. Effect of prenatal exposure to the endocrine disruptor bisphenol A on mammary gland morphology and gene expression signature. J Endocrin 196: 101-112.

14. Atkinson A \& Roy D. 1995. In vivo genotoxicity of bisphenol A. Env Mutagen 26:60-66.

15. Colerangle JB \& Roy D. 1997. Profound effects of the weak environmental estrogen-like chemical bisphenol A on the growth of the mammary gland of Noble rats. J Steroid Biochem Mol Biol 60:153-60.

16. Munoz-de-Toro M, Markey CM, Wadia PR, Luque EH, Rubin BS, Sonnenschein C, Soto AM. 2005. Perinatal exposure to bisphenol-A alters peripubertal mammary gland development in mice. Endocrinol 146: 4138-4147.

17. Newbold RR, Jefferson WN, Padilla-Banks E. 2007. Long-term adverse effects of neonatal exposureto bisphenol A on the murine female reproductive tract. Reprod Toxicol 24:253-258.

18. Murray TJ, Maffini MV, Ucci AA, Sonneschein C, Soto AM. 2007. Induction of mammary gland ductal hyperplasia and carcinoma in situ following fetal bisphenol A exposure. Reprod Toxicol 23:383-390.

19. Signorile PG, Spugnini EP, Mita L, Mellone P, D’Avino A, Bianco M et al. 2010. Pre-natal exposure of mice to bisphenol A elicits and endometriosis-like phenotype in female offspring. General and Comparative Endocrinol 168:318325 .

20. Cabaton NJ, Wadia PR, Rubin BS, Zalko D, Schaeberle CM, Askenase MH et al. 2011. Perinatal Exposure to Environmentally Relevant Levels of Bisphenol A Decreases Fertility and Fecundity in CD-1Mice. Environ Health Perspect 119: $547-552$.

21. Evans JM. 2008. An Integrative Approach to Fibroids, Endometriosis, and Breast Cancer Prevention. Integrative Medicine 7: 28-31. 
22. Lin BC, Suzawa M, Blind RD, Tobias SC, Bulun SE, ScanlanTS, Ingraham HA. 2009. Stimulating the GPR30 Estrogen Receptor with a Novel Tamoxifen Analogue Activates SF-1 and Promotes Endometrial Cell Proliferation. Cancer Research 69:5415-5425.

23. Bertelsen L, Mellemkjaer L, Frederiksen K, Kjaer SK, Brinton LA, Sakoda LC, van Valkengoed I, Olsen JH. 2007. Risk for breast cancer among women with endometriosis. Int J Cancer 15:1372-1375.

24. McLachlan JA, Simpson E, Martin M. 2006. Endocrine disrupters and female reproductive health. Best Pract Res Clin Endocrinol Metab 20(1):63-75.

25. Charlier CJ, Albert AI, Zhang L, Dubois NG, Phoenix GJ. 2004. Polychlorinated biphenyls contamination in women with breast cancer. Clinica Chimica Acta 347:177-181.

26. Recio-Vega R, Velazco-Rodriguez V, Ocampo-Gomez G, Hernandez-Gonzalez S, Ruiz-Flores P, Lopez-Marquez F. 2001. Serum levels of polychlorinated biphenyls in Mexican women and breast cancer risk. J Appl Toxicol 31:270-278.

27. Lopez-Carillo L, Hernandez-Ramirez RU, Calafat AM, Torres-Sanchez L, Galvan-Portillo M, Needham LL, Ruiz-Ramos R, Cebrian ME. 2010. Exposure to phthalates and breast cancer risk in Northern Mexico. Environ Health Perspect 118 (4): 539-545.

28. Yang CY, Ying-Jan W, Pau-Chung C, et al. 2008. Exposure to a mixture of polychlorinated biphenyls and polychlorinated dibenzofurans resulted in a prolonged time to pregnancy in women. Environ Health Perspect 116(5):599605.

29. Gammon MD, Wolff MS, Neugut AI, Eng SM, Teitelbaum SL, Britton JA et al. 2002. Environmental Toxins and Breast Cancer on Long Island. II. Organochlorine Compound Levels in Blood. Cancer Epidemiol Biomark Prev 11:686-697.

30. Cohn BA, Terry MB, Plumb M, Cirillo PM. 2012. Exposure to polychlorinated biphenyl (PCB) congeners measured shortly after giving birth and subsequent risk of maternal cancer before age 50. Breast Cancer Res Treat 136: 267-275.

31. Demers A, AYotte P, Brisson J, Dodin S, Robert J, Dewailly E. 2002. Plasma Concentrations of Polychlorinated Biphenyls and the Risk of Breast Cancer: A Congener-specific Analysis. Am J Epidemiol 155: 629-635. 
32. Sata F, Araki S, Yokoyama K, Murata K. 1995. Adjustment of creatinineadjusted values in urine to urinary flow rate: a study of eleven heavy metals and organic substances. Int Arch Occup Environ Health 68(1): 64-68.

33. CDC (Centers for Disease Control and Prevention). 2012. National Health and Nutrition Examination Survey Questionnaires, Datasets, and Related Documentation. Available:

http://www.cdc.gov/nchs/nhanes/nhanes questionnaires.htm [last accessed June $112014]$.

34. CDC (Centers for Disease Control and Prevention). 2013b. National Health and Nutrition Examination Survey: Analytic Guidelines, 1999-2010. Vital Health Stat 2(161). Available: http://www.cdc.gov/nchs/data/series/sr_02/sr02_161.pdf [last accessed June 11 2014].

35. CDC (Centers for Disease Control and Prevention). 2013. Fourth National Report on Human Exposure to Environmental Chemicals. Available:

http://www.cdc.gov/exposurereport/pdf/FourthReport UpdatedTables Sep2013.p df [last accessed June 6 2014].

36. CDC (Centers for Disease Control and Prevention). 2014. National Health and Nutrition Examination Survey. What's New. Available:

http://www.cdc.gov/nhanes/new_nhanes.htm 


\section{CHAPTER VII}

\section{OVERALL CONCLUSIONS}

The primary objective of the findings in this dissertation was to assess exposure to EDCs (PCBs, BPA, and phthalates) and determine whether exposure to these agents is a contributing factor in reproductive dysfunction in the U.S. general population. In particular, the associations between PCBs and endometriosis and leiomyomas and the associations between PCBs, phthalates, and BPA and reproductive cancers (breast, cervical, ovarian, and uterine) were examined using the CDC's NHANES database.

A number of chemicals are suspected to act as endocrine disruptors (EDs) by mimicking natural or synthetic estrogen resulting in an increased risk of hormonal cancer in women. Polychlorinated biphenyls (PCBs), phthalates and bisphenol A (BPA) have been recognized as endocrine disrupters due to their ability to interfere with reproductive function and development in animals and humans by either increasing estrogen activity or blocking estrogens from acting. Epidemiologic studies on the role of EDCs and reproductive toxicity are inconsistent and lacking, particularly in regards to the role of EDCs in the development of cervical, breast, and uterine cancers. Thus, our specific aims were identified to address gaps in the literature and provide recommendations for future studies.

To support or refute the proposed role of EDCs, secondary statistical analysis was conducted using data from the CDCs 1999-2010 NHANES. NHANES, conducted annually since 1999 by the Centers for Disease Control and Prevention (CDC), is an ongoing cross-sectional survey designed to be nationally representative of the noninstitutionalized, U.S. civilian population. Once eligibility is determined participants 
complete a confidential and voluntary home interview followed by a standardized physical examination in a specially equipped mobile evaluation clinic (MEC). The MEC examination consists of a physical examination, dental examination, detailed face-to-face personal interview, and collection of biological specimens. Each survey includes a nationally representative sample of approximately 5,000 participants.

The first specific aim addressed in manuscript 1 examined the cross-sectional relationship between exposure to PCBs and breast cancer among U.S. women. We analyzed data from female participants (20-85 years of age) with available PCB data using the 1999 to 2004 data cycles. Exposure was based on lipid adjusted serum levels of 6 individual PCB congeners (PCB 074, 099, 118, 138, 153, and 180), the sum of dioxinlike PCBs $(074+118)$, and the sum of non-dioxin-like PCBs $(099+138+153+187)$ in conjunction with self-reported data obtained from the medical and reproductive health questionnaires. We calculated geometric means to compare PCB concentrations in women with a breast cancer diagnosis vs. women without a cancer diagnosis. Geometric means of the 6 PCB congeners were found to be significantly higher among women with breast cancer when compared to the rest of the study population. We used logistic regression models to estimate odds ratios (ORs) and 95\% confidence intervals (CI) for the association between PCB measurements and breast cancer. After adjusting for age, race, $\mathrm{BMI}$, lactation, and age at menarche we found that PCB 138 was significantly associated with breast cancer [odds ratios of 2.88; $95 \%$ CI: 1.14-7.30; $2.93,95 \%$ CI: 1.04-8.26; and 3.43, 95\% CI: 1.12-10.4] in women with higher body burdens of individual PCB congeners. After adjusting for age and race, we also found the sum of 
non-dioxin-like PCBs to be significantly associated with breast cancer [OR of $1.14 ; 95 \%$ CI: $1.00-1.29]$.

The second specific aim, addressed in manuscript 2 examined the relationship between exposure to PCBs endometriosis and uterine leiomyomas among U.S. women, 20-54 years of age. Endometriosis and uterine leiomyomas have been identified as estrogen dependent diseases that occur during the reproductive years, however previous research on the role of EDCs in the development of endometriosis and uterine leiomyomas is conflicting. Due to the role of estrogen in the development of endometriosis and uterine leiomyomas we hypothesized that women with higher body burdens of PCBs would have an increased risk of disease. We calculated GMs to compare PCB concentrations in women who self-reported an endometriosis or uterine leiomyoma diagnosis vs. women who self-reported never being diagnosed with endometriosis or uterine leiomyomas. We used logistic regression models to estimate ORs and 95\% CIs of endometriosis and uterine leiomyomas by concentration of lipidadjusted serum PCBs. GM levels of PCB congeners 138, 153, and 180 were found to be significantly higher among women diagnosed with endometriosis, GM levels of PCB congeners $74,99,118,138,153$, and 180 were found to be significantly higher among women diagnosed with uterine leiomyomas, dioxin-like PCBs were found to be significantly higher in women diagnosed with uterine leiomyomas and non-dioxin-like PCBs were found to be significantly higher in women diagnosed with endometriosis and uterine leiomyomas compared to the rest of the study population. We found PCB 74 and 118 to be significantly associated with uterine leiomyomas [OR of $1.91: 95 \% \mathrm{CI}$ : 1.10 3.29 and $1.91,95 \% \mathrm{CI}: 1.13-3.22$ ] and non-dioxin-like PCBs to be significantly 
associated with endometriosis [OR of 95\% CI: 1.00-1.29] in women with higher body burdens of PCBs.

The third specific aim, addressed in manuscript 3, explored the cross-sectional relationship between exposure to PCBs, phthalates, and BPA and reproductive cancers (breast, cervical, ovarian, and uterine) among U.S. women. We evaluated the risk of breast cancer, cervical cancer, ovarian cancer, and uterine cancer with exposure to 6 individual PCB congeners $(74,99,118,138,153$, and 180), the sum of dioxin-like PCBs (074 and 118), the sum of non-dioxin-like PCBs $(099+138+153+187), 8$ urinary phthalate metabolites (MNP, MEP, MEHP, MBzP, MCPP, MEHHP, MEOHP, and MIB), the sum of DEHP metabolites $(\mathrm{MHP}+\mathrm{MHH}+\mathrm{MOH})$, the sum of total phthalates, and urinary BPA. We calculated geometric means to compare EDCs concentrations in women who self-reported a breast, cervical, ovarian, or uterine cancer diagnosis vs. women who self-reported never being diagnosed with cancer and used logistic regression models to estimate ORs and 95\% CIs for the association between exposure to EDCs and reproductive cancers.

Separate analyses showed geometric mean levels of individual PCB congeners to be significantly higher among women with breast cancer, ovarian cancer, and uterine cancer when compared to the rest of the study population. Mono-(2-ethyl-5hydroxyhexyl) phthalate (MEHHP) was found to be significantly higher among women with ovarian cancer and monoethyl phthalate (MEP) was found to be significantly higher among women with uterine cancer compared to women never diagnosed with cancer, however BPA was significantly higher in women never diagnosed with cancer compared to women diagnosed with breast cancer. When evaluating GM levels in only women with 
phthalate and BPA concentrations above the LOD, phthalate levels did not differ among the study population, however women diagnosed with cervical cancer had significantly higher levels of BPA compared to women never diagnosed with cancer. We found PCB 138 to be significantly associated with breast cancer, cervical cancer, and uterine cancer [ORs of 2.52.; 95\% CI: 1.06-5.99; 3.05, 95\% CI: 1.21-7.69; and 5.83, 95\% CI: $1.63-$ 20.9], respectively, and PCB 74 and 118 to be significantly associated with ovarian cancer [ORs of 6.47, 95\% CI: 1.23-3.41 and 6.68, 95\% CI: 1.39-32.3), respectively, in the final adjusted models. We also found the sum of non-dioxin-like PCBs to be significantly associated with uterine cancer (OR of 1.12, 95\% CI: 1.03-1.23) and the sum of dioxin-like PCBs to be significantly associated with ovarian cancer (OR of 2.02, 95\% CI: 1.06-3.85). We found a very weak association between MEHHP and ovarian cancer (OR of 3.63, 95\% CI: 1.00-13.2, $\mathrm{p}=.0497$ ) but did not find significant associations between any other phthalate metabolites or BPA and reproductive cancers.

In sum, the major findings from the research in this dissertation indicate that exposure to PCBs may increase the risk of endometriosis, uterine leiomyomas, and cancers of the breast, cervix, ovaries, and uterus. Our findings are consistent with the proven contributions of unopposed estrogens to the risk for reproductive toxicity. Exposure to estrogenic environmental chemicals, particularly PCBs, during early development of the breast and endometrium can alter their development, and possibly contribute to the susceptibility to diseases through effects on stem cells.

\section{Limitations}

There are a number of limitations to our study, the most important of which is its cross-sectional design with self-reported data that does not allow for causal inferences to 
be made. Self-reported data increases the risk of recall bias and misclassification bias of cases ad controls with the possibility of undiagnosed or incorrectly reported cancer, endometriosis, or uterine leiomyoma cases, thereby impacting the observed associations in the study. We also had relatively small sample sizes for cervical cancer $(\mathrm{n}=27)$, ovarian cancer $(\mathrm{n}=11)$, and uterine cancer $(\mathrm{n}=26)$, resulting in decreased statistical power within analyses. Missing data on reproductive confounding variables such as parity and lactation also limits the findings of our study. We were not able to assess the potential of additional reproductive health variables in our analysis due the extent of non-response. Furthermore, observed associations could be potentially confounded by lack of information on family history of endometriosis, uterine leiomyomas, and reproductive cancers.

\section{Future Studies}

Although our findings must be interpreted with caution, they indicate that EDCs still deserve consideration for their impact on the female reproductive system. Epidemiological studies on EDCs are often lacking or inconsistent, especially in regards to their in the development of cervical, ovarian, and uterine cancers. Because a single exposure to an internal or external environmental factor alone cannot explain the development of a complex chronic disease, such as cancer, future studies exploring the combined effect of EDCs and their influence in the development of chronic diseases in an individual are warranted. Widespread human exposure to EDC's and the increasing concern for their potential to induce reproductive toxicity, especially in susceptible populations with sensitive gene polymorphisms, warrants a clear need for more research. 
VITA

MARISA MORGAN

1997

$1998-2000$

2000-2002

2002-2013

2004

2008-present

2013-present
B.S., Biology

Virginia Polytechnic Institute and State University Blacksburg, VA

Quality Control Supervisor

Safeway Ice Cream

Capitol Heights, MD

Production Supervisor

Good Humor-Breyers

Clearwater, FL

Science Teacher

Broward County Public Schools

Coconut Creek, FL

M.A., Education: Curriculum and Instruction Florida Atlantic University

Boca Raton, FL

Doctoral Candidate

School of Public Health

Florida International University

Miami, Florida

Environmental Science/Chemistry Teacher

Science Department Chair

American Heritage School

Delray Beach, FL 